The Universizy of Chicago Science Series

\title{
Problems of FERTILIZATION
}

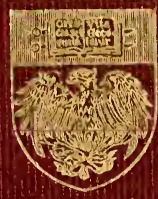

FRANK RATTRAY LILUE 


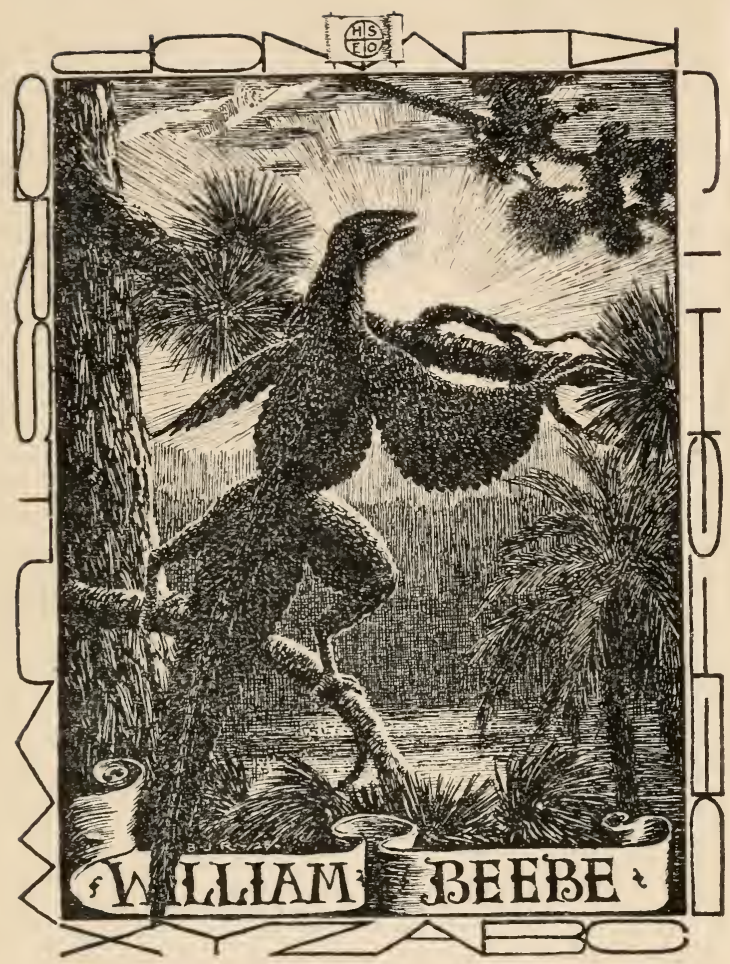




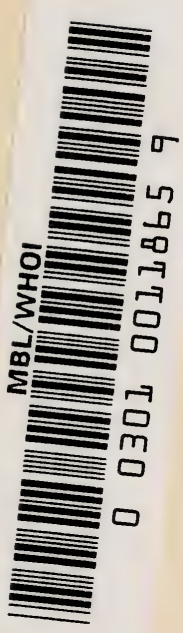





\title{
THE UNIVERSITY OF CHICAGO SCIENCE SERIES
}

\author{
Editorial Committee \\ ELIAKIM HASTINGS MOORE, Chairman \\ JOHN MERLE COULTER \\ ROBERT ANDREWS MILLIKAN
}




\section{DHE UNIVERSITY OF CHICAGO SCIENCE SERIES, established by the Trustees of the University, owes its origin to}

a belief that there should be a medium of publication occupying a position between the technical journals with their short articles and the elaborate treatises which attempt to cover several or all aspects of a wide field. The volumes of the series will differ from the discussions generally appearing in technical journals in that they will present the complete results of an experiment or series of investigations which previously have appeared only in scattered articles, if published at all. On the other hand, they will differ from detailed treatises by confining themselves to specific problems of current interest, and in presenting the subject in as summary a manner and with as little technical detail as is consistent with sound method. They will be written not only for the specialist but for the educated layman. 
PROBLEMS OF FERTILIZATION 
THE CNIVERSITY OF CHICAGO PRESS

CHICAGO, ILLINOIS

THE BAKER \& TAYLOR COMPANY

NEW YORK

THE CAMBRIDGE UNIVERSITY PRESS

LONDON AND EDINBUREH

THE MARUZEN-KABUSHIKI-KAISHA

TOKYO, OSAKA, KYOTO, FUKUOKA, SENDAI

THE MISSION BOOK COMPANY

SHANGHAI 


\title{
PROBLEMS OF FERTILIZATION
}

\author{
By
}

FRANK RATTRAY LILLIE

Professor of Embryology

University of Chicago

THE UNIVERSITY OF CHICAGO PRESS CHICAGO, ILLINOIS 
Copyright IgI9 By

The University of Chicago

All Rights Reserved

Published May Igro 


\section{PREFACE}

The following discussion of the problems of fertilization is an outgrowth of the writer's own studies in this field. It is an attempt to present the actual status of the various problems in a critical but not in an exhaustive manner, and is thus to be regarded as a point of departure for future work as much as a brief summary of attained results. The necessary limits of the volume have imposed restrictions which have permitted scant justice to numerous excellent pieces of work with which all special students are familiar; for this the absence of textbook intention and style may perhaps be additional excuse. The part of the subject that deals with the basis of biparental inheritance is purposely treated more summarily than other problems, because so much that is really extraneous to the problem of fertilization proper is involved in the discussion.

The inevitable conflict between the strictly biological and the physicochemical methods of analysis of biological problems emerges in typical form in the problems of fertilization. It is the writer's opinion that it will long continue to exist, but that there is an ultimate reconciliation, if not in sight, at least in prospect, on logical grounds. An equal hospitality to the results of both methods of inquiry is therefore adopted. The tendency toward excessive simplification of the physicochemical school is constantly being checked by the biological school, and the conservatism of the latter has been more than once rudely shaken by the former. These mutual 
assaults suggest co-operation such as is carried out at the Marine Biological Laboratory of Woods Hole. A large share of recent work on the subject has as a matter of fact been done in this institution, including the writer's own work and that of numerous other authors cited below.

Chapter $\mathrm{i}$ is reprinted slightly modified from an address delivered before the American Society of Naturalists and the Zoölogical Section of the American Association for the Advancement of Science, December 30 , I9I5, published in Science, N.S., Vol. XLIII, January I4, I9I6. 


\section{CONTENTS}

List OF Illustrations . . . . . . . . . . . . . xi CHAPTER

I. The History of the Fertilization Problem • . I

II. The Place of Fertilization in the Life-History . 3I

III. The Morphology of Fertilization . . . . 44

IV. The Physiology of the Spermatozoön . . . . 9I

V. The Physiology of Fertilization . . . . . I $^{2} 9$

VI. The Problem of Specificity in Fertilization. . i $8_{4}$

VII. The Problem of Activation . . . . . . . 227

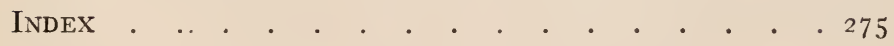

\section{8}





\section{LIST OF ILLUSTRATIONS}

Fig. i. Spermatozoa of Various Animals . . . 49

Fig. 2. Drawings from Photographs of Nereis Eggs in a Suspension of India Ink in Sea-Water 52

Fig. 3. Penetration of the Spermatozoön in the Egg of Nereis, from Sections . . . . . . 54

Fig. 4. Spermatozoön In the Oligochaete Rhynchelmis, IN THE EGg OF THE BAT Vespertilio noctula, AND IN the EgG of the SnaIl Physa fontinalis . . . . . . . . . . . 56

Fig. 5. The Formation of the Fertilization MemBRANE IN THE EgG of the SEA URchin Strongylozentrotus purpuratus . . . . . $5^{8}$

Fig. 6. Entrance of Spermatozoön and Formation of the Fertilization Membrane in Ascaris megalocephala

Fig. 7. Fertilization of the Egg of the Sea Urchin Toxopneustes

Fig. 8. Sections of Successive Stages Showing the Internal Phenomena of Fertilization in Nereis

FIG. 9. Development of Ascaris megalocephala, AND Pterotrachea At Various Stages . . . . 66

Fig. io. Fertilization of a Nematode (Ancyracanthus cystidicola) . . . . . . . . .

Fig. it. Effects of Centrifugal Force on Penetration of the Spermatozoön In Nereis . . . 72

Fig. i 2. Horizontal Section of the Germinal Disk of the Pigeon's Egg

Fig. i3. Photograph of the Aggregation of a Sperm SUSPENSION of Nereis 
Fig. I4. Reaction of a Sperm Suspension of Nereis PAge to a Drop of i Per Cent $\mathrm{CO}_{2}$ SeAIVATER 105

Fig. I5. Diagram of the Reaction of Spermatozoa of Nereis to a Drop of I Per Cent $\mathrm{CO}_{2}$ IN SEAWATER . . . . . . . . . . 106

Fig. i6. Curve of Fertilizing Power of Perfectly Fresh Sperm Suspensions of Arbacia . . 135

Fig. i7. Curve of Fertilizing Power of Sperm Suspensions of Arbacia.About 20 Minutes Old 137 Fig. i8. Imbibition of Water by Arbacia Eggs in Diluted Sea-Water . . . . . . . I50

Fig. i9. Curve of Fertilization Superimposed upon Butyric Acid Treatment in Arbacia . . I68 


\section{CHAP'TER I}

THE HISTORY OF THE FERTILIZATION PROBLEN

The two primary interests and compelling motives of mankind have always been hunger and love- the instincts of self-preservation and race-preservation. The reasoning faculty of man early turned with eager interest to the great problem of reproduction, but for a long time without attaining results that could be called scientific; and it was not until well into the nineteenth century that the problems connected with sexual reproduction could be scientifically formulated by separating the problem of fertilization from all its extraneous surroundings. In early human culture reproduction received its only interpretation at the hands of priests and mystery men; its first philosophical and scientific treatment was one of the distinctions of the Greeks, especially of that great philosopher and father of science, Aristotle, who combined observation and reflection in the interpretation of nature. Aristotle devoted a separate treatise, which has come down to us, to animal reproduction. Among other things he studied the development of the chick day by day with so much detail that Harvey felt impelled to say, I,900 years later: "Aristotle among the ancients, and Hieronymus Fabricius of Aquapendente among the moderns, have written with so much accuracy on the generation and formation of the chick from the egg that little seems left for us to do." 
From the time of the Greeks to that of Harvey $\left(6_{5} \mathrm{I}\right)$ there was but little progress in the knowledge of reproduction and none in the theory, as will appear from the views of Aristotle, the current views of medical men of Harvey's time, and of Harvey himself. Aristotle says:

The male is the efficient agent, and by the motion of his generative virtue (genitura), creates what is intended from the matter contained in the female; for the female always supplies the matter, the male the power of creation, and this it is which constitutes one male, another female. The body and the bulk, therefore, are necessarily supplied by the female; nothing of the kind is required from the male; for it is not even requisite that the instrument, nor the efficient agent itself, be present in the thing that is produced. The body then proceeds from the female, the vital principle (anima) from the male; for the essence of every body is its vital principle (anima). ${ }^{\mathrm{x}}$

With more common sense, if with less metaphysical subtlety, the physicians of the Middle Ages held, according to Harvey, that conception is due to a mingling of male and female seminal fluids, "the mixture having from both equally the faculty of action and the force of matter; and according to the predominance of this or that geniture does the progeny turn out male or female" (quoted from Harvey, Ex. 32).

Harvey's observations contained much that was new and significant, and the facts that he discovered were inconsistent both with Aristotle's ideas and with those of the physicians. They were, however, inadequate for sound generalization.

Wandering between two worlds, one dead

The other powerless to be born,

${ }^{2}$ De Gen. Anim. ii. 4, quoted from Harvey, "On the Generation of Animals," Ex. 29. 
he descended deeper into the slough of metaphysics than Aristotle, and committed himself to the fantastic idea that conception in the uterus is identical with, or at least analogous to, conception in the brain; and that the ovum is the product of such unconscious uterine desire or conception, and receives no material substratum from the male! ${ }^{r}$ The theory of reproduction was no whit more advanced in the middle of the seventeenth century than in the time of Aristotle.

The use of the microscope in biological research began in the seventeenth century; it was the improve-

$r$ "Since there are no manifest signs of conception before the uterus begins to relax, and the white fluid or slender threads (like the spider's web) constituting the 'primordium' of the future 'conception' or ovum, shows itself; and since the substance of the uterus, when ready to conceive, is very like the structure of the brain, why should we not suppose that the function of both is similar, and that there is excited by coitus within the uterus a something identical with, or at least analogous to, an 'imagination' (phantasma) or a 'desire' (appetitus) in the brain, whence comes the generation or procreation of the ovum. For the functions of both are termed 'conceptions,' and both, although the primary sources of every action throughout the body, are immaterial, the one of natural or organic, the other of animal actions; the one (viz., the uterus) the first cause and beginning of every action which conduces to the generation of the animal, the other (viz., the brain) of every action done for its preservation. And just as a 'desire' arises from a conception of the brain, and this conception springs from some external object of desire, so also from the male, as being the more perfect animal, and, as it were, the most natural object of desire, does the natural (organic) conception arise in the uterus, even as the animal conception does in the brain.

"From this desire or conception, it results that the female produces an offspring like the father. For just as we, from the conception of the 'form' or 'idea' in the brain, fashion in our works a form resembling it, so, in like manner, the 'idea' or 'form' of the father existing in the uterus generates an offspring like himself with the aid of the formative faculty, impressing, however, on its work its own immaterial 'form'" (from William Harvey, "On Conception," I651). 
ment of this new instrument of investigation and its application to the study of the reproductive substances that furnished the first fundamental advance in the theory of reproduction at the hands of Leeuwenhoek, viz., the discovery of the spermatozoa ${ }^{\mathbf{x}}$ in 1677 .

This discovery aroused the greatest interest in scientific circles; a number of investigators repeated the observations and a spirit of speculation which led to wild flights of the imagination was aroused. Leeuwenhoek had soon to defend his priority in the matter and to protest against certain very imaginative views. Thus in a letter dated June 9, I699, ${ }^{2}$ he defends his priority and combats the notion that the human form can be observed in the spermatozoa. He inveighs especially

${ }^{1}$ This discovery is sometimes credited to Hamm, described as a student of Leeuwenhoek's. The latter himself describes the occurrence as follows (Phil. Trans., I678, containing a letter from Leeuwenhoek dated November, I677): A certain Professor Cranen, who had frequently visited Leeuwenhoek for microscopical demonstrations, requested by letter that he should give Dominus Hamm, a relative of his, some demonstrations of his observations. On his second visit D. Hamm brought in a glass vial some seminal fluid and stated that he had observed living animals in it; Leeuwenhoek confirmed this observation and repeated it many times. In this letter he gives a fair description of the spermatozoa, their form, size, and movements, and stated that he had observed them three or four years previously and mistaken them for globules. He did not at this time speculate as to the meaning of the spermatozoa, but in true scientific spirit began to make comparative observations, and in 1678 he described and figured spermatozoa of the rabbit and frog among others.

The credit of this discovery seems to me to belong rightly to the investigator whose wide experience in the field of microscopical anatomy and whose scientific acumen enabled him to grasp the possible significance of the discovery, not to the chance observer who called Leeuwenhoek's attention anew to the subject.

${ }^{2}$ Phil. Trans., Vol, XXI. 
against a certain Dr. Dalen Patius, who claimed to have seen the human form, "the two naked thighs, the legs, the breast, both arms, etc., the skin being pulled up somewhat higher did cover the head like a cap."

Leeuwenhoek states that he can find nothing of the sort, but he adds:

I put this down as a certain truth, that the shape of the human body is included in an animal of the masculine seed; but that a man's reason shall dive or penetrate into this mystery so far, that in anatomizing one of these animals of the masculine seed we should be able to discover the entire shape of the human body, I can not comprehend.

In a letter dated two weeks later he distinguishes two sorts of these animalcules, and concludes that the one sort is male and the other female.

In France, in the year 1694, Nicholas Hartsoeker claimed to have been the first to have discovered the spermatozoa, more than twenty years previously, although he did not publish until I678, a year later than Leeuwenhoek's publication. Hartsoeker's ideas are characterized by a high degree of precision. He believes that each spermatozoön conceals beneath its "tender and delicate skin" a complete male or female animal. The egg is merely a source of nourishment for the real germ contained in the spermatozoön. In birds the spermatozoön enters an egg to be nourished; there is but a single opening in the egg, situated over the so-called germ, and this opening closes after a single spermatozoön is admitted; but if two spermatozoa enter they unite and form a double monster. In mammals the tail of the spermatozoön is the umbilical cord; this unites with the ovum, i.e., the placenta, and the latter 
with the uterus. Each one of the male animals (spermatozoa) incloses an infinity of other animals both male and female, which are correspondingly small, and these male animals inclose yet other males and females of the same species, and so forth in a series which includes all the members of the species which are to be produced up to the end of time. No difficulty was found in this conception, for the atomic theory of matter was not yet placed on a scientific basis.

Thus was founded and flourished for its brief day the school of the spermatists. Unhampered by any scientific conception of matter, living or non-living, there was no obstacle to the eye of faith and no impediment to the age-old longing to make an intelligible universe out of the scraps of experience.

In the entire eighteenth century, although speculation continued rife, there was only one notable contribution to our subject. This was the work of the Abbe Spallanzani, Expériences pour servir à l'histoire de la génération des animaux et des plantes, published in Geneva in 1785 . His working hypotheses were naturally in the spirit of the times. Theories of reproduction, he says, may be reduced to two.

The one explains the development of organisms mechanically, the other supposes them to pre-exist, and waiting only for fertilization to develop them. The second system has given birth to two different parties, one believing that the organism is preformed in the ovum, the other that it is performed in the spermatozoön.

Spallanzani believed that his observations destroyed the epigenetic theory as propounded by Buffon and others, beçause they demonstrated the existence of the "fetuses" 
(ova) in the females of toads, frogs, and salamanders, prior to the act of fertilization, which according to the epigenesists animates or creates the germ. For the same reason the spermatists must also be wrong. Spallanzani thus combated epigenesis as understood in the eighteenth century, and also the ideas of the spermatists, and he was led to deny that spermatozoa are necessary for fertilization, and to hold that the fertilizing power of the seminal fluid resides, not in the spermatozoa, but in the fluid medium that accompanies them; and this in spite of the fact that his final experiments really proved the reverse.

His work contains a great wealth of observation and experiment, so that it will be possible merely to indicate some of his chief results. In the first place he demonstrated that in frogs and toads fertilization takes place outside of the body, and for the first time he successfully carried out artificial insemination, thus laying the foundation for the artificial propagation of many animals. In making these experiments he thought he found cases in which seminal fluid devoid of spermatozoa would fertilize and thus fell into the error, which he was so ready to accept from his opposition to the spermatists, that the fluid medium of the seminal fluid was the fertilizing substance. He also investigated the conditions of successful insemination, with reference to the duration of fertilizing power, exposure to various chemicals, to heat, etc. The amount of dilution of which the seminal fluid was capable was likewise carefully investigated. By experiment he excluded the idea that fertilization might be an effect of an emanation, or vapor, arising from the sperm. 
He concluded that the seminal fluid acts by accelerating the vital processes; it enters the body through pores and stimulates the action of the heart. This idea offered no difficulty to one who believed that the organism was preformed in the ovum, and it was supported by the observation that the beating of the heart was the first observable movement of the embryo. Bonnet suggested to him the problem: If the spermatic fluid might stimulate the heart of the embryo in the process of fertilization, why might not other fluids produce the same effect? He was thus led to attempt the first experiments on artificial parthenogenesis; he tried to start the development of eggs by electricity, by the action of extracts of all the various organs, by vinegar, dilute alcohol, lemon juice, and other substances, all without effect.

It is interesting to see how his experiments led to hypotheses, and these, even though wrong, to further experiments, some of which, like his experiments on artificial parthenogenesis, were not taken up again in a fruitful way for over a century.

His final experiments are those so often quoted as furnishing the proof that fertilizing power resides in the spermatozoön. He showed that, if diluted sperm be filtered through a sufficient number of layers of filter paper, the filtrate has no fertilizing power, whereas the residue washed off the filter paper will fertilize. But he did not himself draw the correct conclusion; he says the experiment proves "that filtration removes from spermatized water its fertilizing power, inasmuch as the seminal fluid which was contained in it remains on the filter papers, from which one can extract it by 
pressing them." It is perfectly clear that Spallanzani himself never held that the spermatozoa themselves were the fertilizing agents, but, on the contrary, he contests this idea strongly as leading to spermatist delusions.

After Spallanzani there was no real advance in the theory of fertilization until the publication of Prevost and Dumas' New Theory of Reproduction in I824. 'They observed that young animals incapable of breeding, old animals beyond the breeding stage, the infertile mule, and birds outside of the breeding season possess no spermatozoa, and they conclude that these facts "sufficiently prove the importance of the animalcules, and show that there exists an intimate relationship between their presence in the reproductive organs and the fertilizing power of the animal." In a long series of experiments they investigated the conditions of fertilization in frogs: all conditions that destroy the animalcules destroy also the fertilizing power of sperm suspensions; the filtrate of a sperm suspension devoid of spermatozoa will not fertilize; the redissolved residue of a suspension evaporated to dryness will not fertilize, etc.; the number of eggs fertilized is always less than the number of "animalcules" employed. They came to the conclusion, therefore, that "the prolific principle resides in the spermatic animalcules."

In their subsequent publications they concluded that it is "infinitely probable that the number of animalcules employed in fertilization corresponds to that of the embryos developed .... so that the action of these animalcules which we regard as the male reproductive elements is individual, not collective." 
They concluded that a spermatozoön penetrates each egg and becomes "the rudiment of the nervous system, and that the membrane (germ disk of the egg) in which it is implanted furnishes, by the diverse modifications which it undergoes, all the other organs of the embryo."

These studies gave a new impetus to the study of fertilization; some were convinced that Prevost and Dumas were essentially correct, while others still adhered to the idea that the fluid part of the seminal fluid was the fertilizing medium. Thus the celebrated embryologist Bischoff in 1842 does not hesitate to declare outright for the latter view, "that only the dissolved part of the semen penetrates into the egg and thus completes fertilization." He considered that

Valentin's hypothesis united all the facts: the seminal fluid is so unstable chemically as to break down as soon as the particles come to rest; it is similar to the blood in this respect, but it is not in regular circulation and the function of maintaining its chemical composition is relegated to the movements of the spermatozoa.

However, Bischoff subsequently became convinced that the spermatozoa were themselves the essential agents, though he still refused to believe in the penetration of the egg. Kölliker had put forward a contact theory of fertilization, which Bischoff regarded merely as a statement of facts requiring further development. He therefore adopted the idea of catalyzers, at that time a new idea in chemistry, and held that the spermatozoön was essentially a catalytic agent, i.e., as he defined it, "a form of matter characterized by definite transformation and internal movement" which it transmits by contact to the egg, which is in a condition of maximum 
tension or inclination to assume the same form of transformation and movement. Fertilization is thus not a process of union and fusion as in ordinary chemical combination, but a catalytic process, as defined above.

This point of view deserves to be emphasized as one of the first attempts at a physicochemical explanation of fertilization.

For some time naturalists were divided between the two points of view, viz., that of Prevost and Dumas, that the sperm penetrated into the egg, and that of Kölliker and Bischoff, that it acted by contact. Lallemand (I84I) well expresses the view of those who believed in the union of the ovum and spermatozoön.

Each of the sexes furnishes material already organized and living. . . . . A fluid obviously can not transmit form and life which it does not possess. . . . Fertilization is the union of two living parts which mutually complete each other and develop in common. . . . . When one embraces in a single point of view the reproduction of all living beings, one arrives at the following more general formula: Reproduction is the separation of a living part which may either develop separately or acquire from another living part the supplementary elements necessary for the ulterior development of a being similar to the type. . . . The preservation of the type is due to the extension of the same act which has produced the development of each individual being.

This is the most complete statement of the principle of genetic continuity that I have found in the literature of this period.

These observations and conclusions were found on the eve and early morrow of the great biological generalization, the cell theory. Though Schwann interpreted the ovum as a cell ( 1838 ), this view did not at once become dominant and was generally accepted only after 
over twenty years of discussion. The view that spermatozoa were parasitic organisms was more or less current until Kölliker in I84I showed by their development that they were modified cells. Nevertheless, there was, strictly speaking, no immediate application of these results to the problems of fertilization.

The half-century from I824 to I 874 yielded relatively little advance in fertilization theory; the opinion that the spermatozoön actually penetrated into the ovum gradually gained ground, largely from the very logic of the situation, but partly from various observations. Bischoff's contact theory, which was the only alternative, was criticized, because if the sperm does not penetrate, but remains outside of the membrane, there is absence of that direct contact between sperm and egg substance postulated by the theory. Wagner's criticism was also very effective; a ferment does not determine the character of a reaction, but the spermatozoön does, for it transmits paternal characteristics. In the way of observations Barry (I840), Newport ${ }^{\mathrm{I}}$ (I854-55), Meissner, ( 1855 ), and others maintained observations of penetration of the ovum by the spermatozoön; Keber (1854) laid especial emphasis on the micropyle as adapted for entrance of a spermatozoön. These observations were on the whole inconclusive, for actual penetration was not observed but inferred from the presence of spermatozoa inside the egg membrane. Moreover, the spermatozoön could not be discovered within the egg.

INewport's observations rose to a higher plane than those of the others, for he actually observed in the frog's egg (I) that the first plane of cleavage is in line with the point on the egg artificially impregnated, (2) that it marks the plane of symmetry of the embryo, (3) that the head of the young frog is turned toward the same point. 
The modern period.--The preceding period ( $1824-74$ ) was coincident, as we have seen, with the early history of the cell theory, but the demonstration of the unicellular character of the ovum and spermatozoön had little effect upon the problems of fertilization. The cell theory was still incomplete; the free formation of the nuclei was still held by competent naturalists, and nothing was known of the phenonema of karyokinesis. The cytological investigations of the next ten years (1874-84) were destined to lay the foundations of the modern nuclear theory in its broad outlines. The fertilization studies of this period were mainly morphological, and while it is correct to say that they were largely dominated by the growing nuclear theory it is also strictly true that they contributed in no small measure to its upbuilding. Though the penetration of the spermatozoön into the egg had long been suspected, it was first clearly demonstrated at this time; the origin of the egg nucleus by two successive divisions of the germinal vesicle was discovered; the origin of the sperm nucleus from the head of the spermatozoön, the sperm aster, the union of the egg nucleus and the sperm nucleus, the relation of these to the first cleavage spindle, the origin of the fertilization membrane, the ill effects of polyspermy and the theory of its prevention, and finally the doctrine of the equivalence of the egg and sperm nuclei, and the biparental character of the nuclei of sexually produced organisms, as first laid down by Van Beneden, were products of the period also. No period of cytological research seems to me of greater significance than this.

There was almost a complete cessation of investigation from 1855 to 1873 , when the dawn of the modern 
period broke suddenly. In I873 Bütschli observed in the egg of a nematode the approach and contact of the two structures, which we now know to be the germ nuclei, immediately preceding the first cleavage of the ovum. But no interpretation was presented. In I874 Auerbach described the appearance of two nuclei at opposite ends of the elongated egg of Rhabdites; these increase in size, migrate toward the center of the egg, meet, rotate through $90^{\circ}$, and fuse together. A dicentric figure appears and cleavage follows. What is the origin of these two nuclei and the significance of their union? The fusion of two nuclei was at the time entirely without analogy. Auerbach states: "It is natural to assume that, as for the reproduction of organisms the copulation of two individuals, or at least of two cells in some form or other, is so frequently necessary, so here a similar condition is found for nuclear reproduction."

Auerbach supposes the two nuclei which appear at opposite ends of the elongated egg to have arisen freely; one of these comes from the end where the spermatozoa had penetrated, the other from the opposite end, where the germinal vesicle had disappeared. The difference of origin influences the quality of the nuclear materials arising, according to his conception, de novo; fusion of the nuclei counteracts the differences thus arising; but all this would be undone if the division of the fusion nucleus followed along the plane of the union; hence the rotation through $90^{\circ}$.

In the next year Bütschli again observed fusion of nuclei in nematode eggs before the first cleavage. However, he did not accept Auerbach's interpretation, but he tended to regard it as a general law of nuclear 
formation that first two or several small nuclei arise, and subsequently fuse; this he finds to occur even in the blastomeres of the four- and eight-cell stages.

About the same time (I875) Van Beneden also observed similar phenomena in the rabbit's egg. He did not see spermatozoa enter the egg, but he found them with their heads closely applied to the surface in every unsegmented egg, and came to the conclusion that fertilization consisted essentially in fusion of the spermatic substance with the superficial layer of the vitellus. At a little later stage he found a small nucleus in the cortical layer of the egg; this he called the peripheral pronucleus; a central pronucleus appeared simultaneously. They grow, approach one another, and meet in the center. Later there is only one nucleus, probably formed by the union of the two.

As I have shown that the spermatozoa attach to the surface of the vitellus and mix with its superficial layer, it appears probable to me that the superficial pronucleus is formed, partially at least, at the expense of the spermatic substance. If, as I think, the central pronucleus is constituted of elements furnished by the egg, the first nucleus of the embryo would be the result of union of male and female elements. I put forth this latter idea simply as a hypothesis, an interpretation which may or may not be accepted.

The way was now clear for the definitive solution of the old riddle of the relation of the egg and spermatozoön which was quickly furnished by O. Hertwig and Hermann Fol. The observations of these authors appear to have been made independently and nearly simultaneously. In 1875 Hertwig observed and described correctly the principal phenomena of fertilization in the sea urchin egg. He did not actually see the penetration of the 
spermatozoön, but he observed the sperm nucleus and its aster so soon after that he had no doubt of the correct interpretation; he also observed the approach of the sperm nucleus and the egg nucleus to the center of the egg and their apparent fusion.

Fertilization has been previously interpreted as a fusion of two cells, but we have now seen that the most important process involved is the fusion of the two nuclei. The union of the egg nucleus with the sperm nucleus is necessary to produce a nucleus endowed with living forces adequate effectively to stimulate the later developmental processes in the yolk, and to control them in many respects.

Fol's observations, made partly independently of Hertwig's and partly after the publication of Hertwig's first paper, supplemented Hertwig's in several important respects: (I) He observed the details of penetration of the spermatozoön with a clearness that has never been surpassed for these forms. (2) He gave the first correct account of the maturation divisions and origin of the egg nucleus (Hertwig regarded the latter as being the persistent nucleolus of the germinal vesicle). (3) He paid special attention to the origin of the fertilization membrane and founded the classic theory that it was an adaptation to prevent polyspermy. (4) He was the first one adequately to present the harmful effects of polyspermy.

The period initiated by these two men was characterized mainly by the repeated demonstration of penetration of the spermatozoön, the formation of a nucleus from the sperm head, and the fusion of this nucleus with the egg nucleus. It was also gradually demonstrated that the egg nucleus is genetically derived from the 
germinal vesicle by karyokinetic divisions. Thus the genetic continuity of the germ nuclei with nuclei of preceding cell generations was established. As yet the character of the fusion of egg and sperm nuclei had hardly been raised, for the chromosome problems and hypotheses were in a nascent state. Flemming's discoveries concerning chromosomes and their reproduction in karyokinesis by splitting date only from $1876-78$.

All the problems of cell morphology were in a fine state of fermentation during this time, the really classic period of cell morphology; the foundations of our present knowledge of cell division were being laid; before the decade $1870-80$ it had been firmly established that cells arise only by division from pre-existing cells; but two views of the origin of nuclei were still held, one that of free formation, according to which the nuclei of daughtercells had no genetic connection with the nucleus of the mother-cell, and the other that nuclei arise by division from a preceding nucleus. Little by little as a result of numerous investigations by many investigators, both zoölogists and botanists, the matter cleared up. In r878 Flemming was able to outline the whole scheme of karyokinesis substantially as we now understand it.

The fundamental biological principle of genetic continuity was foreshadowed by the founders of the cell doctrine and was more or less distinctly foreseen by some of their contemporaries, as in the case of Lallemand. It was yet more clearly expressed in Virchow's famous aphorism, omnis cellula e cellula (1856); but it could not become an established guiding principle in genetic research until the entire cell cycle of the individual lifehistory was worked out in broad outline, until the process 
of cell division was accurately ascertained and applied to the genealogy of the germ cells, until the respective parts of ovum and spermatozoön in the origin of the new generation were understood, nor until the hoary doctrine of spontaneous generation was banished bodily from the field of biology. These were all accomplishments of that great decade in biological research (1870-80), for which the studies of the preceding thirty years had furnished ample preparation. The entire superstructure of modern genetic research rests upon the foundations then laid.

Professor Mark's paper on Limax (I88I) is a point of departure between the fertilization studies of the seventies and those that were to follow. Professor Mark observed that the pronuclei come together but do not fuse to form a first cleavage nucleus, as had been described for other animals. "The first cleavage nucleus does not have a morphological existence." The pronuclei persist after the appearance of the cleavage centers; their membranes then gradually disappear.

In 1883 Van Beneden published his now classic paper on Ascaris. The pronuclei do not fuse; both are included in a single amphiaster; each produces two chromosomes; these divide and their halves form the daughter-nuclei. In the nuclei of the first two cells there are thus equal numbers of male and female elements; and there are reasons to believe that even in these two nuclei they do not fuse; it is probable that they remain distinct in all derivative cells, including the immature eggs and spermatogonia. In the egg the chromatin is composed of two distinct parts, and "it is legitimate to suppose that each is the equivalent of a male and a 
female chromosome, and that in the formation of the polar globules each throws out the male chromatin which it contains.'

Van Beneden by a veritable stroke of genius thus anticipates the entire chromosome doctrine of the present time, even though certain aspects of his interpretation were not entirely fortunate.

With the establishment of the nuclear theory, destined soon to be elevated into the doctrine of chromosome individuality, a certain duality of cell life was recognized in which nucleus and cytoplasm, however interdependent, were regarded as playing specific rôles. But there was no logical reason for stopping at duality, and the centrosome soon came to be recognized under Van Beneden's and Boveri's leadership as a third organ of cell life reproducing itself by division. The development of this idea was due, not only to studies of karyokinesis, but also to the series of fertilization studies which began with Boveri's classic papers on Ascaris (I887-88). In these papers Boveri is convinced of the necessity of making "the sharpest distinction between fertilization and heredity, i.e., between the question how egg and spermatozoön produce a cell capable of division, and the question how these cells come to be capable of reproducing the qualities of the parents in the offspring"; this distinction has since been generally recognized. Boveri's solution of the fertilization problem was in terms of the centrosome hypothesis: the egg is devoid of the organ of cell division, the centrosome; capacity for division, hence the initiation of the developmental processes, is restored through the introduction of a centrosome into the egg by the spermatozoön. 
This conception exerted a dominating influence on the series of fertilization studies which followed; the questions as to the origin of the sperm aster with its contained centrosome in the egg, and as to the genetic continuity of the sperm centrosome with the centrosomes of the cleavage amphiaster, were energetically investigated by a series of students for the next fifteen years or more, and similar studies have continued with less energy down to the present time. Collectively these publications constitute a fairly adequate record of the morphology of the fertilization process in animals, a large part of which was furnished by American students.

The morphological analysis of fertilization seems now to be fairly complete; there may still be disturbances, such as recent attempts to trace mitochondria back to the sperm, which seems destined to share the adverse fate of the similar attempt to trace the centrosomes to the sperm; but there is not likely to be any great modification of the existing data, which seem to me to demonstrate, effectively if not absolutely, that the sperm head contains all the substances necessary for fertilization. We have thus attained a more or less definitive solution of the morphological relations of egg and spermatozoön in the fertilization process.

The cytologist working with chromosomes and the geneticist with Mendelian factors have traced maternal and paternal elements through the life-history in a very satisfactory manner, so that we are beginning to see how certain strands of the web of life cross the gap of successive generations. It remains for the biology of the future to elucidate the chemical foundations of 
chromosome behavior and to identify the Mendelian factors in these chemical foundations.

The problems of the immediate reaction of the reproductive elements and the physiology of fertilization are not touched by this morphological analysis, though they had been present in the minds of investigators from the beginning. The experimental investigation of these problems dates from Spallanzani, as we have seen, but they did not become dominant until the morphological problems of fertilization were in an advanced stage of solution. They constitute, however, the more immediate problems of fertilization, considered in a restricted sense.

We have had two lines of attack since the studies of Oskar and Richard Hertwig published in 1887 really initiated the modern period in the physiology of fertilization. The one is a direct experimental analysis of the fertilization process itself; the other is the attempt to imitate the action of the spermatozoön by chemical and physical agencies-in short, the studies on artificial parthenogenesis. I shall not attempt in the present chapter to deal with the latter, which constitute one of the most interesting and suggestive chapters in modern biology, beyond attempting to define their relation to the problems of fertilization proper.

It was soon found in the course of studies on artificial parthenogenesis that no single physical or chemical agency suffices to initiate development in all eggs, and that when the various agencies effective in all the successful experiments are assembled they constitute a fairly complete list of agencies to which protoplasm in general is irritable. The idea then arose that the common factor 
must be the effective one, but no common factor has been found, or can be found, in the agents themselves; the only common factors are in the reproductive cells. This leaves the method of parthenogenesis in the same position as the method of analysis; that is, in the position of determining what are the changes in the egg itself that initiate development, and what is the nature of their dependency upon the external agent or spermatozoön. The answer to these questions cannot proceed exclusively from parthenogenetic studies, though, to the extent that the same questions are involved, parthenogenesis and fertilization studies must furnish the same answer. But there are obviously fundamental problems of fertilization that cannot be touched by methods of artificial parthenogenesis.

The conditions to be fulfilled in fertilization involve, not only penetration of the spermatozoön, or some part of it, into the egg, but also reaction between the two, which is evidenced by the behavior of both partners; for it is possible for a spermatozoön to penetrate an egg and no reaction to be evidenced in the behavior of either the egg or sperm, as when immature eggs are penetrated by mature spermatozoa. We may therefore speak of a fertilization reaction when the behavior of both partners indicates that the process is proceeding normally. Fertilization has its quantitative aspect, and the reaction may be complete or exhibit varying degrees of incompleteness. For a normal fertilization reaction certain internal conditions of the partners and certain external conditions of the medium must be realized. The study of the external conditions throws light upon the reaction, because the nature of the internal conditions may be 
inferred from the necessary, from the inhibiting, and from the favoring conditions of the medium.

The fertilization reaction, like all biological reactions, requires certain conditions of the environment, such as definite range of temperature and chemical composition of the medium. In the first place, if these are exceeded in either direction so far as to injure the cells the fertilization reaction either does not take place or it is rendered abnormal. The cause of the failure, or the abnormality, in such cases lies in some change of the internal composition of one or the other of the germ cells. The classic experiments of this kind are those of Oskar and Richard Hertwig published in 1887. These investigators studied the effects of high temperature, of various injurious chemical reagents, and of mechanical shock on the germ cells separately before fertilization, and on the process of fertilization itself at various stages. Many exceedingly interesting observations were made, and problems were raised that were not then ripe for solution. Other experiments of a similar kind have since been made, but their consideration properly belongs to the problems of the internal factors, for the phenomena observed depend upon internal changes of the germ cells.

In the second place, there may be modifications of the medium which do not directly injure the germ cells, but which inhibit or favor the fertilization reaction. Examples of inhibiting phenomena are found in Professor Loeb's studies of the relations of ions to the fertilization reaction, or my own on the inhibiting action of blood or tissue secretions of the same species on fertilization. The most striking example of conditions 
favoring fertilization is the action of alkalis in enabling interclass hybridization, discovered by Jacques Loeb. Such experiments furnish important data for the analysis of the reaction, but it is obvious that their interpretation must depend upon internal conditions of the fertilization reaction.

In the third place, the membranes of the egg and of the spermatozoön must influence the occurrence, rate, and extent of the fertilization reaction according to the degree of their permeability to the substances concerned; the egg membrane is of course more especially concerned; its rôle in the occurrence of parthenogenesis has been studied especially by R. S. Lillie; and $I$ have found in the case of the starfish egg that a resistant egg membrane may entirely block the fertilization reaction, though the block may be removed by agents that render the membrane more permeable.

The internal conditions of the fertilization reaction may be grouped under three heads: (I) maturity of the germ cells; (2) irreversibility of the reaction; (3) specificity of the reaction.

r. Maturity.-Concerning conditions of maturity of the spermatozoön, but little definitely is known, except that it will not fertilize before its differentiation is complete. Whether the cause of this lies entirely in deficient motility, or partly also in incomplete chemical differentiation, we do not know, though there are some reasons for thinking that the latter factor may be involved. In the case of the ovum our knowledge is in a much more advanced stage. We know that the fertilizable condition, which represents the final maturity of the ovum, arises rather suddenly, usually lasts but 
a short time, and is lost as an immediate consequence of the fertilization reaction. (a) That the fertilizable condition arises suddenly has been shown especially by the work of Delage on the starfish egg and of Wilson on the egg of Cerebratulus. Their experiments on merogony showed that parts of the full-grown ovum taken prior to the rupture of the germinal vesicle are incapable of fertilization; but, soon after the rupture of the germinal vesicle, parts, whether nucleated or not, readily fertilize. Hertwig's observations (1877) also showed a complete failure of the fertilization reaction in primary ovocytes of the sea urchin before rupture of the germinal vesicle, even when spermatozoa penetrated. I have observed the same thing in Chaetopterus. (b) Eggs of Platynereis lose their capacity for fertilization almost immediately after coming into seawater, even though spermatozoa may penetrate (Just); eggs of the frog become unfertilizable after half an hour in water (Spallanzani); eggs of the wall-eyed pike completely lose their fertilizability after ten minutes in water (Reighard). Usually fertilization capacity begins to fall off in one or two hours after eggs are laid in most marine animals, though in some, as in the sea urchin, it may persist much longer.

2. Irreversibility.-Once fertilized, eggs do not fertilize again, nor do parts of such eggs that are freed of the fertilization membrane. It should therefore be impossible to superimpose parthenogenesis and fertilization; and the studies of C. R. Moore show this to be the case. Apparent superposition appears in all cases to be due to incomplete reactions, which cease and may be subsequently resumed. The fertilization reaction 
appears to be irreversible; and the appearance of reversal in parthenogenesis may be referred, like superposition of fertilization on parthenogenesis, to incompleteness of the initial reaction.

3. Specificity is an outstanding feature of the fertilization reaction, the significance of which is not weakened by any hybridization experiments. We need not stop to define the limits or the consequences of hybridization in order to justify the assertion that no theory of fertilization which fails to include the factor of specificity as one of the prime elements can be true.

The fundamental character of specificity is illumi-. nated by the phenomena of self-sterility; in species where this occurs the eggs and sperm of the same individual are sterile inter se, though fertile with those of all other individuals. This has led some botanists to the conception of individual stuffs; but Correns' experimental analysis led him to the conclusion that the specific factor is not an individual stuff but a definite combination of stuffs for each individual. The combination arises always with the individual and disappears with it. The only biological parallel of such phenomena is found in the individual blood composition revealed by serological studies. That there is a common factor in species and individual specificity no one who has studied both sets of phenomena can doubt.

A consistent theory of fertilization must take account of all these phenomena, not only the internal factors of maturity of germ cells and the specificity of their reactions, but also the external factors that favor or inhibit the reaction. I have attempted to show in a series of papers that the fertilizable condition of the egg depends 
upon the presence of a specific substance which is produced at the time of rupture of the germinal vesicle and which disappears completely after fertilization. If this substance be present in the egg in adequate amount the egg can be fertilized, otherwise not. It may be obtained in solution in the sea-water and recognized by its capacity for agglutinating sperm suspensions of the same species, in some cases at least. If it is thus possible to associate the fertilizable condition of the ovum with a definite substance, we have a base from which an analysis of fertilization can be made.

If the existence of such a substance be admitted, it must operate either by activating some substance in the spermatozoön, which is to be regarded as the effective agent in subsequent changes, or we must regard it as the effective agent which is transformed from an inactive to an active state by some substance in the spermatozoön. If we take the first alternative, we have no explanation of parthenogenesis, whereas if we regard the egg substance as the active agent, the explanation of parthenogenesis proceeds along the same lines as that of fertilization. Moreover, I have been able to show by an analysis of the phenomenon of blood inhibition of fertilization that the first point of view is untenable.

This substance may therefore be called the fertilizing substance, or fertilizin. By its reaction it is shown to be a colloidal substance, not giving the usual protein tests, and exhibiting some of the properties of a ferment, as shown by Richards and Woodward. Fertilization would thus be a three-body reaction between the sperm receptors, fertilizin, and egg receptors linked in line; and it is possible to show that inhibiting agencies may 
operate at the various linkages of such a reaction. In its reaction with the sperm the fertilizin of different species exhibits a certain degree of specificity, which should be more fully studied, but which has been partly explored by Jacques Loeb and myself.

This form of hypothesis takes into account the internal factors both of maturity of germ cells and of their specificity; it is also adapted to explain the environmental conditions of fertilization extremely well; and it is consistent with the results of parthenogenesis, and the known relations of parthenogenesis and fertilization to the permeable or impermeable conditions of the egg membrane.

In the following pages we shall discuss the various problems whose history has thus been outlined. The discussion can be no more than a record of progress.

\section{REFERENCES}

AUERBACH, LeOpold.

1874. Organologische Studien (see pp. 177-262). Breslau. Bischoff, T. L. W.

I842. Entwickelungsgeschichte des Kaninchens (chap. ii).

I 847. "Theorie der Befruchtung und über die Rolle, welche die Spermatozoiden dabei spielen," Arch. für Anat. u. Phys., pp. 422-42.

BOVERI, T.

I887. "Ueber die Befruchtung der Eier von Ascaris megalocephala," Sitzungsber. d. Gesell. fiir Morph. u. Phys. (München), Band 3, pp. 7I-80.

i887. "Ueber den Antheil des Spermatozoons an der Theilung des Eies," ibid., pp. r54-64.

I887. "Zellenstudien," Heft I, Jen. Zeitschr. fïr Naturw., Band 2r, pp. 423-5I5.

r888. "Zellenstudien," Heft II, ibid., Band 22, pp. 685-882. 
I890. "Zellenstudien," Heft III, ibid., Band 24, pp. 3 I4-40I.

I89I. "Befruchtung," Ergeb. der Anat. und Entwickelungsgeschichte, Band I, pp. 364-485.

BÜTSCHLI, O.

I875. "Vorläufige Mittheilung über Untersuchungen betreffend die ersten Entwickelungsvorgänge im befruchteten Ei von Nematoden und Schnecken," Zeitschr. fiir wiss. Zool., Band 25, pp. 20I-16.

I876. "Studien über die ersten Entwickelungsvorgänge der Eizelle, die Zelltheilung und die Conjugation der Infusorien," Abh. d. Senck. Naturf. Gesell., Band Iо, pp. 2I3-464.

Fol, Hermann.

I876. "Sur les phénomènes intimes de la division cellulaire," Comptes rendus de l'Acad. des Sci., T. 83, pp. $667-69$.

I877. "Sur le commencement de l'hénogenie chez divers animaux," Arch. de zool. exp. et gén., T. 6, pp. I45-69.

I879. "Recherches sur la fécondation et le commencement de l'hénogenie chez divers animaux," Genève soc. phys. mem., XXVI, 89-397.

HaRtsoeker, Nicholas.

1694. Essay de dioptrique (pp. 227-33). Paris.

Harvey, William.

I651. De generatione animalium.

Hertwig, O.

I876. "Beiträge zur Kenntniss der Bildung, Befruchtung und Theilung des thierischen Eies," Morph. Jährb., Band I, pp. 347-434.

I877. Theil II, ibid., Band III, pp. I-86.

I878. Theil III, ibid., Band IV, pp. I56-2I3.

Hertwig, O. ANd R.

I887. "Ueber die Befruchtungs- und Theilungsvorgänge des thierischen Eies unter den Einfluss äusserer Agentien," Jen. Zeitschr. für Naturw., Band 20, pp. I 20-24I, 477-5IO. 


\section{LALLEMAND}

I84I. "Observations sur le rôle des zoospermes dans le génération," Ann. des sci. nat., Sér. 2, T. I5, pp. 262-307.

Leeuwenhoek, Antonius.

I677. Phil. Trans., XI-XII, I040-43.

I699. Ibid., XXI, 30I-8.

MARK, E. L.

I88I. "Maturation, Fecundation and Segmentation of Limax campestris," Bull. Mus. Comp. Zoöl. Harvard University, VI, I73-625.

Newport, George.

I854. "On the Impregnation of the Ovum in the Amphibia," First Series, Phil. Trans., CXLI, I69-242; Third Series, ibid., CXLIV, 229-44.

Prevost et Dumas.

I824. "Nouvelle théorie de la génération," Ann. des sci. nat., T. I, pp. I-29, I67-87, 274-92; T. II, pp. IOO-I 2I, I 29-49.

I827. "Mémoir sur le développement du poulet dans l'œuf," ibid., T. I2, pp. 4I4-43.

Spallanzani, AbBé.

I785. Expériences pour servir a l'histoire de la génération des animaux et des plantes. Geneva.

VAN BENEDEN, E.

I875. "La maturation de l'œuf, la fécondation et les premières phases du développement embryonaire des mammifères," etc., Bull. de l'Acad. Roy. de Belgique, Sér. II, T. 40, pp. 686-736. See also Quart. Jour. Micr. Sci., XVI (I876), I 53-82.

I883. "Recherches sur la maturation de l'œuf et la fécondation," Arch. de biol., T. 4, pp. 265-640. 


\section{CHAPTER II}

THE PLACE OF FERTILIZATION IN THE LIFE-HISTORY

Fertilization is essentially the phenomenon of the union of two cells known as gametes to form a single cell known as the zygote. Considered in this broad sense, it is practically a universal phenomenon among animals and plants. The formation and union of gametes probably always goes hand in hand with sex, even in those cases among the Protista when the gametes have not yet been shown to be sexually differentiated.

There is perhaps no phenomenon in the field of biology that touches so many fundamental questions as the union of the germ cells in the act of fertilization; in this supreme event all the strands of the webs of two lives are gathered in one knot, from which they diverge again and are re-woven in a new individual life-history. It is the central decisive event in the genesis of all sexually produced animals and plants. Thus from one point of view it envisages the entire problem of sex; from another point of view it constitutes the basis of all development and inheritance. The elements that unite are single cells, each usually incapable, under natural conditions, of continued existence or development - on the point of death; but by their union a rejuvenated individual is formed which constitutes a link in the eternal procession of life by virtue of its power of reproduction. Thus to consider the antecedents and the consequents of the process of fertilization would be to outline all of biology. 
Our purpose, however, is to focus on the moment of fertilization itself, feeling sure of the great significance of any adequate analysis of such an event. Even so doing, we are dealing with a highly complex situation in which all of our knowledge of the morphology and physiology of cells is requisite for a statement of the problems.

The biologist who surveys the stupendous panorama of sex in the plant and in the animal kingdom must feel that there is a universal biological significance of fertilization, in terms of either function or composition. By some biologists emphasis has been laid on the aspect of rejuvenation and by others on the mingling of the parental germ plasms as a source of diversity and variation within the species - on amphimixis, in brief.

The development of an organism after a very early stage is characterized by decreasing rate of metabolism; that is to say, at a certain early stage, which will be more fully defined later, the organism possesses its maximum growth energy, which, in the case of a mammal for instance, may be more than a hundred times that possessed at birth. The growth energy decreases from its maximum point most rapidly at first, with increasingly diminishing rate until full growth is attained. Thereafter the processes of growth and destruction practically balance, for a time, up to old age and death.

Charles S. Minot deserves the credit for first clearly defining these principles in a quantitative way. He showed that in the early stages of embryonic development, from the ninth to the fifteenth day of gestation, rabbits add 704 per cent to their weight daily, and inferred that in yet earlier stages the rate of in- 
crement was probably at least r,ooo per cent daily. From the fifteenth to the twentieth day of gestation the rabbit adds only 2I 2 per cent daily to its weight. Four days after birth the increment is about 17 per cent daily; twenty-three days after birth only about 6 per cent; two months after birth less than 2 per cent; at two and one-half months less than I per cent; and after full growth is attained, about two hundred and twenty days after birth, the weight no longer increases regularly. The processes of breaking down and repair in the organism tend to balance. He showed that similar principles hold in the development of man, guinea-pig, and hen.

We have here, indeed, a general principle of development, which presumably holds for all metazoa, which may be expressed by saying that in embryonic stages the period of most rapid loss of growth power occurs, and, if this is identical with the process of growing old, that senescence is most rapid in exceedingly early stages of development. The underlying conception has long been appreciated by naturalists; it is an old idea, which it would be difficult to trace to its ultimate source, that organisms start out with a high charge of growth energy, which is gradually dissipated in the process of growing old.

The point of maximum efficiency of the organism in the life-history does not, however, correspond with the starting-point, the fertilized egg, but to an early following stage of development. The germ cells themselves have, indeed, in the process of their differentiation completely lost growth capacity, and exhibit also in terms of differentiation all the signs of senescent cells. 
Following the union of the ovum and spermatozoön in the act of fertilization, there is a rapid acceleration of metabolism, which can be measured in various ways, mounting, in stages succeeding cleavage, to a maximum from which the curve of senescence, which has been outlined above, takes its start.

Fertilization thus initiates a period of rejuvenescence which is brief and rapid and apparently complete. However, in forms that reproduce asexually, rejuvenescence may be effected in other ways without any participation of gametes; and in parthenogenesis a certain amount of rejuvenescence at least occurs without fertilization. In most such animals, however, sexual reproduction and fertilization occur either regularly or irregularly in certain generations.

It is thus readily seen how the idea of rejuvenescence came to be associated with the fertilization problem. The germ cells alone in most animals (and all the higher ones) possess this capacity of resuming youthful conditions after differentiation, and they do so (except in case of parthenogenesis) only after union in fertilization. The exceptions, however, show that in this respect fertilization is not an absolutely unique process.

Child ( 19 I $_{5}$, p. 58) defines senescence and rejuvenescence as follows: "Senescence is primarily a decrease in rate of dynamic processes conditioned by the accumulation, differentiation, and other associated changes of the material of the colloid substratum. Rejuvenescence is an increase in rate of dynamic processes conditioned by the changes in the colloid substratum in reduction and dedifferentiation." If we accept this definition as a reasonable physiological formulation of the processes 
of senescence and rejuvenescence, we gain a physiological conception of the sense in which the mature gametes may be termed old or senescent, and of the sense in which fertilization may be said to induce a process of rejuvenescence.

The gametes are old in the sense of possessing a high degree of differentiation. The egg cell is more or less loaded with a highly inert material, the yolk, and the spermatozoön is highly differentiated in a different sense. With the activation of the ovum by fertilization there begins a process of resorption and utilization of yolk, and the cleavage cells gradually consume, and thus free themselves from, this encumbrance. The differentiated parts of the spermatozoön are lost, and the nucleus enters into the nucleoplasmic activities of the zygote. It is improbable that this is the whole story of dedifferentiation, and Child lays strong emphasis in this definition and elsewhere on changes in the colloidal system, but the nature of such changes in relation to the process of rejuvenescence remains unknown.

The inner significance of sex and fertilization in the life-history cannot, however, be confined within these boundaries. Sex seems to be very nearly a universal attribute of living beings, either actual or potential, even in organisms that do not utilize it invariably for purposes of reproduction; and it hardly suffices to say that in such cases the condition is an inherited one that has lost partially or wholly its function in the lifehistory. Sexual differentiation seems to represent an inevitable dimorphism of living matter for which we possess no satisfactory analogy, and fertilization appears to be a consequence of such dimorphism. The gametes 
are not merely senescent, if we take this view of their differentiation, but they possess properties with respect to one another that no other senescent cells possess with reference either to one another or to the gametes.

The second most general aspect of fertilization concerns the union in one individual of materials derived from two, and the consequent combination of certain characters of each of the parents in the zygote. 'The entire process of biparental inheritance depends on the preparation of the materials prior to union, the nature of the union itself, and the subsequent redistribution of such materials in development. Since fertilization deals only with the nature of the union, we shall not be concerned with processes of inheritance. It will therefore suffice to point out here the most general implications of this aspect of the subject.

The union is undoubtedly the chief source of the heritable variations that we can directly observe. In a freely interbreeding population the germ plasms of no two individuals are precisely alike, and the differences often extend to numerous factors. The combinations and recombinations that occur as a result of fertilization in successive generations produce, therefore, the greatest possible amount of diversity of which the population is capable on the basis of the organization of the germ plasm, assuming equal chances and viability of all crosses. Material is thus offered for natural selection to work on. But beyond this there is a relation between vigor of offspring and zygotic combinations, in very many cases at least, in favor of heterozygous as compared with homozygous matings. Certainly not all com- 
binations produce equal vigor, and one factor in many cases in the production of increased vigor of offspring is found in the union of contrasting germ plasms, whether with reference to one or to several characters.

These several problems appear in their simplest forms in the life-histories of certain Protozoa, and they have been studied most intensively in ciliates, especially in Paramecium. It has long been recognized that for a true comparison of the protozoan life-cycle to that of Metazoa, the period between two divisions does not suffice. It is true that two individuals result from such a division, but these are comparable in many respects to cell generations in the metazoan body, with the main difference that the cells remain associated in the latter case but not in the former.

Looked at in this way, it is frequently possible to distinguish periods of youth, maturity, and senescence in a protozoan life-history comparable to the same period of a metazoan individual. This point of view goes back to Bütschli (г876), but was first placed on an experimental basis by Maupas (1888-89), who regarded the process of conjugation in ciliates as a rejuvenating process: The ex-conjugant begins a cycle of cell generations with a full store of energy; under suitable nutritive conditions a series of fissions follows. During the early part of the series there is no regular tendency toward conjugation, but later in the series (after several hundred generations usually) the tendency to conjugate in pairs becomes very strong and may result in veritable epidemics of conjugation. Maupas calls this the stage of sexual maturity. Individuals that do not succeed in conjugating then gradually pass into a period of 
senescence ending in death. The ex-conjugants are, however, rejuvenated and begin new life-cycles.

Maupas thus distinguished periods of youth, sexual maturity, and old age in the ciliate life-cycle; and he believed that conjugation brought about a complete renewal of youth. He believed, moreover, that diverse ancestry of the conjugating individuals was important for rejuvenation, and that union of too closely related individuals was likely to be abortive in this respect.

These views stood in the sharpest contrast to those of Weismann, who held "that the deeper significance of every form of amphimixis-whether occurring in conjugation, fertilization, or in any other way-consists in the creation of that hereditary individual variability which is requisite for the operation of the process of selection, and which arises from the periodical mingling of the individually different hereditary substances." Moreover, Weismann was not simply content to emphasize this aspect of conjugation, but he also rejected and ridiculed the rejuvenation conception: "To my mind it is difficult to understand how an almost exhausted vital force could be raised again to its original state of activity as the consequence of a union with another equally exhausted force." Of course such a proposition gains its strength from its form rather than from its substance.

To explain the death of individuals that fail to conjugate, Weismann supposes that, when the long prepared period of conjugation approaches, the appropriate nuclear maturation processes occur; the result of such maturation is to organize the individuals as gametes, which die like any gametes which fail to unite. 
These problems have been studied very intensely in Paramecium in recent years by Calkins, Woodruff, Woodruff and Erdmann, Jennings, and others. Most observers have detected cycles in the life-history consisting of "a more or less periodic alternation of high and low vitality as measured by the division rate" (Calkins, I9I 5). The period of depression or low vitality may lead to conjugation in certain strains exactly as Maupas observed; on the other hand, high vitality may be restored by certain changes in the culture medium, as Calkins showed; or high vitality may be resumed apparently spontaneously without conjugation over and over again for periods of years and through thousands of generations, as Woodruff first observed in a certain strain of Paramecium aurelia. The analysis of the last case showed that each such period of depression and restoration was accompanied by a process of nuclear reorganization comparable in many respects to those taking place in conjugation: the macronucleus breaks up and is finally resorbed, the micronuclei divide twice, but do not carry out the third division, which in conjugation produces the gametic nuclei; a new macronucleus is formed from the micronuclei, and the normal nuclear organization is gradually restored.

To this spontaneously recurring process of reorganization Woodruff has applied the name "endomixis," thus emphasizing its resemblance in many respects to amphimixis. He finds that this process is essential to the continuation of the life of the culture (Woodruff, I9I7), for its discontinuance is invariably followed, within the time of one or two rhythms, by death of the the culture. Moreover its regular periodicity is a 
function of time rather than of cell generations. It is obviously an expression of senescence in its descending phase and of rejuvenescence in its ascending phase if these terms are to have any precise biological significance. These organisms may thus continue to live indefinitely, as Weismann contended, but they are not eternally young, though they bear with them a fountain of youth in the process of endomixis that may cause indefinite rejuvenation.

How, now, does this determination bear on the question of whether conjugation does or does not involve a rejuvenation process? Obviously it involves no contradiction, for in conjugation we have an equally complete process of nuclear reorganization; the added factor of nuclear exchange between the partners and and nuclear syngamy in each may, however, act detrimentally to the life of the organism, as Jennings showed. Endomixis definitely' demonstrates, however, that the rejuvenescence theory of conjugation went too far in asserting that conjugation itself, presumably in all its phases, is necessary for rejuvenescence. Calkins has interpreted the phenomenon of endomixis as a kind of parthenogenesis, admitting its rejuvenating influence; but in so doing, it seems to the writer, he has relinquished the most distinctive part of Maupas' theory. Both Calkins and Jennings, moreover, have shown that conjugation of even the most closely related individuals has no injurious effect, and have thus removed another pillar of Maupas' edifice.

Jennings (I912) has also ingeniously shown that if conjugants are separated in the very first stage of the process they may continue to multiply with undimin- 
ished vigor, and he points out that we cannot therefore assume, "as has been done by some authors, that if the animals continue to multiply after conjugation, this shows that conjugation has had a rejuvenating effect, for the same specimens continue equally without conjugation." The phenomenon of endomixis was not known at the time that this was written, and Jennings therefore did not determine its occurrence in the separated conjugants; but it is reasonable to assume that it occurred soon, if not immediately, because it is apparently a normal process in all races of Paramecium. He concludes from his very extensive, well-controlled series of experiments that "there is no evidence that conjugation in the infusoria increases the reproductive power, or rejuvenates the organism physiologically in any way" (Jennings, I9I3a).

In these experiments Jennings demonstrated that conjugation, on the average, decreases the rate of fission very greatly instead of increasing it; it produces a great amount of variation in this respect, ranging from a total loss of capacity for fission to a rate nearly equal to the original, and also variations in other characteristics. "What conjugation does is to bring about new combinations of germ plasm, just as is done in the sexual reproduction of higher animals. One result of this is to give origin to many variations, in the sense of inherited differentiations between different strains. Some of the new combinations are better adapted to the existing conditions than others; these survive while the others die out" (Jennings, I9r3b).

In respect to conjugation, Paramecium and the ciliates generally are quite aberrant in comparison with other 
protozoan groups. Other types of Protozoa exhibit frequently a more definite type of life-cycle, "so that a cell picked out at one phase of the life-cycle is quite a different type of individual from one picked out at another phase" (Calkins, I9r6). In these cases, conjugation occupies a definite place in the life-cycle quite comparable to its place in Metazoa; and it may apparently be equally connected with processes of rejuvenescence. However, it is clear that rejuvenescence considered as a process of differentiation and relief from "cumulative metabolic differentiations" (Calkins) may be accomplished in Protozoa, as in certain Metazoa, at other times than that of conjugation (fertilization).

The only result of conjugation or fertilization common to the animal kingdom as a whole is biparental inheritance. The association of fertilization with reproduction or with rejuvenescence is not a universal one, and therefore not a necessary one in the most general sense. In the evolution of the animal kingdom, however, the processes have become more and more inseparably associated in the higher phyla, so that sexual reproduction becomes the only method for the entire organism, whether of reproduction or of rejuvenescence.

Sex and fertilization remain for the present ultimate biological categories. We possess innumerable data concerning their manifestations from low to high forms in the animal kingdom; and the researches of recent years have contributed greatly to our understanding of the physiology and genetics of sex, and the morphology and physiology of fertilization. It is only by a continuation of such studies that we can hope to advance farther into the problem of their ultimate significance. 


\section{REFERENCES}

Calkins, Gary N.

I915. "Cycles and Rhythms and the Problem of "Immortality' in Paramecium," Amer. Naturalist, XLIX, $65-76$.

I9r6. "General Biology of the Protozoan Life Cycle," Amer. Naturalist, L, 257-70.

Child, C. M.

I9r5. Senescence and Rejuvenescence, pp. 48I. The University of Chicago Press.

Jennings, H. S.

I912. "Age, Death, and Conjugation in the Light of Work on Lower Organisms," Pop. Sci. Monthly, June, I9I 2.

I9I3. "The Effect of Conjugation in Paramecium," Jour. Exp. Zoöl., XIV, 279-39г.

Jennings, H. S., and Lashley, K. S.

I913. "Biparental Inheritance and the Question of Sexuality in Paramecium," Jour. Exp. Zoöl., XIV, 393-466.

Minot, C. S.

1908. The Problem of Age, Growth, and Death. New York. WOODRUFF, L. L.

I9I5. "The Problem of Rejuvenescence in Protozoa," Biochem. Bull., IV, 37 I-78.

I9I7. "Rhythms and Endomixis in Various Races of Paramecium aurelia," Biol. Bull., XXXIII, 51-56.

I917. "The Influence of General Environmental Conditions on the Periodicity of Endomixis in Paramecium aurelia," Biol. Bull., XXXIII, 437-62.

Woodruff, L. L., AND ERdmann, R.

I914. "A Normal Periodic Reorganization Process without Cell-Fusion in Paramecium," Jour. Exp. Zoöl., XVII, $425-5$ I6. 


\section{CHAP'TER III}

\section{THE MORPHOLOGY OF FERTILIZATION}

Before beginning this subject it is necessary to prepare the ground a little by certain considerations on the germ cells themselves. To go at all fully into their characteristics and history would require a volume in itself, and the present considerations will be strictly limited to what is necessary for understanding fertilization.

I. THE RELATION OF MATURATION OF THE GERM CELLS TO FERTILIZATION

After the full growth of the ovum and during or immediately before fertilization the ovum forms two small cells, known as the polar bodies, by a process of karyokinetic division (see Figs. $4 d, 8 c, 9 d$, pp. 56, 62, and 66). If the first of those cells divides, as sometimes happens, four cells are produced by the fully grown ovum, three of which are rudimentary, viz., the polar bodies, and the other is the mature ovum, which is not appreciably reduced in size by the divisions. The polar bodies take no part in development, but degenerate, though they frequently remain attached to the egg for a considerable period of time. They are formed at that end of the axis, or chief developmental gradient of the ovum, which is known as the animal pole.

The polar bodies are essentially abortive ova, and the divisions by which they are formed correspond precisely in their nuclear phenomena to the last two 
divisions of the spermatocytes by which the four functional spermatids, or immature spermatozoa, are formed. These divisions in the history of both spermatozoön and ovum, known as the maturation divisions, are concerned in reduction of the chromosomes to onehalf that characteristic of the species (haploid number), an event that always precedes fertilization; so that the union of the two germ cells in fertilization restores the species or diploid number.

The reduction divisions are preceded in both spermatogenesis and ovogenesis by a pairing of chromosomes in the so-called growth period to form bivalent chromosomes (tetrads); it is believed that the two members of a pair are always maternal and paternal, respectively, in their origin. In one of the reduction divisions the members of each pair separate again and pass into different daughter-cells, while in the other division each chromosome divides in the usual fashion. The germ cells are thus prepared, not only by reduction in number of the chromosomes, but by differential distribution of the latter for their subsequent union.

The maturation divisions of the sperm cells always occur prior to the special differentiation of this cell as a locomotor cell, and thus long before fertilization; but those of the ovum, which requires no subsequent differentiation to function as a fully mature gamete, do not occur until the time of fertilization or immediately preceding it. Both kinds of cells lose their capacity for division after maturation unless they unite in fertilization; but many ova lose this capacity prior to maturation, or-during the course of the maturation 
divisions, and either do not begin, or do not complete, their maturation divisions, as the case may be, unless fertilized. Thus the maturation and the fertilization of the ovum frequently overlap.

The following cases may be recognized: (I) The ovum loses its capacity for division at the end of its period of growth. The large nucleus, known as the germinal vesicle, undergoes none of the preparatory stages of karyokinesis unless the egg be fertilized; this is the case, for instance, in certain annelids and nematodes, of which the annelid Nereis may serve as a type. (2) The ova of the annelid Chaetopterus, of the nemertean Cerebratulus, and of the lamellibranch Cummingia pass through the prophases of the first maturation division, but the karyokinetic process is arrested in the mesophase of this division, and the ovum will die in this condition unless fertilized. (3) In the case of the ova of many vertebrates the first polar body is formed, and the prophase of the second maturation division begins, but the process then stops unless the egg be fertilized. (4) In the echinids and some other animals maturation is completed without fertilization.

In the first three cases the spermatozoön remains more or less quiescent within the egg during the completion of the maturation divisions, and the internal events of fertilization are resumed after the formation of the second polar globule. These variations in the time at which the egg reaches the period of inhibition or quiescence affect the morphological features of fertilization in certain important respects; they must be borne in mind also in the interpretation of experiments. 


\section{EXTERNAL AND INTERNAL FERTILIZATION}

The devices for insuring the meeting of the sexual elements are numerous and varied. In general the conditions must be such as to give scope for movement of the sex cells toward one another. Among the Metazoa, to which our account is limited, the ovum is incapable of movement as a whole. The spermatozoön is motile, and its activities can be maintained only in an aqueous medium of suitable composition (see chap. iv); seawater is such a medium for most marine animals, and the simplest conditions of union of the germ cells are found in those marine animals that cast their reproductive products into the sea-water, there to meet. Such are most echinoderms, many annelids, tunicates, lamellibranchs, and bony fishes. These forms are the most favorable for study of fertilization, for the ova, as well as the spermatozoa, are produced in large quantity, and the conditions and time of their union may be arbitrarily determined. For these reasons many of the most thorough studies in both the morphology and the physiology of fertilization have been made on such marine animals. But external fertilization is not confined to marine animals; it is also found in fresh-water fishes and in anurous amphibia.

Many marine and fresh-water animals have, however, acquired methods of internal fertilization, the ovum being fertilized within the body of the female; and the same is true naturally of all terrestrial animals. This involves organs of copulation, more or less complex secondary sexual characters, and special forms of mating behavior. In such cases the meeting of the germ cells is more certainly assured, and they are produced in 
relatively small numbers as a general rule. The study of fertilization is, therefore, usually more difficult technically in such cases; and the process is not readily accessible to experimental investigation, when it occurs in the interior of the body. For these reasons such forms have not been used so extensively for study as animals with external fertilization. Nevertheless morphological studies of fertilization, at least, have been made in nearly all classes of the animal kingdom.

\section{THE SPERMATOZOÖN}

In all animals, excepting the nematodes and Crustacea, the spermatozoön is flagellate; it usually exhibits three readily distinguishable parts: head, middle piece, and tail. Within this common morphological form there is the greatest possible diversity of organization, so that it is probable that the spermatozoön of every species is morphologically distinguishable. Such differences are not usually, however, related in any determinable way to the processes of fertilization themselves. It is indeed probable that certain broad features of difference in organization are adaptive in the sense that they are related to the conditions of fertilization in certain groups; but it seems evident that many of them are results of specific chemical and physical composition in the given environment. It would not be profitable, therefore, to examine their form variations from our point of view, and the series of figures (Fig. I ; cf. also Figs. 3, 4, 6, 7) may serve to give an idea of some of the best-known variations in form and size.

Of the three divisions of the flagellated spermatozoön the head is the most massive, containing the dense, 
concentrated chromatin of the nucleus, including always, as its history shows, the haploid number of chromosomes. It frequently bears anteriorly a process called for obvious
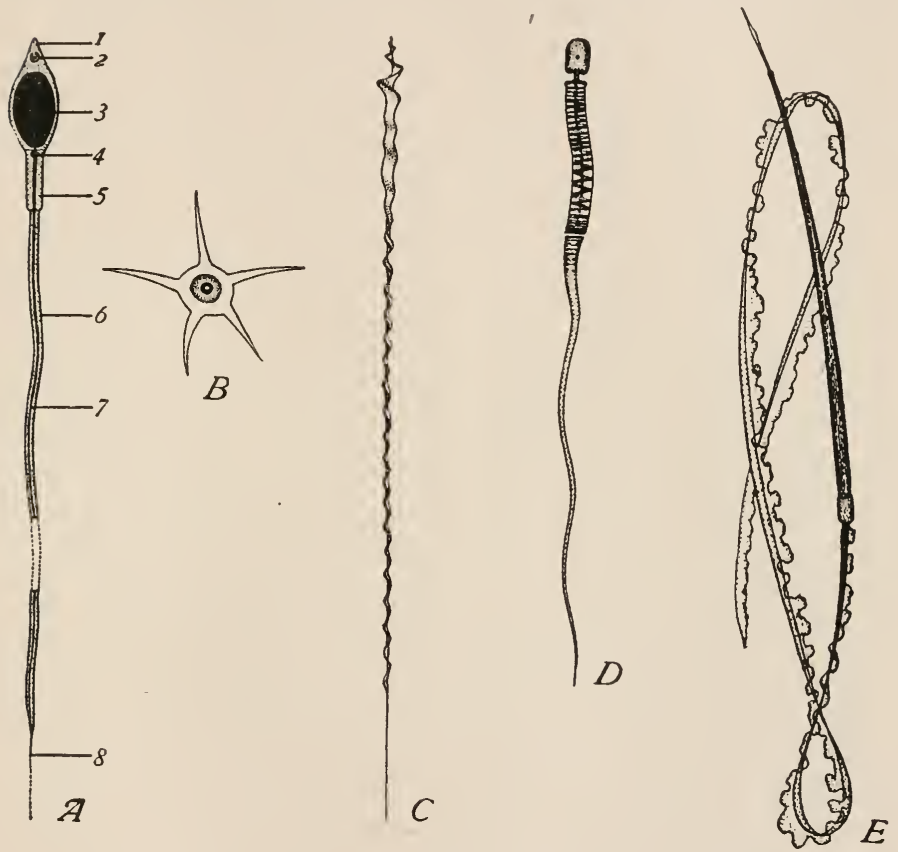

Fig. I.-Spermatozoa of various animals: $A$, Diagram of the flagellate spermatozoön (after E. B. Wilson): I, perforatorium; 2, acrosome; 3, nucleus; 4, centrosome (end knob); 5, middle piece; 6, involucre (envelope) of the tail; 7 , axial filament; 8 , end piece. $B$, Spermatozoön of a crab (Maia, after Grobben). C, Spermatozoön of a bird (Phyllopneuste, after Ballowitz). D, Spermatozoön of a salamander (Amphiuma, after McGregor).

reasons the perforatorium. There is usually no distinguishable cytoplasmic mantle around the nucleus, though theoretically such a mantle should be present. The middle piece usually includes the centrosomal 
structures and mitochondria of the spermatid; the tail includes an axial filament which arises from the centrosome in the middle piece or at the base of the head; this is surrounded by a protoplasmic involucre, except for the end piece, which is usually free.

IV. THE ENTRANCE OF THE SPERMATOZOÖN AND THE CORTICAL CHANGES OF THE EGG

Under the usual conditions of insemination the number of spermatozoa vastly exceeds that of the ova. Depending upon the concentration of the sperm, an ovum may be associated with one to several hundred spermatozoa. As spermatozoa tend, under uniform conditions, to form a homogeneous suspension, i.e., to be equally spaced, their actual aggregation with reference to the ova indicates some form of mutual interaction which has been variously interpreted. An old and favored form of interpretation has been in terms of chemotaxis; the ovum was supposed to secrete some substance that directs the movements of the spermatozoa toward it. Many ova (e.g., echinoderms, some annelids, etc.) possess a gelatinous external layer which seems to entangle spermatozoa and hold them, and this is undoubtedly a factor in such cases in the aggregation of spermatozoa around the eggs. There is also the possibility in some cases that spermatozoa adhere to ova and thus tend to aggregate, and this adhesion may be specific. Such questions will be discussed later.

In most species but a single spermatozoön enters the ovum, and as soon as this happens others are in some way barred. Normally such ova are monospermic, but if the ova are injured before insemination, two or 
more may enter a considerable percentage of eggs; and the same result may be obtained to a lesser extent by very heavy insemination. Such polyspermy in normally monospermic ova leads to abnormalities which soon result in the death of the eggs. There are, however, certain species which are normally polyspermic; most of these, as, e.g., Selachia, reptiles, and birds have very large ova. These questions will also be discussed later.

The actual penetration of the spermatozoön into the ovum was first observed in the sea urchin by Fol, in 1876 . (See discussion in chap. i, p. 16.) According to his account the first spermatozoön which comes in contact with the gelatinous layer that surrounds the egg enters it at once and its point comes in contact with the egg, usually within a second or two. The movements of the tail then slacken and the head of the sperm elongates and enters the egg. The tail remains visible for some seconds; then it disappears from sight. The head of the sperm forms a small nucleus, "male pronucleus," within the egg. In the starfish he described a small protuberance of clear protoplasm, the "fertilization cone," arising from the surface of the egg at the point of contact of the spermatozoön, lasting but a few seconds, and appearing to aid in the engulfing of the spermatozoön in the egg.

In most forms the process of penetration is so rapid that the details are not readily observed; in Nereis, however, I have found a form in which the final penetration of the spermatozoön does not occur until about fifty minutes after insemination, in which, therefore, all the details of the penetration may be observed (Figs. 2 and 3). The egg is provided with a tough 
FIG. 2.-Drawings from photographs of Nereis eggs, in a suspension of India ink in sea-water : $a$, before insemination; $b$, three minutes after insemination; $c$, twelve minutes after insemination. $a$, The uninseminated egg is bounded by a strong membrane of almost chitinous consistency; within this is a cortical layer without yolk granules, and of alveolar structure; $b$, immediately after attachment of the spermatozoön (not shown in the figure) the egg extrudes a transparent jelly from the alveoli of the cortical layer; $c$, the secretion of the jelly is completed; the walls of the emptied alveoli of the cortical layer now appear as radiating lines crossing the perivitelline space. The spermatozoön is seen (to right) with a cone of ink extending into the jelly where its tail lies; the protoplasm of the egg forms a fertilization cone which crosses the perivitelline space and touches the membrane beneath the spermatozoön. 
vitelline membrane beneath which is an alveolar cortical layer (Fig. 2a); the large germinal vesicle is central in position; the protoplasm contains numerous yolk spheres and a broad equatorial band of refringent oil drops. When insemination takes place, a large number of spermatozoa become attached to the ovum, if the sperm is present in excess. In about two or three minutes all spermatozoa, with the exception of one, which is alone concerned in the subsequent fertilization, begin to be carried away from the surface of the egg by an outflow of jelly, derived from the alveoli of the cortical layer, which are gradually emptied, thus establishing a perivitelline space crossed by the delicate protoplasmic walls of the original alveoli. A transparent fertilization cone then arises from the inner wall of the perivitelline space opposite the attached spermatozoön and extends across the space until it touches the membrane at the point of attachment of the spermatozoön (Fig. $2 C$ ). The perforatorium of the spermatozoön pierces the vitelline membrane and becomes imbedded in the cone. These phenomena occupy about fifteen minutes. The cone then gradually flattens out, but stained sections show that it persists as a modified area of the protoplasm. For about thirty minutes more no obvious changes occur. The head of the spermatozoön then disappears rather abruptly into the ovum, and the tail and middle piece are left behind on the surface of the vitelline membrane.

Stained sections show the details of the final penetration of the sperm head very beautifully (Fig. 3). The complex made up of the head of the spermatozoön and the fertilization cone act as a unit. The cone 
retreats into the interior of the protoplasm and the head of the spermatozoön becomes a narrow chromatin band as it enters through the minute aperture in the vitelline membrane. It is quite obvious that the initiative in the final act of penetration is on the side of the

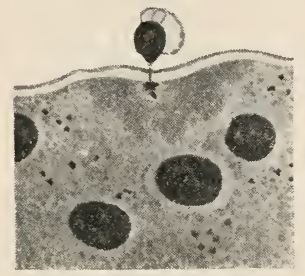

a

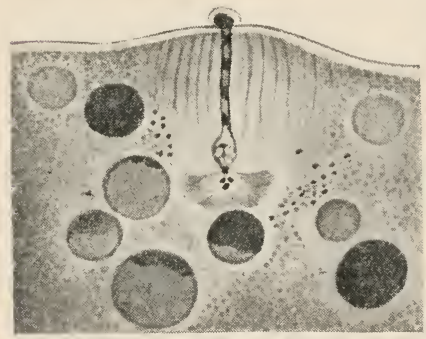

d

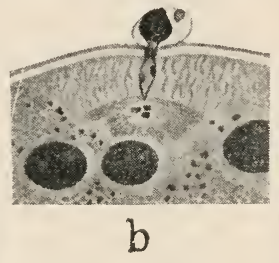

b

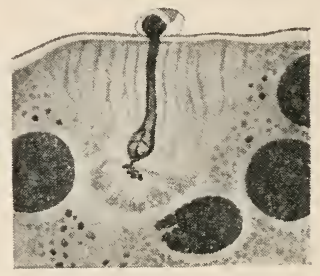

C

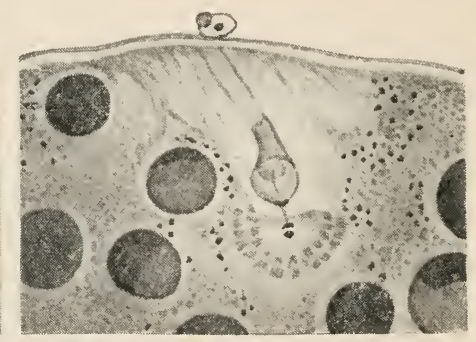

e

FIG. 3.-Penetration of the spermatozoön in the egg of Nereis, from sections: $a, 37$ minutes after insemination; $b, c, d$, three stages from eggs killed $48 \frac{1}{2}$ minutes after insemination; note that the cone sinks into the egg and draws the spermatozoön after it; $e, 54$ minutes after insemination; the head of the spermatozoön now entirely within the egg is contracting; note that the middle piece remains on the membrane; it does not enter the egg; the tail also remains outside.

ovum. The fertilization cone is engulfed by the egg protoplasm and draws the sperm nucleus after it. These events can be understood by assuming that the spermatozoön causes a local diminution of surface tension of the egg in the first place, thus causing an 
outflow of protoplasm which is the fertilization cone; that then by coagulation in the cone the surface tension of this region rises until it is overflowed by the surrounding protoplasm and sinks into the interior. The much more rapid penetration in other forms can be understood on similar principles.

In Nereis we have seen that the head of the spermatozoön alone enters the egg. The tail and middle piece remain outside. This is exceptional; in most cases the entire spermatozoön enters, as for instance in nematodes, Crustacea, mollusks, some insects, amphibia, and mammals (Fig. 4). In some sea urchins, according to descriptions of various authors, the tail is left outside, but the middle piece enters with the head. The middle piece and tail represent cytoplasmic elements, and the head is mostly nuclear material; it would appear from the case of Nereis that the latter is sufficient of itself for the subsequent events of fertilization; the middle piece and tail are concerned primarily in accessory functions of fertilization, such as locomotion. In the writer's opinion this is their only necessary function, and their entrance into the egg in most animals is incidental; however, this conclusion runs counter to certain conceptions, and we shall therefore return to its discussion later.

With the attachment of the spermatozoön to the egg and its penetration there are always associated certain changes in the cortex of the ovum which vary considerably in their morphological expression in different forms. The case of Nereis shows that actual penetration is not necessary for these changes, but the act of penetration is so rapid in most forms that it is 
usually completed before the cortical changes are evident. These changes are the most obvious indicia of successful insemination, and, as they are usually accepted in experimental parthenogenesis as indications of initiation of
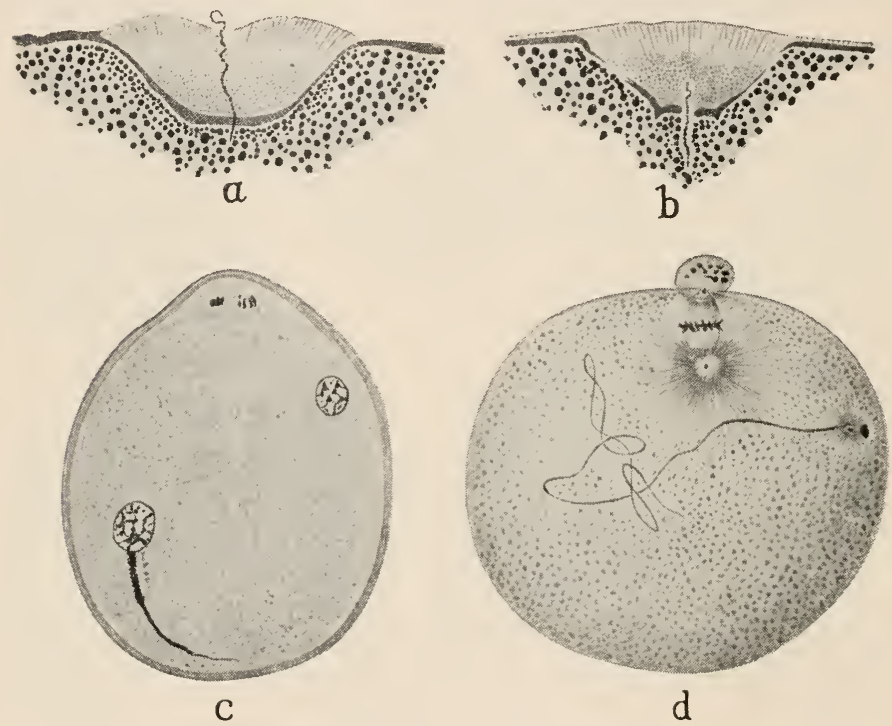

FIG. 4.- $a$ and $b$, penetration of the spermatozoön in the oligochaete Rhynchelmis (after Vejdovsky and Mrázek). Note the extensive yolkfree cone produced in the egg cytoplasm. $c$, Spermatozoön in the egg of the bat Vespertilio noctula (after Van der Stricht). The entire spermatozoön enters. $d$, The spermatozoön in the egg of the snail Physa fontinalis (after Kostanecki and Wierzejsky). The long coiled tail of the spermatozoön lies in the egg cytoplasm; sperm centrosomes with aster between tail and head.

development, it is important to describe them. They are of great significance for the physiological problems which are considered later, and we must examine them with a view to distinguishing the general from the more special features. 
It is obvious that from a functional point of view all the environmental relations of the ovum are involved in the character of the cortex; changes affecting its permeability must concern the rate of cellular respiration, access of water and electrolytes to the interior, and discharge of substances from the cell-in short, conditions that affect its metabolism and hence the rate of developmental processes. We have seen in the case of Nereis that the cortical changes involve a discharge of material in the form of a clear jelly from the cortex of the egg and the consequent appearance of a perivitelline space. In most other eggs, if there is a discharge of material it is of such a nature as not to be morphologically distinguishable. It has been inferred in certain cases from the fact that the diameter of the egg appears to be slightly reduced following insemination (see p. I48); however, such measurements are pretty close to the margin of error.

In practically all eggs a perivitelline space appears between the vitelline membrane and the surface of the egg as a result of insemination. The appearances vary here according as there is, or is not, a definite vitelline membrane prior to fertilization. When such a membrane is present, as in all vertebrates for instance, it merely becomes more conspicuous in consequence of the formation of the clear space. In the frog's egg the formation of the perivitelline space, which develops rapidly after insemination, enables the egg to rotate within the membrane in accordance with the specific gravity of its constituent parts. In teleost eggs the appearance of the space is accompanied by a clearing of the cortical layer of protoplasm, which has been 
interpreted as due to a discharge of numerous minute refringent droplets previously present. In some other cases a membrane appears to be formed as a result of fertilization, separated from the surface of the egg by a narrow perivitelline space. Such a membrane is hence often called the fertilization membrane. In the sea urchin (Fig. 5) the appearance of this membrane

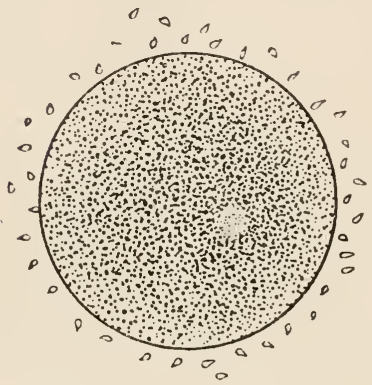

$a$

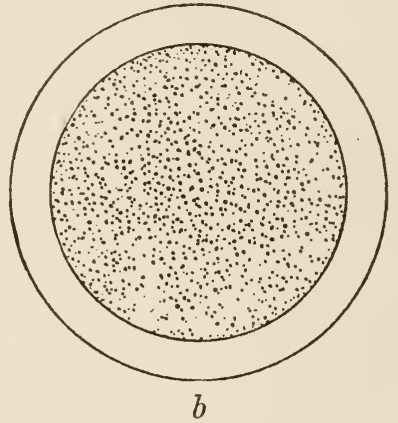

FIG. 5. - The formation of the fertilization membrane in the egg of the sea urchin Strongylocentrotus purpuratus: $a$, unfertilized egg surrounded by spermatozoa; $b$, the same egg about two minutes later after the entrance of the spermatozoön (from Loeb, Artificial Parthenogencsis. and Fertilization, p. 17 ; by permission of the author).

is a very obvious and reliable indicator of fertilization. Fol, who first observed it, regarded it as a device for the prevention of polyspermy, as it begins to form at the point of penetration of the spermatozoön and spreads over the entire periphery "with a rapidity that would be inconceivable if one did not witness it." Whether it is a preformed delicate membrane that is merely elevated from the surface of the egg or a kind of secretion from the egg can hardly be answered from observation alone, 
though the former view appears to be more probable. In Ascaris megalocephala a very thick and resistant fertilization membrane is formed as an immediate result of fertilization (Fig. 6).

These changes have no doubt some common physiological basis. Their special features may, however,
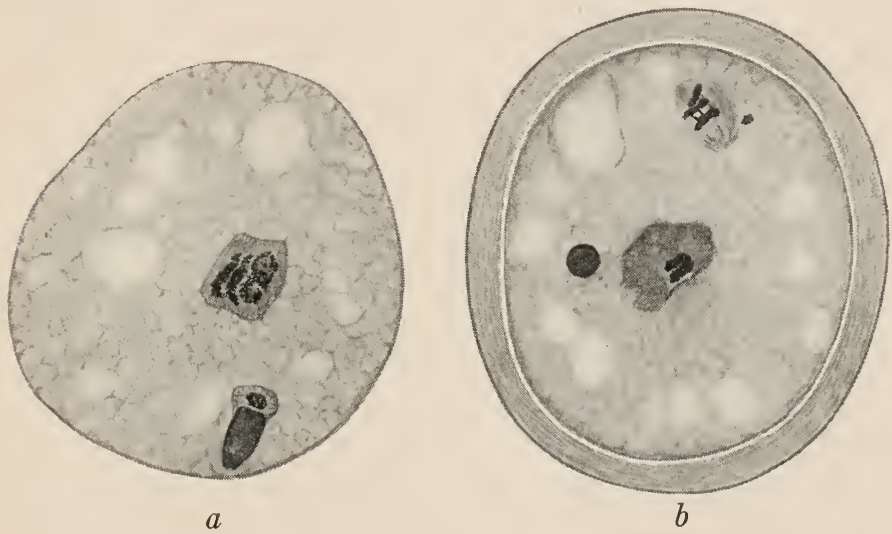

FIG. 6.-Entrance of the spermatozoön and formation of the fertilization membrane in Ascaris megalocephala: a, The entire spermatozoön within the egg; central germinal vesicle with tetrads; the egg is membraneless. $\quad b$, The spermatozoön has reached the center of the egg and its cytoplasmic parts are disintegrating. First maturation spindle near the surface. A thick fertilization membrane has been formed, separated from the egg by a narrow perivitelline space.

also be adaptive in other senses. Thus the thick resistant fertilization membrane of Ascaris protects against the digestive juices of the host, the horse, and the rotation of the frog's egg rendered possible by the perivitelline space, equalizes internal strain due to differences in specific gravity of parts of the egg, and is quite essential to normal development. 


\section{THE INTERNAL PHENOMENA OF FERTILIZATION}

The morphological study of this subject consists in following the parts of the spermatozoön within the egg and in determining as far as possible their relations to constituent parts thereof up to the time when they can no longer be separately distinguished. The nuclear and cytoplasmic parts of the spermatozoön have very distinct histories and will therefore be separately treated.

I. The germ muclei.-The nucleus derived from the head of the spermatozoön is known as the sperm nucleus or male pronucleus. It is destined to unite with the egg nucleus or female pronucleus derived from the internal daughter-chromosome group of the second maturation division of the egg. In those cases in which the spermatozoön enters the egg prior to or during maturation the sperm nucleus must await the completion of the maturation divisions of the egg; it has therefore more time and undergoes more extensive changes before union with the egg nucleus than in those cases in which maturation of the egg is completed before fertilization.

Immediately after penetration the head of the spermatozoön rotates around a transverse axis through $180^{\circ}$ (Figs. $7 a-f, 8 a$ ), so that the base, which was external immediately after entrance, becomes oriented toward the center of the egg and the apex is directed externally (Henking, Wilson, Boveri, Meves, Lillie, etc.). This phenomenon is very general, and it may be universal. No adequate explanation has been found for it, and its significance is quite obscure. It is, however, correlated with the development of the sperm aster which always arises at the base of the sperm head. 
The sperm nucleus arrives in the egg with its chromatin in the most condensed condition. The nucleus then begins to enlarge by imbibition of fluid and tends

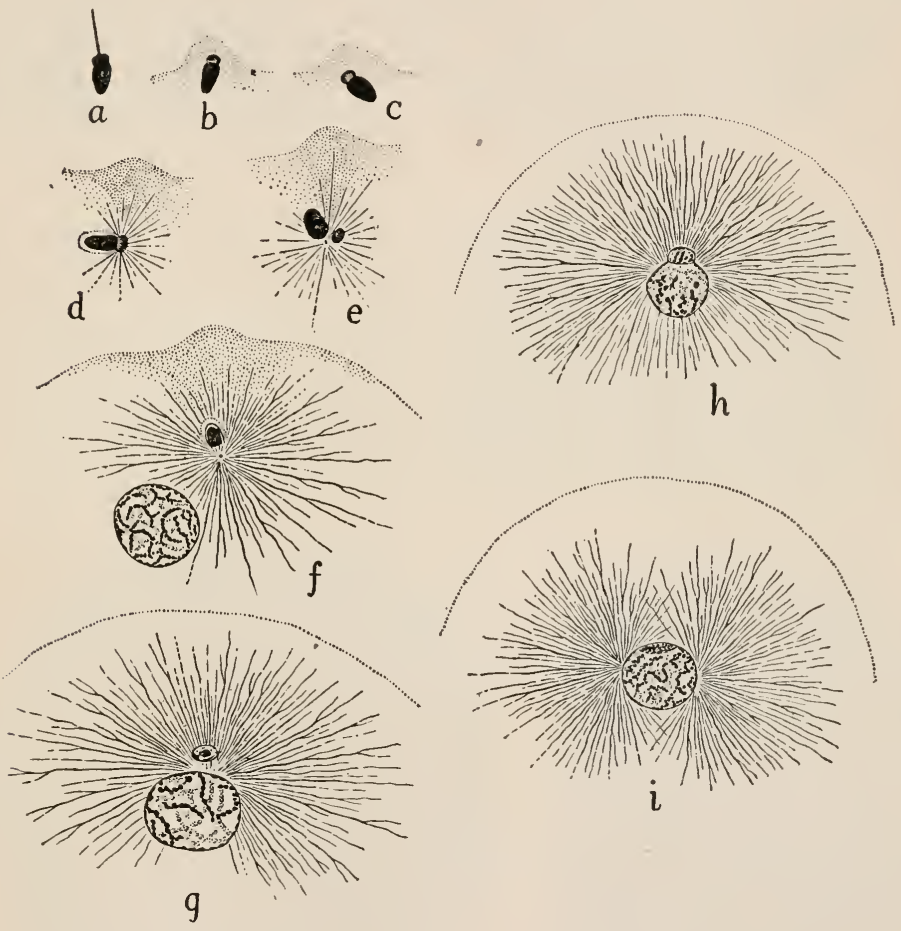

FIG. 7.-Fertilization of the egg of the sea urchin Toxopneustes (after E. B. Wilson): $a$, the spermatozoön; $b, c$, the sperm head and middle piece immediately after entrance; tail apparently absent; beginning of rotation $c ; d$, rotation half-way completed; origin of sperm aster; $e$, rotation completed, middle piece separated from sperm centrosome; $f, g$, approach of the germ nuclei; growth of the sperm aster; $h$, meeting of the germ nuclei; division of the sperm aster; $i$, first segmentation nucleus in which the sperm and egg components are readily distinguished. 

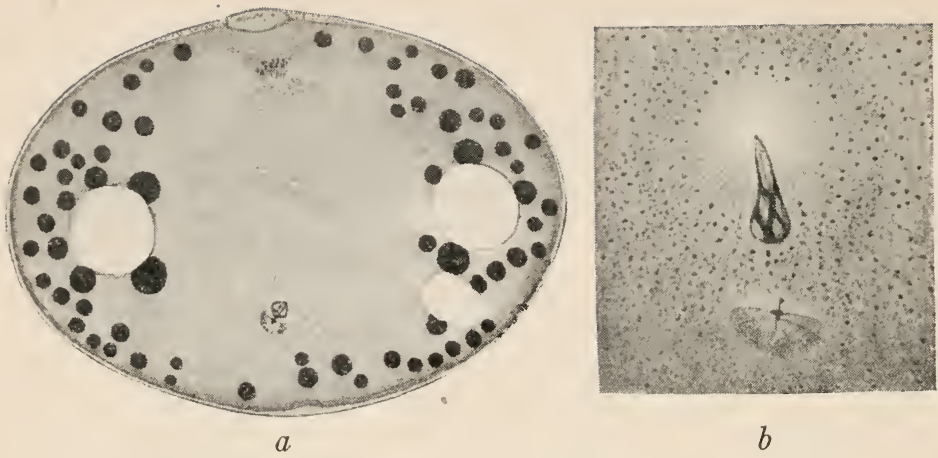

FIG. 8.--Sections of successive stages showing the internal phenomena of fertilization in Nereis.

$a$, Section of an egg 54 minutes after insemination. Cf. Fig. $3 e$. The head of the spermatozoön has rotated, the sperm nucleus is becoming rounded, and the sperm aster is beginning to arise opposite to the cone. The latter marks the apex of the sperm head. The first polar body is fully formed. $b$, The sperm cone-nucleus-aster complex of an egg 64 minutes after insemination. The sperm cone is now separated from the nucleus, and is destined soon to disappear. The sperm aster and centrosome better developed.
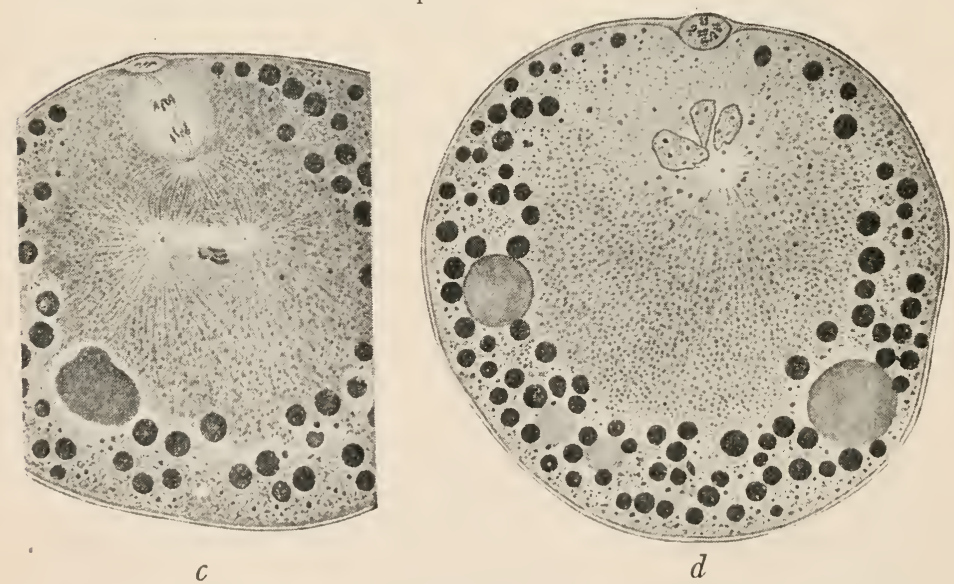

FIG. 8 (continued). $-c, 67$ minutes after insemination; stage of anaphase of second maturation division. The sperm aster has divided, forming an amphiaster. $d, 77$ minutes after insemination. The sperm nucleus lies to the left below; the sperm amphiaster has become reduced. The egg nucleus, which is formed by fusion of chromosome vesicles, is represented by two still unfused parts to the right above. 
to become vesicular. This change, however, proceeds relatively slowly during the maturation of the egg; in some cases, in which the enlargement of the sperm nucleus begins in the early stages of maturation of the egg, there is a halt or actual decrease in size during the later stages until the second polar body is formed, when the definitive increase in size ensues (e.g., Unio, according to Lillie, I895). In such cases the sperm nucleus after penetrating a short distance may cease to move (Unio), or it may penetrate to the center of the egg and then come to rest (Nereis, Fig. $8 c$ ). After maturation is completed the sperm nucleus and the egg nucleus enlarge in practically equal tempo and come together in a predetermined region of the egg (Figs. $8 d, e, 9)$.

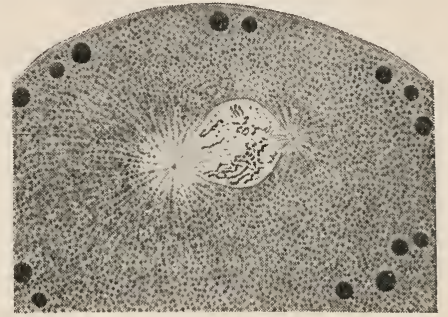

$e$

FIG. 8 (continued).- $e$, Somewhat later. The two germ nuclei have fused and the first cleavage spindle is forming with unequal centers. The chromosomes of sperm origin lie below; those of egg origin, above. Only a few of the latter fell in the plane of section.

They are then usually of the same size and appearance, so that they can be distinguished only by their positions or associations.

When maturation of the egg is completed before fertilization, as in the sea urchin, the egg nucleus and the sperm nucleus proceed directly to the place of meeting, and the sperm nucleus is much smaller than the egg nucleus at the time of union (Fig. $7 g, h, i$ ). The chromatin is, however, much more condensed and is equal in quantity to that of the egg nucleus; if the nuclei 
are prevented from meeting rapidly, e.g., by the use of anaesthetics, as in E. B. Wilson's experiments (I90I), the sperm nucleus may grow to the size of the egg nucleus, and, after recovery from the anaesthetic effect, the two equal nuclei unite.

We have, therefore, to consider two questions to the extent that morphological observation admits: (a) What determines the movements of the germ nuclei within the egg and their union? (b) What is the nature of the union quantitatively and qualitatively?

a) As regards the first question, Roux, in $188_{3}-87$, resolved the movements of the sperm nucleus within the egg into two components, which he called the penetration path and the copulation path. His observations were made on the frog's egg, in which the spermatozoön leaves behind it a trail of pigment, marking out its path, which is usually curved or exhibits an angle. He conceived the first part of the path to be a continuation of the direction of penetration; the second part of the path he conceived to be determined by an attraction between the egg nucleus and the sperm nucleus. That there is an energy of penetration of the spermatozoön which persists in the same direction after entrance into the egg is scarcely tenable, because the penetration itself is not a result of the locomotor energy of the spermatozoön; there is also no reason to assume that the nuclei as such exert attraction on one another. Such an assumption has no basis in fact beyond the actual meeting of the germ nuclei, which can equally well be explained on other more reasonable and less mystical grounds. The view has been presented that the movements of the sperm nucleus 
are brought about by the sperm aster, the fibers of which were supposed to act as contractile elements.

The movements of the germ nuclei within the egg depend on conditions of equilibrium of the various cell constituents which constitute a definitely ordered stream of events. The localization of the nucleus within the cell is always determinate. We have therefore to conceive that, as both sperm nucleus and egg nucleus are in physiological relations to the same mass of cytoplasm, which is preparing to divide, they must reach the same position of equilibrium within the cell, and hence of necessity meet. Their coming together is due, not to mutual attraction, but to independent movements toward the same part of the developing egg. This tendency cannot, however, manifest itself until after maturation is completed; hence the movements of the sperm nucleus prior to the completion of maturation are not always directed toward the ultimate place of union of the germ nuclei, being under the influence of a different condition of equilibrium of the egg cytoplasm. The curved or bent path of the spermatozoön in certain cases follows from this, and it is not found in the echinids, where maturation is complete before fertilization.

b) The two nuclei thus united may fuse together to form a single nucleus called the first segmentation nucleus, in which it may be difficult to distinguish the two components for a certain period of time. But in many, perhaps most, cases the changes preparatory to the first cleavage of the egg begin before such a fusion occurs, and in these cases it is easy to determine that each germ nucleus contributes the same number of chromosomes to the first segmentation spindle (Fig. $9 a, b, d$ ). 
These are the only components of the germ nuclei that can be traced morphologically beyond this time. Even in those cases in which a typical first segmentation nucleus occurs (Fig. $7 i$ ) it is equally certain that the maternal and paternal chromatins form equal chromo-
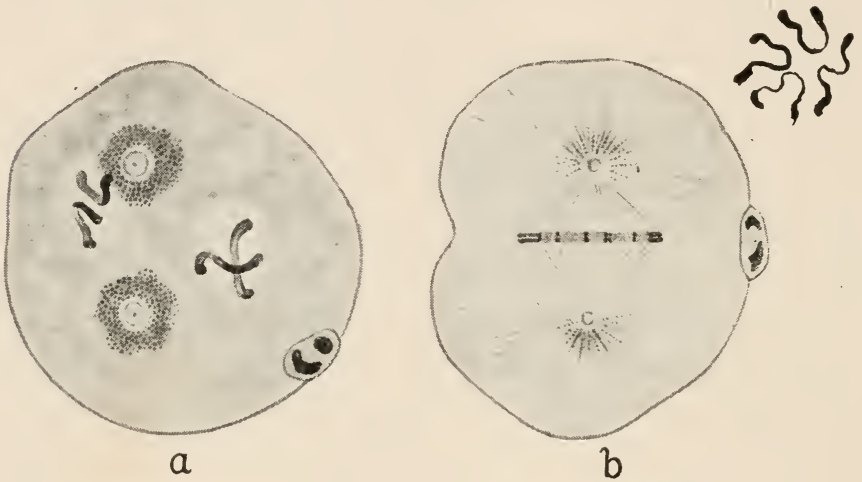

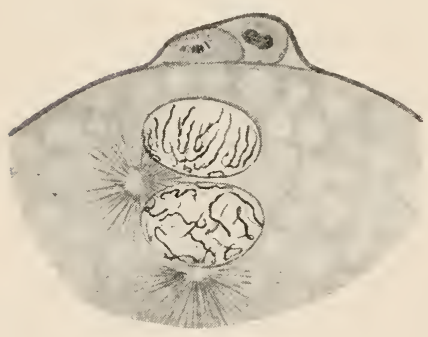

C

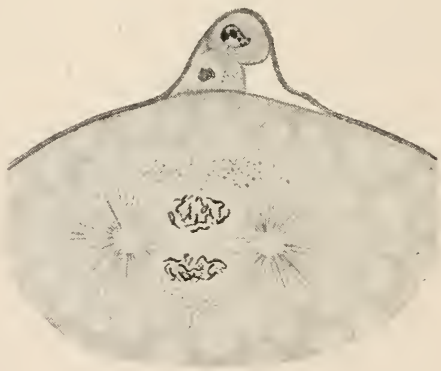

d

Fig. 9.-(After Boveri): $a$, Pronuclei of Ascaris megalocephala, approaching between the attraction spheres of the first cleavage spindle, each containing two chromosomes. $b$, The first cleavage spindle fully formed; it contains four chromosomes which are shown in a polar view of the same spindle in the small figure to the right above. Two of these chromosomes are of maternal and two of paternal origin. c, Meeting of germ nuclei of Pterotrachea (pteropod); each contains sixteen chromosomes. $d$, Formation of the first cleavage spindle in Pterotrachea. The maternal and paternal chromosome groups are separate. 
some groups upon the first segmentation spindle, because they are usually slightly separated and it is known that each germ nucleus contains only the haploid number of chromosomes, whereas the first segmentation spindle has always the diploid number.

Van Beneden ( 1883 ) was the first to discover this invariable law of fertilization; he discovered that in Ascaris megalocephala each germ nucleus produces two chromosomes, so that the first segmentation spindle contains four (Fig. 9). These divide longitudinally in the usual way so that the first two cells each receive four daughter-chromosomes, two of maternal origin and two of paternal origin; he assumed that this condition was transmitted to all subsequent generations of cells, which thus possess nuclei of biparental origin. This involves the idea that maternal and paternal chromatins remain distinct within each cell throughout the life-history, and thus a basis is furnished for explaining both the intimate intermingling of paternal characteristics in the offspring and the independent behavior of such characteristics in heredity. Subsequent studies of the behavior of the germ nuclei include a large number of forms and have demonstrated the same principles to be universal.

We must dwell further upon this question. Undoubtedly the most fundamental fact which the morphological study of fertilization has revealed is the equivalence of the germ nuclei with reference to the chromosomes. This is a definite and undeniable positive result which is in perfect agreement with the equivalence of the sexes in inheritance. In all other respects the germ cells are differentiated in opposite directions; 
in this one particular they are demonstrably alike. No wonder that this determination has furnished the foundation for the most elaborate chromosome theories from the time of Weismann until the present day, which have been supported, changed, and rectified by the most painstaking investigations of chromosome behavior in all stages of the cycle of the germ cells.

This morphological and genetic equivalence is also physiological in the sense that either germ nucleus is adequate in itself for purposes of development. This is proved for the egg nucleus by artificial parthenogenesis, and for the sperm nucleus by those experiments in which an enucleated fragment of an egg fertilized by a single spermatozoön has been proved to develop (merogony, see p. I62).

Differences between the germ nuclei on the morphological side have been shown to occur between those chromosomes which are concerned in sex determination (Morrill, I910; Mulsow, I912; see Fig. Io); on the genetic side differences exist, undeterminable morphologically, which depend on the genetic history of the individual and which are of an entirely similar order in both germ nuclei. The foundation of all genetic theory of sexually produced organisms thus rests upon the demonstrated equivalence of the germ nuclei.

2. Other constituents of the spermatozoön in the egg.In addition to the nucleus the spermatozoön usually introduces certain cytoplasmic constituents into the egg, but as contrasted with the nucleus there has been the greatest difficulty in tracing the fate and determining the significance in fertilization of these elements, which, moreover, vary greatly in different groups of 
animals. In some cases, as in Ascaris, the quantity of cytoplasm thus introduced is very considerable (Fig. 6a); in other cases, as in Nereis (Fig. 3), none can

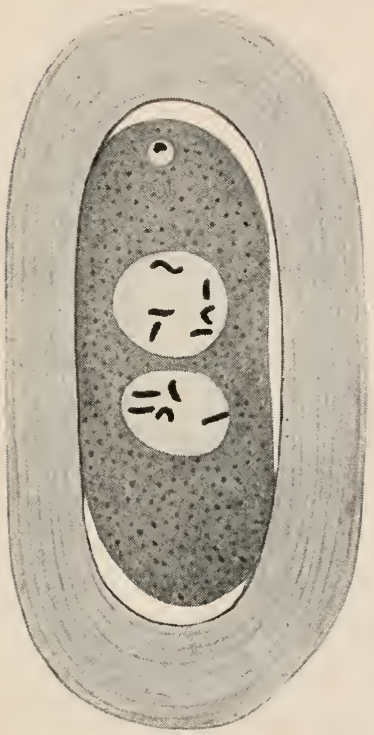

$a$

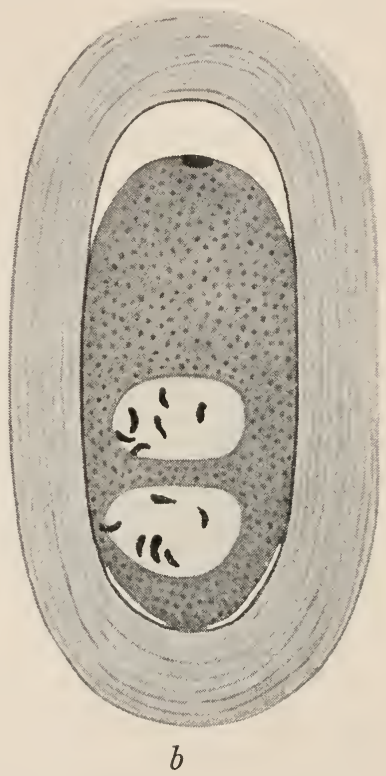

FIG. Io.-Fertilization of a nematode (Ancyracanthus cystidicola) (after Mulsow): In each figure the upper nucleus is the egg nucleus, the lower the sperm nucleus. In both figures the egg nucleus contains six chromosomes; in $a$ the sperm nucleus contains five chromosomes, in $b$ six. The combination $6+5$ in $a$ gives the male number, eleven; the combination $6+6$ in $b$ gives the female number, twelve. The two classes of spermatozoa are hence regarded as male producing and female producing respectively.

be demonstrated to occur. It is generally believed with good reason that the perforatorium and tail have no further significance in fertilization after penetration is once achieved; in any event they are not traceable 
after a very early stage. Attention has been focused, largely on theoretical grounds, on two constituents intimately associated with the middle piece of the spermatozoön, viz., the centrosome and the mitochondria derived from the spermatid.

a) The sperm centrosome: Shortly after penetration of the spermatozoön in very many animals an aster arises in association with the sperm nucleus (Figs. $4 d, 7,8$ ); it is centered at the base of the sperm head in all cases in which its actual beginning has been traced, and it has therefore been supposed to be caused by the middle piece of the spermatozoön; a central body soon appears in the aster; this is the sperm centrosome, which has been regarded, therefore, as derived from the middle piece; these observations have been correlated with the histogenesis of the spermatozoön, in which it has been shown in many cases that the centrosome (or part of the centrosome) of the spermatid is located in the middle piece. It was therefore concluded that the centrosome of the sperm aster within the egg is derived from the centrosome of the spermatid. It was further determined in a considerable number of cases that the sperm aster by division forms an amphiaster which produces the first cleavage of the egg (Figs. 7, 8). From reasoning of this kind Boveri deduced his famous theory of fertilization that the initiation of development is due essentially to the introduction of an active division center into an egg devoid of centrosomes, and hence without capacity for division. This conception obviously involves a whole theory of cell division, and reciprocally such a theory should be supported or weakened by the facts of fertilization. 
The exact facts about the origin of the sperm aster in fertilization should therefore be most carefully ascertained. In the sea urchins, where the process was first carefully studied, the aster begins to be visible shortly after the rotation of the sperm head has begun. It is focused at the base of the sperm head, thus in the region of the middle piece; the latter is not, however, in the center, but to one side, of the aster, as Meves's very detailed study shows (cf. Fig. 7e). A differentiated centrosome is not demonstrable in the center of the forming aster (Fig. $7 d$ ), or at most, as Boveri says, it is such an immeasurably small granule that it can be seen only in especially favorable cases, and then only because of its position; it is never to be seen prior to the origin of the aster. In Nereis, in which the middle piece of the sperm does not enter the egg, the sperm aster appears at first to be focused at the base of the sperm nucleus itself and only by degrees separates from it and acquires a distinct centrosome (Figs. 8a, b,c). I have, moreover, been able, by application of a strong centrifugal force to the inseminated eggs, to remove not only the middle piece but also variable parts of the base of the sperm head itself before penetration, so that a reduced sperm nucleus forms after penetration. In the case of such nuclei asters form at the base, opposite to the perforatorium, in the usual way, which are more or less proportional in size to the nuclear fragment concerned (Fig. I I). This shows that the sperm nucleus itself in this case has the capacity to induce localized aster formation in the egg cytoplasm; this reaction might be conceived to be due to a specific centrosome substance contained within the nucleus, but for this there is no evidence. 
The formation of asters is postponed in some animals until about the time of meeting of the germ nuclei, and then it is often difficult to determine whether or not

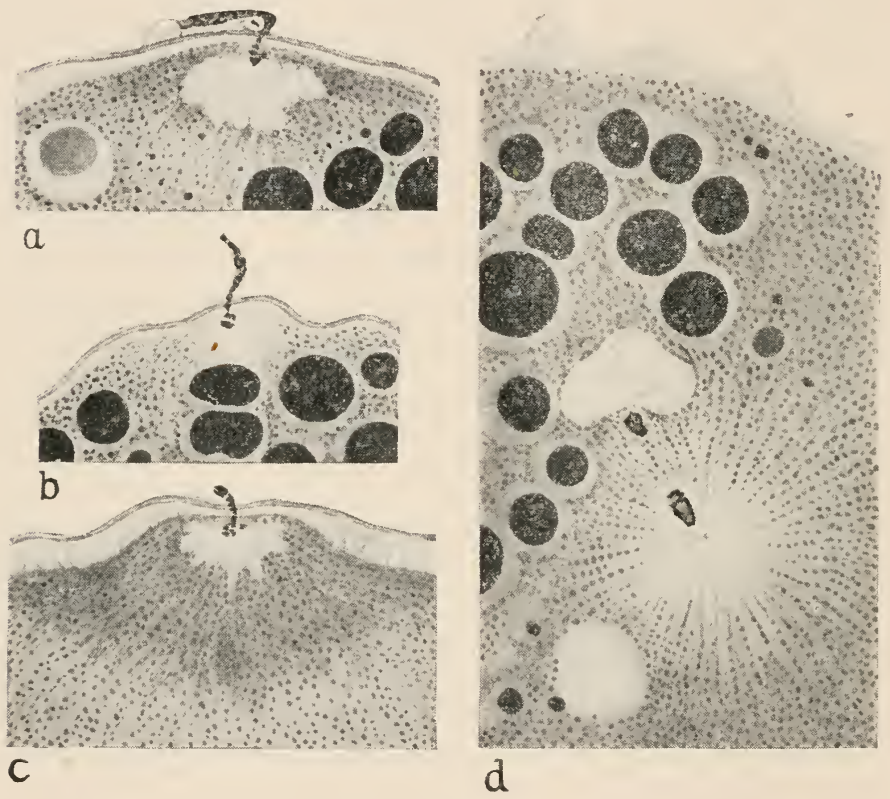

FIG. II.-Effects of centrifugal force on penetration of the spermatozoön in Nereis: $a, b$, and $c$ show removal of varying portions of the sperm head before penetration; $d$ shows the later history of an egg into which a minute portion of the spermatozoön has entered; this part has produced a sperm aster and centrosome, although it represents only a fraction of the apical end of the sperm head similar to the piece shown in $c$.

the sperm components are alone concerned in it. In Crepidula (Conklin) and Unio (Lillie) there is evidence that each germ nucleus causes formation of one aster of the first cleavage. 
In those cases in which the history of the sperm aster is clearly shown throughout (echinids, many annelids and mollusks, ascidians, etc.), the central body of the aster soon divides in two centrosomes which move apart with consequent formation of an amphiaster (Figs. 4, 7, 8), which becomes the achromatic part of the first cleavage spindle. In echinids (Fig. 7), in which maturation is completed and the egg nucleus formed prior to insemination, the division takes place about the time of meeting of the germ nuclei, for there are no preparatory changes remaining to be accomplished by the egg and the two nuclei therefore unite very rapidly. The plane of the separation in this case is at right angles to the line uniting the centers of the two germ nuclei. In those cases in which the egg has part of the maturation process still to complete the sperm amphiaster remains more or less quiescent during maturation (Fig. 8), but it may entirely disappear (Unio) or diminish to a variable extent (e.g., Nereis), and the asters of the first cleavage spindle are to this extent new formations, though certainly in some cases, and possibly in others, formed around the original centers.

The morphological variations are very numerous with respect to the genetic behavior of the first cleavage amphiaster when we compare all the various species studied. As the physiological foundation must be supposed to be uniform we can interpret the morphological variations as due to time differences in the components of the physiological reactions in different species.

When we find that the sperm nucleus behaves differently in respect to aster formation from the egg 
nucleus within the same body of cytoplasm we must attribute this either to the presence of some specific substance originally present with the former, but not with the latter, or to some other differential organization of the substances of the nuclei concerned. Boveri took the former alternative and formulated it in terms of a morphological theory of cell division. He thus brought under one point of view the origin and localization of the sperm aster and the phenomena of cell division, so that the theory of fertilization became part of a theory of cell division. He stressed cell division as the fundamental factor of development and overlooked the more immediate and essential result of activation of metabolism.

The centrosome theory of cell division has not, however, maintained itself in the face of advancing knowledge of cell morphology and physiology. Boveri's theory of fertilization would thus lose much of its significance even if it were demonstrated that the sperm centrosome is a derivative of the spermatid centrosome, and this is far from being the case. Not only is there a hiatus in the history, but the experiments on Nereis previously cited show that the sperm nucleus itself contains material for inciting formation of a sperm aster and its centrosome. It is possible to attribute this to specific centrosome material contained within the nucleus, if the centrosome theory of cell division is adhered to, but it is also possible to explain it in a more physiological manner to be considered hereafter (p. 265). A finer morphological analysis is no doubt possible and will be useful, but we must recognize the fact that in fertilization we are dealing with a physio- 
logical process that requires experimental methods for its solution.

b) The mitochondria in fertilization: The other cytoplasmic element that has been claimed to play an important rôle in fertilization is the mitochondria (called plastochondria by Meves), which form such an apparently important constituent of all classes of cells. The special protagonist of the significance of this substance in fertilization is Meves, who maintains that it is concerned in the transmission of hereditary characteristics, basing this view on the part that he believes it to play in protoplasmic differentiation. He found an apparently very demonstrative case in Ascaris megalocephala (Meves, I9I I), the spermatozoa of which contain large numbers of mitochondrial granules in the large cytoplasmic body surrounding the nucleus (cf. Fig. 6). The entire spermatozoön penetrates in this case, and the mitochondrial granules continue to surround the nucleus long after penetration; by degrees they become intermingled with the mitochondria of the egg, and Meves even hazarded the conjecture that they possibly united by pairing with the mitochondrial granules of the egg; he therefore considered his view that the mitochondria play an important rôle in heredity justified.

Pursuing the matter farther Meves (I9I4) made an exceedingly careful study of the fate of the middle piece of the spermatozoön in the fertilized eggs of echinids. By a veritable triumph of technique he found that this minute fragment could be traced intact into one of the first two cells; in successive cell divisions it always passes intact into one of the daughter-cells only, and may be found in the eight-celled stage either 
in one of the animal or one of the vegetative quartet; he even traced it to the thirty-two-celled stage. Thus it is not broken up and distributed to all of the cells, as the theory that it represents a substratum for bearing heredity factors would require, nor does it exhibit any signs of activity. In the egg of an ascidian (Phallusia) the same author (I9I3) could follow the sperm plastochondria through part of the fertilization stages, but then lost sight of them. Van der Stricht, in the bat, and Lams, in the guinea-pig, found that the tail of the spermatozoön and connecting piece which carries plastochondria pass into one only of the first two cells. Finally, in Nereis, according to my own observations, the middle piece of the spermatozoön, which is usually supposed to carry the plastochondria, does not enter the egg at all.

Whatever may be the function of the mitochondria in cell physiology it must be admitted that the study of fertilization has shown no reason for the assumption that their introduction into the egg by the sperm is necessary for the transmission of paternal characteristics. The variable quantity in different cases and the distribution to single blastomeres in certain cases exclude the hypothesis that they have any specific paternal hereditary effect. There is no reason to deny that sperm mitochondria function in the egg when present, but if so it is probable that they are not differentiated in their chemical composition or genetic behavior from the mitochondria of the egg itself.

3. The egg cytoplasm.-The egg cytoplasm and its inclusions constitute an exclusively maternal material which determines many of the characters of early embry- 
onic stages; such characters are therefore exclusively maternal. The materials of the cytoplasm are, however, being constantly consumed in the metabolism, and the process of renewal and increase of such materials involves interaction of nucleus and cytoplasm; therefore the purely maternal cytoplasm soon disappears and is replaced by cytoplasm formed under the influence of the biparental zygote nucleus. Maternal cytoplasmic characters cannot therefore survive long in the lifehistory, unless the cytoplasm contains elements either that survive as such or that increase independently of the nucleus. Mitochondria granules may be such elements, and in plants also plastids, including the chlorophyll grains of chloroplasts. There may be conceivably other chemical substances that have a purely cytoplasmic history, but for this we have little evidence. We have, however, adequate cytological grounds in such persistent elements of composition of the egg cytoplasm for the explanation of the rather rare cases of exclusively maternal inheritance from a zygote known to the geneticists. Purely paternal inheritance probably does not exist in any regularly formed zygote, and this constitutes an independent line of negative evidence against cytoplasmic inheritance from the male side.

\section{POLYSPERMY}

The ova so far considered are normally monospermic; there are, however, certain ova into which more than one spermatozoön enters normally, and practically all ova may become polyspermic under abnormal conditions. We may thus distinguish normal, or physiological, and pathological polyspermy. 
I. Physiological polyspermy.-Physiological polyspermy occurs in vertebrates possessing eggs of large size devoid of a strong membrane and micropyle, in which penetration of the spermatozoön may occur at any spot within a large area. We may conceive in such cases that the protective mechanism against penetration of supernumerary spermatozoa, which begins to form at the point of penetration and spreads, does not extend itself with sufficient rapidity to protect the entire fertilizable surface from other spermatozoa. The large eggs of sharks, of some amphibia, of reptiles, and of birds are thus polyspermic. Polyspermy occurs in the eggs of several classes of insects which possess several micropyles (Henking, I89I). Among animals possessing small eggs it occurs apparently only.in Bryozoa, in which the spermatozoa are united in bundles (Bonnevie, 1907).

In all cases of normal polyspermy only one of the sperm nuclei formed from the entering sperm heads unites with the egg nucleus, and the supernumerary sperm nuclei are disposed of in certain ways. Thus the fertilization in such cases is finally monospermic. In the fertilization of the pigeon, for instance, from about twelve to twenty-five spermatozoa enter the germinal disk as soon as the ovum is released from the ovary (Harper, I904). The second maturation division occurs after this, and during this time the sperm heads accumulate in a ring of protoplasm surrounding the maturation spindle at some distance from it (Fig. I2). After completion of this division and formation of the egg nucleus one of the sperm nuclei moves centrally and unites in the usual way with the egg nucleus, while 
the supernumerary sperm nuclei move away from the center as though repelled and accumulate in the peripheral periblast. Here they undergo division and produce cell areas in the periblast, which are a conspicuous

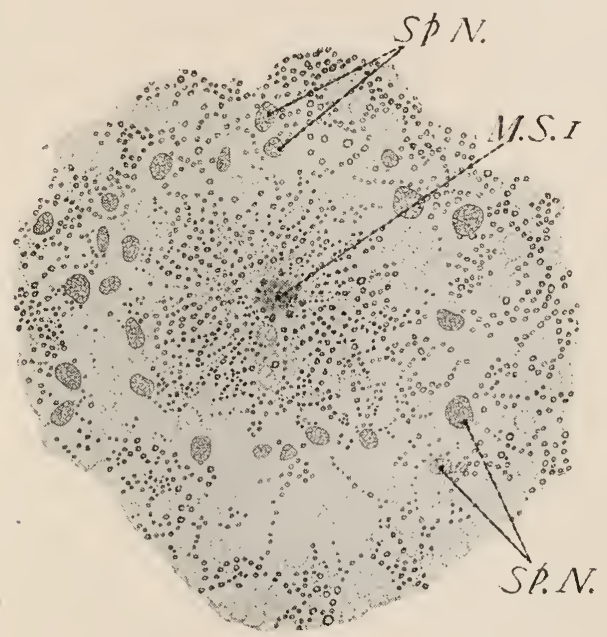

FIG. I 2,-Part of a horizontal section of the germinal disk of a pigeon's egg freed from the ovary, but not yet in the oviduct. First maturation spindle (M.S. I) cut transversely in the center; sperm nuclei $(S p . N$.) surrounding it (after E. H. Harper).

feature of the development up to about the thirtytwo-celled stage, at which time, according to Miss Blount; they begin to degenerate, and soon entirely disappear. The segmentation nucleus in this case is thus formed of the union of the egg nucleus and a single sperm nucleus in the usual way, and all nuclei of the embryo are derived from this by karyokinetic division.

In Selachia the phenomena are similar, but Rückert maintains that the supernumerary sperm nuclei persist 
in the periblast which forms extra-embryonic tissue. It may be, however, that this conclusion is due to confusion with other nuclei of the periblast derived from the segmentation nucleus.

The peripheral migration of the supernumerary nuclei furnishes an interesting problem. Miss Blount has suggested in her study of these nuclei in the pigeon that the phenomenon can be understood on the simple assumption that migration of the sperm nuclei is always into unfertilized protoplasm, i.e., such as has not yet been modified by the sperm nuclei; the central protoplasm surrounding the egg nucleus is thus modified by the first sperm nucleus that moves into it, but the peripheral protoplasm is still virgin soil.

There would thus seem to be no advantage connected with physiological polyspermy; at the most it is harmless, and merely represents a condition in which the final determination of the successful spermatozoön is completed within the egg. Such eggs have in some way overcome the usually harmful effects of polyspermy. Bonnevie (1907), however, is of the opinion that in Bryozoa at least it is significant for the maintenance of the organism; she suggests that the supernumerary spermatozoa furnish extra-nuclear chromatin of physiological importance. There is, however, no adequate foundation for such a view at present.

2. Pathological polyspermy.-Eggs normally monospermic may be entered by more than one spermatozoön if they are allowed to become stale before insemination; the same result may be attained by exposing them to the action of various injurious substances, such as chloroform, chloral hydrate, cocaine, nicotine, strychnine, quinine, 
and many others, in appropriate concentrations for proper periods of time. Moreover, a very heavy insemination of any normal lot of eggs will usually yield a small percentage of polyspermy. The number of spermatozoa that may enter under such circumstances may vary from two to a considerable number. The first student of this subject, Fol, in 1877 , determined for the starfish and sea urchin that polyspermic eggs divide in more than two 'cells at the first cleavage and their subsequent development is never normal.

In 1887 O. and R. Hertwig published a detailed study of polyspermy in the sea urchin; each sperm nucleus forms an aster which subsequently divides to form an amphiaster. If only two sperm nuclei are present both unite with the egg nucleus, and the two amphiasters produce a four-poled karyokinetic figure, or tetraster; the egg divides simultaneously into four cells, but the subsequent division of the cells is always in two each. Triasters sometimes form, owing to fusion of two asters, and a simultaneous division of the egg into three cells follows. If more spermatozoa enter, all sperm nuclei do not necessarily unite with the egg nucleus; two or more may unite with the egg nucleus and a multipolar figure results; the other sperm amphiasters then associate themselves with this figure and very complex karyokinetic systems result.

In the frog (Herlant, I9I I), each sperm nucleus forms an aster, as in the sea urchin, but the egg nucleus unites with only one of the sperm nuclei; the supernumerary sperm nuclei form karyokinetic figures also. Thus in the case of dispermy two karyokinetic figures result, one of which contains the chromosomes of the egg and 
one sperm nucleus, the other only the chromosomes of the supernumerary sperm nucleus. In the case of trispermy we have three karyokinetic figures-one diploid, two haploid. The dispermic egg divides in two cells and the trispermic in three, but each of these cells is binucleated. In the dispermic egg one nucleus of each cell is diploid, the other haploid; in trispermic eggs this applies to two of the cells, but the two nuclei of the third cell are both haploid. In subsequent divisions the proportions of diploid nuclei is maintained.

In the sea urchin, in the frog, and also in all other cases so far as known, pathological polyspermic eggs produce abnormal embryos, which soon die. Boveri has made a most careful and interesting analysis of conditions in the sea urchin, which led him to the conclusion that the ill effects are due in this case to abnormal distribution of the chromosomes. Taking the simplest case of dispermy he shows that the distribution of chromosomes in the tetraster is highly irregular and a matter of chance, from which it results that the four nuclei formed have different numbers of chromosomes. This would not in itself account for the abnormal results, because it is known that half the diploid chromosome number is sufficient for normal development, and he could show that the number in each nucleus exceeds this number on the average. From this he argues that the chromosome composition of the nuclei must be on the average inadequate; that not merely a given number of chromosomes, but a definite qualitative composition of the chromosome group, is necessary for normal development. He thus con- 
ceives that the chromosomes of each germ nucleus are qualitatively differentiated, and that a full representation of chromosome qualities is necessary for normal development. His experiments constitute an argument for qualitative differences of chromosomes which has been generally accepted. The result is reached by exexclusion of other possible causes of abnormality. This subject leads into certain phases of cytology that do not belong in our field.

The case of the frog is somewhat different, in that the nuclei are either definitely diploid or haploid. Herlant comes to the conclusion that the cause of death in this case is the different size of the nuclei and their associated cell bodies in the same embryo, which renders normal functioning impossible, and other more obscure probable causes of disharmony associated with this principle.

For the subject of morphology of fertilization the study of polyspermy is significant in two principal respects: (I) It furnishes the demonstration that the sperm nucleus is different from the egg nucleus, owing either to association of a centrosome with it or for other cause; because we find that each sperm nucleus produces a definite effect on the cytoplasm of the egg, the formation of an aster, which the egg nucleus itself does not produce in the cases studied. (2) The inevitable pathological result, when more than one sperm nucleus is concerned in the development, furnishes important evidence for the nuclear theory of heredity. On the physiological side the study of polyspermy is significant from other aspects, which we shall examine later. 


\section{FERTILIZATION AND SYMMETRY}

In 1854 the English naturalist Newport, who had devoted much time to a series of brilliant observations and experiments on the fertilization of the ova of Amphibia, reported "that the first cleft of the yolk is in a line with the point of the egg artificially impregnated, and that the head of the young frog is turned toward the same point." He thus made the discovery, which has since been confirmed by Roux, Schulze, Brachet, and others, that there is a definite relation between the point of penetration of the spermatozoön and the symmetry of the resulting embryo in the case of the frog. As a result of these studies it has been shown that the penetration of the spermatozoön determines that meridianal plane of the polarized egg in which the first plane of cleavage usually forms, and in which the axis of the embryo probably always arises. Subsequent research has also confirmed Newport's statement that the head of the embryo is turned toward the point of penetration.

Roux attempted the first theoretical explanation of this fact on the basis that the path of the spermatozoön determines the plane of apposition of the germ nuclei. The division of the zygote nucleus must, he thought, run at right angles to the plane of apposition in order to secure impartial distribution of maternal and paternal nuclear constituents to the two cells. Thus the first plane of cleavage would pass along the penetration path of the spermatozoön and approximately through the point of entrance. In certain cases, however, it was shown that the first plane of cleavage did not coincide either with the plane of symmetry or with the fertilization meridian. Brachet's experiments 
on the frog's egg have shown that in such cases the plane of symmetry and the fertilization meridian nevertheless coincide. Roux's theory therefore does not hold except for the direction of the first plane of cleavage, which in the frog may not coincide with the plane of symmetry.

There is, however, no necessary relation between the fertilization meridian and the plane of symmetry, because polyspermic eggs develop a plane of symmetry, and so also do parthenogenetic eggs. The relationship which has been shown to exist in certain cases must therefore depend upon a certain time relationship in the course of the two processes. The influences radiating from the spermatozoön establish a gradient from its original eccentric position, which may influence the direction of the plane of symmetry in which there is also a gradient, if its determination is synchronous, as in the frog.

In the case of the annelid Nereis the observations of Just (I9I2) show that the plane of symmetry is at right angles to the fertilization meridian. Here again we have obviously an interaction of two distinct gradient processes, which, however, attain a different equilibrium from the frog. The data on this subject are few, owing to the difficulty of making the necessary determinations. The ova of many animals are definitely bilaterally symmetrical before fertilization, which has therefore nothing to do with its determination. The conclusion would therefore seem to be that, when the determination of symmetry and fertilization overlap, the former may be affected as to its orientation by the latter. 


\section{REFERENCES}

BINFORD, RAYMOND.

I9I3. "The Germ Cells and the Process of Fertilization in the Crab, Menippe mercenaria," Jour. of Morph., XXIV, I $47-200$.

Blount, Mary.

I909. "The Early Development of the Pigeon's Egg, with Special Reference to Polyspermy and the Origin of the Periblast Nuclei," Jour. of Morph., XXII, I-64.

BONNEVIE, KRISTINE.

I907. "Untersuchungen über Keimzellen der Bryozoen," Jen. Zeitschr. für Naturw., Band 42, pp. 567-98.

BOVERI, T.

See references at end of chapter $i$.

I895. "Ueber das Verhalten der Centrosomen bei der Befruchtung des Seeigel-Eies," etc., Verh. Phys.med. Gesell., Wïrzburg, Band 29, pp. I-75.

I9or. "Zellenstudien," Heft 5. "Ueber die Natur der Centrosomen," Jen. Zeitschr. für Naturw., Band 35, pp. I-220.

1902. "Ueber mehrpolige Mitosen als Mittel zur Analyse des Zellkerns," Verh. Phys.-med. Gesell., Würzburg, Band 35, pp. 67-9o.

1907. "Zellenstudien," Heft 6. Die Entwickelung dispermer Seeigeleier. Ein Beitrag zur Befruchtungslehre und zur Theorie des Kerns (p. 292) (earlier references here). Jena: Gustav Fischer.

Brachet, A.

1904. "Recherches expérimentales sur l'œuf de Rana fusca," Arch. de biol., T. 2 I.

I9II. "Recherches sur l'influence de la polyspermie expérimentale dans le développement de l'œuf de Rana fusca," Arch. de zool. exp. et gén., Sér. 5, T. 6, pp. I-IO०.

Conklin, E. G.

I893. The Fertilization of the Ovum. Biological Lectures, Woods Hole. 
Conklin, E. G.

I902. "Karyokinesis and Cytokinesis in the Maturation, Fertilization and Cleavage of Crepidula and Other Gasteropoda," Jour. Acad. Nat. Sci. (Philadelphia), Ser. 2, Vol. XII.

I904. "Experiments on the Origin of the Cleavage Centrosomes," Biol. Bull., VII, 22 I-26.

Fol, Hermann.

I877. See references at end of chapter $i$.

I89ı. "Le quadrille des centres. Un épisode nouveau dans l'histoire de la fécondation," Arch. sci. phys. nat. Genève (3), T. 25, pp. 393-420; also in Anat. Anz., VI, 266-74.

Foot, Katherine, and Strobell, Ella C.

I903. "The Sperm Centrosome and Aster of Allolobophora foetida," Am. Jour. Anat., II, 365-69.

GRIFFIN, BRADNEY B.

I 899. "Studies in the Maturation, Fertilization and Cleavage of Thalassema and Zirphaea," Jour. of Morph., $\mathrm{XV}, 58_{3}-634$.

HARPER, E. H.

I904. "The Fertilization and Early Development of the Pigeon's Egg," Am. Jour. Anat., III, 349-86.

Henking, $\mathrm{H}$.

I89I. "Untersuchungen über die ersten Entwicklungsvorgänge in den Ejern der Insekten, II," Zeitschr. fïr wiss. Zool., Band $5 \mathrm{I}$.

Herlant, Maurice.

I9II. "Recherches sur les œufs di- et" tri-spermiques de grenouille," Arch. de biol., T. 26, pp. Іо3-336.

Hertwig, O. AND R.

I 887 . See references at end of chapter $\mathrm{i}$.

JORDAN, E. O.

I893. The Habits and Development of the Newt (Diemyctylus viride'scens)," Jour. of Morph., VIII, 269-366. 
Just, E. E.

I912. "The Relation of the First Cleavage Plane to the Entrance Point of the Sperm," Biol. Bull., XXII, 239-5I.

King, Helen Dean.

I90I. "The Maturation and Fertilization of the Egg of Bufo lentiginosus," Jour. of Morph., XVII, 293-342.

Kostanecki, K., and Wierzejsky, A.

I896. "Ueber das Verhalten der sogenannten achromatischen Substanzen im befruchteten $\mathrm{Ei}_{\text {e. Nach Beobach- }}$ tungen an Physa fontinalis," Arch. für mikr. Anat. und Entwickelungsgesch., Band 47, pp. 309-86.

Lillite, Frank R.

I90I. "The Organization of the Egg of Unio Based on a Study of Its Maturation, Fertilization and Cleavage," Jour. of Morph., XVII, 227-92.

I9I 2. "Studies of Fertilization in Nereis: III, The Morphology of the Normal Fertilization of Nereis; IV, The Fertilizing Power of Portions of the Spermatozoön," Jour. Exp. Zoöl., XII, 4I3-76.

MEAD, A. D.

I898. "The Origin and Behavior of the Centrosomes in the Annelid Egg," Jour. of Morph., XIV, I82-218.

Meves, F.

I9I . "Ueber die Beteiligung der Plastochondrien an der Befruchtung des Eies von Ascaris megalocephala," Arch. für mikr. Anat. und Entwickelungsgesch., Band 76, pp. 683-713.

I912. "Verfolgung des sogenannten Mittelstückes des Echinidenspermiums im befruchteten $\mathrm{Ei}$ bis zum Ende der ersten Furchungsteilung," ibid., Band 80, pp. $8 \mathrm{I}-\mathrm{I} 23$.

I9I3. "Ueber das Verhalten des Plastomatischen Bestandteiles des Spermiums bei der Befruchtung des Eies von Phallusia mammillata," ibid., Band 82, Abt. II, pp. $215-60$. 
Meves, F.

I9I4. "Verfolgung des Mittelstückes des Echinidenspermiums durch die ersten Zellgenerationen des befruchteten Eies," ibid., Band 85, Abt. II, pp. I-8.

Morrill, Charles V.

1910. "The Chromosomes in the Ö̈genesis, Fertilization and Cleavage of Corcid Hemiplera," Biol. Bull., XIX, $79^{-\mathrm{I}} 26$.

MULSOW, KarL.

I9I2. "Die Chromosomencyklus bei Ancyracanthus cystidicola," Arch. fiir Zellf., Band 9, pp. 63-73.

NEWPORT, GEORGE.

I854. See references at end of chapter i.

Oppel, Albert.

I892. Die Befruchtung des Reptilieneies," Arch. fïr mikr. Anat. und Entwickelungsgesch., Band 39, pp. 2I 5-90.

Roux, W.

I887. "Die Bestimmung der Medianebene des Froschembryos durch die Copulationsrichtung des Eikernes und des Spermakernes," Arch. f. mikr. Anat., Band 29, pp. I 57-2I 2 .

RÜCKERT, J.

I 895. "Ueber das Selbständigbleiben der väterlichen und mütterlichen Kernsubstanz während der ersten Entwickelung des befruchteten Cyclops Eies," Arch. mikr. Anat., Band 45, pp. 339-69.

I899. "Die erste Entwickelung des Eies der Elasmobranchier," Festschrift zum 70. Geburtstag von C. v. Kupffer (pp. 58I-704) (see earlier references here). Jena.

Schulze, O.

I899. "Ueber das erste Auftreten der bilateralen Symmetrie im Verlauf der Entwickelung," Arch. für mikr. Anat. und Entwickelungsgesch., Band 55, pp. 202-3I.

Совотта, J.

I 895. "Die Befruchtung und Furchung des Eies der Maus," Arch. mikr. Anat., Band 45, pp. 15-92. 
VAN Beneden, E.

I883. See references at end of chapter $\mathrm{i}$.

VAN DER STRICHT, O.

I898. "La formation des deux globules polaires et l'apparition des spermocentres dans l'œuf de Thysanozoon brocchi," Arch. de biol., T. I5, pp. 367-46г.

I902. "Le spermatozoide dans l'œuf de chauve-souris (V. noctula)," Verh. d. Anat. Gesell., pp. I63-68.

Vejdovský, F., AND Mrázek, A.

I903. "Umbildung des Cytoplasma während der Befruchtung und Zelltheilung. Nach Untersuchungen am Rhynchelmis-Eie," Arch. für mikr. Anat. und Entwickelungsgesch., Band 62, pp. 431-579.

WheELER, W. M.

I897. "The Maturation, Fecundation and Early Cleavage of Myzostoma glabrum, Leuckart," Arch. de biol., T. I5, pp. I -77 .

WiLson, E. B.

I895. "Archoplasma, Centrosome and Chromatin in the Sea Urchin Egg," Jour. of Morph., XI, 443-78.

I896. The Cell in Development and Inheritance. New York: Macmillan.

I901. "Experimental Studies in Cytology: II, Some Phenomena of Fertilization and Cell-Division in Etherized Eggs," Arch. fiur Entwickelungsmech., Band 13, pp. 353-95.

Wilson, E. B., ANd Leaming, E.

I895. An Atlas of Fertilization and Karyokinesis of the Ovum. New York.

Wilson E. B., and Mathews, A. P.

I895. "Maturation, Fertilization and Polarity in the Echinoderm Egg," etc., Jour. of Morph., X, 3I9-42. 


\section{CHAPTER IV}

\section{THE PHYSIOLOGY OF THE SPERMATOZOÖN}

\section{INTRODUCTION}

What are the forms of behavior of flagellated spermatozoa? What conditions are optimum? What changes in environment are significant? Such questions are vital for the study of the physiology of fertilization; but the subject has not been studied with the attention that its importance deserves. Such knowledge as we possess demonstrates that spermatozoa are exceedingly sensitive organisms in certain respects. With reference to the reaction (i.e., $\mathrm{H}$ ion equilibrium) of sea-water, for instance, the spermatozoa of certain marine forms are as delicate indicators as we possess. The general belief appears to be that in the medium in which fertilization takes place spermatozoa are in a condition of ceaseless random activity; but are their movements entirely undirected? Do they indeed differ from other organisms in exhibiting no directiveness of behavior? To what stimuli do they respond?

\section{GENERAL}

Spermatozoa are almost invariably immobile in the testis and the efferent ducts. They become active in the medium in which insemination takes place. Among marine animals there are great variations in this respect. Thus the spermatozoa of most annelids and sea urchins and many other forms become exceedingly 
active in sea-water; but in the case of the starfish they usually do not activate greatly in sea-water, save in the presence of excess of $\mathrm{OH}$ ions or secretions of the eggs of the same species, a matter to which we shall return. In mammals the spermatozoa are active in the ejaculate which contains secretion of the prostate and other glands. Sperm taken from the epididymis will activate in physiological salt solution.

Spermatozoa are probably incapable of receiving nourishment outside of the gonad after they are fully differentiated; certainly in the case of all forms with external insemination there is no opportunity for the restitution of substance. We must therefore regard these cells as charged with their full available store of energy in the testis and their capacity for locomotion as thus determined and limited. They therefore have a strictly limited period of life, the duration of which will be determined by their activity. The store of energy is saved when they are motionless and expended when in motion. Thus we find that sperm suspensions will retain their fertilizing power for a relatively long time if activity is reduced, and will lose it relatively rapidly if activity is great. Cohn (I9I8) has determined that the total $\mathrm{CO}_{2}$ production of spermatozoa is the same whether their life be long or short.

The amount of energy produced has not been measured, but it is necessary to describe it as surprisingly large; a certain degree of motion may be kept up for hours at a time. The source of the energy is certainly in the cytoplasm, as the highly condensed nucleus is in a condition which all cytological experience interprets as a state of quiescence. If in the cytoplasm, 
the cytological data would suggest the mitochondria as a source of energy. 'This is, however, purely speculative, for the subject has not been studied from this point of view; but the universal presence of mitochondria in the sperm suggests some important function, and they are almost certainly not heredity material.

The locomotion of flagellated spermatozoa seems to be essentially similar in all animals. The spermatozoa of Nereis in their free movements through the water describe spiral paths with rather close-set turns. As soon as a spermatozoön comes in contact with a surface it tends to move round and round in circles in contact with the surface in anticlockwise direction; the forward component of the locomotion is largely eliminated under these conditions. The movement is due to successive beats of the tail, and it is an interesting fact that under certain conditions of aggregation the successive beats of the aggregated spermatozoa may become synchronous; the rate is about $\mathrm{I} 20$ a minute at $20^{\circ} \mathrm{C}$. under such circumstances (Lillie, I9I3).

The spermatozoa of sea urchins also swim spirally when freely suspended. "The spirals máy be so steep that the spermatozoa appear to swim in almost a straight line, and they then move relatively rapidly across the field of the microscope. On the other hand, the incline of the spiral may be so gentle that the spermatozoa appear to be swimming almost in circles" (Buller, 1902). The spermatozoa of sand dollars behave similarly. Ballowitz (1890) and Dewitz (1885, 1886) describe similar forms of behavior for various insects, Massart (I888, г889) for Amphibia. 
The conditions under which spermatozoa are usually observed are not favorable for observation of unimpeded locomotion; the material is usually observed in the form of suspensions of greater or less density in which the individual spermatozoa are continually colliding with one another and with the walls of the chamber in which they are confined. Under such circumstances the distribution of active spermatozoa should be uniform, like the molecules of a gas, and this condition is found in perfectly fresh suspensions. However, it usually does not last long and various forms of aggregation result.

The spermatozoa of Nereis suspended in sea-water give a very striking reaction which illustrates the point. If a drop of dry sperm from a mature Nereis is mixed in about 6 c.c. of sea-water in a Syracuse watch crystal it makes a uniformly milky suspension; in a few seconds clouds begin to appear, and in fifteen to fortyfive seconds these usually draw together in white solidlooking masses uniformly spaced through the fluid (Fig. 13). The intervening fluid becomes quite clear and the masses quickly settle on the bottom. The rate of formation of these masses and their number and size depend on condition of the animal furnishing the sperm, temperature, "freshness" of the sperm, reaction of the medium, etc. Sperm suspensions of most animals do not, however, exhibit such marked aggregations.

\section{BEHAVIOR OF SPERMATOZOA}

The function of the spermatozoön is apparently bound up with its capacity for locomotion; it is probable that immobilized sperm will not fertilize, in 
spite of Schücking's (1903) statement to the contrary. Loeb (I9I5) has shown that spermatozoa will not fertilize in the presence of an immobilizing concentration of $\mathrm{NaCN}$, no matter how concentrated the sperm, "while the same sperm when it revives from the effect

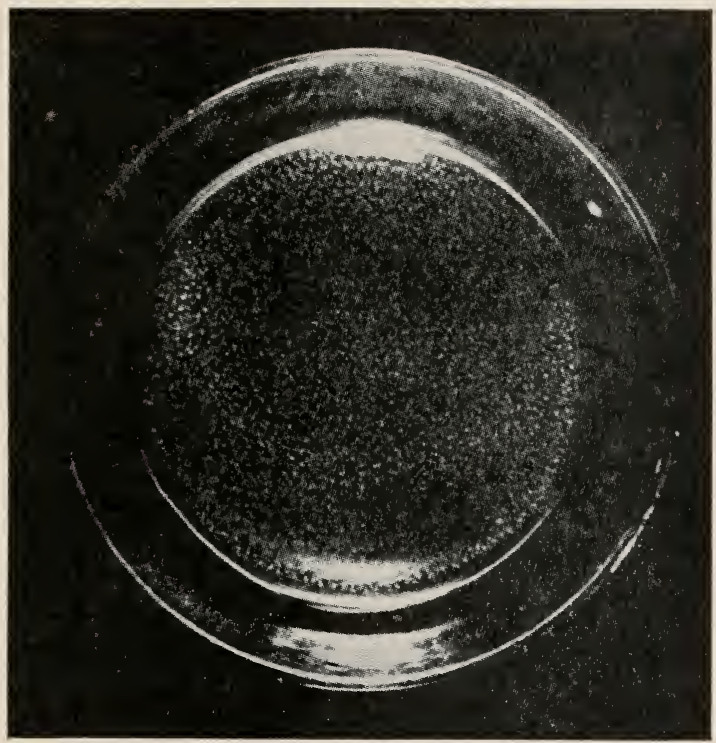

FIG. I3.- Photograph of the aggregation of a sperm suspension of Nereis, taken 90 seconds after mixing thę suspension (natural size).

of $\mathrm{NaCN}$ "fertilizes the same eggs at once." The experiment is not conclusive proof of the necessity of motility for fertilization, because the block in the fertilization reaction might conceivably be due to some other effect of the $\mathrm{NaCN}$. The experiment, however, renders it very probable that motility of the sperm is necessary. 
But motility is not the exclusive requirement; the spermatozoön must exhibit other definite forms of behavior with reference to the egg. It has, however, proved impossible to analyze the behavior of the spermatozoön by direct observation of fertilization. Hence it is desirable to observe the various forms of behavior of spermatozoa apart from the egg in the expectation of being able to utilize the information thus gained in the study of fertilization.

Spermatozoa are highly specialized cells with reference to behavior as well as to structure and function. Their principal behavior reactions appear to be with reference to temperature, contact, and chemical stimuli. They are, indeed, like all cells, also sensitive to changes in osmotic pressure; but we have no evidence of reaction to light or gravitation. Their behavior consists in changes in rate of activity, in maintaining contact with surfaces either at rest or not, in alterations in direction of locomotion, and in adhesion to one another or other surfaces.

I. Light, Gravity, Osmosis, Temperature

By way of clearing the ground we may first consider the least known, or least effective, possible sources of stimulation.

a) Light.-So far as known, animal spermatozoa are quite indifferent to light conditions. The chlorophyllbearing spermatozoa of many plants, however, exhibit definite responses to illumination. These are entirely lacking in animals, but we cannot suppose that the metabolism remains the same under all light conditions, and no doubt careful investigation would show some effect of presence or absence of light or of rays of different length on the activity of spermatozoa. 
b) Gravitation.-Similarly animal spermatozoa are not known to exhibit any definite reaction to gravitation. 'The spermatozoa of marine forms are of somewhat greater specific gravity than the sea-water, hence they tend to sink when at rest, or may be precipitated by the centrifuge.

c) Osmotic pressure.-Spermatozoa of Nereis are apparently more sensitive to increase than to decrease of osmotic pressure. They are fairly active in 5 c.c. of sea-water plus 2.5 c.c. of distilled water, but are paralyzed in 5 c.c. of sea-water plus I c.c. of $2 \frac{1}{2} \mathrm{M} . \mathrm{NaCl}$ (Lillie, I9I3).

d) Temperature.-Temperature affects the rate of movement of spermatozoa; it is rather difficult to measure rate of movement directly, but in the case of Nereis the aggregation reaction described on page 94, which is a function of the activity, gives us a means of ready observation:

At $13^{\circ} \mathrm{C}$. No aggregations form.

At $15^{\circ} \mathrm{C}$. Slight signs of aggregation in four minutes.

At $18^{\circ}-19^{\circ} \mathrm{C}$. Aggregation in from two to four minutes; much fewer in number than at higher temperatures.

At $20.5^{\circ} \mathrm{C}$. Numerous aggregations in one minute.

At $23.5^{\circ} \mathrm{C}$. Yet more numerous aggregations in thirty seconds.

At $26.5^{\circ} \mathrm{C}$. No aggregations form until the temperature falls to about $23^{\circ}$.

Thus in this case temperatures from 20 to $23 \cdot 5^{\circ} \mathrm{C}$. are optimum. At $I 5^{\circ}$ the movements of the spermatozoa are too slow to produce the aggregation reaction, and at $26.5^{\circ}$, although the movements are 
extremely active, they are apparently unco-ordinated, so that the aggregation reaction is not given.

As a general principle the rate of activity of spermatozoa is a function of the temperature, like other biological processes, and the temperature range varies with the species.

\section{Contact}

All kinds of spermatozoa studied exhibit contact reactions. Dewitz (1885, I886) appears to have been the first to study this subject; he showed that the spermatozoa of the cockroach maintain contact with solid bodies and free surfaces of liquids; he studied their thigmotactic rotations on the surface of the egg, which finally result in the penetration of the micropyle of this hard-shelled egg. In a drop beneath a raised cover slip they divide in two groups, one in contact with the floor, the other with the roof of the inclosed space, and are absent in between. They are in constant motion, describing circles of varying diameters always in the same sense (anticlockwise), with reference to the surface of contact; but these two groups appear to revolve in opposite directions under the microscope, owing to the direction of observation.

Massart (I888, I889) studied the reactions of the spermatozoa of the frog and showed that in a drop beneath a raised cover slip they also divide in two actively rotating groups, one in contact with the slide below and the other with the cover slip above; similarly in a hanging drop they accumulate in contact with the glass above and the free surface of the drop below. Buller (I902) states that when sea urchin spermatozoa "come in contact with a surface they either become 
fixed to it at once or, more often, they rotate upon it; and in the latter case, looking from them to the surface in question, in a counterclockwise direction."

In contact with any solid object Nereis spermatozoa tend to carry out circus movements in an anticlockwise direction when fresh, but may soon come to rest. This thigmotactic reaction appears to be due to exaggeration of the rotation component of the ordinary spiral course; it is the cause of aggregations in favoring places, such as angles, etc. Such contact reactions of spermatozoa must be regarded as very significant for fertilization.

The change from a progressive to a rotary form of locomotion thus appears to be a very general form of reaction of spermatozoa to contact stimuli. This may take place without any change in the rate of activity or of metabolism and would obviously lead to aggregation of spermatozoa in any region providing a stimulus which acts in this way.

3. In Relation to Reaction of the Medium; $\mathrm{H}$ and $\mathrm{OH}$ Ions

a) Activity effects. - The spermatozoa of many marine organisms are extremely sensitive to changes in the normal reaction of the sea-water, as indicated by their activity. In the case of Nereis the addition of acids (sulphuric, hydrochloric, nitric, acetic) to the sea-water caused paralysis at $n / 1,000$ and decrease of activity up to $n / 5, \infty 00$. The spermatozoa of sea urchins are not so sensitive and those of some other marine forms much less so. If sea-water is saturated with $\mathrm{CO}_{2}$ the spermatozoa of all forms are completely paralyzed, and this paralysis will last in the case of Nereis until the charged sea-water is diluted over a hundred times; in I per cent of the $\mathrm{CO}_{2}$ charged sea-water the 
spermatozoa show no movement, and it is not until a dilution of 0.33 per cent is reached that normal activity is possible. Arbacia sperm exhibits traces of movement at 2.5 per cent and Chaetopterus at over 20 per cent. There is thus considerable variation in this respect (Lillie, I9I3).

Acids decrease the activity of spermatozoa up to complete paralysis, and at higher concentrations cause death. Alkalies have in general the reverse action, increasing activity up to the lethal point. The death phenomena of sperm suspensions under acids and alkalies exhibit a striking difference in gross appearance, the acid-killed sperm suspension remaining in a condition of dispersal, whereas in the alkali- $(\mathrm{KOH}$ or $\mathrm{NaOH}$ ) killed sperm suspensions the spermatozoa are fused in strands which tend to anastomose; a similar gross effect upon sperm suspensions is also produced by the salts of trivalent metals (Gray, I9I5).

The degree of activity of spermatozoa is a function of the $\mathrm{H}$ ion concentration of the medium, other things being equal. Kölliker (I856), Günther (I907), Gray (I9I5), and Cohn (I9I8) have all recorded similar observations. It is important to note a fact emphasized by Gray that spermatozoa inactivated by acid can be reactivated by the addition of alkali if the concentration of acid used in the experiment has not been too great; the inactivation and agglutination produced by excess of alkali, on the other hand, is irreversible.

Cohn (I9I8) has shown that the inactivation by $\mathrm{H}$ ions has very important consequences for the functioning of the spermatozoa, because they are constantly giving off $\mathrm{CO}_{2}$ into the medium. If the sperm sus= 
pension be above a very low degree of concentration the $\mathrm{H}$ ions thus liberated soon reach a sufficient degree of concentration to decrease the movements of the spermatozoa, and ultimately stop them entirely. The life of the spermatozoa is thus longer in more concentrated than in more dilute sperm suspensions because they are sooner inactivated by their own $\mathrm{CO}_{2}$ and the available store of energy is not used up so rapidly. Spermatozoa thus inactivated can be restored to full activity merely by diluting sufficiently with normal sea-water.

The effect of concentration of the sperm suspension on the duration of life of the spermatozoa has been measured by Cohn, who used the fertilizing power as index of vitality. The following table (after Cohn) gives the results of one such experiment:

The Length of Life, as Measured by the Fertilizing Power, of Sperm Suspensions of Arbacia of Different

CONCENTRATIONS

\begin{tabular}{|c|c|c|c|c|c|}
\hline \multicolumn{2}{|c|}{ Age of SPERm } & \multicolumn{4}{|c|}{ Concentration of Sperm Suspensions* } \\
\hline Hours & Minutes & ${ }_{4}$ Per Cent & I Per Cent & 0.5 Per Cent & 0.25 Per Cent \\
\hline 14 & IO & IOO & 98 & 67 & Io \\
\hline 23 & 40 & 100 & 98 & I5 & o \\
\hline 47 & 0 & 100 & 0 & 0 & 0 \\
\hline 71 & 55 & 98 & 0 & $\ldots \ldots \ldots$ & $\ldots \ldots \ldots$ \\
\hline 92 & 0 & 85 & $\ldots \ldots \ldots$ & $\ldots \ldots \ldots$ & $\ldots \ldots \ldots$ \\
\hline
\end{tabular}

* Percentage of eggs fertilized at age of sperm in same horizontal row.

The eggs used for each test were always fresh. The sperm suspensions were made up at the same time by percentage volume of sperm to sea-water; they were then allowed to age, as shown in the left-hand column, 
and each was tested for fertilization power at the ages given by adding I drop of sperm to 5 drops of eggs in Io c.c. of sea-water. Such sperm suspensions when perfectly fresh will fertilize roo per cent of eggs when so used. The table shows that the fertilizing power falls off with age in inverse proportion to concentration. This is in inverse relation to activity and to $\mathrm{CO}_{2}$ and $\mathrm{H}$ ion concentration. The last point was demonstrated by measurements of the rate of increase of $\mathrm{H}$ ion concentration in sperm suspensions of varying concentration, which runs parallel with the longevity.

In spite of the more rapid rate of increase in $\mathrm{H}$ ion concentration with sperm concentration Cohn was able to show that the amount of $\mathrm{CO}_{2}$ produced per unit of sperm is ultimately the same in more concentrated and in more dilute suspensions; the difference is merely in the rate of combustion, which is more rapid in proportion to activity. The more dilute suspensions use up their available store of energy more rapidly, the more concentrated suspensions less rapidly.

b) Aggregation and chemotaxis.-We have seen that fresh active sperm suspensions of Nereis rapidly form dense aggregations (p. 95, Fig. 13) in masses. Under a low power of the microscope each mass appears like a swarm of bees, owing to intense rotary activity of the peripheral spermatozoa. But those in the interior of the dense mass must be quiescent. The reaction is dependent on the existence of a certain $\mathrm{H}$ ion concentration of the sea-water, for if the sea-water be rendered hyperalkaline the aggregations do not form, however intense the activity of the spermatozoa. The reaction is in fact due to rapid $\mathrm{CO}_{2}$ production by the sper- 
matozoa, which tend to accumulate in any region of increased $\mathrm{CO}_{2}$ tension. Any area of greater concentration of spermatozoa, by producing more $\mathrm{CO}_{2}$ than other areas, becomes a center of aggregation, which, when once begun, is bound to proceed to the limit on account of increased $\mathrm{CO}_{2}$ production. The reaction cannot take place in the presence of excess of alkali, owing to neutralization of the acid as fast as formed; and a $\mathrm{CO}_{2}$ tension of the entire medium sufficient to inhibit movement will likewise prevent aggregation.

It is obvious that the aggregation phenomenon can be explained by assuming a positive orientation of the spermatozoa in a $\mathrm{CO}_{2}$ gradient. It has also been suggested (Cohn, I918) that it is due merely to gradations of activity, and therefore presumably of the range of unimpeded movement: activity decreases with rising $\mathrm{CO}_{2}$ tension; the spermatozoa in regions of higher $\mathrm{CO}_{2}$ therefore tend to remain there, but those without, owing to their wider range of movement, tend to move into and remain within such regions.

On the second assumption it is difficult to see how it happens that the aggregations become so dense. Neither are the spermatozoa motionless in such aggregations as required by this theory, but they can be actually observed to be exceedingly active around the periphery of the aggregations, and their movements are almost exclusively those of rotation such as are exhibited in the thigmotactic response.

In the attempt to analyze the matter farther, the reaction of spermatozoa to solutions of $\mathrm{CO}_{2}$ in sea-water was tested by the writer by the Pfeffer capillary-tube method, which consists of introducing capillary tubes 
filled with the solution to be tested into sperm suspensions and observing the reactions of the spermatozoa to the open end of the tube. Sea-water was charged to saturation with $\mathrm{CO}_{2}$, and various dilutions of such charged sea-water were employed. The capillary-tube. method, however, though giving positive results, proved inadequate, on account of the very slight diffusion from the open end of the tube. It was then found that the injection of a drop of the solution into a sperm suspension mounted beneath a raised cover slip gave results at least ten times more delicate. Such a drop is confined above and below by the glass surfaces, and by diffusion a $\mathrm{CO}_{2}$ gradient is established around its margin. ${ }^{\mathrm{I}}$

If a drop of a I per cent $\mathrm{CO}_{2}$ solution in sea-water ${ }^{2}$ be introduced into a fresh milky sperm suspension of Nereis the following configuration develops in a few seconds (Fig. I4a). A ring of densely aggregated, very active spermatozoa forms near the margin of the original drop, and a similar linear aggregation extends from

${ }^{x}$ The insistence of certain investigators on the Pfeffer capillarytube method (e.g., Loeb, I9I6, p. 93) for studying chemotaxis of spermatozoa is difficult to understand. The effectiveness of the Pfeffer method depends upon diffusion from the open end of the tube, and the gradient is therefore established for the greater part without the tube. The amount of diffusion depends on the diameter of the tube, which is rarely stated by investigators; the walls of the tube, moreover, provide a source of thigmotactic stimulation, thus interfering with the pure chemotactic reaction. My method of confining a drop in the medium between glass surfaces I to $2 \mathrm{~mm}$. apart provides a gradient more surely than the tube method, and one which lasts sufficiently long for all practical purposes. It is, moreover, much simpler and more easily controlled, and is not complicated by the thigmotactic factor.

${ }^{2} \mathrm{CO}_{2}$ saturated sea-water diluted a hundred times with normal sea-water. 
this to the margin of the slide along the path in which the pipette was introduced and withdrawn (cf. Fig. I5). The ring and linear aggregation are separated from the general sperm suspension by a clear space I. 5 to $2 \mathrm{~mm}$. in width. No such reaction takes place with reference to a drop of normal sea-water. Greater

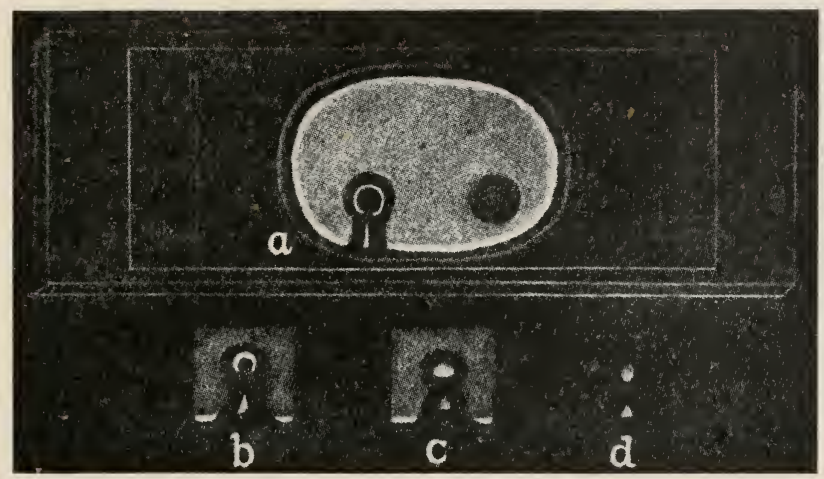

FIG. I4.-Reaction of a sperm suspension of Nereis to a drop of I per cent $\mathrm{CO}_{2}$ sea-water (natural size). The preparation $(a)$ is mounted on a slide beneath a raised cover slip. $a$ shows the form of the reaction after I5 seconds; $b, 75$ seconds; $c$, I05 seconds; $d$, I95 seconds. In $d$ the general suspension has aggregated. The drop to the right in $a$ is a control drop of sea-water. Note in $a$ that the spermatozoa also withdraw from the margin of the preparation, thus in the direction of increasing $\mathrm{CO}_{2}$ tension.

dilutions of the $\mathrm{CO}_{2}$ sea-water will act positively in the case of fresh sperm suspensions. The ring forms well within the margin of the drop in the case of $\mathrm{I} / 200$ dilution. In case of stronger $\mathrm{CO}_{2}$ solutions the ring is wider and tends to grow at the periphery as the $\mathrm{CO}_{2}$ diffuses outward. In general the aggregation tends to occur at a place in the $\mathrm{CO}_{2}$ gradient near the point of paralysis of the spermatozoa. 
It is clear from this experiment that the spermatozoa react positively in a $\mathrm{CO}_{2}$ gradient where the tension is above a certain point; the aggregation caused by a more concentrated drop grows because the diffusion of

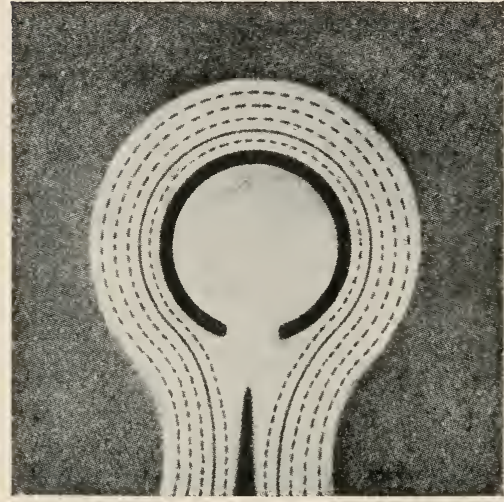

FIG. 15.-Diagram of the reaction of spermatozoa of Nereis to a drop of I per cent $\mathrm{CO}_{2}$ in sea-water. The dark background represents the sperm suspension; the thick open circle and streak below, the aggregation; the unbroken line represents the original boundary of the $\mathrm{CO}_{2}$ drop; the concentric broken lines in the clear zone represent the $\mathrm{CO}_{2}$ gradient.
$\mathrm{CO}_{2}$ from the center furnishes a widening ring of the necessary concentration. To furnish a gradient the concentration of $\mathrm{CO}_{2}$ must exceed that in the sperm suspension, which is a function of its density and age; on the other hand, a limit is set to the differential which furnishes the reaction by the fact that a concentration of about I per cent of the $\mathrm{CO}_{2}$ sea-water paralyzes the spermatozoa. The gradient that determines the reaction must, therefore, exist within very narrow limits.

Such aggregation with reference to $\mathrm{CO}_{2}$ is obviously the same in principle as the aggregations formed spontaneously in sea-water. Indeed, aggregations afterward form spontaneously in the unaffected part of such a preparation. The spermatozoa at the periphery of the ring caused by $\mathrm{CO}_{2}$ are in much more rapid move- 
ment than those in the general suspension, where they mutually impede one another's range of movement, so that it seems impossible to explain the aggregation on the assumption that it is due to $\mathrm{CO}_{2}$ paralysis. This is a factor in the result, for the spermatozoa that gain the center of the drop are paralyzed, but paralysis explains neither the initial aggregation nor its growth.

The behavior of the spermatozoa at the margin of aggregations is curiously like the thigmotactic reaction previously discussed; they move very actively in circles of increasingly short diameter before coming to rest. At a certain point in the $\mathrm{CO}_{2}$ gradient the circus movements predominate over those of translation; thus spermatozoa reaching this point in the gradient are practically imprisoned, although active, and this without reference to the way in which the point in the gradient is reached.

If the clear zone of a fresh preparation be carefully examined it can be seen that the spermatozoa are moving across it in streams directly toward the center; none move in the opposite direction. For some minutes this steady centripetal migration of the spermatozoa across the clear zone may continue, but by degrees it ceases, though the rotary movement of the spermatozoa at the margin of the aggregation continues for a long time. The persistence of the aggregation is thus due to a behavior change which is the same as that given in response to contact. But the cause of the aggregation lies in directive movement up the $\mathrm{CO}_{2}$ gradient (chemotaxis). This interpretation supplements the account given in my fifth study of fertilization (I9I3).

The sperm of Nereis exhibits similar behavior with reference to other acids, thus demonstrating that the 
$\mathrm{H}$ ion is the effective factor. The spermatozoa of Arbacia exhibit a similar but much less pronounced behavior and only to considerably higher concentration of $\mathrm{CO}_{2}$, which agrees with their greater tolerance to $\mathrm{H}$ ions.

Alcohol is a substance which paralyzes the spermatozoa of Nereis at 5 per cent, and greatly decreases activity at 2 per cent. However, it does not cause aggregations similar to acids when tested under the same conditions. But on the assumption that acid aggregations are due to progressive paralysis, i.e., that the acid acts as a trap, it is difficult to explain why alcohol does not act similarly, though the difference is readily understood if acids cause a specific form of behavior and alcohol does not. Nor do the spermatozoa of Nereis exhibit any aggregation effect with reference to drops of heated or cooled sea-water, which have respectively activating and inhibiting effects.

If the principle of chemotaxis may be regarded as applying to spermatozoa in the foregoing sense, as I believe to be the case, it is obvious that this form of reaction may be of some significance in bringing the egg and spermatozoön together in the process of fertilization; we shall consider this subject later, but the fact of capacity for chemotactic aggregation is of itself by no means a proof that such aggregation is a factor in fertilization.

\section{Reactions to Egg Secretions}

The reactions of spermatozoa to egg secretions of their own and other species may obviously be of great significance for the study of normal and hybrid fertilization. In the study of this subject it is important 
to distinguish between egg secretions and egg extracts; we shall understand by secretions the normal exudates of the egg in the medium in which insemination takes place, and by extracts the water-soluble substances that may be derived from the egg by crushing or plasmolysis in an aqueous medium. It is obvious that the extracts will contain more substances than the secretion, and different kinds.

In the first place it is known that the eggs of marine animals give off $\mathrm{CO}_{2}$ into the sea-water before fertilization. But in addition to $\mathrm{CO}_{2}$ other substances of complex composition are given off; these are known mainly by their effects on spermatozoa. Four such effects may be noted in the case of the egg secretions of Arbacia and Nereis and some other forms, viz.: (I) activation: the spermatozoa are stimulated to increased activity, which is naturally followed sooner or later by a state of rest; (2) aggregation: the spermatozoa are aggregated; (3) agglutination: the spermatozoa become stuck together in temporary clumps. (The first three effects are noted on sperm suspensions of the same species.) (4) The fourth effect is noted only on some, but by no means all, foreign sperm suspensions; it is a toxic effect, which is evidenced by irreversible agglutination and destruction of the foreign spermatozoa. The spermatozoa of Nereis for instance are thus destroyed by the egg secretion of Arbacia, but the effect is not reciprocal. It is possible that the last effect is produced, not by an egg secretion proper, but by blood carried over into the egg suspension.

It does not necessarily follow that there are four substances concerned in these biological reactions, but 
there are certainly three, and we shall examine the evidence as we proceed.

Methods of studying egg secretions: The present account concerns marine animals exclusively; sea-water is thus the medium of the experiments. Eggs are allowed to stand in small quantities of sea-water, and in a short time the sea-water is found to contain the substances concerned. For the sake of brevity we shall call this sea-water, egg water. The indicator is a sperm suspension of definite concentration in sea-water, which can be best expressed in percentages of the dry sperm to the sea-water of the suspension; a I per cent suspension, i.e., I part of dry sperm to 99 parts sea-water, is a good concentration. The most generally useful method of testing the reactions is to place some drops of the sperm suspension on a slide and cover it with a long cover slip supported by glass rods about I $\mathrm{mm}$. in diameter; the egg water to be tested is then injected into the suspension with a capillary pipette operated by a long rubber tube held in the mouth. By this method one can observe under the microscope all the types of reaction. But some kinds of observations are better made in test tubes or other containers.

Egg extracts, as contrasted with egg secretions, are prepared by mechanically breaking down the eggs in sea-water, by grinding dried eggs in sea-water, or by plasmolyzing in distilled water. In the latter case the distilled water extracts may be brought to the composition of normal sea-water by addition of its volume of sea-water evaporated to half its original volume. We shall distinguish such preparations as egg extracts from the egg water containing merely the normal secretions of the eggs. 
a) Activity effects. - The spermatozoa of some animals, e.g., Nereis and Arbacia, are normally active in sea-water, and the specific egg water causes no noticeable acceleration of their rate of movement under optimum conditions. Others again are very inactive, but may be aroused to intense activity by the specific egg water or egg extract. This is true of the spermatozoa of Asterias, for instance, during the summer season at Woods Hole. But an activating substance is probably present even in the case of species like Arbacia. Loeb points out that the spermatozoa of both sea urchins and starfish are immobile in a neutral $n / 2 \mathrm{NaCl}$ solution in which they will continue to live for days, but the addition of specific eggs will in each case cause immediate and often intense activity. There is a certain amount of specificity in these effects, as is shown by the following table, taken from Loeb (I9I5):

Specificity of Activation of Sperm by Eggs

\begin{tabular}{|c|c|c|c|c|}
\hline & Asterias $\hat{~}$ & Asterina $\hat{s}$ & $\begin{array}{c}\text { Arbacia fran- } \\
\text { ciscanus } \hat{\delta}\end{array}$ & $\begin{array}{l}\text { Strongylocentro- } \\
\text { tus purpuratus oै }\end{array}$ \\
\hline $\begin{array}{l}\text { Asterias }{ }^{\circ} \\
\quad \text { (immature) }\end{array}$ & $\begin{array}{l}\text { Immediately } \\
\text { very motile }\end{array}$ & $\begin{array}{l}\text { No activa- } \\
\text { tion }\end{array}$ & $\begin{array}{l}\text { Moder- } \\
\text { ately } \\
\text { active }\end{array}$ & $\begin{array}{l}\text { Slight effect } \\
\text { in immedi- } \\
\text { ate contact } \\
\text { with egg }\end{array}$ \\
\hline $\begin{array}{l}\text { Asterina } \stackrel{9}{\text { (immature) }} \\
\text { (immatis }\end{array}$ & Not motile & $\begin{array}{l}\text { Violent ac- } \\
\text { tivity }\end{array}$ & $\begin{array}{l}\text { Violent } \\
\text { activity }\end{array}$ & $\begin{array}{l}\text { Slight effect } \\
\text { only near } \\
\text { the egg }\end{array}$ \\
\hline $\begin{array}{l}\text { Arbacia } \\
\quad \text { franciscanus } \\
\text { (mature) }\end{array}$ & $\begin{array}{l}\text { Slightly } \\
\text { motile }\end{array}$ & No motility & $\begin{array}{l}\text { Immedi- } \\
\text { ately } \\
\text { active }\end{array}$ & $\begin{array}{l}\text { Immediately } \\
\text { motile }\end{array}$ \\
\hline $\begin{array}{l}\text { Strongylocentrotus } \\
\text { purpuratus }+ \\
\text { (mature) }\end{array}$ & $\begin{array}{l}\text { Slightly } \\
\text { motile after } \\
\text { some time }\end{array}$ & $\begin{array}{l}\text { Slight effect in } \\
\text { immediate } \\
\text { contact with } \\
\text { the eggs }\end{array}$ & $\begin{array}{l}\text { Immedi- } \\
\text { ately } \\
\text { active }\end{array}$ & $\begin{array}{l}\text { Immediately } \\
\text { active }\end{array}$ \\
\hline
\end{tabular}

Thus the two kinds of starfish spermatozoa seem to exhibit considerable specificity in their activation, 
whereas the sea urchin spermatozoa do not to the same extent. The latter are, however, to be regarded as always nearer the threshold of activity. Loeb points out that the activating substance is different from the agglutinating substance, because after removal of the latter the activating substance is still found. ${ }^{\mathrm{r}}$

The relationship between activity of the spermatozoa and presence of egg secretions may obviously be a significant factor in fertilization, because it is probable that completely immotile spermatozoa will not fertilize.

b) Aggregation and agglutination.-If a drop of Arbacia egg water be injected into a sperm suspension of the same species beneath a raised cover slip a very violent reaction may be observed under a low power of the microscope. In the first second the spermatozoa within the drop are aroused to intense activity and form small agglutinated masses; these then fuse with the greatest rapidity to form larger agglutination masses for a period of three to five seconds, after which no more fusion of masses takes place. While this has been going on in the interior of the drop a ring has formed at the margin, and a clear zone arises external to it. The ring is at first continuous, but it ruptures in numerous places in two or three seconds, and each segment contracts quickly to an agglutinated mass. Such masses, whatever their original form, quickly contract into spheres. In a period of time varying from a few seconds to a few minutes, depending on the concentration of the egg water, the agglutination disappears. The

I His statment that "Lillie seems to take it for granted that the substance of the egg which causes sperm agglutination is identical with the substance which stimulates the spermatozoa into greater activity" rests upon no such statement of mine. 
spermatozoa are then for a time relatively immobile. The same observations were also made on Nereis. Loeb (I9I4) has reported the occurrence of the same phenomenon in various species of sea urchins, Glaser (I9I4) in Asterias, and Just (19I8) in Echinarachnius.

The drop of egg water, two to four millimeters in diameter, may be regarded as equivalent, in a chemical sense, to a much magnified egg, and the reactions of the spermatozoa to it as similar to reactions to the actual egg, with this exception, that the solid surface is lacking. We see here three kinds of effects of the specific egg water, viz., activation, aggregation, and agglutination. ${ }^{\mathrm{I}}$ The aggregation effect evidenced by the ring and clear zone with reference to the introduced drop is entirely similar to the aggregation of spermatozoa of Nereis produced by $\mathrm{CO}_{2}$ and other acids. In the case of the egg water it is complicated by simultaneous agglutination; but it is possible to eliminate the agglutination effect (Lillie, I9I3) by neutralizing the agglutinating substance and to leave the aggregating effect

"The term "agglutination" will be used exclusively for this reversible phenomenon of adhesion of living cells for a longer or shorter time. Agglutination in this sense has no effect destructive of the life of the spermatozoön, toxic or otherwise. This seems to the author a correct biological use of the term. Certain other substances, such as $\mathrm{KOH}, \mathrm{NaOH}$, or certain fluids of other species, cause an irreversible sticking together of spermatozoa, which is obviously a different phenomenon biologically and is usually destructive. This is to be distinguished sharply from biological agglutination. Confusion is likely to arise in the use of the term, because Loeb, for instance, has called the caustic alkali effect "real sperm agglutination" (I9I4, pp. I 26-27). He is here using the term in its etymological significance. The effect of caustic alkalies is also strikingly different in appearance; anastomosing cords of sperm are formed constituting a network; the strands never contract into spheres as in agglutinated sperm; moreover, the spermatozoa are motionless and evidently dead. 
intact. ${ }^{\mathrm{I}}$ In this case the ring of spermatozoa remains unagglutinated. Thus the aggregating and agglutinating substances are distinct. We have previously discussed the significance of the ring formation with external clear zone with reference to acids in the case of Nereis and arrived at the conclusion that this is a true chemotactic reaction of spermatozoa; the same conclusion must hold for the egg water of Arbacia, which thus contains a substance derived from the eggs which determines aggregation of spermatozoa.

Egg substances that thus activate and direct the specific spermatozoa and render them adhesive are well adapted to favor the fertilization reaction which we shall consider later.

Doubt has been expressed as to the presence of a chemotactic agent in egg secretions of animals. Buller (1902), who investigated the subject in various species of sea urchins, using the tube method of Pfeffer, obtained only negative results. He states that they went in and out of the tubes containing egg water with indifference, and he failed to discover any other substance to which they would give a chemotactic response in the sense of entering the solution in the tubes and remaining there. J. de Meyer (I9II), later using precisely the same methods, often obtained plugs of spermatozoa several millimeters long in tubes containing egg water. He thus disagrees entirely with Buller; but as

${ }^{x}$ While this book was in press there appeared Forced Movements, Tropisms and Animal Conduct by Jacques Loeb, in which he again returns to the attack against chemotropism of spermatozoa. His somewhat inaccurate account of the writer's views and experiments lends some plausibility to criticisms which have no real foundation; the fundamental problem involved receives no real consideration. 
neither author gives any quantitative data it is difficult to find the cause for the disagreement. As I have pointed out before, the tube method is crude as compared to the injected-drop method, being ten to twenty times less delicate. A negative result cannot be trusted for this reason, and a positive result is not necessarily due to chemotactic orientation, for spermatozoa once in such a tube, even by chance, might be imprisoned there by any paralyzing effect of the contents.

The agglutination effect is a very definite and characteristic reaction, differing from mere aggregation in the following particulars: in the latter the spermatozoa are merely loosely associated, and slight agitation is sufficient to scatter them; in the agglutinated masses the spermatozoa are stuck together and are not separated by shaking. In the case of Nereis, where the agglutination is firmer than in Arbacia, the masses may be broken up into smaller coherent masses by needles or preserved intact in killing fluids. The agglutinating substance also produces its characteristic effect when shaken up and evenly distributed in a vial of sperm suspension, but an aggregative substance cannot of course exert a chemotactic effect in the absence of a gradient. The agglutination reaction is also spontaneously reversible, unlike aggregation; moreover, it cannot be repeated if the reaction is complete, owing to complete fixation of the agglutinable substance born by the spermatozoön. Although at one time Loeb (I9I4) held that the agglutination was probably a "tropistic phenomenon," he has since abandoned this view (I9I5, p. 275). The agglutinated spermatozoa are living and 
apparently in nowise injured, in which respect isoagglutination differs from the frequent toxic effects of foreign egg secretions, which may cause permanent adhesion of spermatozoa in masses.

The phenomenon of agglutination of sperm suspensions by egg water probably does not occur in all animals. Thus I have been unable to observe it in the starfish, though Glaser (I9I4) reports its occurrence in this form. Absence of sperm agglutination, however, is not evidence for absence of a comparable secretion of such ova, for the adhesion of the spermatozoa is evidently a result of a surface physical change of spermatozoa which may be less in some forms than in others. Thus while in some species the spermatozoa are efficient indicators for the substance, they need not be so in all. This does not, however, in the least detract from the usefulness of the indicator when present.

Loeb points out that sperm suspensions paralyzed by $\mathrm{KCN}$ do not agglutinate in specific egg water; thus motility of the spermatozoön is necessary for the reaction; this is readily understood on the principle that energy of impact is necessary for adhesion. Loeb also states that the duration of the reaction is dependent to some extent on the alkalinity of the medium. "The more alkaline the latter the more rapidly the cluster scatters. The presence of a salt with a bivalent metal, especially $\mathrm{Ca}$, seems necessary for the cluster formation."

The agglutination reaction may be studied in a quantitative way. The reaction is reversible, as we have seen; with high concentration of the agglutinating substance it may be several minutes before the aggluti- 
nated masses break up and reversal is completed; with low concentrations, on the other hand, the agglutinated masses are smaller and their disintegration is correspondingly more rapid. It is therefore possible to establish a unit concentration of the agglutinating substance defined as the greatest dilution at which an unmistakable reaction is given. Such a reaction lasts only four or five seconds, and the agglutinated masses are too small to be seen with the unaided eye. Any given egg water may therefore be rated by the amount of dilution required for reduction to unit strength, as containing Io or 100, or 6,400, etc., agglutinating units. The highest concentration obtained in my experiments on Arbacia was I 2,800 units. Just (I919) has obtained an equally high concentration in Echinarachnius egg water.

c) Properties of the agglutinating substance.-We may now examine some of the properties of the agglutinating substance: first, its biological properties; second, its physical and chemical properties.

Biological properties: Apart from the data already considered we may note that the eggs alone produce this substance; it is not contained in the blood (perivisceral fluid), even of mature females, or in extracts of any other tissues. We thus have a specific relation between egg and spermatozoön that does not obtain between any other tissues and the spermatozoön. The substance is tissue specific.

It is produced by mature eggs alone and ceases to be produced by fertilized eggs. Thus its production period coincides exactly with the'fertilizable period of the ovum. The greatest care has been taken to determine this point; no quantity of ovarian substance 
containing only immature eggs yields even a trace of sperm-agglutinating substance; and after the eggs are once fertilized and the jelly, which is soaked with the substance, is removed from around the eggs no trace of this substance is ever to be detected from these eggs (cf. also Just on Echinarachnius, I9I9).

The agglutinating substance is secreted by fertilizable eggs of Arbacia as long as they remain in a fertilizable condition. However, the jelly membrane of each egg is saturated by the substance, as is readily shown by killing the eggs by heat until they are thoroughly coagulated, when the jelly still continues to give off the substance in large quantities into the seawater. Loeb (I9I4) maintains that in Strongylocentrotus purpuratus of California, eggs deprived of jelly lose completely and permanently the power of agglutinating the sperm of its own species; that the jelly alone contains the agglutinating substance. This is not the case in Arbacia, for after the unfertilized eggs have been deprived of jelly, either by shaking or by $\mathrm{HCl}$, and washed several times to remove any last traces of jelly, they still continue to produce the agglutinating substance. Thus I could show that, whereas the acid solvent which removed the jelly from a given lot of eggs contained only 400 agglutinating units, after a series of washings that represented a dilution of the solvent remaining with the eggs of $12,700,800$ times, the last washing agglutinated the spermatozoa. In other experiments this process was carried much farther.

In a considerable number of experiments, not only by myself (I9I3, I9I4), but also by C. R. Moore (I9I7), 
the capacity of Arbacia eggs to continue the production of the agglutinating substance for a long period of time after removal of the jelly has been demonstrated. Glaser (I9I4) obtained the same result. To obtain clear evidence of the reaction from such eggs the observations must be made under the microscope, preferably by the raised cover-slip method, immediately after addition of the egg water, for the reaction lasts only from five to fifteen seconds and the agglutinations are microscopic in size. It would appear probable from Loeb's account that he used only macroscopic methods, and this may be the reason for his negative statement concerning Strongylocentrotus.

The case of immature eggs also shows that the agglutinating substance is distinct from the jelly, because these eggs are already provided with jelly, but egg water from them contains no agglutinating substance. It would therefore appear that this substance begins to be produced during the process of maturation of the egg and is discharged from the egg into the jelly, which becomes saturated with it, and will therefore continue to yield it up to sea-water even when separated from the egg. These results are completely confirmed by Just (1919) for Echinarachnius.

The agglutination is between the heads of the spermatozoa, which obviously become adhesive as a result of action of the egg water; the tails of the spermatozoa are apparently unaffected; the adhesive change, however, soon passes away, hence the subsequent reversal of agglutination. The loss of adhesive properties may be due to solution of the adhesive substance in the sea-water or to a physical change in the substance. 
In the case of Nereis it could be seen that in agglutinated masses the heads of many of the spermatozoa are swollen into spherical form and have lost their normal strong refringibility; in such a case they are usually motionless and, when not fused with one another, appear to be glued to the slide or cover slip.

De Meyer (I9II) observed that egg extracts of Echinus, which contain certainly other substances than the secretions of uninjured eggs, cause a strong swelling of the head of the spermatozoön, including the nucleus, and other transformations depending on the strength of the extract and the duration of its action; the swelling may increase the diameter as much as eight times. The middle piece also swells and may divide. The spermatozoa thus come to resemble small cells. Thus he states that in sea-water extract of eggs the spermatozoa undergo some of the changes which occur within the normally fertilized egg.

Chemical and physical properties: The agglutinating substance is colorless; it will not pass through a Berkefeld filter, but passes readily through special hardened filter paper; it is non-dialyzable; it is extremely heat-resistant, being destroyed only slowly at the boiling-point; it may be kept in sea-water for months, though it slowly disintegrates. It is obviously colloidal in its character, but Glaser (I9I4) has determined that it does not give the usual protein tests: Millon's reagent gave a white precipitate with no color changes on boiling; the biuret test was negative; $\mathrm{HNO}_{3}$ gave no ring, but a faint cloudiness; the xanthoproteic test gave no precipitate, but the solution turned distinctly yellow; the Adamkiewicz test was negative; Fehling 
gave no reduction; bisubnitrate gave no reduction. Richards and Woodward (r915) point out that the efficiency of the agglutinin, like pepsin, varies with the square root of the concentration. If the efficiency is measured by the number of seconds the spermatozoa remain agglutinated, and the concentration is measured by units of strength, a curve results of approximately the formula $y^{2}=\operatorname{II} x$, where $y$ represents the efficiency and $x$ the concentration (Richards and Woodward, I9I5). The same authors also state that $\mathrm{X}$-radiation affects solutions of the agglutinating substance in the same sense as ferments, accelerating in a short exposure (about two minutes), non-effective in a five-minute exposure, and inhibitive in a longer exposure. It thus possesses some ferment analogies.

A completely agglutinated sperm suspension in which reversal has occurred is not capable of reagglutination by the addition of more of the agglutinating substance, and the substance disappears from an agglutinated suspension when not present in excess. The agglutination has therefore some of the usual characters of a chemical reaction. Glaser (I9I4) has also made the same determination. Schücking (1903) also holds to a union of the agglutinating substance of the egg with the agglutinable substance of the sperm for similar reasons. The writer (19I4) has determined that I c.c. of 3 per cent sperm suspension of Arbacia will fix about 64 units of the agglutinating substance, i.e., I c.c. of egg water of 64-unit agglutinating strength. In more specific terms, if I c.c. of 3 per cent sperm be added to I c.c. of 64-unit egg water and the spermatozoa be precipitated after agglutination by centrifuging, the 
agglutinating substance is found to be absent from the supernatant fluid. If a lesser quantity of sperm be employed some agglutinating substance will remain free. Whether we are dealing here with a true chemical union, or merely with a process of adsorption is not yet determined.

If sperm suspensions are allowed to stand for some hours they reach a condition where they will agglutinate only with strong solutions. If the binding power is then tested it is found that they fix as much of the agglutinating substance as when fresh. The fixing power of the sperm is thus entirely independent of its capacity for being agglutinated, which depends upon the freshness of the spermatozoa. The binding capacity would appear, therefore, to depend upon the presence of a certain substance borne by the spermatozoön which we may call the agglutinable substance. We may suppose that in stale sperm suspensions this substance may be cast off and lie free in the medium. But this has not been actually determined.

\section{5. "Hetero-Agglutination" and Specificity}

The egg waters of Arbacia and of Nereis possess substances each agglutinating for its own sperm. If we test the Nereis egg water on Arbacia sperm we find that it is entirely negative; if on the other hand we test the Arbacia egg water on Nereis sperm the latter is apparently strongly agglutinated. At first sight it would seem that there is specificity in the one direction but not in the other with reference to the agglutinating substances. If, however, we examine the effect of the Arbacia egg water on Nereis sperm more carefully we find that the reaction bears quite a different character 
from either iso-agglutination. The adhesion of the spermatozoa is permanent, not reversible, and if the egg water be strong the spermatozoa are killed. Moreover, the blood of Arbacia produces the same effect on Nereis sperm, as its egg water, whereas it is an indifferent medium for the specific sperm. The conclusion is therefore suggested that the "hetero-agglutinin" and the "iso-agglutinin" of Arbacia egg water are different substances.

This can in fact be demonstrated in more than one way. Thus an Arbacia egg water that originally acted both on Arbacia and Nereis sperms was found to have lost all effect on Nereis sperm after seventeen days, whereas it retained undiminished its agglutinating effect on its own sperm (Lillie, I9I3). The non-specific substance was destroyed by the chemical changes in the egg water, but the specific substance remained. It is also possible to precipitate out all of the Nereisactive substance with Nereis sperm and leave the full complement of iso-agglutinating substance. Thus a sample of Arbacia egg water was found to have 800unit iso-agglutinating power; it had also a powerful effect on Nereis sperm but was negative at onesixteenth dilution. The addition of two drops of a I per cent sperm suspension of Nereis to I c.c. of the egg water completely neutralized the Nereis active substance but left the original 800-unit strength of the isoagglutinating substance. The sperm of a teleost was also found capable of neutralizing the hetero-active substance, leaving the iso-agglutinating substance intact. The hetero-active substance would thus appear to be rather generally toxic to foreign sperm. It 
occurs, as we have seen, in the blood of the sea urchin and is present there in greater concentration than in the egg water; so it is certainly not tissue specific as is the iso-agglutinin.

It is therefore certain that the iso-agglutinins of Arbacia and of Nereis are without action on the heterologous sperm. But these forms belong to different phyla. How is it as between more closely related forms? Just (I9I9) has found that egg water of Arbacia agglutinates the sperm of Arbacia and Echinarachnius; the egg water of the latter will agglutinate its own sperm but not that of Arbacia. The relations are thus similar to Arbacia and Nereis; and correspondingly Just was able to show that two distinct substances are involved in the Arbacia egg water. Loeb (I9I4, p. I25) notes that the egg water of the sea urchin Strongylocentrotus purpuratus will agglutinate both its own sperm and that of $S$. franciscanus but the latter not so strongly; the egg water of $S$. franciscanus will agglutinate its own sperm but not that of $S$. purpuratus. Here again the specificity is not reciprocal, and this suggests the possibility that the hetero-agglutinating substance of $S$. franciscanus may be a distinct substance from the iso-agglutinating substance. Loeb, however, did not investigate this possibility.

The results thus far obtained are too meager to permit a generalization on the specificity of the agglutination reaction. There is a considerable degree of specificity in such reactions, as we have seen, but we do not yet know how far this extends.

Certain observations indicate an absence of agglutinating effect of egg water on specific sperm of certain 
species; we do not indeed know how widespread the phenomenon may be. Where it occurs we have a definite indicator of a reaction; the failure of the indicator in certain species is no evidence of lack of such reaction, for the fundamental reaction is on the individual spermatozoön; the agglutination is a consequence of secondary conditions such as the concentration of the sperm suspension, the rate of movement of the affected cells, and the composition of the medium; it may also be that the reaction in certain species does not involve such physical alteration of the sperm protoplasm as to permit of agglutination to one another. We must therefore, I believe, utilize such positive indications as we have in our analysis, leaving the negative cases for future investigation.

The fertilization reaction proper is considered in chapter vii. It is obvious that for the purposes of this reaction, which involves adhesion and ultimate fusion of the gametes, activation of the spermatozoön, tendency to collect in the region of egg secretions, the thigmotropic reaction, and the development of an adhesive surface by action of the agglutinating substance of the egg constitute forms of behavior exactly suited to the final accomplishment. The layer of jelly that invests the ova of most marine forms acts mechanically to entangle the spermatozoa, and it also concentrates the action of the egg secretions, with which it is heavily charged.

The meeting of the egg and the spermatozoön is to be regarded neither as a matter of random activity of the spermatozoön alone, as some have been inclined to regard it, nor yet exclusively as a result of direct orientation of the spermatozoön toward the egg by 
chemotaxis, as others have supposed. It appears really to be a more complex event in which the various forms of behavior of the spermatozoön may all play a part, as indicated.

\section{BALLOWITZ, EMIL.}

\section{REFERENCES}

I 890. "Untersuchungen ueber die Structur der Spermatozoen," Zeitschr. fïr wiss. Zool. (See pp. 392-93).

BulLER, A. H.

1902. "Is Chemotaxis a Factor in the Fertilization of the Eggs of Animals?" Quart. Jour. Micr. Sci., XLVI, I $45-76$.

Cohn, Edwin J.

I917. "The Relation between the Hydrogen Ion Concentration of Sperm Suspensions and Their Fertilizing Power," Anat. Rec., II, 530.

I918. "Studies in the Physiology of Spermatozoa," Biol. Bull., XXXIV, 167-218.

Dewitz, $J$.

1885. "Ueber die Vereinigung der Spermatozoen mit dem Ei," Arch. für d. ges. Physiol., Band 37, pp. 219-23.

I886. "Ueber Gesetzmässigkeit in der Ortsveränderung der Spermatozoen und in der Vereinigung derselben mit dem Ei," ibid., Band 38, pp. 358-85.

Dungern, Emil von.

I902. "Neue Versuche zur Physiologie der Befruchtung," Zeitschr. für allgem. Physiol., Band I, pp. 34-55. See also Centralblatt für Physiol., r9or.

Gemmil, James J.

Igoo. "On the Vitality of the Ova and Sperm of Certain Animals," Jour. of Anat. and Physiol., XXXIV, I6 3.

Glaser, Otto.

1914. "A Qualitative Analysis of the Egg Secretions and Extracts of Arbacia and Asterias," Biol. Bull., XXVI, ${ }_{3}^{6}{ }_{7}-86$. 
Glaser, Otto.

I915. "Can a Single Spermatozoön Initiate Development in Arbacia?" Biol. Bull., XXVIII, I49-53.

Gray, JAMES.

I9I5. "Note on the Relation of Spermatozoa to Electrolytes and Its Bearing on the Problem of Fertilization," Quart. Jour. Micr. Sci., N.S., LXI, I I9-26.

Günther, Gustav.

I907. "Ueber Spermiengifte," Arch. für d. ges. Physiol., Band I 8 , pp. 55 I-7 I.

Just, E. E.

I919. "The Fertilization Reaction in Echinarachnius parma. II, The Rôle of Fertilizin in Straight and Cross-Fertilization," Biol. Bull., XXXVI, i I-38.

Kölliker, A.

I 856. "Physiologische Studien über die Samenflüssigkeit," Zeitschr. für wiss. Zool., Band 7, pp. 20I-73.

LILLIE, FraNK R.

I913. "Studies of Fertilization. V. The Behavior of the Spermatozoa of Nereis and Arbacia with Special Reference to Egg Extractives," Jour. Exp. Zoöl., $\mathrm{XIV}, 515-74$.

1914. "Studies of Fertilization. VI. The Mechanism of Fertilization in Arbacia," ibid., XVI, 523-9o.

I915. "Sperm Agglutination and Fertilization," Biol. Bull., XXVIII, r8-33.

"Studies of Fertilization. VII. Analysis of Variations in the Fertilizing Power of Sperm Suspensions of Arabacia," ibid., pp. 229-51.

I.OEB, JACQUES.

1914. "Cluster Formation of Spermatozoa Caused by Specific Substances from Eggs," Jour. Exp. Zoöl., XVII, I 23-40.

I915. "On the Nature of the Conditions Which Determine or Prevent the Entrance of the Spermatozoön into the Egg," Amer. Naturalist, XLIX, 257-85. 
Loeb, Jacques

I916. The Organism as a Whole from a Physicochemical Viewpoint. New York: G. P. Putnam's Sons.

Löw, O.

1902, I903. "Die Chemotaxis der Spermatozoa im weiblichen Genitaltract," Sitzungsber. d. königl. Akad. d. Wiss., Math. Naturw. Kl., Wien, Band I I I-I 2.

MAssart, Jean.

I888. "Sur l'irritabilité des spermatozoides de la grenouille," Bull. de l'Acad. Roy. des Sci. de Belgique, T. I 5, pp. 750-54.

I889, "Sur la pénétration des spermatozoides dans l'œuf de la grenouille," ibid., T. I8, pp. 21 5-20.

De Meyer, J.

I9I I. "Observations et expériences relatives à l'action exercée par des extracts d'œufs et d'autres substances sur les spermatozoides," Arch. de biol., T. 26, pp. 65-IOI.

MoORE, C. R.

I9I7. "On the Capacity for Fertilization after Initiation of Development," Biol. Bull., XXXIII, 258-95.

Pfeffer, W.

I884. "Locomotorische Richtungsbewegungen durch chemische Reize," Untersuchungen a. d. bot. Inst. zu Tïbingen, Band I.

RichaRds, A., AND WoODWARD, A. E.

I9I5. "Note on the Effect of X-Radiation on Fertilizin," Biol. Bull., XXVIII, I40-47.

SchÜCKING, A.

1903. "Zur Physiologie der Befruchtung, Parthenogenese und Entwickelung," Arch. fïr d. ges. Physiol., Band 97, pp. 58-97.

Wrnslow, G. M.

1903. "Note on Circular Swimming of Sand-Dollar Spermatozoa," Science, N.S., XVII, I 53. 


\section{CHAP'TER V}

\section{THE PHYSIOLOGY OF FERTILIZATION}

\section{INTRODUCTION}

It is commonly said that there are two main problems in the physiology of fertilization, viz.: the initiation of development, or activation, and biparental inheritance; but these are more properly results of fertilization. Indeed so long as we regard fertilization primarily as a function of prospective significance in the life of the organism we shall miss the more specific aspects of the process. Once fertilization is accomplished development and inheritance may be left to look after themselves.

Fertilization must be regarded as a reaction possessing very definite biological and biochemical characters. But it is not a single reaction in either a biological or chemical sense; it is rather a series of reactions which cannot be regarded as complete until full capacity for development and inheritance is attained by the zygote. Fertilization may therefore be partial, which may be indicated by early cessation of the developmental process or deficiency of developmental energy. It is obvious that partial fertilization will furnish an important means of analysis.

The reactions of fertilization form an irreversible series, though it is conceivable that some of them taken singly may be reversible. Spermatozoa have no effect on already fertilized eggs and do not penetrate into them; this condition arises very early in the fertilization 
reactions, so that the entrance of more than one spermatozoön does not usually occur. With reference to reversibility the ovum differs from most cells. A nerve cell or a gland cell or a muscle cell after functioning returns to the functional condition again; but, so far as our evidence goes, this is not true of the egg cell or of the spermatozoön; their functioning is essentially a progressive process, the cycle of which occupies an entire generation. From this point of view the lack of reversibility is readily understood.

Fertilization is a specific reaction in the sense that it occurs usually only between the gametes of the same species. Hybridization is possible within certain indefinite limits, which do not follow any invariable taxonomic rule, though as a general thing it is regarded us increasingly improbable with remoteness of taxonomic relationship. In the echinids and teleosts, however, hybrid fertilization is possible even between different families or suborders. Resistance to hybridization may also be broken down by certain experimental procedures considered later. On the other hand we have the special phenomenon of self-infertility in certain hermaphrodites (see chap. vi).

Certain eggs are normally parthenogenetic, and in others artificial parthenogenesis may be produced by various experimental procedures. It is obvious that in such cases the activating effects of fertilization are produced, and that the analysis of parthenogenesis must have very direct bearings on this problem of fertilization. We shall therefore utilize the results of such studies to a certain extent, but only as an aid in the analysis of fertilization (see chap. vii). 
It is usual to regard penetration of the spermatozoön as synonymous with fertilization, but we may have fertilization well begun after mere attachment of the spermatozoön and without any penetration, as in Nereis; on the other hand we may have penetration without any fertilization, if the egg is not in the proper condition. A complete fertilization reaction involves penetration, which thus furnishes one of the problems of fertilization; but it is not fertilization in itself.

\section{THE FERTILIZABLE CONDITION OF THE GAMETES}

The fertilization reactions are possible only during a definite limited time in the life of the gametes. This has usually been attributed to rapid aging after the fertilizable condition is once attained, but a careful examination of the loss of fertilizing power may enable us to define this problem more exactly.

I. The spermatozoön.-Spermatozoa attain fertilizing power after the completion of histogenesis and the attainment of full motility. Unripe spermatozoa will not fertilize. After ripening, spermatozoa retain fertilizing power for variable periods depending on the species and on the conditions. Within the gonads or in the seminal ducts spermatozoa are motionless and may remain in good condition apparently indefinitely until ejaculated. In the case of animals with internal fertilization the life of spermatozoa within the genital tract of the female may also be considerable. In birds (fowl) spermatozoa may retain power for two or three weeks. In most mammals the period is shorter; but in bats, for instance, copulation occurs in the fall, and ovulation and fertilization are delayed until the spring. 
The females of many insects possess seminal receptacles in which spermatozoa received from the male may be stored up for long periods; in the case of ants and bees, for instance, spermatozoa within the seminal receptacles may retain their fertilizing power for years.

The actual conditions of vitality and fertilizing power can, however, best be studied in forms with external insemination, especially marine forms. Sea urchins furnish ideal material for such a study. In this case it has been shown, especially by the studies of E. J. Cohn (I918), that the vitality and fertilizing power endure in inverse ratio to activity. Concentrated sperm suspensions retain their vitality longer than more dilute suspensions because they rapidly produce a paralyzing concentration of $\mathrm{CO}_{2}$ (see p. IOI). Similarly, any substance that will paralyze the spermatozoa without killing them, such as dilute acids, $\mathrm{KCN}$, etc., will prolong the period of fertilizing power. Cohn has shown that Fuch's (1915) result on increase in duration of fertilizing power of sperm suspensions in specific egg water as compared with similar suspensions in sea-water is due to the paralyzing effect of the water on the sperm.

The question may now be raised whether the fertilizing power of sperm suspensions is dependent exclusively on motility, or whether the presence of a specific substance borne by the sperm is not also necessary? Such a substance must be borne superficially, for the fertilization reaction begins immediately after attachment of the spermatozoön to the egg. Loeb (19r3, p. 227) at one time postulated the idea that the sperm bears a lysin-like substance producing superficial cytolysis of the egg, which he regarded as the first step 
in initiation of development. Such a substance might conceivably be lost by the spermatozoön without detriment to its vitality, leaving the spermatozoön in a motile condition but without capacity for fertilization.

The conception of a fertilizing substance borne by the spermatozoön seems to be a necessary one, but the conception that it acts on the egg as a cytolytic agent is no longer maintained. The attempt has been made by a number of investigators (Winkler, I900; Gies, I90I; Robertson, 1912) to extract such a substance from spermatozoa, but without success in the production of a solution that will cause development of the egg of the same species.

T. B. Robertson ( r9r2) has extracted, by a very complex process, from the sperm of the sea urchin an acidsoluble substance which caused the production of atypical membranes on sea urchin eggs, especially where the action was reinforced by previous treatment of the eggs with $\frac{3}{8} \mathrm{NSrCl}_{2}$. No development took place. It seems doubtful to the writer that this represents the specific membrane-producing substance of the spermatozoön, as Robertson maintains. The substance proved markedly poisonous to the eggs, an effect that was not removed by treatment with hypertonic seawater. It seems possible that some cleavage product of the sperm proteins was concerned. As the results of other authors (Gies, etc.) have been negative, and, moreover, as Loeb has treated the subject quite fully in his book on Artificial Parthenogenesis and Fertilization (chap. xix), we need not consider this matter in detail.

A mere negative finding in this type of experiment is, however, inconclusive. It is conceivable, as Loeb 
has pointed out, that the postulated fertilizing substance of the spermatozoön requires the motive power of the spermatozoön to make it effective against the egg, which is the only indicator, and that it will not act in solution; it is also possible that it is labile in solution, or that methods employed in the endeavor to isolate it have been too brutal. We have seen (pp. I I $2 \mathrm{ff}$.) that spermatozoa carry an agglutinable substance which is lost after reaction with the agglutinating substance of the egg; the presence of such a substance could not be demonstrated by mere isolation methods.

The writer (1915) has employed another method for demonstrating the existence of such a substance. He showed that the rate of loss of fertilizing power of sperm suspensions of Arbacia is inversely proportional to their concentration and that in great dilutions the loss of fertilizing power is many times more rapid than the loss of motility. This was ascribed to loss of a specific substance by the spermatozoön, for the other factors for successful insemination were maintained constant. Other observers (e.g., Schücking, I903, and Glaser, I9I4) have noted that several spermatozoa appear to be needed for fertilization of a single ovum, because fertilization usually failed under the conditions of their experiments unless a number of spermatozoa were present simultaneously in the jelly around the egg. Glaser postulated a mass effect of spermatozoa in fertilization as well as an individual effect to explain this. The writer could, however, demonstrate that mass effect is not necessary if the sperm suspensions are sufficiently fresh, and that the appearance observed by Schücking and Glaser is found only with suspensions not perfectly fresh. 
The fertilizing power of sperm suspensions may be expressed in curves whose ordinates are percentages of fertilization, and the abscissae a geometrical series of dilutions of I per cent sperm in powers of 2. This method was adopted for the abscissae because of the method of successive half-dilutions used in many experiments, and because the enormous range of fertilizing power made it impossible to compare results on one

$\begin{array}{lllllllllllllllllllllllllllll}0 & 1 & 2 & 3 & 4 & 5 & 6 & 7 & 8 & 9 & 10 & 11 & 12 & 13 & 14 & 15 & 16 & 17 & 18 & 19 & 20 & 21 & 22 & 23 & 24 & 25 & 26 & 27\end{array}$

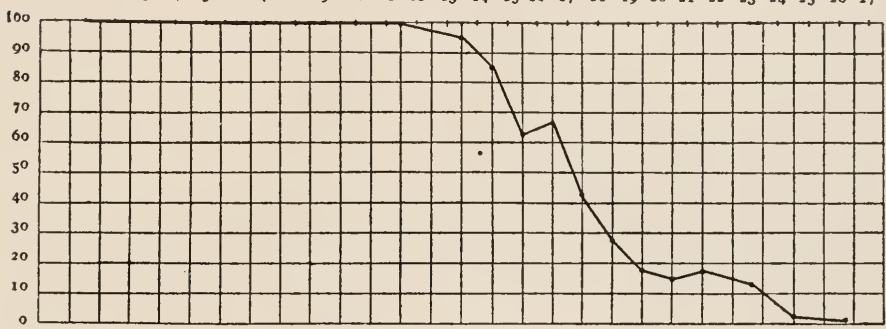

FIG. I6.-Curve of fertilizing power of perfectly fresh sperm suspensions of Arbacia. The ordinates give percentages of eggs fertilized. The abscissae represent dilutions of the sperm in powers of 2, viz.: I $=\frac{1}{2} ; 2=\frac{1}{2} ; 3=\frac{1}{2} 3$, etc.

scale with an arithmetical progression. When it is realized that fertilizing power may extend to $\mathrm{I} / 90,000,-$ ○० of I per cent the necessity of the geometrical series in the abscissae will become apparent.

Figure 16 is prepared from data of experiments calculated to bring eggs and sperm together in the freshest possible condition of the sperm. In general measured quantities of washed eggs were put in measured amounts of sea-water, and measured quantities of definitely calibrated sperm suspensions added and stirred in as uniformly as possible. A control of unfertilized eggs in 
sea-water was always kept to guard against chance fertilizations. To illustrate: the last four determinations of the curve were made as follows: In four crystallization dishes were placed I,000 c.c. sea-water $(A)$, 3,000 c.c. sea-water $(B)$, I,000 c.c. sea-water $(C)$, 3,000 c.c. sea-water $(D)$. To each was added 2 c.c. of a washed egg suspension. The sperm was then prepared as follows: (I) one drop dry sperm to $3 \cdot 3$ c.c. seawater at 9:43 A.M.= I per cent; (2) I c.c. sperm I to 99 c.c. sea-water at $9: 43 \frac{1}{2}$ A.M. $=\mathrm{I} / \mathrm{I} 00$ per cent;

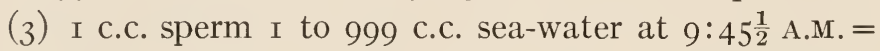
I/I,, 00 per cent. To $A$ was added I drop sperm 2 (I/Ioo per cent) at $9: 43 \frac{3}{4}$; to $B$ one drop sperm 2 (I/ Ioo per cent) at $9: 44 ;$ to $C$ one drop sperm 3 (I/ I, , ० per cent) at $9: 45^{\frac{3}{4}}$; to $D$ one drop sperm 3 (I/I,ooo per cent) at $9: 45^{\frac{3}{4}}$. An assistant stirred in the sperm thoroughly as added. The sperm concentration in $A$ was therefore $\mathrm{I} / \mathrm{I} 00 \times \mathrm{I} / 30 \times \mathrm{I} / \mathrm{I}, 000=\mathrm{I} / 3,000,000$ per cent; in $B$ it was $\mathrm{I} / 9,000,000$ per cent; in $C, \mathrm{I} / 30,000,000$ per cent; in $D, \mathrm{I} / 90,000,000$ per cent; I/3,000,000 per cent falls between $2 \mathrm{I}$ and 22 on the scale, and the others as shown. The exact times of mixing the sperm are given because, as will appear beyond, time is an extremely important factor with reference to fertilizing power.

To appreciate the extent of the greatest dilution it may be said that beyond a dilution of I/Io,ooo per cent -(between I 3 and $\mathrm{I} 4$ on the scale) one can rarely find a single spermatozoön in the jelly of the fertilized eggs. At about I/2,000 per cent (I I on the scale) the sperm suspension does not even appear opalescent. We may therefore feel reasonably sure that beyond about I4 or 
I 5 on the scale no egg will receive more than one spermatozoön.

In further elucidation of the curve (Fig. I6) I may say that the critical (steep) part was covered by several determinations for each point. Thus there are five determinations averaged for the positions between I3 and I5, seven between I5 and I8, five between I 8 and 20 , and six between 20 and $2 \mathrm{i}$. The determinations beyond $2 \mathrm{I}$ are single determinations. For the first part of the curve up to I3 there are numerous determinations. There are great variations in the single determinations compared with one another; these averages must therefore be regarded only as approximate values. With a sufficiently large number

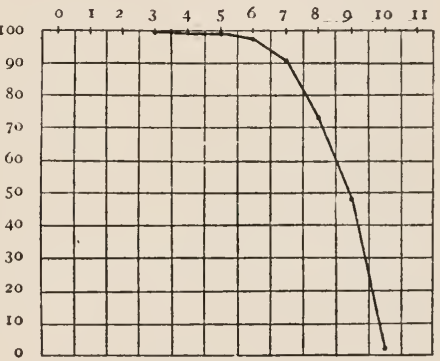

FIG. I 7.-Curve of fertilizing power of sperm suspensions of A rbacia about 20 minutes old. Ordinates and abscissae as in Fig. 16. of determinations the irregularities between I 5 and I 7 and between I9 and 22 would no doubt disappear. But it is improbable that the general form of the curve would undergo any essential change even with a much more extensive series of determinations.

If now we compare this curve of fertilization with perfectly fresh sperm with sperm suspensions about twenty minutes old we get the result shown in Fig. I7. It will be seen that fertilizing power ceases at $\frac{\mathbf{1}}{2}{ }^{\text {10 }}$ after thirty minutes. If now one determines by comparison the rate of complete loss of fertilizing power of 
sperm suspensions of different concentrations it is found that sperm suspensions of $\mathrm{I} / 240,000$ per cent. decline to zero in their fertilizing power in about six minutes, those of $1 / 30,000$ per cent in about sixteen minutes, those of $\mathrm{I} / 300$ per cent not until after more than two hours, while I per cent sperm may maintain fertilizing power for two or more days.

At the time when sperm suspensions are losing their fertilizing power one can observe the phenomenon described by Schücking and Glaser at the proper concentration of sperm. Thus in one of the writer's experiments eggs were added to a I/ I 28 per cent sperm suspension that was on the point of complete loss of fertilizing power. In ten eggs selected at random an average of nine spermatozoa was counted in the jelly in an optical section. The spermatozoa were still active, but the eggs did not fertilize.

Gemmill (I900) observed a relation between duration of fertilizing power and concentration of sperm in the sea urchin and concluded that the more rapid exhaustion of spermatozoa in dilute suspensions is due to dilution of a hypothetical nutritive medium which keeps the spermatozoa of concentrated suspensions in a vigorous condition. This explanation is not only purely hypothetical but comes back to the principle of loss of motility, which, as we have seen, cannot apply in this case.

The writer therefore holds that spermatozoa tend to lose their fertilizing substance in proportion to dilution, so that they may thus become ineffective, whatever their motility. For reasons discussed later it seems probable that this fertilizing substance is identical with 
the agglutinable substance of the spermatozoön, which is apparently lost by staling, as we have previously seen.

The main principle of this discussion, viz., that spermatozoa may lose their fertilizing power for other causes than loss of motility, or that motility alone is not an adequate criterion of fertilizing power of spermatozoa, has obvious important bearings. The mere fact that spermatozoa may retain their motility ,for three weeks or more in the human genital tract (Waldeyer, I906) by no means proves that they retain their fertilizing power during all this time, although this has been almost universally assumed. In an excellent paper published after his death, Mall (I9r8) points out the many contradictions and unnecessary assumptions that this belief entails with reference to the facts of human conception, and he concludes that it is probable that spermatozoa have lost their fertilizing power by the time they have passed the tube. Bryce and Teacher (I908) and Triepel (I9I4-I5) also conclude that fertilization must occur within forty-eight hours after copulation.

2. The ovum.-Ova attain a fertilizable condition rather suddenly, as a rule at the very end of the period of growth or at the beginning of the maturation period. The egg of Nereis is fertilizable before the rupture of the germinal vesicle, but the ova of sea urchins, starfish, Dentalium (mollusk), and Nemerteans are not fertilizable until the germinal vesicle has begun to break down (see section on merogony). Ova may, however, be penetrated by spermatozoa at an earlier period but without any fertilization reaction occurring. 
O. and R. Hertwig (I887) were the first to observe this: under the influence of chloral hydrate spermatozoa penetrate unripe sea urchin eggs in large numbers, but the eggs remain unchanged and the sperm heads undergo no change within the egg. Under normal conditions spermatozoa do not usually penetrate into such unripe eggs. The writer has observed penetration of unripe ovocytes of Chatopterus without any subsequent reaction 'of egg or sperm. Wilson (I903) has observed for Cerebratulus, and Delage (гог $a$ ) for the starfish, that enucleated portions of ova, full grown but with intact germinal vesicle, will not give any fertilization reaction, but as soon as the germinal vesicle has broken down similar pieces readily fertilize.

Fertilization capacity thus arises suddenly in ova. The most natural working hypothesis is that this is due to formation of a definite substance essential for fertilization. This is a conception that we shall examine more fully later on. For purposes of reference we shall call this (for the present) hypothetical substance fertilizin.

The fertilizable condition of the ovum is not of indefinite duration. Indeed in many cases its duration is exceedingly brief. The most remarkable case of this kind is found in the annelid Platynereis megalops, which has been very beautifully analyzed by E. E. Just (I9I5). Fertilization is normally internal in this animal and the eggs are laid as soon as fertilized. Artificial insemination may be successfully performed by mixing the ova and spermatozoa dry, i.e., without any contact with sea-water until after insemination; but sea-water may be added 5 seconds later. If, how- 
ever, the eggs are placed in sea-water for even a few seconds before insemination they cannot be normally fertilized even if the sea-water be filtered off. The effect may be graded by using minimal quantities of sea-water. But the sperm can remain in sea-water for some time, and after filtering off the sea-water they will normally fertilize dry eggs. Washed eggs will not fertilize, but washed sperm will.

The time factor involved in these experiments is far too short to give any support to the assumption that sea-water "injures" the eggs in other ways; it is also impossible to postulate a membrane effect of the sea-water inhibiting entrance of the spermatozoön, because the effect can be graded readily so as to permit penetration, but in this case cleavage does not occur. The results permit of only one conclusion, viz.: that unfertilized eggs lose in sea-water a substance necessary for fertilization. Just was also able to demonstrate a substance in the sea-water used for washing the eggs that has an agglutinating effect on both Platynereis and Nereis sperm.

The case of Platynereis is unusual with reference to the very brief duration of the fertilizable condition of the ovum in the medium for development. But there are many other forms in which the fertilizable period is very brief. For instance, Reighard (1893) states that it is not possible to fertilize the eggs of wall-eyed pike that have lain in water, and he gives the following table (p. I42) in order to substantiate the statement. "Five lots of twenty-five eggs each were prepared for fertilization by placing them in watch glasses in the usual way and to each lot, after it had been a certain 
time in water, was was added freshly prepared milt as follows:

\begin{tabular}{|c|c|}
\hline $\begin{array}{c}\text { Milt Added } \\
\text { after }\end{array}$ & $\begin{array}{l}\text { Percentage of } \\
\text { Fertilized Eggs, } \\
\text { i.e., Segmented }\end{array}$ \\
\hline Lot $\mathrm{I} \ldots \ldots \ldots \ldots 2 \mathrm{~min}$ & 40 \\
\hline Lot $2 \ldots \ldots \ldots 4 \mathrm{~min}$. & I 7 \\
\hline Lot $3 \ldots \ldots \ldots 6$ min. & IO \\
\hline Lot $4 \ldots \ldots \ldots \ldots 8$ min. & 5 \\
\hline
\end{tabular}

Even two minutes in water has great detrimental effect, and at ten minutes all eggs have lost capacity for fertilization. Similarly the egg of the frog is incapable of being fertilized after lying in water a short time (Spallanzani and others).

We can explain such cases, as already suggested, by the loss of the hypothetical fertilizin. Other eggs are apparently better protected with reference to their fertilizin content. Starfish eggs rapidly lose capacity for fertilization after separation of the first polar body. The egg of the sea urchin will bear repeated washings in sea-water without loss of fertilization capacity; but after a certain number of washings before insemination the developmental energy of the fertilized eggs becomes progressively reduced. The writer regards the gelatinous covering of these eggs as a protection against loss of fertilizin, and has shown (chap. vii) that after complete removal of jelly sea urchin eggs are much less resistant against loss of fertilizing capacity by repeated washings. Loeb has suggested that loss of vitality would account for the result (I9I5, p. 283), but, apart from the vagueness of the suggestion, there are other reasons for assigning a more specific cause, which will be discussed later. 
Finally all eggs completely lose fertilization capacity after fertilization, a problem that we shall discuss in chapter vii.

We have thus seen reason to believe that the fertilizable condition of gametes is associated with the presence of a definite substance in each. The evidence is perhaps more conclusive in the case of the ovum than in the case of the spermatozoön. But we are justified in using this conception as a working hypothesis, and it will be found very useful in subsequent analysis.

The capacity for parthenogenesis also exhibits parallel relations to fertilization capacity. Delage (І 90 I $a$ ) was the first to notice this; in his experiments on cytoplasmic maturation in the egg of the starfish he notes that capacity for fertilization arises first with the breaking down of the germinal vesicle; this condition lasts until the appearance of the first polar body, but when the second polar body is about to appear fragments are less fertilizable, "even if they do not become completely resistant to merogonic fertilization." He finds a similar critical period for parthenogenesis; shortly after the germinal vesicle breaks down, parthenogenic agents are peculiarly efficacious; this gradually disappears before the second polar body is formed. "There is a single point in the physiological curve of the egg when the least disturbing action may cause it to turn toward parthenogenesis."

R. S. Lillie (I9I5) has made a more detailed examination of this point with reference to heat parthenogenesis in the eggs of the starfish. A short exposure of the eggs to temperatures between $32^{\circ}$ and $38^{\circ} \mathrm{C}$. will cause the development of almost every egg to a freeswimming larval stage; for each temperature there is 
a well-defined optimum exposure, and the temperature coefficient is over ıо. "The responsiveness of the eggs to this form of treatment was found to depend on the stage of maturation; warming before the dissolution of the germinal vesicle had begun was ineffective, and in fact inhibited maturation entirely; the most favorable period lay between the breakdown of the germinal vesicle and the separation of the first polar body; after both polar bodies had separated development was imperfect and never proceeded far,- even membrane formation then failed in many eggs."

Thus while the eggs of the starfish are still in a condition of unimpaired vitality, as is shown by continuation of the maturation divisions, they lose capacity both for fertilization and parthenogenesis.

The inference that the failure to respond to parthenogenetic agents is due to loss of some substance in sea-water was strongly supported by Just $(1915 b)$ in a study of heat parthenogenesis in Nereis. He found that eggs of Nereis which were first washed in sea-water could not be induced to develop by exposure to warmed sea-water, or only an exceedingly small percentage are affected; if, however, the eggs are exposed, without previous contact with sea-water, to a favorable temperature for an optimum time in a small quantity of seawater, all of them may segment, and as many as 20 per cent may develop into trochophores. Just found that capacity for heat parthenogenesis is lost much more rapidly in sea-water than capacity for fertilization, but the latter is also affected, though at a lesser rate. These capacities he found to run parallel to loss of spermagglutinating substance by the eggs. 
III. PHYSIOLOGICAL INDICIA OF THE FERTILIZATION REACTION

We have already considered the morphological signs of fertilization but may again summarize them: (I) There are invariably certain cortical morphological changes, such as formation of a fertilization membrane (echinoderms and nematodes), formation of a perivitelline space (most animals), and secretion of jelly (Nereis, Platynereis). (2) Maturation is set in process or resumed, provided it is not complete before fertilization. (3) In the egg a sperm aster is usually formed, the sperm nucleus enlarges and metamorphoses, and the germ nuclei unite. What are the immediate physiological consequences or indicia?

I. Changes in rate of oxidation.-Warburg (1908-14) determined that the rate of consumption of oxygen by fertilized eggs of the sea urchin is six to seven times that of unfertilized eggs, and that the rate of oxygen consumption increases progressively for some time. Loeb and Wastenys (I9I2-I3) found the increase in fertilized eggs of Strongylocentrotus purpuratus to be four or five to one as compared with unfertilized eggs. But they did not find any significant change in oxygen consumption in the starfish egg after fertilization (I912). These authors also determined that membrane formation by artificial means causes a comparable increase in the rate of oxidation. The materials of comminuted unfertilized eggs of sea urchins (mechanical [Warburg, I9r4], or by cytolysis [Loeb and Wastenys, I9r3]) also show an equal or greater increase in oxygen consumption as compared with an equal amount of intact unfertilized eggs. It would therefore appear 
that the material of unfertilized eggs is in a highly oxidizable condition. Comminuted material of fertilized eggs consumes no more oxygen than intact fertilized eggs.

The inference has been drawn from these oxidation studies that the same metabolic activities present before fertilization are accelerated, and that this is the real essence of activation. But the fact that in the starfish there is no measurable increase in oxidation after fertilization, although we have the same phenomenon of initiation of development (activation), sets such a conclusion in a rather doubtful light. It is probable that in the case of the starfish there is an increase in the rate of oxidation during maturation, thus before and independent of fertilization. The connection between fertilization and increase of oxidation may thus be incidental. If we realize that the egg is a highly complex system, and that the rate of oxidation as measured is a gross result without any distinction of kind or location, the obvious alternative stands out that we may be measuring quite different metabolic activities before and after fertilization. If this were the case, it is obvious that the net result in terms of oxygen consumption might not change or might show either a gain or a loss, depending on the nature of the system. There may be a retardation of some processes and an acceleration of others, giving a different net result in the sea urchin and starfish, for instance. The mere determination of gain in oxygen consumption, even if it were a universal fact, is not adapted to carry us very far in the problem of fertilization without a more minute analysis. 
2. Changes in permeability.-The increase in oxygen consumption of fertilized eggs of the sea urchin indicates a readier access of oxygen to the material of the egg, and not a change in the oxidizable character of the material, because the comminuted material of the unfertilized egg also consumes more oxygen than the intact egg. The egg membrane must therefore be more permeable to oxygen after fertilization than before in those cases in which increase of oxidation after fertilization occurs. There are several other evidences of an increase in permeability of the egg membrane as a result of fertilization.

Among these is the escape of substances from the egg which previously escaped more slowly or not at all. Carbon dioxide is an example of the first kind; there is a sudden increase of $\mathrm{CO}_{2}$ production at the time of fertilization in the sea urchin corresponding to increased oxygen consumption (Lyon). As an example of the second kind the escape of pigment from the eggs of Arbacia at the time of fertilization may be noted; Lyon and Shackell (roro) have described this phenomenon, which has also been observed by other investigators. The extrusion of jelly from the egg of Nereis previously described (p. 53) is another striking instance; the egg of Ascaris megalocephala similarly excretes a considerable amount of material at fertilization which forms the thick resistant egg membrane of this form. According to Reighard (I893) the egg of the wall-eyed pike similarly excretes a substance from its cortical layer at the time of fertilization, and the same is probably true of teleosts in general.

Diminution in the size of the egg following fertilization due to loss of materials has also been carefully 
measured by Glaser (I9I4); individual eggs of Arbacia were measured before and after fertilization, and in nearly all cases a measurable decrease in diameter was recorded, in some cases as much as ro per cent. In the starfish the decrease was found to be still greater. The contrary results of McClendon (I9Io) on Arbacia may be interpreted as due to the great individual variations in size of the eggs, which were measured in a statistical and not in an individual way.

Loeb (1908) believes that to explain the tension of the fertilization membrane (in Strongylocentrotus) it is necessary to assume some slight loss of colloids from the egg at fertilization, but he was unable to detect any measurable difference in the diameter of fertilized and unfertilized eggs. Okkelberg (1914) has determined by careful measurements of individual eggs that fertilization produces an average decrease of $\mathrm{r} 3.48$ per cent in the volume of the eggs of the brook lamprey. He thinks that the substances lost include some colloid material.

The increase in permeability resulting from fertilization has also been tested in other ways. McClendon (r9ro) demonstrated an increase of electrical conductivity as a result of fertilization or action of parthenogenetic agents in the egg of Toxopneustes; he determined the resistance (reciprocal of conductivity) of unfertilized eggs to be $595 \mathrm{ohms}$ and that of the same eggs after fertilization to be $455 \mathrm{ohms}$; from this he argues that the egg becomes more permeable to ions, on which the conductivity depends, at the beginning of development. Gray (г13) made similar determinations. Lyon and Shackell (rgro) have also shown that eggs 
become more permeable to certain intra-vitam dyes immediately after fertilization. Harvey (I9ro) confirmed this and showed also a temporary increase in the permeability toward alkalies. Lyon (I909) shows that about double the amount of oxygen is liberated from $\mathrm{H}_{2} \mathrm{O}_{2}$ by fertilized eggs of sea urchins as compared with equal amounts of unfertilized eggs, beginning about three minutes after insemination. This may be explained by increased permeability by which peroxide and catalase come more easily together.

R. S. Lillie (г16-18) has shown that after fertilization Arbacia eggs take up water by osmosis several times more rapidly than before fertilization; if a mixture of fertilized and unfertilized eggs be placed in hypotonic sea-water (forty parts sea-water plus sixty of tap water) it is possible within two or three minutes to distinguish the fertilized eggs by their greater diameter. The volume of water entering the fertilized egg in three minutes was found to be II $\times 10^{5} \mu^{3}$ and the unfertilized egg, $3.6 \times 10^{5} \mu^{3}$. Osmotic equilibrium is reached within about eight minutes in the case of the fertilized egg; in the case of the unfertilized egg the entrance of water is more gradual, and many of the eggs break down before osmotic equilibrium is reached. Figure I8 furnishes a comparison of the rate of entrance of water.

The rate of entrance of water is essentially constant during the period of exposure in the case of both fertilized and unfertilized eggs relative to the existing gradient of osmotic pressure, which demonstrates that the differences between the two sorts is due to a difference in the resistance of the membrane to the passage of water. The amount of water which enters or leaves 
the cell is finally the same in both fertilized and unfertilized eggs, thus again demonstrating a membrane effect. Eggs which have been treated with parthenogenetic agents show an increase of permeability comparable to that of fertilized eggs, but of a more fluctuating character.

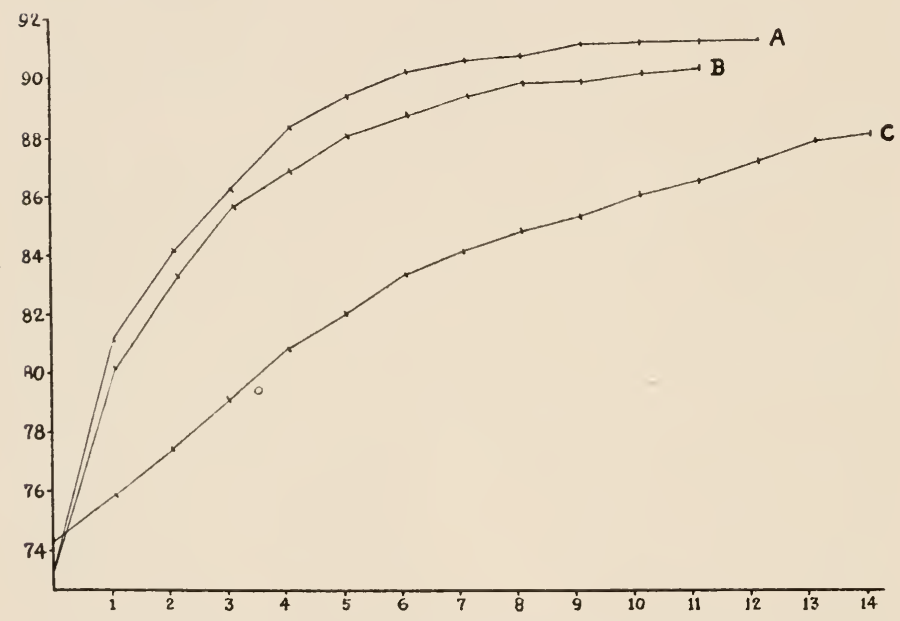

FIG. I8.-Imbibition of water by Arbacia eggs in diluted sea-water (6o volumes tap water plus 40 volumes sea-water). The curves are measurements of diameters at different intervals after placing in diluted sea-water. Ordinates are diameters in micra, abscissae minutes after placing in the hypotonic medium. $A$, fertilized eggs; $B$, eggs with artificial membranes; $C$, unfertilized eggs (after R. S. Lillie).

In the reverse experiment, of subjecting fertilized and unfertilized eggs to the action of hypertonic seawater, R. S. Lillie (I9I8) has shown that fertilized eggs lose water much more rapidly, as is to be expected; and the two kinds of eggs can thus be separated by gravity in tall tubes of hypertonic sea-water. 
The condition of greater permeability, to water does not arise all at once, but gradually during the first fifteen minutes after insemination; this is a matter of great significance in considering the relation of change of permeability to the fertilization reactions.

The behavior of the fertilized and unfertilized eggs of Echinarachnius to hypotonic and hypertonic seawater is similar to that of Arbacia; but the starfish (Asterias) shows an interesting contrast to both, as there is little difference between fertilized and unfertilized eggs with reference to exosmosis and endosmosis (R. S. Lillie, I9ı8). A comparable contrast with reference to oxygen consumption in the sea urchin and starfish eggs respectively has already been noted (p. I45).

R. S. Lillie (г17) distinguishes two possibilities with reference to the relation which changes of permeability may bear to the activation process.

The first possibility is that, after fertilization and as one of the secondary consequences of this process, the general conditions of permeability in the egg are permanently modified, and that the protoplasmic surface-layer or plasma-membrane from that time on remains more permeable and more subject to changes of permeability than before; there is, in fact, considerable evidence that this is the case. The second possibility, which is the one suggested by the resemblances between the conditions of activation of the resting egg and those of stimulation in general, is that the primary event in the activation process, as well as in the stimulation process, is a temporary increase of permeability; upon this initial change follow the other changes expressive of the general response or activation of the egg-cell. A temporary or initiatory increase of permeability is thus to be distinguished from a permanent alteration in the general properties of the plasma-membrane involving increased permeability. There is good reason to believe that both of these processes are concerned in the activation of the resting egg. 
Summarizing this section we have the following evidences of increase of permeability of the plasma membrane at the time of fertilization: increase of oxygen consumption, escape of substances from the egg at the time of fertilization (increased $\mathrm{CO}_{2}$, pigment, jelly in Nereis, etc.), decrease in volume of the egg, increase of electrical conductivity, increased permeability to certain intra-vitam stains, greater catalytic power of fertilized eggs, increased permeability to alkalies, increase in rate of osmotic change with reference to water.

There can be no doubt that the permeability of the egg increases at the time of fertilization in some cases at least. On the other hand it is certain that this change is less in some eggs than in others. No doubt the great differences in vitality of unfertilized eggs of different species are dependent, in part at least, on such variations. Later on we shall discuss the rôle of permeability changes in the complex of fertilization processes.

3. Changes in physical state.-Many observers have noted that changes in the physical state of the protoplasm of the egg accompany fertilization. Thus the eggs of Ascaris megalocephala, which have an irregular outline prior to fertilization, become definitely spherical soon after the entrance of the spermatozoön as the fertilization membrane forms; on the other hand the eggs of Nereis, which have a very regular contour before fertilization, become decidedly irregular in outline fifteen to twenty minutes after insemination, and gradually resume the spherical state before the first polar body is formed. A decided difference in the behavior of the 
cytoplasm to mechanical shocks (e.g., shaking) has been similarly noted in the sea urchin egg by several investigators.

Such changes have recently been more carefully investigated by Heilbrunn (I9I5) and by Chambers (I9I7). Heilbrunn tested the viscosity of the protoplasm of the egg of the sea urchin by the use of the centrifuge, and found that the separation of protoplasmic granules of different specific gravity by centrifugal force is much more readily effected before than after fertilization. The protoplasm is much more fluid before than after fertilization, and this can mean only a tendency toward gelation in a colloidal system such as protoplasm; this change was observed to begin two and one-half minutes after insemination. Heilbrunn also determined that a variety of parthenogenetic agents, and he believes all such agents, produce a similar gelation effect, and he was therefore led to regard the coagulation change as the primary event in activation of the egg.

Chambers investigated this subject by means of the micro-dissection method as part of a study of the cell aster which he interprets as a reversible gelation phenomenon. When the sperm aster appears in the egg of Echinarachnius about three minutes after penetration of the spermatozoön, it can be shown to be a more rigid area by the fact that it can be pushed and rolled in the surrounding more liquid cytoplasm by the microdissecting needle. As the aster increases in size the gelation effect extends. Chambers thus localizes the gelation due to fertilization in the sperm aster, though Heilbrunn's results appear to indicate a more general effect; there is, however, nothing in Chamber's result 
inconsistent with the idea of a general gelation effect, which is decidedly more pronounced in the region of the aster. Karyokinesis is, according to Chambers, essentially a reversible gelation effect. The gel area represented by the sperm aster is a preparation for the first cleavage of the egg.

4. Chemical changes. - The initiation of development which is associated with fertilization involves a progressive chain of chemical changes, but it is obvious that these lead us outside of the field of fertilization proper, beyond the stage of indicia of fertilization. There is, however, one very striking change occurring at the very beginning of the fertilization reactions that deserves notice here. I allude to the complete loss of sperm-agglutinating substance by the egg. This was first observed by the writer in the case of Nereis, and was subsequently more carefully studied in Arbacia (I9I4-I 5). As long as eggs of Arbacia retain capacity for fertilization they produce this substance, which is readily recognizable by its agglutinating action on sperm suspensions of the same species. But if the adherent jelly which also contains this substance is removed from fertilized eggs and the substance present before fertilization is washed off, not a trace of the agglutinating substance can be derived from the fertilized eggs. There is a complete loss of sperm-agglutinating substance and with it a loss of capacity for further fertilization reaction at the moment of fertilization. This determination has been confirmed by Glaser (I9I4), by Just (I9I9), and by Moore (I9I6). The writer was convinced by this and other data, discussed later, that the agglutinating substance is necessary for fertilization. 
Its loss therefore constitutes a very striking chemical change directly due to fertilization. A similar loss follows the effective action of parthenogenetic agents which render the eggs insusceptible to fertilization (Lillie, I9I4; Moore, 1916).

\section{PARTIAL FERTILIZATION}

As fertilization is a series of processes it should be possible to arrest the series at various stages and thus to discover the value of the various steps for development. The experiments which have been directed toward this end are not very numerous, as considerable difficulties exist in arresting the progress of fertilization without destroying the entire zygote.

The writer (I9II-I2) found ideal material for solution of part of this problem in the egg of Nereis. As we have previously seen, the spermatozoön produces the cortical changes before its penetration into this egg, which does not occur until about forty-five minutes after initiation of the cortical changes. During this time it is imbedded in the jelly secreted by the egg. If the egg be centrifuged at the proper time, the jelly, which is of much less specific gravity than the egg, separates from it completely, and in so doing frequently removes the spermatozoön. That the centrifuging process itself is not deadly is proved by the fact that those eggs from which the spermatozoön is not removed always segment and may develop approximately normally.

The eggs from which the spermatozoön is removed complete the maturation process which is initiated by the spermatozoön, but they never segment. The egg 
nucleus (female pronucleus) arises and attains the same size as in normally fertilized eggs. The chromosomes of the first cleavage spindle then form in the usual fashion and at the usual time, accompanied by disappearance of the nuclear membrane. But, whereas in the presence of a sperm nucleus cytoplasmic asters accompany these changes and a spindle rapidly arises, in the absence of the sperm nucleus there is absolutely no sign of cytasters or evidence of spindle formation. The chromosomes lie naked in the cytoplasm, surrounded by a clear area. Each chromosome then splits longitudinally in the usual fashion, but the halves do not separate. At the time of the telophase of the normal first cleavage there is a tendency to scattering and breaking up of the chromosomes. When the normal eggs have reached the two- and four-celled stages, the scattering and breaking up of the chromosomes have progressed much farther in the unsegmented eggs, and in the course of two or three hours there remains no differentiated nucleus or chromosomes, but only numerous chromatic granules scattered throughout the cytoplasm.

This experiment then shows that the fertilization processes may be divided physiologically as well as morphologically into the two main phases of the external and internal phenomena. The external action is adequate to produce the cortical changes alone, but not the entire series of developmental events. In most eggs the penetration of the spermatozoön is so rapid that it accompanies or precedes the cortical changes, and it is therefore difficult to ascertain whether the cortical changes are dependent on penetration or not. Loeb 
(1913) has, however, been able to show, by means of hybridization experiments, that the cortical changes in the sea urchin are not dependent on penetration. He found that the sperm of Asterias would cause the formation of fertilization membranes in the eggs of Strongylocentrotus purpuratus in hyperalkaline sea-water, but only a fraction of them segmented. Cytological observation showed that the spermatozoön penetrated only a similar fraction, presumably the ones that segmented. In others there was external action of the spermatozoön alone. The eggs which had not been entered by the spermatozoön could be caused to develop by treatment with hypertonic sea-water. It is therefore probable that it is a general rule of fertilization that the spermatozoön sets the cortical changes of the egg in operation before penetration.

Similarly the activation of the egg by means of parthenogenetic agents has been shown in certain cases to be clearly divisible into two phases. This is shown most clearly by Loeb's famous method of inducing development in sea urchin eggs, which consisted of a brief treatment with butyric acid or some other cytolytic agency, producing the cortical changes alone, which required to be supplemented by after-treatment with hypertonic sea-water or certain other agencies to induce complete development. Loeb explained this result by supposing that the cortical changes in themselves have something of excess in them, leaving the egg in a sickly condition, and that this effect was counteracted by the second treatment. Whether this is a correct explanation or not we need not now inquire (see chap. vii), but we should note that the transition from the first to the 
second phase is much more gradual in most forms than it is in the sea urchins and usually gives the impression of being a continuous process.

We have seen previously that the spermatozoön bears a substance essential for fertilization, which is readily lost. We may therefore suppose that it is this substance which activates the cortical changes of the egg.

The questions may now be raised: (I) How soon after entrance of the spermatozoön into the egg is the activation process completed? (2) Is there a quantitative relation in the internal phenomena of activation? Wilson (1903) observed that if the fertilized eggs of Cerebratulus be cut in two shortly after the penetration of the spermatozoön in such a way that one part contains the sperm nucleus and the other the egg nucleus, only the former develops, while the part containing the egg nucleus completes its maturation but goes no farther; it was therefore incompletely fertilized at this time. Ziegler (1898) observed that if the egg of the sea urchin be so constricted after fertilization that one part contains the sperm nucleus and the other the egg nucleus, the part that contains the sperm nucleus undergoes cleavage and develops farther; in the other part the egg nucleus undergoes remarkable transformations, dissolving and reappearing, a process which is repeated several times, but this part does not undergo cleavage. In spite, therefore, of the presence of the sperm nucleus in a constricted portion of the same egg, the part containing the egg nucleus was not completely fertilized. Yet we know from experiments on artificial parthenogenesis that the egg nucleus is capable of complete activation without participation of the sperm nucleus. 
Boveri (1895) has also observed that, if freshly fertilized sea urchin eggs be broken into fragments by shaking, those fragments which contain the egg nucleus alone do not usually segment, though the nucleus enlarges, dissolves, and reappears, but some such pieces may segment once or twice and then stop (I902).

It is evident, therefore, that the sperm sets in operation a progressive series of processes within the egg and that complete activation is not attained by any means at once after entrance of the spermatozoön, and probably not until about the time of union of egg and sperm nuclei.

The question arises whether this is a purely quantitative relation or whether the spermatozoön is involved in a series of qualitatively different processes each of which requires its aid or other extraneous support. There is at present no evidence for the latter conception. On the quantitative side we would have the two questions, whether the sperm activates by means of a substance which it slowly releases, or whether it activates a substance, or ferment-like bodies, contained within the egg. As Loeb has pointed out, if the first assumption is correct we would expect that two spermatozoa would cause a more rapid progress of events within the egg than a single spermatozoön; but this is not the case; dispermic eggs segment in the same tempo as monospermic eggs.

The writer (I9I2) has observed that portions of sperm nuclei obtained by centrifuging Nereis eggs during fertilization before penetration of the spermatozoön produce an effect in terms of the sperm aster roughly proportional to their size; this can be understood in 
either of the foregoing senses; but there is apparently no slackening in rate of the processes, which merely occur on a smaller scale or with less energy. Theoretically such experiments should enable one to determine how much of the spermatozoön is essential for complete activation, but the practical difficulties have so far prevented such a determination.

The quantitative side of fertilization furnishes a very interesting problem. It would seem that incomplete activation of the egg is not compensated in later stages but sooner or later results in a complete arrest of the vital machinery.

It is possible that we should also include in the conception of partial fertilization cases of fertilization with stale or injured gametes; if either the egg or spermatozoön be involved development takes a slower tempo and ceases sooner or later with development of various abnormalities. Such conditions may obviously grade all the way up to the normal (see Stockard, Dungay, Hertwig). Such results should not, however, be understood in a purely quantitative sense, but also in the sense of a growing disharmony dependent on variation in the degree of the effect upon different portions of the egg.

In the case of the artificial induction of parthenogenesis the quantitative aspect of activation has been very accurately measured by $R$. S. Lillie (1915) in the case of the starfish egg. Under the influence of higher temperatures (about $29-36^{\circ} \mathrm{C}$.) or butyric acid (about $\mathrm{N} / 260$ concentration) the activation process is started in the egg. If the process is allowed to proceed to a certain optimum stage and the eggs are then returned 
to sea-water of normal temperature and composition, the eggs develop normally to the formation of larvae. If, however, the process is interrupted too soon, the egg is able only to begin the first processes; but within a suitable period of time renewal of the action to the optimum extent will bring about complete activation. The activation process can thus be arbitrarily interrupted and resumed, and this with either high temperature or butyric acid alone, or with combination of the two in either order. The optimum time of exposure to high temperature shows a very high temperature coefficient $\left(\mathrm{Q}_{\mathrm{I0}}=200-400\right)$, but the quantitative details do not concern us here (see chap. vii).

\section{POLYSPERMY AND MEROGONY-THE PROBLEM OF} REVERSIBILITY

The fertilized egg does not react to fresh spermatozoa, and these do not enter it. The change which produces this condition takes place so rapidly that only one spermatozoön normally enters, though hundreds may be present in the immediate neighborhood of the egg, and many may reach it apparently simultaneously. The fact of monospermy has been known since the time of the classic researches of Hertwig and of Fol. As is well known, Fol proposed the theory that the fertilization membrane prevented entrance of supernumerary spermatozoa and constituted the mechanism for prevention of polyspermy. Its formation is, however, much too slow to account for the facts; and it has been repeatedly shown that removal of the fertilization membrane does not render the egg more susceptible to superimposed insemination. 
The mechanism for the prevention of polyspermy must operate at an exceedingly high rate of speed; this is readily appreciated when we consider that it is effective in selecting only one out of the many spermatozoa that appear to the eye to reach the ovum simultaneously. It must therefore be effective before the fertilization membrane forms, so that it becomes somewhat superfluous to inquire whether this membrane furnishes an unnecessary further protection. This subject is discussed further in chapter vii.

An excellent method for experimental investigation of this problem was discovered by $\mathrm{O}$. and R. Hertwig (I887), who found that when sea urchin eggs are broken into fragments the non-nucleated fragments may be fertilized no less than the nucleated fragments, a phenomenon that subsequently became known as merogony. Boveri (1889), Morgan (1895), and Seeliger (1894-96) utilized this method for study of the problem of nuclear transmission of hereditary qualities; Driesch and others for problems of physiology of development; and the method was subsequently used for testing the changes in the cytoplasm of the egg with reference to fertilizability.

The classic experiments along the latter lines are those of Delage (1898, I899, I90 I) and of E. B. Wilson (1903). Delage's observations included sea urchins, starfish, an annelid (Lanice), and a mollusk (Dentalium). Fragments taken from eggs with intact germinal vesicle are unfertilizable; but fragments taken from eggs in which the germinal vesicle has begun to break down may fertilize, and after complete dissolution of the germinal vesicle fragments are completely fertilizable. 
In the starfish this condition lasts until after the formation of the first polar globule, but when the second polar body begins to appear the fragments are less fertilizable, even if they do not become completely resistant to merogonic fertilization. Wilson made observations similar in many respects in the case of Cerebratulus, and demonstrated in addition that fragments of fertilized eggs are completely unfertilizable. Such fragments have a fresh-cut surface and entirely lack any mechanical protection.

It will be observed that the fertilizable character of the egg bears no relation to morphological membranes in these cases, for in all we are dealing with freshly cut picces with an exposed surface. The egg passes from a non-fertilizable to a fertilizable condition, and after fertilization to a non-fertilizable condition again. A fragment of a fertilized egg, devoid of the sperm nucleus, does not return to a fertilizable condition. There is no indication that the processes so far are reversible.

We may express these results by saying that the egg has acquired a physiological protection, as contrasted with the earlier assumed mechanical protection, against polyspermy.

Superposition of fertilization on parthenogenesis.-Inasmuch as fertilization and activation of the egg by parthenogenetic agents produce similar morphological and physiological results on the whole, it would seem that both methods should produce eggs equally resistant to superimposed fertilization. If this were not the case it would seem that artificial activation is not the full equivalent of fertilization with reference to initiation of development in spite of the similarity of results 
attained, or that the process of artificial activation, unlike normal fertilization, is reversible. The first alternative runs counter to all the physiological determinations, and the second is of so fundamental a character that it requires most careful analysis.

Loeb (I9I3) found that eggs of Strongylocentrotus purpuratus, in which membrane formation had been induced by butyric acid, could be fertilized by sperm if the membrane were torn by shaking; they differed therefore in this respect from eggs in which membrane formation had been induced by fertilization; but it is noteworthy that such eggs differ from normally fertilized eggs in requiring a second treatment after membrane formation to induce development, so that the activation by butyric acid is incomplete: Loeb (I9I3) also determined that eggs of the same form when treated with hypertonic sea-water alone might begin development, but some of them come to a standstill in the 2-, 4-, 8-, or I6-celled stage, and that such eggs were fertilizable in the sense that insemination may cause the formation of a separate membrane around each blastomere; they then resume development in a perfectly normal way, according to Loeb, and become normal larvae. Here again fertilization is superimposed upon incomplete parthenogenesis. Loeb concluded merely in connection with these experiments that the block to polyspermy is not due to the changes necessarily connected with development.

In later papers (1913b and 1915) he found that alkalies induce development of eggs of Arbacia in a manner somewhat similar to that of butyric acid; but if the eggs after treatment for the proper length of time 
are put into a solution which prevents their development (sea-water with chloral hydrate or $\mathrm{NaCN}$ ) when taken out they behave as though nothing had happened to them. He considers this a demonstration that artificial activation can be reversed. Now it is notable that in such treatment no visible change occurs in the alkali, but only after transfer to sea-water. It would seem then to be a reasonable interpretation that such changes are prevented by the chloral or $\mathrm{NaCN}$. What is reversed therefore in this case is at most a condition which permits of cortical changes in sea-water. If the eggs are placed from the alkali in sea-water, even if only for a few minutes, before the chloral or $\mathrm{NaCN}$ sea-water, they will not "reverse."

It is apparent that such results can be as readily understood in the quantitative sense of partial or arrested activation as in terms of reversal. The fertilization reaction has definite quantitative relations, as we have seen in discussing partial fertilization; the same is true of any part of the series of reactions, and it certainly holds for the cortical reactions in activation. If, therefore, the cortical reactions are incomplete in any experiment the possibility of superimposing fertilization on such incomplete reactions might remain.

C. R. Moore (I9I6) has shown in experiments conducted under the writer's observation that such a quantitative relation actually obtains. To understand the experiments and results it is essential to examine the character of artificial activation by means of butyric acid, which was the agent used in both Loeb's and Moore's experiments. The strength of the acid and time of exposure are variable factors. Fifty c.c. sea-water +2.8 c.c. $N /$ ıо 
butyric acid is a very favorable strength for artificial activation; it was therefore used constantly in these experiments. Now it must be emphasized that there is no visible change in the eggs while in the butyric acid; but when the eggs are transferred to sea-water, if the time of exposure has been right, the eggs form membranes as they do after insemination, and subsequent treatment with hypertonic sea-water will cause them to develop normally. By varying the time of exposure to the butyric acid we get varying degrees of activation as expressed in membrane formation by the eggs and in their capacity for development; this proceeds up to an optimum. If the exposure to butyric acid be prolonged beyond the optimum the capacity for development gradually falls off to zero.

It is clear that butyric acid produces a condition of pre-activation in which the egg activates when returned to its normal environment; but if the treatment be too short the pre-activation is insufficient; if it be too long some other condition arises that inhibits normal activation.

If, then, insemination is practiced on these eggs after their return to sea-water, it is found to be successful in inverse proportion to the degree of activation induced in the sea-water up to the optimum point, at which superimposed insemination has no effect. Beyond this the curve of superimposed fertilization shows a second rise and fall to zero. At the optimum point for artificial activation, at which all eggs form membranes and are capable of development after treatment by hypertonic sea-water, the sperm has absolutely no fertilizing effect on the eggs, whatever its concentra- 
tion, even if the membranes formed by the butyric acid be entirely destroyed. Such eggs are therefore comparable to normally fertilized eggs in respect to their unfertilizable condition. Moore has shown that, if they be very heavily inseminated, spermatozoa may enter them, but there is absolutely no reaction between sperm and egg.

Thus in the case of Arbacia, on which these experiments were performed, there is no possibility of superimposing fertilization upon parthenogenesis after optimum exposure to the activating agent. But if the exposure to the activating agent be too short, or too long, some degree of capacity for fertilization exists, which is expressed in Figs. I9 $a, b$. But development due to insemination after too long exposure to butyric acid is never normal. It is obvious that we are dealing here with a quantitative relation that would be as true for each egg as for the entire culture. The individual variability of the eggs is what gives the percentage results.

If we were to assume the presence of a single activable substance within the egg for which the spermatozoa have a certain affinity the results concerning superposition of fertilization on parthenogenesis could be expressed as follows: Shorter exposure to the artificial activating agents leaves varying amounts of the activable substance unengaged for sperm action; the optimum exposure leaves none free; too long action leaves some unengaged, owing to secondary conditions produced in the pre-activation period, which hamper the development after insemination. Moore has shown that there is a close approximation in the content of the sperm-agglutinating substance of the eggs to this 
hypothesis and has therefore confirmed the writer's opinion that this is the activable substance of the egg.

The same author. (Moore, I9I7) has also examined Loeb's statement concerning the fertilizability of eggs treated by hypertonic sea-water with results concordant
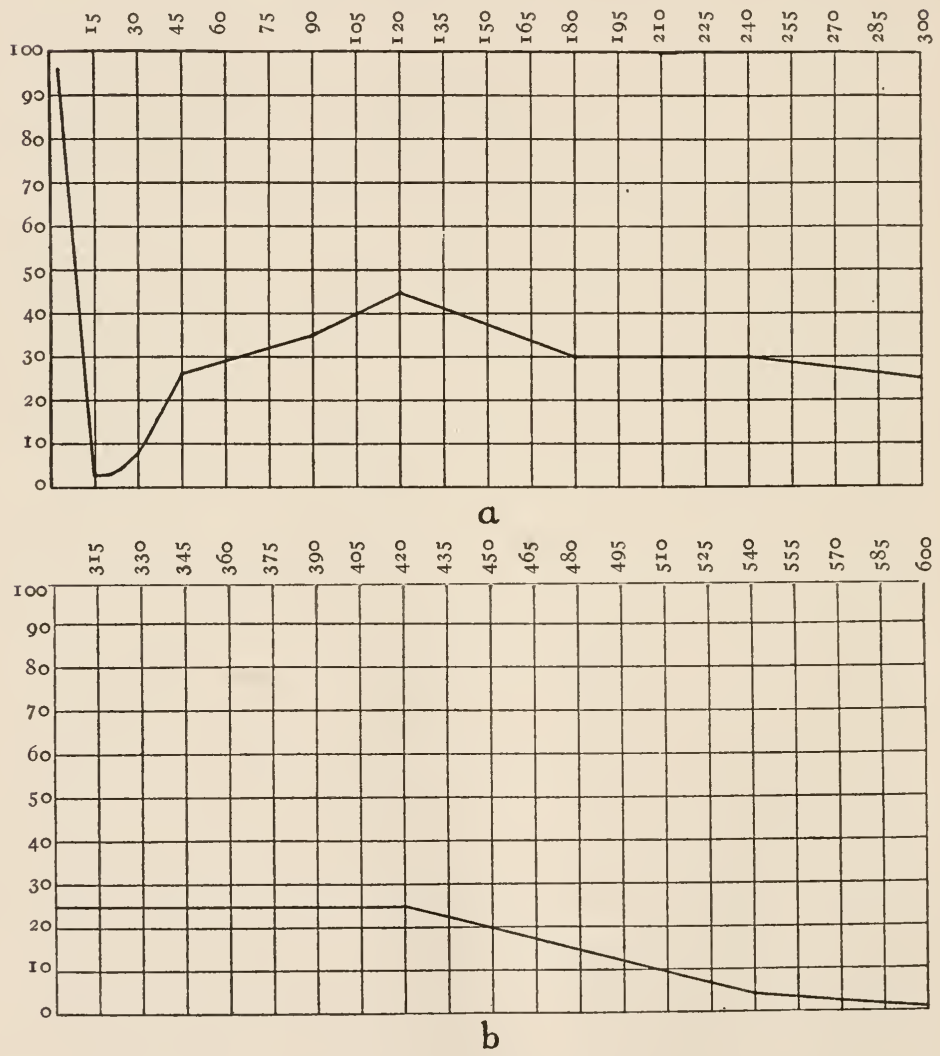

Fig. 19.-Curve of fertilization superimposed upon butyric acid treatment in Arbacia. Curve $b$ continues curve $a$. The ordinates represent percentages of fertilization as measured by cleavage and the abscissae length of previous exposure to butyric acid in seconds (after C. R. Moore). 
with the above: "The superposition of insemination on the optimum hypertonic treatment does not increase the percentage of development." This is in no sense inconsistent with Loeb's statement that the block to polyspermy is not due to changes necessarily connected with development, whatever this may mean; but it is a result that renders in the highest degree improbable that reversal of activation of the egg occurs. Activation is a part of the fertilization reactions, and there remains no evidence that it is reversible, whether induced by fertilization or by artificial means.

Godlewski (I9I2) has shown that the sperm of Chaetopterus will enter the eggs of sea urchins and cause normal membrane formation; but such eggs do not segment, and soon die. If, however, they are exposed after the hybrid fertilization to the action of hypertonic sea-water for a short period of time, they may segment regularly and develop to larvae. He speaks of this as superposition of parthenogenesis on hybrid fertilization. This determination in no way runs counter to our interpretation, however it may be named. It is quite clear that the hypertonic sea-water has no activating effect in this experiment, but on the contrary inhibits an in: jurious effect of the foreign sperm.

Herbst's experiments (I909 and 1912), in which he superimposed hybrid fertilization on partial parthenogenetic activation and secured a shifting of inheritance in the maternal direction, deal primarily with problems of hybridization. As far as the problem of superposition is concerned the experiments are perfectly consistent with Moore's interpretation, because the parthenogenetic activation was incomplete. 
VI. EXTERNAL CONDITIONS OF FERTILIZATION

The fertilization reactions that we have been considering are dependent, not only on the internal conditions of the gametes, but also on the nature of the medium in which insemination occurs. Fertilization always occurs in an aqueous medium containing a balanced solution of salts, of which $\mathrm{NaCl}, \mathrm{MgCl}_{2}, \mathrm{KCl}$, and $\mathrm{CaCl}_{2}$ are the chief. In such a medium fertilization depends, within the usual range of temperature, on reaction of the medium (acidity or alkalinity) and the balance and concentration of the salts. Sea-water is a medium of this kind in which the variable factors can be readily controlled. Most studies have therefore been made on marine animals; but there is abundant evidence that the same principles apply to other animals.

The effect of reaction of the medium may be shown by some hitherto unpublished experiments on starfish eggs made in I9I4. In the summer these eggs (at Woods Hole) frequently do not fertilize very readily in normal sea-water, but they may be made to do so by a slight increase in the alkalinity; on the other hand an increase of acidity tends to inhibit fertilization; the following experiment demonstrates the principle. A series of eleven watch glasses is laid out in the order I to II, of which the center one (No.6) contains normal sea-water, those to the left increasing concentrations of $\mathrm{HCl}$, and those to the right increasing concentrations of $\mathrm{NaOH}$ in sea-water as follows: No. I, $N / 500$ $\mathrm{HCl}$; No. 2, $\mathrm{N} / \mathrm{I}, 000 \mathrm{HCl}$; No. 3, N/2,000 HCl; No. 4, $\mathrm{N} / 4,000 \mathrm{HCl}$; No. $5, \mathrm{~N} /$ ı,, $000 \mathrm{HCl}$; No. 6, normal seawater; No. $7, \mathrm{~N} /$ I, $000 \mathrm{NaOH}$; No. 8, N/4,000 NaOH; No. 9, $N / 2,000 \mathrm{NaOH}$; No. Iо, $N /$ I,, $00 \mathrm{NaOH}$; No. I , 
$\mathrm{N} / 500 \mathrm{NaOH}$. The same quantity of a single lot of eggs was then added to each crystal and was fertilized with the same quantity of a single lot of sperm. The percentage of eggs that segmented in each dish were as follows: Glass No.

$\begin{array}{lllllllllll}\text { I } & 2 & 3 & 4 & 5 & 6 & 7 & 8 & 9 & \text { IO } & \text { II }\end{array}$

Percentage

$\begin{array}{lllllllllll}\circ & 2.5 & 8 & 22.5 & 45 & 53 & 84 & 92.5 & 88.5 & 89 & \circ\end{array}$

In the highest concentration of acid the unsegmented eggs were devoid of fertilization membranes, thus unfertilized, but in the highest concentrations of the alkali the unsegmented eggs had membranes and were thus fertilized, but cleavage was inhibited by the $\mathrm{OH}$ ions.

It will be observed that the curve derived from the percentages of eggs fertilized ascends regularly from the acid to the alkaline end of the series. Very striking demonstrations of the favoring effects of $\mathrm{NaOH}$ on fertilization may be obtained from eggs that give only a very low percentage of fertilization in normal seawater, but may give a very high percentage in alkalized sea-water.

The presence of alkali favors the reaction between the egg and spermatozoön, probably because it tends to make the plasma membrane permeable and thus to permit a closer relation between the activable substance of the egg and the activating substance of the spermatozoön; this favors entrance of the spermatozoön into the egg. The use of a hyperalkaline medium to facilitate fertilization was first made by Loeb in a successful attempt to produce heterogeneous hybridization, and has since been widely extended for the same purpose. It should be noted that the reaction is favored only in the actual presence of the alkali; previous treatment of 
eggs alone, of sperm alone, or of both, before insemination in normal sea-water does not increase the percentage of fertilization. We are therefore probably dealing with a rapidly reversible modification of the surface of one or both kinds of gametes.

With reference to the question of balance of salts, the only systematic experiments are those of Loeb (I9I4, I9I $5^{b}$ ), who found that, for the fertilization of eggs of the sea urchin, the presence of $\mathrm{Ca}$ and $\mathrm{OH}$ ions is very important. Eggs and sperm washed in neutral $\mathrm{N} / 2 \mathrm{NaCl}$ will not fertilize in this salt alone, nor in combinations of two or more of $\mathrm{NaCl}, \mathrm{MgCl}_{2}$, and $\mathrm{KCl}$ in the proportions and concentrations in which these salts exist in sea-water, though the spermatozoa may be very active and fill the jelly of the eggs. But the addition of $\mathrm{CaCl}_{2}$ to $\mathrm{NaCl}$, or to $\mathrm{NaCl}$ and $\mathrm{MgCl}_{2}$, or to $\mathrm{NaCl}$ and $\mathrm{MgCl}_{2}$ and $\mathrm{KCl}$ in the sea-water proportions will induce normal fertilization; this will happen even more promptly and certainly if a little $\mathrm{NaOH}$ is added at the same time. Loeb states (I9I4) that calcium possesses an almost specific action for fertilization of the sea urchin egg, and it is important to note that it increases sperm agglutination also, according to the same author.

We shall not inquire here just how the $\mathrm{CaCl}_{2}$ or $\mathrm{NaOH}$ acts in such cases, but will hold the recorded facts for discussion in connection with other data.

\section{OTHER BLOCKS TO FERTILIZATION}

Any environmental defect that prevents fertilization may be considered as a block, and in that sense the present section is a continuation of the preceding. It 
is obvious that the examination of conditions that impede or prevent fertilization without injury to the life of the gametes must furnish means for analysis.

It is a fact well known to embryologists that contamination of the eggs of some marine invertebrates with blood or tissue exudates of the species reduces considerably the percentage of fertilization; it is therefore a common practice to wash the eggs once or several times in sea-water before insemination. That this effect is more or less specific was proved by the writer in a series of experiments, hitherto unpublished, which show that the filtered plasma of the coelomic fluid of sea urchins which inhibits fertilization in sea urchins actually increases the percentage of fertilization in the starfish.

The effect in the case of the sea urchin may be shown by the following table:

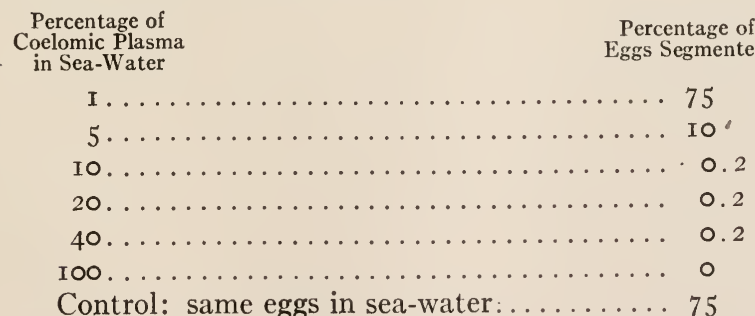

A series of dilutions of the filtered plasma was made as shown in the left-hand column; and identical fertilizations of eggs of Arbacia were made simultaneously in each. An excess of sperm was used in each case. It is clear that the plasma in this case had a strong inhibiting effect on the process of fertilization. The inhibition operates on the initial stages because membranes 
are not formed and the spermatozoa do not penetrate into the egg, although they are numerous and active. Other samples of plasma did not inhibit so strongly, and very wide individual variation with reference to this effect was found, which is possibly due to variation in the state of maturity of the gonads. The same principle holds also for the starfish; thus in a series of dilutions of the coelomic fluid of the starfish, Io per cent, 20 per cent, 40 per cent, 80 per cent, Ioo per cent, the percentages of segmentation following fertilization of the eggs of the same species were 62 per cent, 43 per cent, 50 per cent, 32 per cent, 26 per cent, I I per cent; in sea-water 98 per cent of the control eggs segmented.

If one takes Asterias eggs which are resistant to fertilization in sea-water, a condition often found, the addition of Arbacia coelomic fluid may prove very beneficial, as the following experiment shows: a series of six watch glasses was laid out containing 5 c.c. of the following: (I) sea-water (control), (2) 5 per cent filtered plasma of Arbacia in sea-water, (3) ro per cent of the same, (4) 20 per cent of the same, (5) 40 per cent of the same, (6) 80 per cent of the same. Equal quantities of active Asterias sperm were then added to each, and in three minutes equal quantities of Asterias eggs which had stood one hour in sea-water to allow them to reach the most favorable stage for fertilization. The percentages of eggs that segmented were (I) O, (2) 90 per cent, (3) 90 per cent, (4) 40 per cent, (5) 1o per cent, (6) o. In (4), (5), and (6) membranes formed though the eggs did not segment. This experiment was typical of many performed. The reciprocal experiment was not tried. 
The action of the heterologous plasma may be supposed to be due to a definite membrane effect enabling interaction between sperm and egg substances. Its interest in the present connection is to show that the inhibiting effect of the species plasma cannot be due merely to colloid content, which is common to both kinds of plasma, but that it has something specific in it.

Does the inhibitor act on the egg or on the sperm or by intervening in the reaction between the two? Experiments undertaken to answer this question showed that both eggs and sperm exposed to the plasma and washed free of it again were fertilizable. 'The plasma therefore merely interferes in some way with the reaction. The great variability of the effect of different samples of plasma ranging all the way from o to roo per cent also shows that we are not dealing merely with a general colloid effect.

It cannot be supposed that the plasma operates by preventing the adhesion of the spermatozoön to the egg if this is brought about by agglutination, because it was found that the agglutination of spermatozoa by means of egg secretions takes place as readily in the plasma as in sea-water.

There are two other possibilities: (I) the plasma might be supposed to harden the membrane or change its permeable character; or (2) it might be supposed to inhibit the action of the activable substance (fertilizin) of the egg by deviation effect. If the latter were true it should then be possible to prevent the inhibitory action of the plasma by first saturating it with the activable substance. This was found to be true. If a 
sample of plasma be divided in two parts, and one part be saturated with egg secretions by adding a large quantity of eggs, it is found that this portion has entirely lost its inhibiting properties. This matter will be discussed in more detail in a later section (see chap. vii).

A curious form of inhibition was discovered by Godlewski (I9I I) and described by him under the name "antagonism of sperm." The matter was subsequently investigated by Herlant (1912). Godlewski found that sperm of the annelid Chaetopterus would call forth membrane formation in the eggs of the sea urchin Sphaerechimus. If, however, the sperm of Chaetopterus was mixed in proportions ranging from equal parts to two to eight with the sperm of Sphaerechinus no egg of Sphaerechinus would fertilize in the mixture after it had stood a few minutes. The effect developed gradually. The spermatozoa were perfectly motile, but in some way they antagonized each other's action. He also found that the sperm of Dentalium (mollusk) inhibited fertilization of sea urchin eggs by sperm of their own species used in the same way. The blood also of Chaetopterus and Dentalium acts in the same way. The eggs, however, remain capable of fertilization after some time in the mixture by fresh species sperm.

This author therefore attributed the effect to a reciprocal action of the sperm on one another and not to an action of the mixture on the eggs. He compared the phenomenon to the neutralizing effect which different cytolytic sera sometimes exert on one another, and believed that it probably belonged in the same category; he therefore regarded the result as evidence 
in favor of Loeb's hypothesis that the fertilizing substance of the spermatozoön is a lysin.

Herlant subsequently studied the same phenomenon and pointed out that mere dilution of the sperm mixture in the presence of eggs with pure sea-water would result in some fertilizations, and that eggs that had remained even seventy-five minutes in the mixture could be fertilized with fresh species sperm if they were repeatedly washed. He therefore doubted that there was any profound alteration of either the male or the female sexual elements, and postulated somewhat doubtfully a physical alteration of the surface of the egg in the presence of the sperm mixture.

The two authors thus arrive at somewhat different conclusions; the true solution may involve some combination of these views. The present writer feels, for reasons discussed later, that the serum analogy of Godlewski is a true one in a very general sense, not that the sperm carries a lysin, a conception that has no longer any basis, but in the sense that reactions comparable to serum reactions probably are involved in fertilization. If we were to suppose that the foreign sperm prevents the agglutination of the species sperm to the egg we would perhaps have a workable hypothesis.

In the cases of blood inhibition and sperm antagonism we have two forms of fertilization blocks that suggest biochemical factors in which complex substances play a rôle, and which therefore appear to belong to a different category from deficiency of electrolytes or acidity effect. 


\section{REFERENCES}

BOVERI, $\mathrm{T}$.

I889. "Ein geschlechtlich erzeugter Organismus ohne mütterliche Eigenschaften," Sitzungsber. d. Gesell. fïr Morph. und Physiol. zu München, Band 5, pp. 73-83.

I895. "Ueber die Befruchtungs- und Entwicklungsfähigkeit kernloser Seeigeleier und über die Möglichkeit ihrer Bastardierung," Arch. fïr Entwickelungsmech., Band 2, pp. 394-443.

Bryce AND Teacher.

1908. Contributions to the Study of the Early Development and Imbedding of the Human Ovum. Glasgow.

Chambers, Robert, Jr.

I917. "Microdissection Studies. II. The Cell Aster: a Reversible Gelation Phenomenon," Jour. Exp. Zoöl., XXIII, 483-504.

Cohn, EDwin J.

I9I8. See references at end of chapter iv.

Delage, Y.

I898. "Embryons sans noyau maternal," Comptes rendus de l'Acad. des Sci., T. I 27, pp. 528-3 I.

I899a. "Études sur la mérogonie," Arch. de zool. exp. et gén., Sér. 3, T. 7, pp. 383-4 I 7 .

I $899 b$. "Sur l'interpretation de la fécondation mérogonique et sur une theorie nouvelle de la fécondation normale," ibid., pp. 51 2-27.

I90Ia. "Études expérimentales sur la maturation cytologique et sur la parthénogénèse artificielle chez les échinodermes," ibid., T. 9, pp. 285-326.

г9огb. "Les théories de la fécondation," Rev. gén. des sci. pures et appl., T. I 2, pp. 864-74.

Dungay, Neil S.

I913. "A Study of the Effects of Injury upon the Fertilizing Power of Sperm," Biol. Bull., XXV, 2г3-60.

Fuchs, H. M.

1914. "The Action of Egg-Secretions on the Fertilizing Power of Sperm," Arch. fïr Entwickelungsmech., Band 42, pp. 205-52. 
Fuchs, H. M.

I915. "Studies in the Physiology of Fertilization," Jour. of Genetics, IV, 259-30r.

Gemmill, James J.

I900. See references at end of chapter iv.

Gies, W. J.

I901. "Do Spermatozoa Contain an Enzyme Having the Power of Causing the Development of Mature Ova?" Am. Jour. of Physiol., VI, 53.

Glaser, Otto.

I9I4a. See references at end of chapter iv.

I9I4b. "The Change in Volume of Arbacia and Asterias Eggs at Fertilization," Biol. Bull., XXVI, 84-91.

Godlewski, EMIL.

I9I I. "Studien über die Entwicklungserregung: II, Antagonismus der Einwirkung des Spermas von verschiedenen Tierklassen," Arch. fïr Entwickelungsmech., Band 33, pp. 233-54.

I9I 2. "Studien über die Entwicklungserregung, ibid., pp. I96-254.

Gray, J.

I9I3. "The Electrical Conductivity of Fertilized and Unfertilized Eggs," Jour. Marine Biol. Assoc., pp. 50-59.

HARVEY, E. N.

I9ı. "The Permeability and Cytolysis of Eggs," Science, N.S., XXXII, 565-68.

HeIlbRUnN, L. V.

I915. "Studies in Artificial Parthenogenesis. II. Physical Changes in the Egg of Arbacia," Biol. Bull., XXIX, I 49-203.

Herbst, Curt.

I909. "Verebungstudien. VI," Arch. für Entwickelungsmech., Band 27, pp. 266-308. See also ibid. (I9I2), Band 34, pp. I-89.

Herlant, Maurice.

I9I 2. "Recherches sur l'antagonisme de deux spermes provenant d'espèces eloignées," Anat. Anz., Band 42 , pp. 563-75. 
Hertwig, O. AND R.

r887. See references at end of chapter $i$.

r9r r. Die Radiumkrankheit tierischer Keimzellen; ein Beitrag zur experimenteller Zeugungs- und Vererbungslehre. Bonn: Friedrich Cohen.

Just, E. E.

r915a. "An Experimental Analysis of Fertilization in Platynereis megalops," Biol. Bull., XXVIII, 93-r.I4.

rgr $5 b$. "Initiation of Development in Nereis, ibid., pp. r-r7.

r9r9. See references at end of chapter iv.

Lillie, Frank R.

r9r r. "Studies of Fertilization in Nereis. II. Partial Fertilization," Jour. of Morph., XXII.

r9r2. "Studies of Fertilization in Nereis. IV. The Fertilizing Power of Portions of the Spermatozoön," Jour. Exp. Zoöl., XII, 427-76.

r9r3. See references at end of chapter iv.

r9I4. See references at end of chapter iv.

I9 5 . See references at end of chapter iv.

LILLIE, R. S.

r9r5. "On the Conditions of Activation of Unfertilized Starfish Eggs under the Influence of High Temperatures and Fatty Acid Solution," Biol. Bull., XXVIII, 260-303.

r916. "Increase of Permeability to Water Following Normal and Artificial Activation in Sea-Urchin Eggs," Am. Jour. of Physiol., XL, 249-66.

r9r7. "The Conditions Determining the Rate of Entrance of Water into Fertilized and Unfertilized Arbacia Eggs, and the General Relation of Changes of Permeability to Activation," ibid., XLIII, 43-57.

r9r8. "The Increase of Permeability to Water in Fertilized Sea-Urchin Eggs and the Influence of Cyanide and Anaesthetics upon this Change," ibid., XLV, 406-30.

Loeb, JACQUes.

r908. "Ueber die osmotischen Eigenschaften und die Entstehung der Befruchtungsmembran beim Seeigelei," Arch. fiir Entwickelungsmech., Band 26, pp. 82-88. 
Loeb, Jacques.

I9I3a. Artificial Parthenogenesis and Fertilization. Chicago: The University of Chicago Press.

I9I3b. "Reversibility in Artificial Parthenogenesis," Science, N.S., XXXVIII, 749-50.

I9I4. "On Some Non-specific Factors for the Entrance of the Spermatozoön into the Egg," Science, N.S., XL, 3I6-I8.

I9I5a. "Reversible Activation and Incomplete Membrane Formation of the Unfertilized Eggs of the SeaUrchin," Biol. Bull., XXIX, го3-го.

I9I $5 b$. "On the Nature of the Conditions Which Determine or Prevent the Entrance of the Spermatozoön into the Egg," Am. Naturalist, XLIX, 257-85.

Loeb, J., and Wastenys, H.

I9I 2. "Die Oxydationsvorgänge im befruchteten und unbefruchteten Seesternei," Arch. für Entwickelungsmech., Band 35 , pp. 555-57.

19r3a. "The Relative Influence of Weak and Strong Bases upon the Rate of Oxydations in the Unfertilized Egg of the Sea-Urchin," Jour. of Biol. Chem., XIV, 355-6I.

I9I3 $b$. "The Influence of Bases upon the Rate of Oxidations in Fertilized Eggs," ibid., 459-64.

I9I3c. "The Influence of Hypertonic Solution upon the Rate of Oxydations in Fertilized and Unfertilized Eggs," ibid., 469-80.

1915. "Further Experiments on the Relative Effect of Weak and Strong Bases on the Rate of Oxydations in the Egg of the Sea-Urchin," ibid., XXI, I53-58.

Lyon, E. P.

1909. "The Catalaze of Echinoderm Eggs before and after Fertilization," Am. Jour. of Physiol., XXV, I99-2r3.

Lyon, E. P., and Shackell, L. F.

Igro. "On the Increased Permeability of Sea-Urchin Eggs Following Fertilization," Science, N.S., XXXII, $249-5$ I.

McClendon, J. J.

I910. "Electrolytic Experiments Showing Increase of Permeability of the Egg to Ions at the Beginning of Development," Science, N.S., XXXII, I 22-24, 3 I 7-I 8 
MALL, F. P.

I9I8. "On the Age of Human Embryos," Am. Jour. of Anat., XXIII, 397-422.

MoOre, Carl.

I9ı. "On the Superposition of Fertilization and Parthenogenesis," Biol. Bull., XXXI, I37-80.

1917. "On the Capacity for Fertilization after the Initiation of Development," ibid., XXXIII, 258-95.

Morgan, T. H.

I895. "The Fertilization of Non-nucleated Fragments of Sea-Urchin Eggs," Arch. für Entwickelungsmech., Band 2, pp. 268-80,

Okkelberg, Peter.

I914. "Volumetric Changes in the Egg of the Brook Lamprey, Entosphenus (Lampetra) Wilderi (Gage), after Fertilization," Biol. Bull., XXVI, 92-99.

Packard, Charles.

I9I4. "The Effect of Radium Radiation on the Fertilization of Nereis," Jour. Exp. Zoöl., XVI, 85-13I.

REIGHARD, J. E.

I 893. "The Ripe Eggs and the Spermatozoa of the Walleyed Pike and Their History until Segmentation Begins," Tenth Bienn. Rept. State Board of Fish Comm. of Mich. Lansing.

RoBertson, T. BraIlsFord.

19г2a. "On the Extraction of a Substance from the Sperm of a Sea Urchin (Strongylocentrotus purpuratus) Which Will Fertilize the Eggs of that Species," Jour. of Biol. Chem., XII, I-I I.

I912b. "Studies in the Fertilization of the Eggs of a SeaUrchin (Strongylocentrotus) by Blood-Sera, Sperm, Sperm-Extract, and Other Fertilizing Agents," Arch. fïr. Entwickelungsmech., Band 35, pp. 64-1 30 .

SchüCKING, A.

I903. See references at end of chapter iv. 
Seeliger, O.

I894. "Giebt es geschlechtlich erzeugte Organismen ohne mütterliche Eigenschaften?" Arch. für Entwickelungsmech., Band I, p. 203.

I 896. "Bemerkungen über Bastardlarven der Seeigel," ibid., Band 3, pp. 477-526.

Stockard, Charles R., and Craig, Dorothy.

I904. "An Experimental Study of the Influence of Alcohol on the Germ-Cells and the Developing Embryo of Mammals," Arch. fiir Entwickelungsmech., Band 34, pp. $569-84$.

Triepel, A.

I9I4, I9I5. "Alterbestimmung bei menschlichen Embryonen," Anat. Anz., Band 46, Band 48.

WARBURG, OTto.

I908. "Beobachtungen über die Oxydationsprocesse im Seeigelei," Zeitschr. für physiol. Chem., Band 57, pp. I-I6.

I909. "Ueber die Oxydationen im Ei: II, Mittheilung," ibid., Band 6o, pp. 443-52.

I910. "Ueber die Oxydationen in lebenden Zellen nach Versuchen am Seeigelei," ibid., Band 66, pp. 305-40.

I9r4a. "Ueber die Rolle des Eisens in der Atmung des Seeigeleies nebst Bemerkungen über einige durch Eisen beschleunigte Oxydationen," ibid, Band 92, pp. $23 \mathrm{I}-56$.

I9I4b. "Zellstruktur und Oxydationsgeschwindigkeit nach Versuchen am Seeigelei," Pflüger's Arch. fiir die ges. Physiol., Band i 58, pp. I 89-208.

WiLson, E. B.

1903. "Experiments on Cleavage and Localization in the Nemertean Egg," Arch. fïr Entwickelungsmech., Band I6, pp. 4 I I -60 .

WINKLER, H.

I900. "Ueber die Furchung unbefruchteter Eier unter der Einwirkung von Extractivstoffen aus den Sperma," Nachrichten d. Gesell. d. Wiss. Göttingen.

Ziegler, H. E.

I898. "Experimentelle Studien über die Zelltheilung," Arch. für Entwickelungsmech., Band 4, pp. 249-93. 


\section{CHAPTER VI}

THE PROBLEM OF SPECIFICITY IN FERTILIZATION

In fertilization we have both tissue and species specificity. The spermatozoön does not react with, nor penetrate, other kinds of cells than the ovum (tissue specificity), a fact that suggests the question whether this is due to a chemical specificity of the egg or merely to its physical characteristics. Fertilization is also species specific, but only in a restricted sense, because it is possible to a certain extent between different species or even wider groups (hybridization); the degree of this specificity is subject to rather wide variations in different animal groups, but it is in a very general sense defined by taxonomic relations. Within the species also there are undoubtedly individual variations in fertility, which reach an extreme in the phenomenon of self-sterility in certain ascidians.

\section{TISSUE SPECIFICITY}

Kohlbrugge (I9ro, I9I I, I9г2) maintains that spermatozoa freely penetrate the epithelial cells of the uterine mucosa in animals with internal fertilization that he has studied (bat, mouse, rabbit, hen, dogfish, skate) and may even pass through these into the underlying connective tissue. Sobotta (I9II) was unable to confirm the observations (on the mouse) and showed that most of the spermatozoa degenerate without freeing themselves from the ejaculate. He criticizes Kohlbrugge severely for his methods, and suggests that the 
bodies identified by the latter as sperm heads in the uterine epithelium may be shrunken nuclei. Kohlbrugge has gone as far as to suggest that there may be a fusion of the sperm nuclei and the nuclei of epithelial cells and a consequent stimulation of cell division and growth; but the evidence offered for these suggestions is highly unsatisfactory. However, he presents his observations as a possible explanation of telegony, a phenomenon which has no present status among biologists. The observations of Kohlbrugge require confirmation before they can be accepted as a body of ascertained fact. The same author has also maintained that spermatozoa may enter cleavage cells, or cells of the blastodermic vesicle of mammals; but here also confirmation is lacking.

There is some evidence from the clinical side that the sperm of the male influences the body of the female, and Waldstein and Eckler (1913) maintain that a specific ferment develops in the blood of rabbits a few hours after coitus which is directed against sperm, and may be detected by the method of Abderhalden. This would demonstrate absorption of sperm, but not necessarily in the manner described by Kohlbrugge.

In a considerable number of animals spermatozoa find their way among the tissues either as a result of the method of copulation or otherwise. But they are not known to react with any other cells than the ova. There is quite an extensive literature on this subject; the principal references are Whitman (I89r), Kohl-

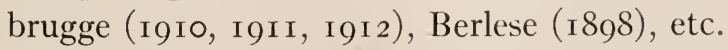

The problem of tissue specificity as between ovum and spermatozoa has not, however, attracted much 
attention. The failure of the spermatozoa to enter other kinds of cells, even though there is abundant opportunity for it, requires some explanation. In the fertilization of Ascaris megalocephala, for instance, the spermatozoa find their way up the long oviduct and may be found in considerable numbers in the interstices between the enormous swollen epithehial cells of the oviduct, but they never enter the latter; in the lumen of the oviduct the membraneless eggs, hardly larger than the oviducal cells, are, however, all fertilized. The reciprocal of this relation is found in sperm agglutination by secretions of ova but by no other tissue products. The writer (I9I3) studied the latter question in detail in the sea urchin and in Nereis and was unable to derive even a trace of sperm-agglutinating substance, either from the blood, which must contain secretions of all tissues, or from any of the tissues individually; but the ripe eggs always produced the agglutinating substance abundantly. There is thus a definite tissue specificity in fertilization due to specific chemical organization of the gametes, as one factor at least.

\section{SPECIES SPECIFICITY}

I. Hybrid fertilization.-The extent to which species specificity in fertilization is due to actual differences in the chemical make-up of interacting substances has caused much discussion. The problems united under this head ally themselves with problems of tissue and blood specificity and have the broadest biological bearing. Specificity may concern different stages of fertilization; in certain hybrid combinations the eggs do not appear to react at all to the foreign sperm; in 
others the foreign sperm may produce cortical changes but fail to penetrate; or the sperm may penetrate, and perish without uniting with the egg nucleus; or it may unite and be secondarily eliminated in the first or later cleavages; or again, without elimination, the combination may prove its incompatibility by abnormalities in development appearing rapidly or slowly; in yet other cases the hybrid may develop fully but remain sterile. Finally we may have completely fertile hybrids from certain crosses of closely related species. The blocks to hybrid fertilization are thus not the same in all cases; even in the case of cortical block it is quite conceivable that we have different causes operative in different cases. This block seems to be readily removable in some instances by mere increase in alkalinity of the medium as first shown by Loeb, but this is by no means always so. The internal blocks on the other hand are not controllable by means hitherto employed.

From the standpoint of preservation of the species it makes but little difference in what stage hybrid fertilization exhibits its incompatability so long as the hybrid does not breed. But from the standpoint of fertilization problems we need consider only the incompatibilities of the stages of fertilization itself.

A brief systematic survey of the field will prepare the way for consideration of the problems. The groups in which the possibilities of hybrid fertilization have been most fully investigated are the echinoderms, teleosts, and amphibia. In some groups, as in insects, birds, and mammals, mating behavior constitutes a serious obstacle to close investigation. 
a) Echinoderms: We may consider the data in taxonomic order: (I) species crosses, (2) genus, family, and ordinal crosses, (3) class crosses, (4) phylum crosses.

I. Shearer, De Morgan, and Fuchs (I9I3) crossed three species of Echinus: esculentus, acutus, and miliaris, in all possible combinations. The fertilization succeeded in all six combinations without any artificial aid, by either increasing the usual concentration of the sperm or changing the chemical composition of the sea-water. Larvae were readily raised from all crosses, but only the crosses $E$. esculentus $+\times E$. acutus $f$ and $E$. miliaris $q \times E$. acutus male gave normal sea urchins.

The cytology of these crosses was studied by Doncaster and Gray (I9I3) and by Gray (I9I3). The behavior of the germ nuclei was normal; but some elimination of chromosomes from the first cleavage spindle occurred in certain of the crosses. A curious fact was that this might occur in one reciprocal of a cross but not in the other. Thus in the cross esculentus of $\times$ acutus of the cytological events are perfectly normal; but in acutus $q \times$ esculentus of there was an invariable elimination of some chromosomes. In this process vesicles formed on certain chromosomes, and often separated from them and came to lie outside of the spindle; other altered chromosomes were often carried entire to one pole without dividing. It was not possible to determine what relation there might be between chromosome elimination and the character of inheritance.

Such elimination of chromosomes from hybrid $z y-$ gotes has often been referred vaguely to incompatibility; 
but in this case it is difficult to suggest why it should exist in one reciprocal and not in the other. Gray (1913) found that treatment of fertilized eggs of $E$. acutus with hypertonic solutions of medium strength caused elimination of some chromosomes, but the phenomenon could not be induced in E. esculentus by similar treatment. He suggests that the chromosome behavior in the reciprocal crosses might be understood on the assumption that the osmotic relations are different in the cross and pure species, owing to different effects, on permeability of the egg, of the foreign and species sperm. This would imply that the eliminated chromosomes are of maternal origin; however, this cannot be proved in the cross under consideration, and it is known that in wider crosses the eliminated chromosomes are of paternal origin generally (Herbst, Balzer, Tennent).

2. Interspecific crosses among the echinoderms seem to have been confined to the genus Echimus, and we are therefore unable to make any general statement concerning the possibilities. But wider crosses within the order have been made very frequently. Vernon (r900) alone attempted forty-nine out of a possible fifty-six cross-fertilizations between eight species belonging to seven genera of sea urchins; only eleven of these gave no sign of cross-fertilization; of the remainder, nine gave only segmentation stages or blastulae or gastrulae, and twenty-nine lived to the stage of eightday plutei.

In Vernon's cross-fertilizations a high sperm concentration seems generally to have been employed. The percentage of eggs fertilized was nevertheless small as compared with species fertilization; in many cases 
exceedingly small. In several instances the eggs were staled for several hours, even up to twenty-four, before fertilization, with resulting increase in the percentage of eggs fertilized; but in the case of Sphaerechinus fertilized by Strongylocentrotus this treatment was not successful. It is important to note that specificity always appeared with reference to the relative ease of fertilization with the specific and foreign sperm.

Tennent (I9Io) made eleven crosses within the order in which the reciprocals belonged to different genera, families, or suborders; and many cross-fertilizations within the order have been made by other observers. Unfortunately for our purpose these studies have been made from the point of view of heredity or chromosome behavior, and the fertilization problems have been referred to only incidentally as a general rule. They are, however, sufficient to show that the chances of success of a cross cannot be postulated wholly on the systematic position of the species. Thus Tennent reports that the cross between Moira $q$ and Toxopneustes of belonging to different suborders takes place very readily and the larvae develop well. The reciprocal cross can also be made, but succeeds best if the Toxopneustes eggs are allowed to stand in sea-water five hours before being fertilized. Hipponoe $q$ crossed

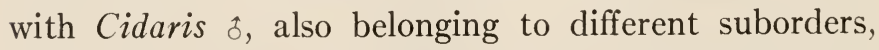
gives poor results; no fertilization membrane is formed, segmentation is irregular, larvae abnormal.

Reciprocal crosses are sometimes quite similar with reference to fertilization; but frequently they are not. Thus Fischel (I906) reports for the crosses between Strongylocentrotus and Arbacia that fertilization never 
succeeds when Strongylocentrotus is the male, but always succeeds when Arbacia is the male. He states that, curiously enough, the Hertwigs obtained the exact opposite result with these genera in another locality. Some authors state only their successful cross-fertilizations, and the facts with respect to the reciprocals are not stated.

Balzer (I9I0) has, however, paid particular attention to this question, and his results may be tabulated as follows:

\begin{tabular}{|c|c|c|c|c|}
\hline & Echinus + & Strongylocentrotus ? & Sphaerechinus + & Arbacia 우 \\
\hline Echinus $\$$ & & $\begin{array}{l}\text { No elimiration } \\
\text { (I) }\end{array}$ & $\begin{array}{l}\text { No elimina- } \\
\text { tion }(2)\end{array}$ & $\begin{array}{l}\text { 28-30 chromosomes } \\
\text { eliminated first } \\
\text { cleavage }(4)\end{array}$ \\
\hline $\begin{array}{l}\text { Strongylo- } \\
\text { centrotus } \hat{\sigma}\end{array}$ & $\begin{array}{l}\text { No elimination } \\
\text { (I) }\end{array}$ & & $\begin{array}{l}\text { No elimina- } \\
\text { tion }(3)\end{array}$ & $\begin{array}{l}\text { 28-30 chromosomes } \\
\text { eliminated first } \\
\text { cleavage }(5)\end{array}$ \\
\hline $\begin{array}{l}\text { Sphaere- } \\
\text { chinus ô }\end{array}$ & $\begin{array}{l}\text { 2I chromosomes } \\
\text { eliminated first } \\
\text { cleavage }(2)\end{array}$ & $\begin{array}{l}\text { 2I chromosomes } \\
\text { eliminated first } \\
\text { cleavage }(3)\end{array}$ & & $\begin{array}{l}2 \text { I chromosomes } \\
\text { eliminated first } \\
\text { cleavage }(6)\end{array}$ \\
\hline Arbacia $\hat{o}$ & $\begin{array}{l}\text { Chromatin elim- } \\
\text { inated blastula } \\
\text { (4) }\end{array}$ & $\begin{array}{l}\text { Chromatin elim- } \\
\text { inated blastula } \\
(5)\end{array}$ & $\begin{array}{l}\text { No elimina- } \\
\text { tion }(6)\end{array}$ & \\
\hline
\end{tabular}

Note.-The reciprocal crosses bear the same number.

Only three of these cross-fertilizations were successful in sea-water, then only occasionally, and quantitative data were not given, viz.: Sphaerechinus of $\times$ Strongylocentrotus ; ; Strongylocentrotus o $\times$ Arbacia $\hat{b}$; Echinus $q \times$ Sphaerechinus $\delta$. The fertilizations recorded were therefore made in hyperalkaline sea-water according to Loeb's method. Very great variability in the capacity for hybridization even by this method was 
encountered as by other authors. But little can be learned, therefore, concerning the kind and degree of the natural specificity of the fertilization reactions in these cases, except what has been stated, viz., that in nine out of the twelve cross-fertilizations hyperalkaline conditions are necessary to permit penetration of the spermatozoön. But, after the cortical specificity is broken down by the hyperalkaline medium, fertilization proceeds normally up to the metaphase of the first cleavage, when elimination of paternal chromosomes occurs regularly in certain cases. In other cases elimination of paternal chromatin is postponed until the blastula stage, and in yet others it does not occur at all. But there is only one case in which the reciprocals behave alike in this respect, viz., in the Echinus $\times$ Strongylocentrotus crosses, among the six pairs of reciprocals.

There is certainly a quantitative specificity in these cases. For a critical examination of the problem of specificity within the class we need a quantitative control of egg and sperm concentration for the specific and the cross-fertilizations which should be reciprocal, and a careful cytological examination of the eggs. In the second place we need also, in all cases in which the gametes are refractory to cross-fertilization, an experimental testing of methods for overcoming the difficulty. Until this is done we cannot say what the measure of specificity really is. In the third place the viability of the crosses should be thoroughly tested; it has been shown in many cases that development becomes abnormal in the blastula or gastrula and, in other cases, in pluteus stages. But some crosses even 
between suborders give strong plutei; however, no one has carried the crosses considered in this section through the metamorphosis, and it is not known whether this is possible.

The heredity of intergeneric and wider crosses within the order is a matter of great interest, but the discussion would carry us beyond the scope of our subject. There is a strong tendency for such crosses to exhibit a preponderance of maternal characters, though this is not always the case. Herbst (I909, I9I2) and Balzer (I9I0) have shown that such cases are, frequently at least, accompanied by an extrusion of paternal chromatin, and they have thus furnished an explanation of some cases of matroclinal heredity. But other authors have pointed out that the direction of inheritance may be related to reaction of the seawater (Tennent), or to seasonal conditions (Vernon), or to factors affecting the growth of the germ cells during their period of growth and maturation (Shearer, De Morgan, and Fuchs). These views are not necessarily inconsistent, for the external factors may operate by modification of chromosome relations.

3. Interclass crosses have also been made in echinoderms. In all such cases it has been necessary to create artificial conditions for the fertilization reaction. The first experiments of this kind were performed by Loeb in 1903, who found that the eggs of Strongylocentrotus purpuratus can be fertilized by the sperm of Asterias (starfish) in the presence of an excess of alkali. Fertilization succeeded best in a solution of roo c.c. sea-water to which I. 2 c.c. $\mathrm{N} / \mathrm{\text {Io }} \mathrm{NaOH}$ had been added. Perhaps 50 per cent formed membranes and 
segmented, and many lived until the third day and formed a rudimentary skeleton, but then died. The characters developed were exclusively maternal. The sperm of certain other starfishes was less effective, but that of a brittle star was equal to Asterias. Only those eggs developed into which a spermatozoön penetrated, but some eggs which formed membranes failed to segment, and Loeb and his students showed that in these cases the membrane had been caused by external action of the spermatozoön alone. Loeb could not succeed in fertilizing the eggs of Arbacia with the sperm of Asterias by this method.

The starfish sperm affect the sea urchin egg only in the presence of the alkali; eggs or sperm previously treated with alkali will not react when brought together in pure sea-water. The effect may be on the spermatozoön or on the egg or on both; but it is obvious that some surface reaction of the egg and spermatozoön is favored by the alkali, because when the sperm once gains entrance to the egg it calls forth the further necessary reactions within it.

In attempting a further analysis of this subject Loeb (I9I4) discovered that if the sea urchin eggs are deprived of their jelly by action of $\mathrm{HCl}$ they cannot be fertilized by starfish spermatozoa with the same use of hyperalkaline sea-water that readily brings about fertilization in the presence of the jelly, although they are readily fertilized with their own sperm. But if an excess of calcium is added to the hyperalkaline seawater the heterogeneous fertilization succeeds in the absence of the jelly, and in this case practically all of the eggs that form membranes segment. In the pres- 
ence of the jelly many eggs form membranes but fail to segment owing to failure of the spermatozoön to penetrate. Loeb suggests that the latter phenomenon may therefore be due to agglutination of the starfish sperm to the jelly.

We gain here a hint that will be further developed in the section on the mechanism of fertilization, viz., that the specific factor in fertilization may concern an agglutination reaction between egg and sperm, as the writer earlier maintained.

In 1906 Godlewski attempted to fertilize sea urchin eggs with sperm of starfish, holothurians, and brittle stars by Loeb's method without success. However, he succeeded in fertilizing eggs of the same genera of sea urchins with the sperm of Antedon rosacea (crinoid) by the same method. The fertilizations succeeded best in the alkaline sea-water with a high concentration of sperm; but some eggs were fertilized when first exposed and then washed in normal sea-water, a fact that shows the main effect of the alkali to be on the egg. A few eggs might develop to normal plutei, thus exhibiting a purely maternal inheritance, in spite of the fact that the sperm nucleus fused with the egg nucleus and no elimination of chromatin could be demonstrated in later stages.

Tennent (I9I0) also succeeded in fertilizing sea urchin eggs with sperm of different echinoderm classes. Thus the eggs of Hipponoe were fertilized with the sperm of Ophiocoma (brittle star) and of Pentaceros (starfish), and the eggs of Toxopneustes with the sperm of Holothuria. The method employed was to allow the eggs to stand two to three hours before adding the 
sperm. A slight cytolysis of the egg is presumably thus induced. The development was highly abnormal in all cases.

4. Sea urchin eggs have also been crossed with sperm of different phyla. Kupelwieser (I 909 and I9I 2) has made a special study of this problem. He investigated the effect of the sperm of fourteen genera of mollusks and annelids on sea urchin eggs and obtained positive but usually scanty results in five cases, the others being negative. A high concentration of sperm and long exposure of the eggs was necessary. In all these cases membrane formation of the egg might also be induced by dead sperm or blood of the species. Strongylocentrotus o $\times$ Mytilus $\delta$ gave the best results. The success of the fertilization seemed to depend on extract present with the sperm, which so affected the surface of the egg that one or more spermatozoa could enter. But if membrane formation occurred too rapidly, as a result of the sperm extract action, the sperm did not enter, and the eggs died. Once within the egg, if the condition was monospermic, events moved normally to a certain stage; an aster formed in association with the sperm nucleus; it then formed an amphiaster while the germ nuclei united. The male nucleus did not, however, form normal chromosomes and was eliminated; but the female nucleus formed its chromosomes, which divided in the usual way, and all nuclei were henceforward haploid and purely maternal. In a very small percentage of cases development might proceed to the pluteus stage, which was usually defective. It was purely maternal as far as it went. In the very usual event of dispermy or polyspermy the phe- 
nomena were essentially similar to dispermy or polyspermy within the species: aster-formation from each sperm nucleus, a tetraster or polyaster first cleavage, abnormal development, and early death. The lack of specificity in the events between penetration and cleavage is thus clearly shown. Kupelwieser, however, concludes that all kinds of spermatozoa possess the same chemical stuff for activation of eggs, an erroneous conclusion which we shall now consider.

Discussion: 'These rapidly reviewed data on echinoderm hybridization demonstrate in an entirely convincing manner the existence of non-specific factors in fertilization; and they also demonstrate with equal clearness the existence of specific factors. The latter are found first in the cortical reactions, which never occur with equal facility in crosses outside the genus, and second in the latest stages of fertilization after union of the germ nuclei. Apparently any spermatozoön that has once crossed the barrier of the egg cortex calls forth the same set of events within the egg. The sperm aster is evidently a non-specific reaction, and when this system is once set in operation it can continue in only one way so long as it is not impeded by incompatibilities of another kind.

As to the specific factors there is unquestionably resistance at the periphery of the egg, which is most promptly and readily overcome by the species sperm. In the interspecific crosses of sea urchins there is not a strong cortical resistance, but the quantitative studies necessary for an evaluation of the specific factor have not been made in this case. When we come to intergeneric and wider crosses within the order we find that 
the cortical resistance to the hybrid fertilization must be broken down by staling of the eggs or dilution of the sea-water, or by modification of the chemical environment, or by high concentration of sperm. Interclass crosses require in all cases apparently the action of some foreign agent on the egg; and the same is true of the interphylum crosses considered, though in this case the concentrated sperm may itself exert a cytolytic action on the egg, which favors penetration.

The specific factor that appears at the end of the fertilization process evidences itself usually in elimination of chromatin; but it is readily conceivable that such a result may not be evident; the fertilization might to all appearance be perfectly normal, and yet subsequent events might demonstrate the incompatibility of the union.

The nature of these specificities need not concern us here, as they can be considered more profitably after other data have been considered.

b) Teleosts: A great many experiments have been carried out in the cross-fertilization of various species of teleosts, between species, genera, families, and orders. Thus Newman (1915) records seventy-eight heterogenic crosses between members of different families or orders of teleosts belonging to fourteen species, and Moenkhaus (I9I0) records eighteen.

Every cross-fertilization attempted was more or less successful in the sense that some or even a large percentage of the eggs segmented; no artificial treatment of the eggs or the spermatozoa appeared to be necessary in order to secure these results, unlike echinoderm crosses. Even in the most distant heterogenic crosses 
development might proceed to a late stage. Sooner or later, however, the heterogenic hybrids proved to be non-viable.

There is, however, according to Newman, definite evidence of specificity in teleosts in the sense that species fertilization succeeds much more readily than any hybrid fertilization. The percentage of hybrid fertilized eggs is always less under given conditions and is frequently extremely small. The more ready union of the species sperm must depend upon some chemical relation between egg and sperm, more highly developed between gametes of the same than between gametes of different species. This obviously operates at the surface, because the subsequent events of fertilization after penetration appear to proceed with equal facility whether the sperm belongs to the same or to a different species. Moenkhaus (I9I0), on the other hand, believes that, in the case of the teleosts studied by him, there is no evidence of any specific adaptation of the egg for its own spermatozoön. No adequate test of such a conclusion appears to have been made. The dry method of insemination usually employed for teleosts exposes the egg to the highest possible sperm concentration and thus renders a quantitative examination of the problem of specificity impossible.

Moenkhaus (I904), Günther and Paula Hertwig (I9I4), and Morris (I9I4) found normal penetration of the spermatozoön, normal behavior of the germ nuclei, and no evidence of chromatin elimination in the hybrid fertilization of the teleosts that they have studied cytologically. However, Pinney (I9I8) reports chromatin elimination in certain teleost crosses in the first and 
second cleavages, though it did not occur in the reciprocal crosses of the same cases.

Newman could find no relation whatever between success in development and taxonomic relationship, though Moenkhaus is of the contrary opinion. Some of the crosses between species of the same genus exhibited much less success in development than other crosses between members of different orders. The eggs of some species (e.g., Fundulus majalis) never hybridize well, while those of others do well with the sperm of all species tried (e.g., Tautoglabrus). Similarly the sperm of some species is better adapted to hybridization than that of other species. There is a frequent marked difference in the success of reciprocal crosses, but there are notable exceptions. In Newman's opinion the factors concerned in success or failure of hybrid development of teleosts are associated with amount, composition, and density of yolk, hardiness or delicacy of the species concerned, and certain mechanical advantages or disadvantages. Chemical specificity thus apparently does not play a leading rôle, though I believe it would be a mistake to assume that it is absent.

c) Amphibia: Hybridization in Amphibia has been studied by Pflüger (I882 and I883), Born (I 883 and I886), and Bataillon (1906, I909, I910) among others in a large number of crosses, especially in the order Anura. The hybrid eggs never develop to metamorphosis, except in the cases of Rana fusca $\hat{\delta} \times$ Rana arvalis $q$ and Bufo vulgaris of $\times$ Bufo cinereus $q$ (Born). The other combinations die at various stages, usually early. With respect to fertilization there is immensely greater success than with respect to viabil- 
ity, as is usual in hybrid combinations. The success of fertilization seems to be entirely unrelated to systematic relationship. This may be illustrated by the usual difference in the success of reciprocal fertilization; even in species of the same genus a cross-fertilization may succeed one way and fail entirely in the reciprocal. Thus Pflüger reports that the eggs of Rana esculenta fertilize readily with the sperm of $R$. fusca, the eggs dying in the blastula stage; but eggs of $R$. fusca can never be fertilized with the sperm of $R$. esculenta. On the other hand Rana esculenta and Rana arvalis fertilize reciprocally. The eggs of Rana fusca could not be fertilized with the sperm of any other anuran (Pflüger), and the same is true of the eggs of Pelodytes (Bataillon); but the eggs of the latter can be caused to develop by the sperm of Triton alpestris belonging to the order Urodela.

Born points out that a higher concentration of sperm is usually required for cross-fertilizations than for straight species fertilizations. He distinguishes three kinds of behavior of the gametes in the crossfertilizations: (I) No reaction; examples: Rana arvalis \& $\times$ Rana fusca ; Bombinator igneus and Rana esculenta reciprocal; Pelodytes \& $\times$ Rana arvalis of. (2) In a second group fertilization is apparently monospermic and normal; examples: Rana esculenta $\times$ Rana arvalis reciprocal, Rana fusca $\hat{\alpha} \times$ Bufo cinereus . . (3) In a third group of cases polyspermy is the rule, followed by early death of the eggs; examples: Bufo cinereus $\hat{} \times$ Bufo vulgaris + , Pelodytes $\$ \times$ Rana esculenta q.

Unfortunately this material has not been studied cytologically in any systematic way. Born believes 
that in his first group the spermatozoa fail to penetrate the egg membranes, and this is probably so, but no experiments have been undertaken to attempt to bring about fertilization by artificial means in these cases. Bataillon found in the case of the eggs of Pelodytes or of Bufo activated by the sperm of Triton that the latter had not entered at all, but had at most pierced the cortex of the egg; he was therefore led to inquire if a similar piercing by a fine needle might not bring about the same results, and in this experiment he succeeded in producing complete parthenogenesis, as is generally known.

It is obvious that the explanation of the curious results in hybridization of Amphibia cannot be given in terms of chemical specificity alone. Pflüger concluded that in general those spermatozoa are most successful in cross-fertilization that have the thinnest heads and sharpest perforatorium; and that eggs are most accessible to hybridization when the spermatozoa of the same species have thicker heads. He had thus a conception that was based purely on the old idea of the mechanical penetration of the spermatozoön into the egg. The results on the Amphibia do not exclude a certain amount of chemical specificity. Fuller knowledge of the mechanism in these forms is necessary for an explanation of the results.

Many of the hybrid fertilized eggs die in the blastula stage, but some combinations at later stages. This has usually been attributed to an incompatibility, chemical or otherwise, between the hybrid chromatins. This idea has been supported in an interesting way by O. Hertwig (1913) and G. Hertwig (1913). The basis 
for the experiment was the demonstration that exposure of spermatozoa to radium emanations injured the sperm, and that it might be so graded as to leave spermatozoa with ability to activate the eggs but to transfer no hereditary effect. Paula Hertwig (I9I3) showed that this was due to failure of the injured sperm nucleus to take part in the cleavage; hence such fertilization is a kind of parthenogenesis, as O. Hertwig had previousty assumed. O. Hertwig showed that in the cross Triton o $\times$ Salamandra of the eggs die in the blastula stage, but if the sperm be first strongly radiated the eggs will produce larvae which possess the haploid number of chromosomes. This shows that egg chromatin alone was concerned in the development and permits the inference that the early death in hybrid fertilization with normal sperm is due to the multiplication of the sperm chromatin. G. Hertwig made a similar determination for the cross Bufo vulgaris $q \times$ Rana fusca $\hat{f}$. Bataillon (1909) showed that in fertilization of Pelodytes $\&$ by Triton the sperm nucleus takes no part in cleavage; nevertheless the eggs die in the blastula stage, owing, evidently, to some other cause than multiplication of the sperm chromatin.

2. Self-fertilization.-As contrasted with our survey of hybrid fertilization we should next consider the data concerning the self-fertilization of hermaphrodite organisms, i.e., the fertilization of the eggs by the spermatozoa of the same individual. If dissimilarity of gametes is the cause that renders hybrid fertilization difficult, it might be expected that the closest possible relationship of gametes, which is found in hermaphrodite individuals, would involve the greatest compatibility of the 
gametes. But, as is well known, this is by no means always the case, for there are both hermaphrodite animals and plants in which self-fertilization is difficult or impossible. Two problems have usually been considered together in this connection, viz., the problem of compatibility in fertilization and the problem of viability and vigor of the offspring of such fertilizations. The latter problem, although related, will not concern us here.

The problem of self-fertilization has not been very widely investigated in the case of hermaphrodite animals. In rhabdocoel Turbellaria reproduction by selffertilization is common; it is also stated to occur occasionally in certain trematodes and cestodes in spite of an elaborate apparatus for cross-fertilization. Oligochaetes and pulmonates appear to reproduce exclusively by cross-fertilization; but Braun (I888) and Colton (I912) have shown that individuals of the pond snail Limnaea reared in isolation from the egg may produce fertile eggs. As parthenogenesis is unknown in mollusks it is almost certain that these eggs were selffertilized. A. H. Cook reports a similar case for Arion (Cambridge Natural History). In the parasite cirripeds (Rhizocephala) reproduction is invariably by selffertilization (J. W. Smith, I906), and the same is true of certain free-living nematodes (Maupas, I900; Potts, I9I0). In both of the latter groups special arrangements exist for insuring self-fertilization. Among the ascidians Cynthia and Molgula appear to be self-fertile, at least to a considerable extent (Morgan, I904), but Ciona in the same group is self-infertile, at least to a considerable extent, which appears to vary somewhat 
for different individuals and localities (Castle, I903; Morgan, I904, I905, I910; Fuchs, I9I4, I9I5).

In plants the problem of self-fertilization was brought to the forefront of investigation by Darwin's classical "Studies on Cross- and Self-Fertilization in the Vegetable Kingdom," and the problem of selfing has been very carefully and extensively studied in recent years by Jost (1907), Correns (1912), East (1915a, 1915b), East and Parke (1917), Stout (19i6 and 1917), and others. The problem in plants is similar in many respects to that in animals, but it should be remembered that in plants the incompatibility that occurs in many cases concerns the growth of the pollen tube, which is more or less abortive on the stigma and in the style of the same flower in such cases, and not the reaction of the actual gametes, which appear usually not to meet. Of course in many plants the pollen of the same flower is perfectly compatible, and in the case of cleistogamous flowers that never open but nevertheless produce perfect seed there is no chance for crossfertilization. The phenomenon of physiological incompatibility of own pollen is more or less sporadic in its occurrence, and in fact the plants in which this occurs form a relatively small class.

The ascidian Ciona is the only known and carefully studied example of physiological self-incompatibility of gametes in the animal kingdom. The various authors who have studied this case (Castle, Morgan, Fuchs) all found certain individuals in which the eggs are not susceptible of fertilization with the sperm of the same individual, although they may be fertilized with sperm of other individuals; and the sperm thus impotent on 
eggs of the same individual may fertilize perfectly the eggs of other individuals. The failure to self-fertilize in these cases is not due to immobility of the spermatozoa in the presence of own eggs, or inability to reach the niembrane of the egg, but it is due to absence of the reaction that leads to penetration of the egg by the spermatozoön. Such incompatibility is by no means universal in Ciona, for all authors have found certain individuals in which self-fertilization may occur to a certain extent.

The determination of the occurrence of selffertilization obviously requires much care to avoid contamination with the sperm of other individuals. The method which was originally employed by Castle in his determinations consisted in comparing the percentages of fertilized eggs from isolated individuals with the percentages from pairs of individuals placed together. Observations were made on the same individuals for five successive days, and the fertilized eggs of each day were separately estimated. The result was that of fifty estimates from ten isolated individuals thirty-seven contained no eggs fertilized, nine from 4 per cent to 25 per cent fertilized, two contained 90 per cent of fertilized eggs, and in two cases no eggs were deposited. The paired individuals yielded twentyfive estimates, of which twenty-three showed roo per cent fertilized, one yielded 20 per cent, and one none fertilized.

To this method of determining the extent of selffertilization the objection has been made that spermatozoa of foreign origin may remain in the atrial cavity or tangled in the branchial basket and give the effect 
of self-fertilization when none exists. But Fuchs has shown that shed spermatozoa will not survive over twenty-four hours in sea-water, so that the tests are probably valid for determinations after twenty-four hours of isolation,. on the assumption that in the case of pairs both individuals shed their gametes. Castle himself suspects contamination in the two cases of apparent self-fertilization yielding 90 per cent of fertilized eggs.

To avoid this objection artificial insemination has been practiced by the three authors named. In these experiments Morgan finds an almost vanishing amount of self-fertilization; while Fuchs working in Naples found that, while in many cases no eggs segmented after self-fertilization, nevertheless Ciona intestinalis as a species is far from being completely self-sterile, though "a greater concentration of sperm is usually necessary to bring about any self-fertilization than would crossfertilize roo per cent of foreign eggs."

May self-fertilization be forced on these eggs? Fuchs found that by increasing the quantity of sperm a higher percentage of self-fertilization could be secured, as shown in the following table:

\begin{tabular}{|c|c|c|c|c|}
\hline \multirow[b]{2}{*}{ • } & \multicolumn{2}{|c|}{ Eggs Selfed } & \multicolumn{2}{|c|}{ Eggs Crossed } \\
\hline & $\begin{array}{l}5 \text { Drops } \\
\text { Sperm }\end{array}$ & 4 c.c. Sperm & $\begin{array}{l}5 \text { Drops } \\
\text { Sperm }\end{array}$ & 4 c.c. Sperm \\
\hline 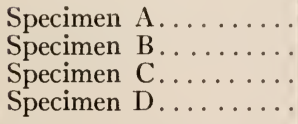 & $\begin{array}{r}0 \\
0 \\
12 \\
0\end{array}$ & $\begin{array}{r}58 \\
22 \\
100 \\
56\end{array}$ & $\begin{array}{l}100 \\
100 \\
100 \\
100\end{array}$ & $\begin{array}{l}100 \\
100 \\
100 \\
100\end{array}$ \\
\hline
\end{tabular}

Equal amounts of eggs of four specimens were added to four equal quantities of sea-wáter, and the first two 
dishes of each were selfed and the second two of each crossed with quantities of sperm shown. The results are expressed as percentages of eggs segmenting. It will be observed that the lesser quantity of sperm sufficed in cross-fertilization to cause the segmentation of every egg, but was without any effect in the case of three of the four self-fertilizations, and fertilized only i 2 per cent in the case of the other; the higher concentration of sperm caused some self-fertilization in every case recorded in the table, though it seems probable from other statements that this is not always the case. Fuchs also determined, as I interpret his results, that staling of the eggs in sea-water increases their susceptibility to self-fertilization up to a certain point; this was in marked contrast to cross-fertilization. Morgan has attempted to bring about self-fertilization by the action of ether, alcohol, chlorotone, and other substances, with results that must in general be regarded as negative, for they were often contradictory.

There appears to be a certain general resemblance between resistance to hybrid and to self-fertilization, because the same conditions may overcome either; it must, however, be admitted that the data on the selffertilization are rather scanty and inconsistent in this particular. The evidence is, nevertheless, adequate to prove that the resistance is cortical in the one case as in the other, and that when this cortical resistance is overcome the internal events of fertilization proceed normally.

Are the eggs of Ciona equally fertile to the sperm of all other individuals, or is there a certain degree of individual as well as of self-incompatibility? In an 
extensive set of trials involving over six hundred fertilizations Morgan found very considerable variations in the percentages of fertilization in different combinations. The experiments were usually conducted with groups of four or six individuals and involved all reciprocals and the self-fertilizations in each case. While all the results cannot be regarded as equally free from error, they nevertheless justify the conclusion, when taken together, that there are very considerable variations with reference to fertilizing power in different combinations, even reciprocal ones, in spite of Fuchs's criticism of this result.

It may be pointed out that the problem of individual incompatibility is not necessarily associated with hermaphroditism and the problem of self-sterility; it is probable that there is a considerable amount of individual variation with respect to gamete compatibility in species with separate sexes, though little is known on this point.

Even when self-fertilization succeeds, the viability of the resulting larvae is relatively slight, although, as will be seen from the following table (after Fuchs), the

\begin{tabular}{|c|c|c|c|c|c|c|c|c|}
\hline & \multirow{2}{*}{\multicolumn{2}{|c|}{ 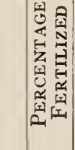 }} & \multirow{2}{*}{$\begin{array}{c}\text { Time } \\
\text { OF } 4 \\
\text { Cells } \\
\text { Min. }\end{array}$} & \multicolumn{2}{|c|}{$\begin{array}{c}\text { TIME of } \\
\text { HaTCH- } \\
\text { ING }\end{array}$} & \multirow{2}{*}{$\begin{array}{l}\text { SetTled } \\
\text { Down }\end{array}$} & \multicolumn{2}{|c|}{ Alive } \\
\hline & & & & $\mathrm{Hr}$. & Min. & & 8 Days & 20 Days \\
\hline Self-fertilized . & $\left\{\begin{array}{l}\mathrm{Aa} \\
\mathrm{Bb}\end{array}\right.$ & $\begin{array}{r}7 \\
<2\end{array}$ & $\begin{array}{l}86 \\
83\end{array}$ & $\begin{array}{l}\text { 19 } \\
\text { 19 }\end{array}$ & $\begin{array}{l}37 \\
30\end{array}$ & $\begin{array}{l}\text { Very few } \\
\text { More }\end{array}$ & $\begin{array}{l}\text { None } \\
\text { None }\end{array}$ & $\begin{array}{l}\text { None } \\
\text { None }\end{array}$ \\
\hline Cross-fertilized & $\left\{\begin{array}{l}\mathrm{Ab} \\
\mathrm{Ba} \\
\mathrm{Ca}\end{array}\right.$ & $\begin{array}{l}100 \\
100 \\
100\end{array}$ & $\begin{array}{l}83 \\
83 \\
86\end{array}$ & $\begin{array}{l}\text { I9 } \\
\text { I9 } \\
\text { I9 }\end{array}$ & $\begin{array}{l}15 \\
27 \\
26\end{array}$ & $\begin{array}{l}\text { Most } \\
\text { Many } \\
\text { Most }\end{array}$ & $\begin{array}{l}\text { Equal } \\
\text { number } \\
\text { of } \mathrm{Ab} \text { and } \\
\mathrm{Ba} \text { more } \\
\text { of } \mathrm{Ca}\end{array}$ & $\begin{array}{l}\text { Fewest of } \\
\mathrm{Ab} \text {, med- } \\
\text { ium num- } \\
\text { ber of } \mathrm{Ba} \text {, } \\
\text { most of } \mathrm{Ca}\end{array}$ \\
\hline
\end{tabular}


rates of development are about the same for self- and cross-fertilized eggs.

In this table each letter stands for an individual, the capital for the eggs and the small letter for the . sperm; thus $\mathrm{Aa}, \mathrm{Bb}$ are self-fertilizations, $\mathrm{Ab}, \mathrm{Ba}$, and Ca cross-fertilizations. An excess of sperm was used in all the fertilizations; the difference in percentage of eggs fertilized when selfed and crossed should be noted. The eggs that are fertilized segment and hatch in the same time, whether selfed or crossed; but the selfed eggs do not survive, while the crossed eggs do. This was the invariable result in a considerable number of experiments, except that in one selfed lot some of the larvae settled down, and four survived over a month.

It is clear from the discussion that the incompatibility of the self-sperm manifests itself in the cortical reaction; for some reason the spermatozoön fails to fuse with the egg, and as a consequence the activation of the egg fails. This result is incidentally another strong proof that the process of union of the gametes is not a mechanical boring-in action of the spermatozoön. The experiments may also be regarded as demonstrating that if the cortical barrier is once passed the other processes of fertilization proceed normally.

Morgan (1910) in his analysis of the subject concludes that the-failure to self-fertilize is due to the absence of a reaction between the egg and the sperm; and elsewhere (1913) he attributes this to the similarity of the hereditary factors carried by the egg and the sperm. The context of his analysis implies that he is thinking of a chemical reaction of the character 
of an immunity reaction in a very general sense. This implies that a certain chemical differentiation of the gametes is necessary for the fertilization reaction, and that such differentiation may be lacking. It seems to the writer that this step in interpretation is along the right line, but it is clear that it needs to be carried farther by more investigation. Nothing would probably contribute more to a comprehension of the biochemical factors on which the fertilization reaction depends than the solution of the problem of self-sterility.

The solution might be carried a step farther if we were to assume that the egg produces an agglutinating substance necessary to bind the sperm for the cortical reaction, but that the agglutinating substance does not operate on own sperm in the case of Ciona. We have seen in chapter iv that ova actually do produce a sperm-agglutinating substance, and the relation of this to fertilization is discussed in the next chapter; the foregoing assumption is therefore not a mere fancy.

Before discussing the matter further let us very briefly review the analogous phenomena in flowering plants, in which, as we have already stated, a relatively small number exhibit the phenomenon of physiological self-incompatibility in pollination. Stout (rgr6) and East (I9I7) have given excellent historical reviews of the literature of this subject. It should be borne in mind in comparing plants with animals that the incompatibility in the former consists in inhibition of growth of the pollen tube and not incompatibility of the actual gametes. There is no evidence that selfsterility in plants is ever due to incompatibility of the actual gametes. 
Darwin has reported more than thirty cases of selfincompatibility, sometimes absolute, sometimes only relative; since then numerous additional cases have been cited. The genera most carefully studied have been Corydalis, Secale, Lilium, Cardamine, Antirrhinum, Reseda, Nicotiana, and Cichorium. Self-sterility is probably never absolute in any species; it may appear in normally self-fertile species sporadically (Stout), or a self-sterile individual may become self-fertile under adverse conditions (East and Park, I9I 7). Pollination of different flowers of the same plant (geitonogamy) may be slightly more successful than strict self-fertilization (autogamy), but not always; in Lilium bulbiferum all the plants of the same clone have been found to be cross-sterile, but seed-sisters, on the other hand, cross-fertile. The phenomenon may thus concern selfsterility of parts of the same flower, sterility between different flowers of the same plant, and sterility between asexually produced offspring of the same plant. Recent experiments (Correns, Stout, East) have also shown that it may be transmitted like Mendelian characters and thus affect in the form of cross-sterility entire sections of a population.

The study of this subject entered a new phase with Correns' experiments on the inheritance of self-infertility. He took two unrelated plants $\mathrm{B}$ and $\mathrm{G}$ of Cardamine pratensis, which were self-sterile, and made the reciprocal crosses $\mathrm{B} \uparrow \times \mathrm{G}^{\jmath} \hat{~ a n d} \mathrm{G} \uparrow \times \mathrm{B} \hat{\jmath}$, constituting series $\mathrm{I}$ and 2 respectively, and then investigated (I) the relations of the parents and offspring to two unrelated plants, (2) the relations of the pollen of both parents to thirty offspring of each series, and (3) the relations 
of all possible combinations of the offspring to one another. The third set of experiments could not of course be fully carried out.

The parents and offspring were shown to be reciprocally compatible with the two unrelated plants. In the second set of experiments he found that the offspring are divisible into two approximately equal classes for each parent, viz., fertile with the parent or sterile, including in the second class some that set seed very scantily. The relation of a given offspring to one parent is entirely independent of its relation to the other. The offspring may therefore be divided into four classes, viz.:

I. Fertile with both parents $B$ and $G=b g$.

2. Fertile with parent $B$, sterile with $G=b G$.

3. Fertile with parent $G$, sterile with $B=B g$.

4. Sterile with both parents $=B G$

The stated result obviously indicates heritable characters concerned in self-incompatibility. Correns assumes that these are to be interpreted as stuffs that inhibit the normal development of self-pollen, whether in a positive sense or in the sense of the absence of a stuff necessary to growth of the pollen tube. If this is so, the behavior of the offspring among themselves with reference to self-sterility should be predicable, and Correns states from the results of crosses of twelve of the offspring with all of the others that the expectation given by the formulae is approximately realized. He argues that the demonstration of the heritability of incompatibility disproves Jost's theory that the selfincompatibility is due to individual stuffs; that is, to the chemical make-up of each individual being specific; 
but he agrees as to the chemical foundation of the phenomenon; each stuff depends on a gene in the germ plasm, and it is the combination of stuffs that is formed by each gametic union that is specific or individual. He thus bases the phenomenon on line combinations of stuffs. Correns must receive the credit of being the first to relate self-sterility to cross-sterility within the species.

Stout (1916, I917) has carried out a very elaborate and finely executed series of experiments on Cichorium. In a combination similar to Correns he made sixtynine back crosses of offspring on a known parent, of which thirty-five were fertile and thirty-four sterile, thus agreeing with Correns' ratios. He observes that "the range of variation in the actual fertility, however, is so great in both cases that the grouping of all offspring into two classes with reference to crossfertility with a parent is of little significance." $\mathrm{He}$ confirms in general the relation of self- and crosssterility within the species which Correns discovered, but believes that Correns' conception of line stuffs is fundamentally wrong. As demonstration of this he shows that self-fertile plants may arise in certain crosses between self-sterile individuals; when these self-fertile offspring of the $F_{I}$ generation were selfed he obtained forty-one self-sterile and thirty-nine self-fertile plants in $\mathrm{F}_{2}$; in $\mathrm{F}_{3}$ of selfed plants, self-fertile and selfsterile plants arose again in about equal numbers. He also shows that neither self-sterility nor self-fertility is a dominant or recessive character in any consistent sense, "and there is a very irregular and sporadic inheritance both of the character as such and the degree of its expression, if the two can in any sense be separated." 
East and Park (19I7), however, demonstrate very conclusively in Nicotiana that "self-sterility is a condition determined by the inheritance received, but can develop to its full perfection only under a favorable environment." Thus at the end of a flowering period and under conditions adverse to vegetative growth, a certain amount of self-fertility may obtain in plants that are entirely self-sterile at other times. The extent of this change varies with the species; but the offspring arising from such self-fertilization are self-sterile, a fact that demonstrates the fluctuating character and environmental origin of the self-fertilization to which the offspring owe their existence. Such self-fertility does not differ from other cases of suppression of characters by environment. When this principle was borne in mind the results of the extensive experiments became intelligible and permitted a consistent genetic analysis.

The view of Darwin that too great uniformity of organization of the gametes operates to prevent successful fertilization recurs in one form or another up to the present time. Darwin cited the infertility that sometimes arises as a result of inbreeding as an analogous phenomenon. It is obvious that Jost's and Correns' interpretations also rest on the ground of too close relationship, assumed by them to be chemical, and related by Correns to heritable genes. East assumes the necessity for the secretion of stimulating substances by the pistils for the growth of the pollen tube that can be "called forth only by a gamete that differs from the somatic cells between which the pollen tube passes" (quoted from Stout, I9I6). Morgan (I9I3) holds that "the failure to self-fertilize, which is the main problem, 
would seem to be due to the similarity in the hereditary factors carried by eggs and sperm." Stout on the other hand, arguing from hybrid incompatibilities, maintains that "the most fundamental principle of sexual fertility is that a marked degree of similarity in constitution is necessary" for the existence of compatibility. He is thus inclined to refer self-incompatibility to constitutional dissimilarity between gametes, which must therefore be strictly of epigenetic origin. He cannot, however, deny the occurrence of a certain amount of cross-incompatibility as a result of heredity; so that his views seem to lack consistency in this respect.

It is obvious that genetic studies cannot solve the problem of self-incompatibility in a physiological sense; on the other hand, if a physiological solution were found the genetic results would be more readily interpretable. The elementary fact that the gametes which produced any hermaphrodite individual were $i p s o$ facto compatible, though they may themselves transmit incompatibility, proves that the latter property is cytoplasmic, belonging to the duplex organization and not to the genes of the mature gametes. Confusion between the possession and transmission of incompatibility must be avoided.

East and Park (I917) have shown that the difference in behavior between compatible and incompatible pollen on the stigma and in the style is that the compatible pollen tube grows with constant acceleration, exhibiting an autocatalytic curve, whereas the incompatible pollen tubes grow at a constant rate and hence fail to reach the ovule before the style withers and growth becomes impossible. They therefore assume that com- 
patible pollen facilitates the formation of substances from the cells of the style that stimulate growth.

If we attempt to seek the explanation along the lines of serum reactions, an obvious possibility that various authors have considered, it must be realized at the outset that for the present only broad analogies can be considered; if a reaction comparable to immune reactions is concerned in fertilization it may belong to a new category and not to any of the recognized categories, whether of lysins, agglutinins, or precipitins. The question would be whether a point of view could be formulated consistent with the specificities both of fertilization and of immunology. The analogy would naturally be with the antigen $\times$ antibody reactions. The principle of the reaction may be illustrated thus: When an animal receives repeated injections of the red blood cells of another species the serum acquires the power of dissolving the red blood cells of the other species (haemolysis); the reaction is specific in the sense both of the species used and also of the kind of cell used. In this case the blood cells injected constitute the antigen, and the dissolving substance formed in the blood of the other animal the antibody. In this case it is found too that another antibody, an agglutinin, is also formed in the serum of the other species. This is more thermostable than the lysin and may therefore be demonstrated by heating the immune serum to $56^{\circ} \mathrm{C}$., which destroys the haemolytic property, but leaves the agglutinating substance intact.

It has also been found that isohaemolysins and isoagglutinins may be developed in certain cases by injecting blood cells of another individual of the same 
species. But it has hitherto been impossible to develop autohaemolysins or autoagglutinins by injection of the broken-down blood cells of the same individual.

This statement will be sufficient for purposes of comparison. The analogy to fertilization would rest on the resemblance of isoagglutination, for instance, to cross-fertilization, and on the absence of autoagglutination to the absence of self-fertilization. But if the egg produces a specific antibody to the sperm, as the analogy suggests, this must be based on some substance in the sperm, which acts as antigen, of different chemical composition from the homologous substance of the egg. Why then should not the antibody develop equally well in the body of a hermaphrodite as of a female, seeing that the postulated differences of gametes must hold equally well for both cases? It is obvious that the serum analogy breaks down here, and some new principle must be invoked; for instance, that antigen and antibody do not react with one another if developed in the same body. But this merely restates the old difficulty.

It is obvious that the principles of immunity cannot apply to fertilization in any such sense. All we can hope to utilize from immunity reactions is the fact of the existence of chemical specificities of an equally definite and specialized character. The mechanism must be quite different in the two cases.

3. Discussion.-If we gather together our discussion of specificity in fertilization it will be seen that the stage in which the phenomenon of specificity most commonly manifests itself, whether in the hybrid fertilization of echinoderms, teleosts, and Amphibia or in the phenomena of self-infertility of Ciona, is in the cortical reactions. 
The various methods used to induce hybrid fertilization-staling of eggs, high concentration of sperm, use of alkalies or other chemicals-have therefore this one feature in common, that they destroy the chemical or physical integrity of the cortex of the egg. 'Thus is rendered possible a form of reaction common to all gametes, the inclusion of the spermatozoön within the egg. Specific factors then do not apparently, intervene until after the meeting of the germ nuclei.

If there is indeed a specific factor in the cortical reaction it can hardly be of a purely physical character, though physical factors must be of significance in any case; for the specific factor must include not only the incompatibilities in hybrid fertilization but also those in self-fertilization where the physical resemblance of the gametes excludes a purely physical explanation of the phenomenon. We are therefore forced to the conclusion that there is a chemical specificity, more or less narrow, in the union of the gametes. The only phenomenon in which we can so far detect a closer approach to this problem is that of sperm agglutination by egg secretions.

A warning is in place here against too much reliance on the phenomenon of specific agglutination in the field of immunology by way of comparison. It may turn out that there is a much closer relationship between these phenomena than we can now detect, or they may represent only superficially similar phenomena with the factor of specificity in common, and that only to a certain extent, at present unknown.

We have the very striking fact reciprocal to specificity in fertilization, that spermatozoa, of certain forms 
at least, are agglutinated together by egg secretions of the same species. This phenomenon is definitely tissue specific, as I have already pointed out. At the present time the extent of specificity between species has been inadequately investigated. This subject has been discussed in chapter iv, and it would appear that there may be a sufficient degree of specificity there to account for the specificities in fertilization, with the exception of self-infertility, which has not been investigated from this point of view. The relation of sperm agglutination to the fertilization reaction itself is considered in chapter vii.

While it is by no means certain that specificity in fertilization depends upon specific agglutination of the spermatozoön to the egg, yet I think it must be admitted that the latter phenomenon furnishes an important clue for the further analysis of the problem of specificity in animals. Until this is made, the temptation to speculate further along these lines should better be resisted.

\section{REFERENCES}

BALZER, F.

I910. "Ueber die Beziehung zwischen dem Chromatin und der Entwicklung und der Vererbungsrichtung bei Echinodermenbastarden," Arch. für Zellforschung, Band 5, pp. 497-621.

Bataillon, E.

1906. "Imprègnation et Fécondation," Comptes rendus de l'Acad. des Sci., 'T. I42, pp. I35I-53.

1909. "L’imprègnation hétérogène sans amphimixie nucléaire chez les amphibiens," Arch. fïr Entwickelungsmech., Band 28, pp. 43-48. 
Batalllon, E.

I9I0. "Le problème de la fécondation circonscrit par l'imprègnation sans amphimixie et la parthénogénèse BORN, G. - traumatique," Arch. de zool. exp. et gèn., Sér 5., T. 6.

I 883. "Beiträge zur Bastardirung der einheimischen Anurenarten," Arch. für d. ges. Physiol., Band 32, pp. 453-518. I886. "Biologische Untersuchungen, II," Arch. fiir mikr. Anat., Band 27, pp. I92-27 I.

Castle, W. E.

r896. "The Early Embryology of Ciona intestinalis," Bull. Mus. Comp. Zoöl. Harvard, XXVII, 203-So.

Colton, Harold S.

I912. "Lymnaea columella and Self-Fertilization," Proc. Acad. Nat. Sci. (Philadelphia), LXIV, I 73-83.

Compton, R. H.

I912. "Preliminary Note on the Inheritance of SelfSterility in Reseda odorata," Proc. Cambridge Phil. Soc., XVII.

I9I3. "Phenomena and Problems of Self-Sterility," New Phytologist, XII, I97-206.

Correns, C.

I9I 2. "Selbststerilität und Individualstoffe," pp. I-32 in Festschr. d. med.-naturw. Gsell. zur 84. Vers. deutscher Naturforscher $u$. Acrzte, Münster j. W.

\section{DARWin, Charles.}

I876. Cross- and Self-Fertilization in the Vegetable Kingdom.

Doncaster, L., and Gray, J.

I913. "Cytological Observations on the Early Stages of Segmentation of Echinus Hybrids," Quart. Jour. Micr. Sci., LVIII, 483-5Io.

EAst, E. M.

I9I 5a. "The Phenomenon of Self-Sterility," Am. Naturalist, XLIX, $77-87$.

I9I $5 b$. "An Interpretation of Sterility in Certain Plants," Proc. Amer. Phil. Soc., LIV, 70-72. 
East, E. M., and Parke, J. B.

I917. "Studies on Self-Sterility: I, The Behavior of SelfSterile Plants," Geneties, II, 505-609.

Fischel, Alfred.

I906. "Ueber Bastardierungsversuche bei Echinodermen," Arch. für Entwickelungsmech., Band 22, pp. 498-525.

Fuchs, H. M.

I9I4. See references at end of chapter v.

I9I 5. See references at end of chapter v.

Godlewski, E.

I906. "Untersuchungen über die Bastardierung der Echinidden und Crinoidenfamilien," Arch. für Entwickelungsmech., Band 2o, pp. 580-643.

Gray, J.

I9I3. "The Effects of Hypertonic Solutions upon the Fertilized Eggs of Echinus (E. esculentus and E. acutus)," Quart. Jour. Micr. Sci., LVIII, 447-8I.

Herbst, Curt.

1909. See references at end of chapter $v$.

I9I 2. See references at end of chapter $v$.

Hertwig, G.

I913. "Parthenogenesis bei Wirbeltieren hervorgerufen durch artfremden radiumbestrahlten Samen," Arch. fïr mikr. Anat. u. Entwicklungsgesch., Band 8I, Abt. II, pp. 87 -I 27 .

Hertwig, G. AND P.

I914. "Kreuzungsversuche an Knochenfischen," Arch. fïr mikr. Anat. u. Entwickelungsmech., Band 84, Abt. II.

Hertwig, O.

1913. "Versuche an Tritoneiern über die Einwirkung bestrahlter Samenfaden auf die tierische Entwicklung," Arch. für mikr. Anat. u. Entwicklungsgesch., Band 82, Abt. II, pp. I-63.

HeRtwig, O. AND R.

I885. "Experimentelle Untersuchungen über die Bedingungen der Bastard-Befruchtung," Jen. Zeitschr. fïr Naturw., Band is (N.F. I 2 ), pp. I $2 \mathrm{I}^{-}-65$. 
Hertwig, Paula.

I9I3. "Das Verhalten des mit Radium bestrahlten spermachromatins im Froschei," Arch. fïr mikr. Anat. u. Entwicklungsgesch., Band 81, Abt. II, pp. I73-82.

Jost, L.

ı907. "Ueber Selbststerilität einiger Blüten," Botan. Zeitung., Heft. V und VI, p. I 2.

Kohlbrugge, J. H. F.

I9ro. "Der Einfluss der Spermatozoiden auf die Blastula," Arch. für mikr. Anat. u. Entwicklungsgesch., Band 75.

r9ro-r I. "Der Einfluss der Spermatozoiden auf den Uterus; ein Beitrag zur Telegonie," Zeitschr. fïr Morph. $u$. Anthropol., Band I 2, pp. 359-68; Band r3, pp. I9-30.

I9I2. "Die Verbreitung der Spermatozoiden im weiblichen Körper und im befruchteten Ei," Arch. fïr Entwickehungsmech., Band 35, pp. 165-88.

Kupelwieser, Hans.

1909. "Entwicklungserregung bei Seeigeleiern durch Molluskensperma," Arch. fïr Entwickelungsmech., Band 27 , pp. $434^{-62}$.

1912. "Weitere Untersuchungen über die Befruchtung der Seeigeleier durch Wurmsperma," Arch. für Zellforschung, Band 8, pp. 352-95.

LiLlie, Frank R.

I9I3. See references at end of chapter iv.

Loeb, Jacques.

1903. "Ueber die Befruchtung von Seeigeleiern durch Seesternsamen," Arch. fiir die ges. Physiol., Band 99, p. 323 .

1904. "Further Experiments on Heterogeneous Hybridization in Echinoderms," Univ. of Cal. Pub., Physiology, II, I 5-30.

1912. "Heredity in Heterogeneous Hybrids," Jour. of Morph., XXIII, I-I5.

I9I4. "Ueber den Mechanismus der heterogenen Befruchtung," Arch. für Entwickelungsmech., Band 40, pp. 3IO-2I. 
Loeb, J., King, W. O., And Moore, A. R.

I9I0. "Ueber Dominanzerscheinungen bei den hybriden Pluteen des Seeigels," Arch. für Entwickelungsmech., Band 29, p. 354 .

Maupas, E.

I900. "Modes et formes de reproduction des nématodes," Arch. de zool. exp. et gén., Sér. 3, T. 8, pp. 463-624.

Moenkhaus, W. J.

I904. "The Development of the Hybrids between Fundulus heteroclitus and Menidia notata with Especial Reference to the Behavior of the Maternal and Paternal Chromatin," Am. Jour. of Anat., III, 29-65.

I910. "Cross-Fertilization among Fishes," Proc. of the Ind. Acad. of Sciences, pp. 353-93.

Morgan, T. H.

I904. "Self-Fertilization Induced by Artificial Means," Jour. Exp. Zoöl., I, I35-77.

I905. " "Some Further Experiments on Self-Fertilization in Ciona," Biol. Bull., VIII, 3 з3-30.

I910. "Cross- and Self-Fertilization in Ciona intestinalis," Arch. für Entwickelungsmech., Band 30, pp. 206-35.

I9I3. Heredity and Sex (see chap. vii). New York: Columbia University Press.

MORRIS, MARGARET.

I9I4. "The Behavior of the Chromatin in Hybrids between Fundulus and Ctenolabrus," Jour. Exp. Zoöl., XVI.

Newman, H. H.

1908. "The Process of Heredity as Exhibited by the Development of Fundulus Hybrids," Jour. Exp. Zoöl., V, 505-63.

I910. "Further Studies of the Process of Heredity in Fundulus Hybrids," ibid., VIII, I I3-6r.

I9I4. "Modes of Inheritance in Teleost Hybrids," ibid., XVI, 447-500.

I9I 5. "Development and Heredity in Heterogenic Teleost Hybrids," ibid., XVIII, 5 I I-76. 
PFLÜGER, E.

I882. "Die Bastardzeugung bei den Batrachiern," Arch. für d. ges. Physiol., Band 29, pp. 48-75.

Pflüger, E., ANd Smith, W. J.

I883. "Untersuchungen über Bastardierung der anuren Batrachier und die Principien der Zeugung," ibid., Band 32, pp. 519-8o.

Pinney, Edith.

- i9r8. "A study of the Relation of the Behavior of the Chromatin to Development and Heredity in Teleost Hybrids," Jour. of Morph., XXXI, 225-90.

Potts, F. A.

1910. "Notes on the Free-living Nematodes," Quart. Jour. Micr. Sci., N.S., LV, 433-84.

REYNOLDS, E.

1915. "Prognosis of Sterility," Jour. Amer. Med. Assoc., LXV, I I 5I-56.

Shearer, De Morgan, and Fuchs.

I9I3. "On the Experimental Hybridization of Echinoids," Phil. Trans. Roy. Soc. London, Ser. B., CCIV, 255362 .

Sмгтн, G. W.

1906. Rhizocephala-Fauna und Flora des Golfes Neapel, Mono. No. 29.

Sовотта, J.

I9II. "Ueber das Verhalten der Spermatozoen im Uterus der Säugetiere; nach den Befunden bei Nagetieren," Zeitschr. für Morph. u. Anthropol., Band I3, pp. 20I-8.

Stout, A. B.

1916. "Self- and Cross-Pollinations in Cichorium intybus with Reference to Sterility," Mem. New York Bot. Garden, VI, 333-454.

1917. Fertility in Cichorium intybus; the Sporadic Occurrence of Self-Fertile Plants among the Progeny of Self-Sterile Plants," Amer. Jour. Bot., IV, 375-95. 
Tennent, David H.

I910. "Echinoderm Hybridization," Pub. No. 132, Carnegie Institution, Washington (other references to same author here).

VERnON, H. M.

I900. "Cross-Fertilization among the Echinoidea," Arch. fiir Entwickclungsmech., Band 9, p. 464.

WALDSTEIN UND ECKLER.

I913. "Der Nachweis resorbierten Spermas in weiblichen Organismus," Wiener klin. Wochenschrift, Jahrg. 26, p. I689.

WhitMan, C. O.

I89I. "Spermatophores as a Means of Hypodermic Impregnation," Jour. of Morpli., Vol. IV. 


\section{CHAP'TER VII}

\section{THE PROBLEM OF ACTIVATION}

The egg may be activated, caused to develop, either by fertilization or by various artificial means that produce parthenogenesis. Fertilization involves also the factors of specificity and of heredity, but experimental parthenogenesis deals with activation alone, and by virtue of variety of methods has become a most instructive method of studying this problem.

Two phases of activation are readily distinguished. In the first of these the plasma membrane and cortex of the egg are affected; in the second the internal protoplasm, and finally the nucleus, are affected, leading up to a karyokinctic process, the first cleavage of the egg. The outstanding fact in activation of the egg is that it is a process which begins in the cortex and extends toward the center. Activation is usually considered "incomplete" if it does not terminate in a normal cleavage, but there may be different reasons for such "incompleteness."

\section{ACTIVATION BY THE SPERMATOZOÖN}

The point of vicw from which analysis must begin is the fact, demonstrated by experimental parthenogenesis, that the egg is an independently activable system. The old idea that the spermatozoön supplies organs or substances necessary for activation must therefore be abandoned. The egg possesses all substances 
needed for activation; the spermatozoön is an inciting cause of those reactions within the egg system on which development depends.

It is probable that the spermatozoön starts the activation of the egg before entering, and that penetration of the spermatozoön into the egg is thereby facilitated; penetration of the spermatozoön is not, as such, the cause of activation. In the case of Nereis this is very clearly seen because the spermatozoön remains external for a long time after the egg has given numerous other evidences of activation (see pp. $5^{\mathrm{I}-5^{2}}$ ). Loeb has also shown that in the hybrid fertilization of sea urchin eggs by starfish sperm the egg may in some instances exhibit activation by membrane formation without entrance of the sperm, which is then permanently excluded, as though the time for such form of reaction on the part of the egg had passed. But in most animals the act of inclusion of the spermatozoön within the egg is very rapid, and membrane formation or other cortical changes follow immediately.

The first step in fertilization is a more or less specific binding or agglutination of the spermatozoön to the egg. We have seen that ova of sea urchins and of some other forms secrete a substance that produces an adhesive quality in spermatozoa and causes them to agglutinate (pp. I 2 ff.). In I9 3 I pointed out that "the adhesive property that the sperm develops under these circumstances may be an important factor in binding the sperm to the egg until it can be incorporated," and that this reaction furnished "evidence of an intimate chemical combination of sperm and egg constituents which begins at the very moment of union." 
In the next year I attempted to show that the presence of the agglutinating substance is necessary for activation in the sea urchin, basing the argument upon three classes of facts: (I) Fertilized eggs, which are of course incapable of reactivation, produce no more of this substance, which disappears at the moment of fertilization. (2) Eggs activated by butyric acid, which are incapable of fertilization, likewise produce no more of it. (3) If eggs are subjected to repeated washings their production of this substance gradually declines, and along with it the capacity for fertilization also. To the last point Loeb has objected that the general vitality of the eggs is also declining under these circumstances; while this may be so in the case of the first experiments that I performed, the objection does not apply with equal force to other experiments in which the protecting jelly of the eggs was first removed by shaking before beginning the series of washings; under these circumstances the parallel loss of agglutinating power and of capacity for fertilization went on much more rapidly.

Moore (I9I6) has also found a parallel loss of agglutinating power and of capacity for fertilization in Arbacia by graded butyric acid treatment for parthenogenesis. He has also shown that eggs exposed to a temperature of $35^{\circ} \mathrm{C}$. lose their agglutinating , power and their capacity for fertilization simultaneously. It requires a temperature of about $4 \mathrm{I}^{\circ} \mathrm{C}$. to cause cytolysis in these eggs, and the evidence is that exposure to $35^{\circ} \mathrm{C}$. does not destroy their general vitality; they remain intact for a long period and, if inseminated, are penetrated by the spermatozoa, which, however, 
exert no fertilizing effect. I may refer here also to the data with regard to other animals already presented concerning the fertilizable condition of the ovum (pp. I 39 ff.), which show that the loss of fertilizing power may be exceedingly rapid and certainly not connected with a loss of vitality on the part of the eggs. These data are most readily understood on the assumption of loss of agglutinating substance on the part of the egg.

Just (I9I9b) has found also in the case of Echinarachnius that the production of the sperm-agglutinating substance is an index of the fertilization capacity of the eggs; immature eggs incapable of fertilization produce none of it; ripe eggs washed in sea-water until they no longer give the agglutination reaction are incapable of being fertilized, and during the washing process loss of capacity for fertilization runs parallel to loss of agglutinating substance; fertilized eggs have lost their agglutinating substance, as have those with membranes fully formed artificially. Those eggs that are highest in agglutination capacity fertilize most readily and produce the most vigorous larvae.

The conception that agglutination of the spermatozoön to the egg is a necessary factor in fertilization may be understood in one of two senses: either that such intimate association is needed for the further action of the spermatozoön, whatever that may be, or in the more special sense that the agglutinating substance is also the substance that activates the egg, and that it is set in operation by the spermatozoön. In favor of the latter more special interpretation is the fact that spermatozoa may enter eggs devoid of agglu- 
tinating substance, but in such cases the spermatozoön exerts no fertilizing action whatsoever. Thus unripe eggs of the sea urchin, which contain no agglutinating substance, may be entered by spermatozoa if high concentrations of sperm are used, but no change results in the egg, and the sperm heads remain entirely unchanged within the cytoplasm. The same phenomenon may be observed, as described by Moore (1916), in the case of eggs treated for the optimum length of time for production of parthenogenesis by butyric acid; these eggs are devoid of agglutinating substance, but after removal of the membranes they may be entered by numerous spermatozoa, which are perfectly inert in the egg cytoplasm; nor do the eggs react as would be expected if the sperm carried a "fertilizing substance."

These facts do not, however, definitely prove that the agglutinating substance is the activating substance of the egg, but they at least show that there is a parallel between absence or loss of agglutinating substance and the capacity of the egg for being activated. The same results would be attained if there were two substances concerned, viz., an agglutinating substance and an activating substance, which were produced or lost simultaneously and which interact in the process of fertilization. This is, as I understand it, substantially the position taken by Miss Woodward in her recent study (I9I8); but since the two effects, the spermagglutinating and the egg-activating, appear and disappear together in these instances, the writer assumed that they may be regarded as due to a single complex substance, for which the name "fertilizin" appeared appropriate. 
The writer (19I4) used the phenomenon of inhibition of fertilization by blood of the species in an attempt to approach this problem a little more closely. In Arbacia the presence of a certain concentration of the perivisceral fluid (blood) of certain individuals inhibits fertilization completely. This is not because agglutination is prevented, for the sperm will agglutinate in any concentration of such blood. Neither is it merely a general colloid effect, such as Robertson (1912b) held might inhibit fertilization, because the blood of some individuals has no such action. The writer therefore reasoned that the action of the blood might be directed against the activating substance of the egg; if this were so, and if the activating substance were contained in the secretions of the eggs like the agglutinating substance, it should then be possible to neutralize the inhibiting action of the blood by saturating it with egg secretions, because the inhibiting substance would then be combined. As a matter of fact it was found that blood which is first treated with large quantities of eggs, and which therefore possesses a high agglutinating power, has lost its power of inhibiting fertilization. The inhibiting action of the blood may therefore be regarded as a deviation effect, in the sense that the activating substance in the presence of blood exerts its effect on some constituent of the blood and not on the egg.

This still does not prove that sperm agglutination and egg activation are due to the action of a single substance, but it shows again by a different method that the capacity for producing both effects is present simultaneously in the egg secretion, and the assumption of a single substance is the simplest hypothesis. 
The conception of the mechanism of fertilization resulting from these considerations would thus be that a substance borne by the egg (fertilizin) exerts two kinds of actions, (I) an agglutinating action on the spermatozoön and (2) an activating action on the egg. In other words the spermatozoön is conceived, by means of a substance which it bears and which enters into union with the fertilizin of the egg, to release the activity of this substance within the egg.

Without stopping here to consider this matter in detail let us note how the conception fits the main principles of fertilization. In the first place it is consistent with the major thesis that the egg is an independently activable system; whether the fertilizin is activated by the spermatozoön or in some other way should make no difference, except in a quantitative sense in certain cases, in the development of the egg. In the second place it explains the association of activation of the egg with fertilization. In the third place it explains the prevention of polyspermy, because, as I have shown (p. 237), all free fertilizin is bound in some way at the moment of fertilization; fertilized eggs produce no more of it. The method of binding we shall consider later. In the fourth place it explains why spermatozoa are inert in immature eggs, for these eggs have not yet produced any fertilizin, as I have shown. It is also entirely consistent with the facts of merogonic fertilization as, determined by Delage and Wilson (p. I62). Finally, it furnishes a basis for understanding the problem of specificity, because the agglutination phenomenon exhibits considerable specificity as we have seen, and it is in certain respects analogous to 
immunity agglutination, in which the specific factor is very marked.

Loeb (I9I4, I9I5, I9I6) has raised the following objections to the conception: (I) That the action of the egg secretions on spermatozoa is probably not a true agglutination; an objection that he later withdrew. (2) That the agglutinating substance is derived not from the egg but from the jelly layer surrounding the egg. This also is incorrect, as I have shown in a separate paper (I9I5; cf. also Just, I9I9). (3) That eggs deprived of their jelly by acid produce no more fertilizin and yet are capable of fertilization. I have shown (Lillie, I9I5) that they do produce fertilizin as long as they remain fertilizable. (4) That eggs of sea urchins activated by butyric acid and hence devoid of fertilizin are yet fertilizable. This objection has been fully discussed already (pp. I6 $5^{-67}$ ). (5) That agglutination is sometimes absent in hybrid fertilization; thus specifically "the supernatant sea-water of Strongylocentrotus franciscanus will not induce cluster formation [i.e., agglutination] of the sperm of S. purpuratus; yet the latter sperm fertilizes the eggs of franciscanus."

The last objection requires some consideration. Agglutination of sperm is merely an indicator of the presence of a certain substance which is none the less present in $S$. franciscanus, as proved by agglutination of its own sperm, even if $S$. purpuratus sperm does not reveal it; it may nevertheless be activated by $S$. purpuratus sperm, and this is all that the theory requires. The phenomenon of agglutination of sperm with each other is not of the least significance as such in fertilization, which consists in the union of a single spermato- 
zoön with the egg. It is a useful indicator that enables us to make certain analyses, but the same principle of fertilization may hold in the entire absence of sperm agglutination. The spermatozoön is modified in the presence of egg secretions of the same species, by union of a substance in the spermatozoön (agglutinable substance) with a substance in the egg secretion (agglutinating substance or fertilizin). If this union renders the sperm heads adhesive, and if the spermatozoa are sufficiently concentrated and motile, they will agglutinate together, otherwise not. But a degree of adhesiveness insufficient for sperm agglutination may be quite adequate for agglutination of the sperm to the egg. As pointed out in chapter vi the quantitative aspect of specificity in fertilization requires much more study, and Loeb has given no quantitative data for the hybrid fertilization in question.

Loeb (I9I5, p. 279) misrepresents the view here developed when he says that the writer has called the egg an antigen, the spermatozoön a complement, and the fertilizin an amboceptor. Such a view is not even implied in anything I have ever written. What I did was to utilize Ehrlich's method of formulating such a three-body reaction for a pictorial representation of what happens in the fertilization of the egg. The inference from the diagram given (Lillie, I9r4, p. 579), on a strict comparison with Ehrlich's conception of haemolysis, would be that a substance borne by the sperm corresponds to the antigen, the fertilizin to the amboceptor, and a substance contained in the egg corresponds to the complement. But it was not suggested that these relations were established by an immunity 
reaction. Only once, and then in a footnote of a paper of earlier date than the one dealing with the mechanism of fertilization, have I alluded to the question whether fertilization may be regarded as involving an immunity reaction (1913, p. 563); the footnote follows: "In the latter case, fertilization itself would have to be regarded as an immunizing process, the sperm acting as antigen after entrance with the egg. It seems, in fact, an almost necessary conception of the general principles of immunity phenomena that the sperm should so act. The question would be, of course, whether there is a connection between any antibodies so formed and the sperm iso-agglutinins produced by the next generation of ova."

Loeb has reversed these relations. However, I would point out again that no comparison to immunity phenomena was made in the fertilizin hypothesis: an analogous pictorial method of representation was adopted, and only that.

Another misunderstanding on Loeb's part is to regard the theory as dealing with the egg and spermatozoön as cells, which, as he well says, are not simple organic compounds. I was always careful to speak of "sperm receptors" borne by the spermatozoön and "egg receptors" borne by the egg as the substances, not otherwise known, concerned in the activation of the egg, together with the fertilizin. They are linked in line thus: sperm receptors-fertilizin-egg receptors, and not directly, as sperm receptors / fertilizin egg receptors because the sperm receptors are able to bind the fertilizin in the absence of the egg receptors but are unable to 
bind the egg receptors (as shown by failure of activation) in the absence of the fertilizin.

Let us return to the fact that fertilized eggs produce no more fertilizin. This is certainly a very remarkable circumstance, because prior to fertilization in the case of the sea urchin they produce it in such abundance as to charge many hundreds of times their own bulk of sea-water with easily detectable quantities. Immediately after fertilization this ceases, and the eggs no longer react to spermatozoa. Are we to conceive that the eggs excrete it all in connection with the cortical changes that take place at the same time? Or is it in some way combined so as to be no longer active? In favor of the latter point of view is the fact that the internal substance of the eggs is capable of neutralizing the sperm-agglutinating action of fertilizin (Lillie, 19r4). This can be shown by cytolyzing eggs deprived of their jelly in distilled water and thus extracting the interior substances; the aqueous extract has at first a powerful agglutinating effect, which, however, disappears entirely in the course of a few hours, whereas the fertilizin secreted by living eggs may last for months. Again, if eggs are repeatedly washed for about forty-eight hours until their production of fertilizin is very much reduced, and are then shaken to pieces in the sea-water containing the fertilizin which they themselves have secreted, the fertilizin present before the shaking is neutralized. I explained this by supposing that eggs contain in their interior a substance capable of combining with the agglutinating group of the fertilizin, but which is separate from it as long as the egg is inactive; this substance I called anti-fertilizin. I therefore proposed the 
hypothesis that fertilization causes this union to occur in the egg, and hence, owing to such binding of the agglutinating side chain of the fertilizin, no sperm reaction is possible.

It will be noted that no postulate is made concerning the mechanism of action of fertilizin on the egg. It is necessary that the substance be present within the cortex of the egg; if it is once lost, fertilizing power goes with it. It operates in the cortical changes of fertilization, for such changes are absent if the substance be removed; it is therefore necessary also, at least indirectly and possibly directly (see p. 265), for the internal changes. The suggestion that the fertilizin may act as a catalyzer is perhaps supported to a certain extent by Richards and Woodward's (1915) determination of some enzyme analogies of this substance. The suggestion is in any event a natural one, as is shown by the rather numerous suggestions in the literature concerning the connection between activation and enzyme action.

Miss Woodward (1918) agrees that fertilizin is necessary for fertilization: eggs of Asterias and Arbacia, from which it has been washed, will not fertilize, but if secretion (fertilizin) be added to such eggs before insemination they will fertilize. The latter observation outruns the determination of the present writer and obviously constitutes a very critical point. The dual nature of fertilizin is shown by its action in agglutinating spermatozoa and by the production of parthenogenesis in eggs of the same species when concentrated on them. Such autoparthenogenesis was first described by Glaser (I9I4c). The writer is not convinced that 
the action of the secretion in this phenomenon is specific, but it obviously deserves attention. This dual action of the egg secretion (fertilizin) is due in Miss Woodward's opinion to two distinct substances, which may be obtained separately by appropriate chemical treatment. The one of these is a sperm agglutinin, the other is a parthenogenetic agent. The latter has fat-dissolving properties, and is assumed to be a lipase, for which the name "lipolysin" was adopted. It has no agglutinating action on the sperm but is a very efficient parthenogenetic agent.

Miss Woodward then proposes a theory of activation in the following terms: "The resting egg contains enzymes which control metabolism, unsaturated fatty acid which inhibits enzyme action, and lipolysin, which reacts with the unsaturated fatty acid to make it innocuous." Activation is then caused by any method that increases the ratio of activating enzymes to fatty acid, such as increase of lipolysin, which destroys the fatty acid, or the action of fat solvents, which produce the same effect directly. It is difficult to see how the spermatozoön can act in any such sense. The theory does not bring together fertilization and parthenogenesis. The rôle of the sperm-agglutinating component of the egg secretion is also left out of account.

This author thus agrees with the writer with reference to the necessity of fertilizin and with reference to its dual capacity, agglutinating the sperm and activating the egg. She believes, however, that two separate substances, not merely two separate side chains of one substance, as the writer supposed, are concerned 
in these effects, and she has worked out a theory of the activating effect which is entirely original. This theory does not explain why the spermagglutinating and the egg-activating properties of egg secretion always go together, as Miss Woodward has herself emphasized in various places in her paper; when the egg ceases to produce the sperm-agglutinating substance it has lost its capacity to be activated. These two properties of the egg secretion hang together normally; their separation under the conditions of chemical analysis may possibly denote a splitting of a single substance of the normal egg.

\section{EXPERIMENTAL PARTHENOGENESIS}

The determination of the existence of a substance in the egg necessary to fertilization obviously does not show in what way activation results. We shall therefore consider the problem of activation from the point of view of experiments in parthenogenesis, often too hopefully called the physicochemical standpoint. The books of Loeb (1913) and Delage and Goldsmith (19г3) treat this subject in detail. We shall confine ourselves to certain outstanding facts and theories of experimental parthenogenesis. In considering these it should be borne in mind that, though the number of forms in which parthenogenesis has been experimentally induced is large, in another considerable number of forms successful methods have not been found; e. g., in the entire vertebrate phylum, with the single exception of the frog. This may be due to secondary conditions of the problem in such cases, or it may be due to failure to reach a correct analysis of the successful results. 
Loeb (1916) holds that the essential feature in the activation of the egg, whether by fertilization or parthenogenesis, is the change underlying membrane formation, which he conceives to be cytolysis of the superficial or cortical layer of the egg. His reason for the latter conclusion is that "all those substances and agencies which are known to cause cytolysis or hemolysis will also induce membrane formation." They are listed as follows: (I) fatty acids; (2) saponin or solanin or bile salts; (3) lipoid solvents, e.g., benzol, toluol, ether, chloroform, etc.; (4) bases; (5) hypertonic or hypotonic solutions; (6) rise in temperature; (7) certain salts, e.g., $\mathrm{BaCl}_{2}$, $\mathrm{SrCl}_{2}, \mathrm{NaCNS}$; (8) the blood serum or cell extracts of certain foreign species. Loeb states that in the case of the sea urchin egg such agents, used so as to restrict the cytolysis to the cortical layer, will cause membrane formation. Rise in temperature has, however, so far been ineffective in the case of the sea urchin egg, though very effective in the starfish and in Nereis. In the case of other eggs again, none of these methods is effective.

In the sea urchin the development does not proceed to cleavage by action of the single agent, except in the case of hypertonic solutions, but a second agency is required to bring about further development. Hypertonic sea-water is the second agent most commonly employed; this when used for the proper length of time insures subsequent normal development. Loeb therefore states that the action of the first agent leaves the egg in a sickly condition, and the action of the second agent is required to save the life of the egg. It is a corrective agent remedying an unavoidable excess of action of the first agent. 
In the case of the starfish, however, action of butyric acid alone is sufficient for complete development; a corrective agent is not required.

If now we ask what is the nature of the postulated cytolysis, and how it activates the egg, Loeb replies that the cytolysis can be explained by assuming that a calcium lipoid compound forms a continuous layer under the surface of the egg; the solution of such a lipoid layer might result in the destruction of a cortical emulsion. It then becomes necessary to assume a catalyzer to explain the increase in rate of metabolism within the egg, and Loeb therefore suggests, following Warburg (I9I4), that the cytolysis, by breaking down the cortical emulsion, releases the catalyzer, assumed to be contained in the cortex, for action on the substrate. Increase in oxidations results, together with certain synthetic processes. Activation of the egg therefore comes down to the release of a catalyzer; cytolysis is simply the means by which this end is attained.

The above is the barest possible sketch of Loeb's theory and gives no idea of the numerous experiments carried on year after year since the time of his original discovery of the phenomenon of artificial parthenogenesis in 1899 . To get an idea of the wealth of experimental data underlying Loeb's analysis the reader must refer to Loeb's own publications, for a brief account to The Organism as a Whole (G. P. Putnam's Sons, I9I6), and for a fuller account with numerous references to original papers to Artificial Parthenogenesis and Fertilization (The University of Chicago Press, I9г3). 
The fact that agents and conditions capable of producing cytolysis may cause membrane formation in the sea urchin egg merely shows that cytolysis may be a subsidiary factor in the activation effect. But that cytolysis is a more fundamental factor is proved, according to Loeb, by the fact that the eggs exposed so as to produce membranes die by cytolysis later, unless saved by a second process. However, any activated egg not developing normally cytolyzes sooner or later from internal causes. Is the death of the eggs not given a second treatment due to cytolytic action of the agent or to some internal cause resulting from activation?

The latter alternative seems to be demonstrated by the cytological examination of eggs treated according to Loeb's method, which has been made especially by Herlant (I9г7; see also Hindle, г9го). The eggs treated by butyric acid alone live for from twelve to twenty-four hours before cytolysis begins. What happens during all this time? After the formation of the membrane and the appearance of the hyaline zone at the cortex the cortical changes cease, and the nucleus becomes the center of activity, increasing in size and moving toward the center of the egg. The nuclear membrane then disappears and a monaster develops around the group of chromosomes formed from the egg nucleus. But no amphiaster forms, and though the chromosomes divide they do not separate in two groups. This occurs in about $\mathrm{I} \frac{3}{4}$ hours at $15^{\circ} \mathrm{C}$., according to Herlant. At the same time the cytoplasm becomes active, but no division takes place. The chromosomes return to the condition of a resting nucleus; a second monaster then appears. This process 
is repeated at least four or five times, the nucleus all the time increasing in bulk. The phenomena then become less regular but still continue to be rhythmical, and no cleavage results.

The activated egg, thus unable to divide, spends its energy in these fruitless ways and ultimately breaks down or cytolyzes, as does any sufficiently abnormally directed egg.

How does the second treatment with hypertonic sea-water save the life of the egg? Briefly, it does this by giving the egg the capacity for regular division and thus directing the energies of the egg into normal channels. Morgan (1896, 1900) and Wilson (r901), among others, had long ago noted that unfertilized eggs of sea urchins react to hypertonic sea-water by forming asters apart from the nucleus. Herlant has shown that one of these cytoplasmic asters, together with the monaster associated with the egg nucleus, form an amphiaster which initiates regular division of the egg nucleus. From this time on everything moves normally.

It is therefore clear that the changes underlying membrane formation do not involve progressive cytolysis; it is the processes of activation aroused by the cortical changes that are responsible for the final death of the egg in the absence of proper co-ordination of nuclear and cell division. It is therefore very doubtful that the changes underlying membrane formation itself should be regarded as cytolytic, unless by extension of the usual meaning of the term "cytolysis." The nature of the cortical changes underlying membrane formation seem to the writer still to be obscure, but it is inadvisable to use a term with a purely pathological 
connotation for a process that occurs in normal fertilization.

Loeb also postulates a similar mechanism for fertilization. To make the parallelism between fertilization and parthenogenesis complete, Loeb emphasizes the fact that the sperm may cause membrane formation without entering the egg, but that, as in the case of artificial membrane formation alone, development goes no farther. Thus fertilization exhibits two phases which Loeb compares to the cytolytic action and the corrective action in his method of artificial parthenogenesis. It is true that any genetic process admits of division, and we have seen in discussing partial fertilization that the action of the spermatozoön may be stopped, not only at the moment of penetration, but at any time thereafter. Such a parallelism between parthenogenesis and fertilization would hold for any theory of activation.

Loeb also holds that the spermatozoön carries a substance (lysin) into the egg which effects an alteration of its surface layer, apparently of the nature of a cytolysis (гі6, p. г 10). If this were so, it would follow that two or more spermatozoa would increase the cortical changes above the normal, but this is not the case; from which it follows that the cortical changes result from action of the egg itself. With reference to the cortical changes, as with reference to the later phases of fertilization, the spermatozoön is merely an activator, and this is why under optimum conditions the egg does not respond more energetically to an excess of sperm than to a single one.

Attempts to isolate a cytolytic substance from spermatozoa have signally failed, as we have seen (p. I33), 
in their purpose of securing a substance that will act on eggs of the same species. But on the other hand watery extracts of sperm may be highly cytolytic to ova of other species, especially of different classes or phyla; there is, however, no tissue specificity in this, for blood or tissue exudates may have the same effect. It is therefore obvious that we must accept the negative result within the species as showing that cytolysins borne by the sperm have no cytolytic function in normal fertilization; they act only on foreign species.

Loeb's theory is based mainly on the study of the sea urchin. However firm may be our conviction that the fundamental phenomena of activation must be the same throughout the animal kingdom, yet we must not fail to realize that each species will show its own peculiar aspects. In the case of the sea urchin one of these is the sharp separation between the two stages on which Loeb lays so much emphasis. In most other forms, e.g., starfish, annelids, frog, the activation process appears continuous, though capable of arrest at various stages. In the case of the frog, however, Herlant (I913) has shown that a separation of two phases similar in principle to that of the sea urchin may readily be recognized.

R. S. Lillie (1908, 1915) has examined certain quantitative aspects of activation with much greater precision in the case of the starfish, and from such determinations different points of view naturally arise. He has determined that definitely timed exposures to supranormal temperatures constitute an almost perfect method for producing parthenogenesis in the starfish. This is the simplest possible method of studying the 
subject, for it is not complicated by the presence of any unusual substance. The action may be varied as to both degree of temperature and period of action. A third variable factor is the age of the eggs after placing in sea-water; the only necessary statement in the last connection is that the eggs of the starfish carry out their entire maturation in sea-water, and that action of increased temperature before the germinal vesicle has broken down is not only ineffective but actually detrimental to the subsequent viability of the eggs. The condition of the eggs then gradually improves for about an hour at the ordinary temperature of the seawater until the time of formation of the first polar body, and from this optimum point the eggs deteriorate. The curve of condition for parthenogenesis coincides with the curve for fertilization, as Delage (I90Ia) first showed.

The method of experiment is to expose eggs in their optimum condition to the temperature to be tested by transferring to sea-water at the desired temperature, and then to transfer samples back to sea-water at normal temperature $\left(19^{\circ}-2 \mathrm{I}^{\circ} \mathrm{C}\right.$.) at stated intervals. The eggs undergo no visible changes in the heated sea-water, but react when transferred to the normal temperature. The following tables (p. 248) showing the results at $3 \mathrm{I}^{\circ} \mathrm{C}$. and $32^{\circ} \mathrm{C}$. will suffice for the discussion.

The first table shows three separate experiments at $3 \mathrm{I}^{\circ} \mathrm{C}$. and two determinations for each experiment: the percentage of eggs forming membranes and the percentage developing to larvae; the second table shows six experiments at $32^{\circ} \mathrm{C}$. with only the latter determination. The following points should be noted: (r) That 
the percentage of eggs developing to larvae may be as high by heat parthenogenesis as by fertilization, for

\section{$3 \mathrm{I}^{\circ}$ C. THREE EXPERIMENTS}

\begin{tabular}{|c|c|c|c|c|c|c|}
\hline \multirow{3}{*}{$\begin{array}{l}\text { DURATION } \\
\text { OF EXPO- } \\
\text { SURE IN } \\
\text { MINUTES }\end{array}$} & \multicolumn{5}{|c|}{ Percentages of Eggs Forming Fertilization-Membranes } & AND LARVAE \\
\hline & \multicolumn{2}{|c|}{ Experiment I } & \multicolumn{2}{|c|}{ Experiment 2} & \multicolumn{2}{|c|}{ Experiment 3} \\
\hline & Membranes & Larvae & Membranes & Larvae & Membranes & Larvae \\
\hline $\begin{array}{l}1-2 \ldots \ldots \\
2 \frac{1}{2} \ldots \ldots \\
3 \ldots \ldots \\
3 \frac{1}{2} \ldots \ldots \\
4 \ldots \ldots \\
5 \ldots \ldots \\
6 \ldots \ldots \\
8 \ldots \ldots \\
10 \ldots \\
12 \ldots \\
14.15 \ldots \\
17-18 \ldots \\
20-21 \ldots \\
25-30 \ldots\end{array}$ & 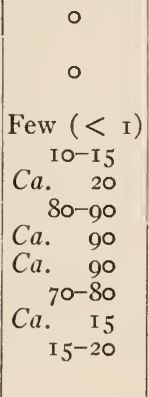 & 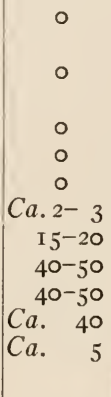 & 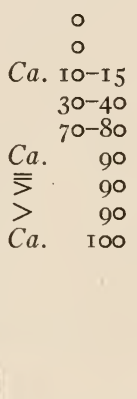 & $\mid \begin{array}{c}C a . \mathrm{I} \\
20-30\end{array}$ & 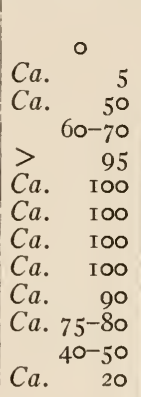 & 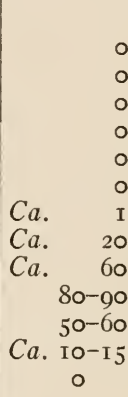 \\
\hline
\end{tabular}

$32^{\circ}$ C. SIX EXPERIMENTS

\begin{tabular}{|c|c|c|c|c|c|c|}
\hline \multirow{2}{*}{$\begin{array}{l}\text { DURA- } \\
\text { TION OF } \\
\text { EXPO- } \\
\text { SURE IN } \\
\text { MINUTES }\end{array}$} & \multicolumn{6}{|c|}{ Percentages of Eggs Forming Free-Swimming Larvae } \\
\hline & Exp. I & Exp. 2 & Exp. 3 & Exp. 4 & Exp. 5 & Exp. 6 \\
\hline $\begin{array}{l}\text { I-3 } \ldots \\
4 \ldots \ldots \\
5 \ldots \ldots \\
6 \ldots \ldots \\
7 \ldots \ldots \\
8 \ldots \ldots \\
10 \ldots \\
\text { 1 } 2 \ldots \\
15 \ldots\end{array}$ & 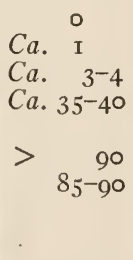 & $\begin{array}{c}<{ }^{0} \\
2-3 \\
20-30 \\
70-80 \\
C a . \quad 95 \\
50-55 \\
15^{-20} \\
0\end{array}$ & 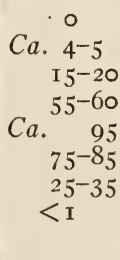 & $\begin{array}{l}0 \\
2-3 \\
25-35 \\
60-70 \\
\sum 90 \\
\sum 90 \\
50-60\end{array}$ & 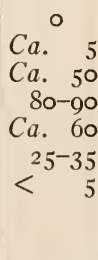 & $\begin{array}{c}0 \\
0 \\
10-15 \\
25-35 \\
50-60 \\
80-90 \\
80-90 \\
\text { Ca. } \quad 20\end{array}$ \\
\hline
\end{tabular}

it is rare to secure $80-90$ per cent developing larvae by fertilization with this material. (2) A short exposure may cause membrane formation with no subse- 
quent development (see the first table above). (3) In each experiment the percentage of reacting eggs increases with time of exposure to an optimum and then decreases. (4) The optimum time for production of larvae at $3 \mathrm{I}^{\circ}$ is $\mathrm{I} 4$ to $\mathrm{I} 5$ minutes; at $32^{\circ}$, from 6 to 8 minutes; that is, the rate of the activation reaction is approximately doubled by a rise of $\mathrm{I}^{\circ}$ in temperature. At $33^{\circ}$ the optimum exposure is about $4 \frac{1}{2}$ to $5 \frac{1}{2}$ minutes; at $34^{\circ}, 3$ to 4 minutes; at $35^{\circ}, \mathrm{I} \frac{1}{2}$ to .2 minutes; and at $36^{\circ}$, I to $\mathrm{I} \frac{1}{4}$ minutes.

The range of effective temperatures is from about $29^{\circ}$ to $38^{\circ}$. The following table shows the time variations for various effects within this range:

APPROXIMATE TIMES OF EXPOSURE REQUIRED TO PRODUCE THE FOLLOWING EFFECTS AT DIFFERENT TEMPERATURES

\begin{tabular}{|c|c|c|c|c|}
\hline $\begin{array}{l}\text { Tempera- } \\
\text { ture }\end{array}$ & $\begin{array}{l}\text { Formation of } \\
\text { Membranes }\end{array}$ & $\begin{array}{l}\text { Minimum for } \\
\text { Larvae }\end{array}$ & $\begin{array}{l}\text { Optimum for } \\
\text { Larvae }\end{array}$ & $\begin{array}{l}\text { Maximum for } \\
\text { Larvae }\end{array}$ \\
\hline $\begin{array}{l}29^{\circ} \ldots \ldots \\
30^{\circ} \ldots \ldots \\
31^{\circ} \ldots \ldots \\
32^{\circ} \ldots \ldots \\
33^{\circ} \ldots \ldots \\
34^{\circ} \ldots \ldots \\
35^{\circ} \ldots \ldots \\
36^{\circ} \ldots \ldots \\
37^{\circ} \ldots \ldots \\
38^{\circ} \ldots \ldots \\
\end{array}$ & 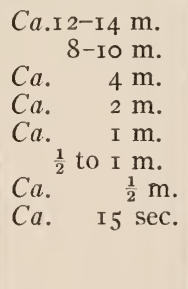 & $\begin{array}{r}20-25 \mathrm{~m} . \\
\mathrm{Ca} . \mathrm{I} 8 \mathrm{~m} . \\
\mathrm{Ca} .8 \mathrm{~m} . \\
4-5 \mathrm{~m} . \\
2^{2}-3 \mathrm{~m} . \\
\mathrm{Ca} .2 \mathrm{~m} . \\
\mathrm{I}-\mathrm{I} \frac{1}{4} \mathrm{~m} . \\
30-45 \mathrm{sec} .\end{array}$ & $\begin{array}{rr} & 30-40 \mathrm{~m} . \\
\mathrm{Ca} . & 28 \mathrm{~m} . \\
\mathrm{Ca} . & \mathrm{I} 5 \mathrm{~m} . \\
7-8 \mathrm{~m} . \\
4 \frac{1}{2}-5 \frac{1}{2} \mathrm{~m} . \\
3-3 \frac{1}{2} \mathrm{~m} . \\
\mathrm{I} \frac{1}{2}-2 \frac{1}{2} \mathrm{~m} . \\
\mathrm{I}-\mathrm{I} \frac{1}{4} \mathrm{~m} . \\
30-35 \mathrm{sec} . \\
\mathrm{Ca} \quad 20 \mathrm{sec} .\end{array}$ & $\begin{array}{lr}\text { ?> } 30 \mathrm{~m} . \\
2 \mathrm{I}-25 \mathrm{~m} . \\
\mathrm{IO}-\mathrm{I} 2 \mathrm{~m} . \\
8-10 \mathrm{~m} . \\
\mathrm{Ca} . \quad 5 \mathrm{~m} . \\
\mathrm{Ca} . & 3 \mathrm{~m} . \\
\mathrm{Ca} . & 2 \mathrm{~m} .\end{array}$ \\
\hline
\end{tabular}

Commenting upon the process underlying the time variation at the different temperatures, R. S. Lillie says:

In endeavoring to form some consistent conception of the nature of this process, the following facts have to be considered. It exhibits a high temperature coefficient: from fifteen to twenty times the duration of exposure is required to induce 
the membrane-formation at $30^{\circ}$ as at $35^{\circ}$; the ratios between $29^{\circ}$ and $34^{\circ}$ and between $31^{\circ}$ and $36^{\circ}$ are the same. At each temperature the proportionate durations of the minimum, optimum, and maximum exposures for forming larvae are approximately the same. In other words the critical change underlying simple membrane-formation is affected by temperature in the same way as that underlying complete activation of development: i.e., the proportionate increase in velocity by rise of temperature is the same in both cases, a fact which can only indicate that one fundamental process-and not two-is concerned in producing both effects. If we assume that the foregoing proportionate increase in velocity prevails through a rise of $10^{\circ}$, a $Q_{10}$ value of from 225 to 400 is indicated, as against the 2 to 3 characteristic of chemical reactions in homogeneous media. Activation by heat thus depends on some critical change in the egg which does not begin until a temperature of about $29^{\circ}$ is reached, but which undergoes very rapid acceleration with further rise of temperature. The liquefaction of gels by heat seems to be the only relevant process which shows these characteristics. The change in viscosity preceding the gelation of a gelatine sol undergoes very rapid acceleration with lowering of temperature, within a few degrees of the temperature of gelation. The inverse process, melting of gels, has a similarly high temperature coefficient. In general the facts suggest that the direct effect of the high temperature is to cause a change in the colloidal system of the egg, of such a kind as to render possible a chemical interaction between substances which in the normal condition of the resting egg are kept apart. This restraining condition may be some physical barrier like a membrane, impermeable to the diffusion of the substances concerned, or it may be a certain state of electrical polarization of the general cell-surface.

Two other important facts in the experiments of this author should also be stated: (I) It is possible to arrest the progress of the activation process by returning the eggs to sea-water at normal temperature, and to cause a renewal later by restoring the tempera- 
ture, and this without interfering with the effect. (2) Precisely similar quantitative relations obtain when the same kind of eggs is activated by butyric acid at normal temperatures, the variables being concentration and time in this case; and moreover it is possible to complete an incomplete action of either temperature or butyric acid by action of the other. There can thus be no doubt that the processes of activation are the same by these two methods.

R. S. Lillie's conclusion is that the fundamental "releasing" process in activation of the egg cannot possibly depend on simple acceleration of some chemical process, such as oxidation, for the temperature coefficient of such processes is of the order $Q_{10}=2-3$, instead of 200-400. There is some change in the nature of degelation or decrease of viscosity in the cortical layer which presumably allows substances to come together and interact which in the condition of the cortex of the unfertilized egg are kept apart. The extent of the following development will depend on the degree of completion of this process. This is of course consistent with the idea of various authors that the cortical changes release a specific catalytic action; but R. S. Lillie's measurements of the releasing change give us a much better idea of these changes than we have previously had.

Other theories of activation.-The veteran French experimental zoölogist Yves Delage (1908 and I9I3; earlier references here) has propounded a theory based upon the conception that the phenomena of cell division depend on a reversible series of gelations and degelations in the protoplasm, changes from gel to sol and 
vice versa, which he proposes to call the theory of colloidal morphogenesis. There is no doubt, as we have previously seen (p. I 53), that such changes are involved in cell division and hence in the phenomena of activation that initiate the first division of the egg. But it seems to the writer that in the series of events of activation these changes do not come first-that they are effects rather than causes of activation. Delage is so conscientious a critic of his own theory, which he says attributes an undemonstrated rôle to intrinsic forces of the egg, viz., of determining other phenomena than those directly dependent on the action of the reagents, that any other critic must be disarmed. The conception is, however, of great historical interest at least, and it led Delage to discover one of the best methods yet devised for activation of sea urchin eggs. A short account of it is therefore desirable.

Delage regards the "first event" (membrane formation), which precedes the segmentation of the egg, as a coagulation; "the second event" (disappearance of the nuclear membrane) as a liquefaction. He thus came to the conclusion that if a coagulative effect could be produced in the unfertilized egg by one reagent, and if this were followed by a liquefactive effect produced by another reagent, development of the egg might be induced. Regarding acids in general as coagulating agents and alkalies as liquefying agents, he was led to try the effect of successive action of acids and alkalies on unfertilized eggs of the sea urchin. The application of this method to eggs in sea-water was without success, but it yielded very beautiful results in hypertonic sea-water. Tannin was finally selected 
as the best acid reagent, as it appeared to possess a particularly strong coagulative effect; ammonia was used . as alkali. He still found, however, that the method did not succeed in sea-water, and finally, for reasons that need not be considered, adopted a mixture of 70 per cent sea-water and 30 per cent of a solution of saccharose estimated to have the same osmotic pressure as the sea-water. To 50 c.c. of this mixture he added twenty-eight drops of a "decinormal" solution of tannin; the eggs were placed in and left five to six minutes; then thirty drops of $N /$ Io solution of ammonia were added to neutralize the acid and to render the mixture slightly alkaline. After an hour the eggs were washed and allowed to develop in sea-water. Delage states that as many eggs may develop by this method as by fertilization, and he even raised some larvae through metamorphosis.

The method is thus very complex and inevitably suggests the question whether it acts according to the theory of causing a coagulation followed by a liquefaction. Miss Lloyd (I9I4), working under Loeb's direction, has made an analysis of this method. She points out that the sugar solution employed was strongly hypertonic as compared with sea-water and showed that the tannic acid is not necessary. The tannic acid employed by Delage was really a I/6o molecular solution, according to later views of its molecular structure, instead of "decinormal," as Delage supposed, and hence the ammonia added renders the solution strongly alkaline. The activation is therefore attributed by this author to the hypertonic action of sugar solution combined with the strong alkaline reaction of the medium, both of which 
Loeb has shown to be effective activating factors in the sea urchin.

Authors who have attributed a directly activating effect to changes in the physical state of the colloids of the egg are Fischer and Ostwald (1905) and Heilbrunn (I9I5); the latter author's results have been reviewed previously (p. o). The view that he maintains is "that the only physico-chemical effect which all parthenogenetic agents possess in common is the production of a gelatinization (or coagulation) within the egg. Hence I regard this gelatinization (or coagulation) as the direct cause of the initiation of development" (1915, p. I9i). In what sense, however, coagulation may be considered to activate the egg is by no means clear; the only demonstrable connection is between coagulation and cell division, but the coagulation involved there is strictly localized (p. ০০o) and not general. For the process of membrane formation itself Heilbrunn (1913) has a different explanation, viz., that it is produced by a lowering of the surface tension of a pre-existing membrane, which is then pushed away from the egg by the internal forces which previously balanced its greater tension. It is only by regarding membrane formation as a mere epiphenomenon that the subsequent coagulation can be treated as a primary activating factor. However, the phenomenon of the primary cortical change is too general to be treated in this fashion, and its character in different animal groups is too varied for it to be a mere phenomenon of decrease of surface tension. The egg activated by a spermatozoön also coagulates in the same sense, as Heilbrunn has shown by his measurements, but Heilbrunn does not maintain that the sperma- 
tozoön introduces a coagulating agent; the coagulation is not the cause but a result of activation.

It must already be obvious that it is difficult to settle the question of priority of incidence of the physical and chemical changes involved in the activation of the egg. A second difficulty equally great is to show how these changes intervene in the physiological events of activation, and a third is to show how the morphological sequence results as a consequence of physicochemical and physiological events. But these are absolutely general biological problems, and the subject of activation of the egg is probably as far advanced with respect to them as any other biological problem, in some respects more so. Investigation will naturally follow these three directions more or less separately and simultaneously. But a view that does not respect all three fields will necessarily be partial and incomplete.

The discussion of parthenogenetic activation would be too incomplete if it did not include an account of Bataillon's brilliant success (I9I0) in producing parthenogenesis in the frog, and of the analysis of the results by Bataillon and other investigators. As is well known, this worker after years of vain attempts to induce the development of frogs' eggs by parthenogenesis finally succeeded by the exceedingly simple method of pricking them with a fine needle. This result has been confirmed by Dehorne (I9I I), Henneguy (I9II), Brachet (I9I I), Loeb and Bancroft (I9I3), McClendon (I9I2), and Herlant (I9I3, I9I7). As a matter of historical justice it should be mentioned that this result was foreshadowed by Guyer (1907) in his remarkable experiments of injecting blood into frogs' eggs, by which some development 
was initiated. In a careful analysis of his own results Bataillon showed that for complete activation by pricking it was necessary that blood or tissue extract should be carried into the egg by the needle; otherwise the development was arrested without cleavage. Herlant (I9I3, I9I7) has confirmed this and has furnished a simple cytological explanation of the result: Eggs that are pressed from the body of the uninjured frog and pricked with a clean needle complete maturation and form a small first segmentation spindle so near the center of the egg that its division produces no effect on the cytoplasm of the egg, which remains undivided. But if the eggs be moistened by blood before pricking, asters arise in the cytoplasm at the point of pricking, and by extension so affect the first segmentation spindle that it remains relatively near the surface of the egg. The division of this spindle then involves that of the egg cytoplasm also, and development proceeds normally. Tadpoles obtained by pricking have been reared to maturity by Loeb and Bancroft.

This method points to some very simple physical change of the cortex as the primary event in activation. Bataillon believed that the cortical change, which he spoke of as a contraction of the egg, involved an excretion of fluid containing substances such as $\mathrm{CO}_{2}$ that inhibited development.

It is significant that recent studies in parthenogenetic activation (Loeb, R. S. Lillie, Bataillon) point to changes in the cortical zone of the egg protoplasm as the primary factor in activation. While the precise nature of these changes still remains obscure, it seems obvious that their effect is to release reactions within 
the cortical zone that were previously inhibited (Loeb, R. S. Lillie). It is natural then to associate the rising rate of metabolism with catalytic action, as Loeb has done. But it should be borne in mind that this is hypothetical, for such a reaction has not been demonstrated. It is then supposed that, when these reactions have been released, the complex mechanism of the egg is set in action; but if the initial reaction is quantitatively incomplete, or otherwise imperfect, the mechanism stops sooner or later, owing in some cases perhaps to too slow a rate, in other cases certainly to lack of co-ordination. Such conditions are in some cases susceptible of adjustment by secondary treatments, as we have seen.

\section{DISCUSSION}

I. The cortical changes.-Eggs that are artificially activated always exhibit a marked slowness in rate of development, even with the best methods, as compared with fertilized eggs. This suggests some factor in fertilization that has not yet been successfully imitated in any artificial way. But apart from this the activation theories resulting from parthenogenesis are not directly applicable to the action of the spermatozoön. The manner of activation. must, however, be the same for the most part; comparison of fertilization and parthenogenesis should therefore serve to complete the theory of activation. The most significant factor that fertilization has to add to the theory of activation would appear to be the association of capacity for fertilization (activation) with a diffusible substance or substances (fertilizin) contained in the cortex of the egg. The theory of artificial activation requires the presence of 
catalytic substances for the interactions that follow the primary cortical effect; but their nature has remained entirely unknown.

Just's experiments (1915b) on heat parthenogenesis in Nereis furnish an experimental basis for the view that the activating substance is readily diffusible. He found that the eggs could be stimulated to complete parthenogenetic development by proper heat exposure, provided that they were not first washed in sea-water. If they were first washed, the eggs lost their capacity for complete heat activation, although they were still fertilizable. This difference can be readily understood on the assumption that the spermatozoön is a more efficient activator than heat, and that there remains after washing a sufficient amount of activable substance for action of the spermatozoön, but not of heat. We have previously pointed out that the sea-water used for washing the eggs contains a sperm-agglutinating substance, and we have given the reasons for identifying this with the activating substance (pp. $229 \mathrm{ff}$.).

How can the spermatozoön exert an effect on the cortex similar to that produced by heat or butyric acid? Heilbrunn (I9I5) suggests that the spermatozoön produces a partial liquefaction or swelling of the vitelline membrane at the point of attachment, thus lowering the surface tension at one point; there is an immediate tendency for the tension to be equalized everywhere, which results in a certain lowering of the tension of the membrane around the entire egg, and elevation of the membrane (usually called membrane formation) results, owing to an overbalance of forces acting outward on the membrane. Such an explana- 
tion might perhaps suffice in a formal sense for the special case under consideration by Heilbrunn, that of the sea urchin. But it can hardly apply to other cases where the cortical changes present a different morphological form (Nereis, for instance, Fig. 2). Loeb has suggested that the sperm bears a lysin which acts on the surface of the egg; the objections to this conception have been already considered (p. 245), and it seems to the writer untenable. R. S. Lillie (19r4) has suggested the idea that contact of the sperm produces an electrical depolarization of the membrane which releases an "impediment to the chemical interaction forming the primary event in the response" (p. 6r4).

There are good reasons for believing that the propagation of the cortical change from the point of impact of the spermatozoön requires a measurable time element. It has been asserted by several observers, beginning with Fol (1877), that the fertilization membrane can be seen to arise first at the point of penetration and to spread thence as fast as the eye can follow it; this is a very delicate observation, owing to the difficulty of seeing the precise point of fertilization at the moment of impact. It is therefore difficult to say how much may be due to subjective impressions in this observation.

Just (I9I9) has, however, recently observed a case in the sand dollar (Echinarachnius), where the rate of the cortical change can be readily followed by the eye; membrane elevation can be observed to proceed as a wave around the egg, beginning at the point of penetration of the sperm. The sperm enters the egg in about twenty to fifty seconds after insemination; the membrane begins to arise at the point of entrance 
about fifteen seconds later, it and is completed in fifteen to twenty seconds more. In this case the entire egg has already become impermeable to sperm at the moment that membrane elevation has begun. There is in fact a "wave of negativity" that sweeps over the egg preceding the wave of membrane elevation, so that any point on the surface becomes impermeable to sperm (unfertilizable) some time before membrane elevation begins. The wave of negativity dates from the time that the tip of the sperm head has entered the cytoplasm. The so-called fertilization cone arises after penetration of the spermatozoön.

The principles of polyspermic fertilization seem to the writer, also, to furnish a demonstration of the point in question. With a perfectly fresh lot of eggs one can raise the percentage of polyspermy by increasing the concentration of the sperm suspension. Since the egg becomes unfertilizable at any point where the fertilization reaction has begun, we would expect that polyspermy would increase with sperm concentration if there were an appreciable time interval in the spread of the reaction from a point, and this is what we observe. With a given sperm concentration also the proportion of polyspermic eggs increases with weakening of the eggs either by action of reagents or by staling. The obvious implication here is that in weakened eggs the cortical change is propagated more slowly. It is noteworthy in this connection that normal polyspermy occurs only in eggs with considerable yolk content and hence large surface.

The conclusion that the cortical change is propagated from the point of fertilization at a rapid but 
measurable rate, which, however, varies with the kind of eggs and with their condition, is well founded. Such a change is not comparable to electrical depolarization or decrease of surface tension. The rate at which the cortical reaction spreads from the point of action of the spermatozoön furnishes a new basis of judgment concerning the probable nature of the change. The general order of magnitude is of a physiological rather than a purely physical sort. It is perhaps hardly necessary to say that the activation of the egg at a given point by the spermatozoön does not present a different problem from artificial activation. It does, however, give an additional point of view with reference to it.

The primary change in activation is not something visible in a morphological sense; the visible cortical changes are due to activation and are obviously specific for the kind of egg concerned; hence the considerable variety that they exhibit in different animal groups. Some theories of artificial activation have erred in respect to undue emphasis on the morphological change as though it were primary instead of being secondary or even tertiary. The analysis implies, first, a physical alteration at the point of fertilization; second, chemical reaction in which a specific catalyzer is concerned; third, the visible cortical effect. The writer is not fully convinced that the chemical reactions may not be set up directly, but this point is perhaps a minor one.

Loeb (I9IO) has suggested that in the process of ${ }^{\circ}$ cytolysis which he conceives to underly the activation of the egg "certain substances which were solid are liqufied and enabled to diffuse into the egg. If it could be shown that these substances were of such a 
nature as to start or accelerate the chemical processes underlying development the connection between membrane formation and causation of development would become intelligible." This idea seems to me to be entirely consistent with the fertilizin hypothesis. This substance, which is contained in the cortex, may be conceived as exerting a ferment-like action as it penetrates into the egg or is carried in by the spermatozoön, though this conception must remain for the present hypothetical. It corresponds to what I have called elsewhere (I9I4) binding of the ovophile group of the fertilizin.

2. The internal changes.-The problem of the internal events of activation presents two aspects: first, that of change in metabolism evidenced by increased oxygen consumption in some cases, by initiation of development in all cases; and second, the problem of proper co-ordination of the karyokinesis of the first cleavage. Under the first head it would seem that all degrees of activation are possible up to the optimum, which in this case appears to correspond with the maximum, for we do not know any cases in which defects in the induced development are due to excessive activation, i.e., to too rapid rate of the processes activated or initiated. As we have seen, polyspermy does not induce such a condition; its evil effects result from other causes; neither does excessive action of parthenogenetic agents cause an excessive increase in rate of metabolic activities, but rather a decreased rate. It is possible to grade the action of parthenogenetic agents to various degrees of activation; beginning, for instance, with the production of membrane formation 
alone as the first readily observed evidence of activation, a slight increase in action of the agent may bring eggs to the point of cleavage; slightly more may induce cleavage in a small proportion of the eggs; more yet a larger proportion of normally developing eggs, up to the optimum action, beyond which the reaction becomes unfavorable (cf. R. S. Lillie, I9r 5).

Under the second head it is not only necessary that the rate and kind of metabolism should reach a certain optimum, but also that the processes initiated should be properly co-ordinated. Thus if the processes within the egg exhibit a lack of co-ordination with reference to regular segmentation, the entire developmental process may go astray, whatever its rate. This is often the case with artificial activation, as we have seen in discussing the necessity for a double treatment in parthenogenesis of the sea urchin (p. 243).

In the case of fertilization, the karyokinetic phenomena center around the sperm nucleus at first, and the egg nucleus is later drawn into the same sphere of influence. We have already discussed the theory that the leading part taken by the sperm component is due to a special organ (centrosome) intimately associated with it (p. 7I). There is no good reason for adhering to this view, which has been quite generally abandoned.

We have seen that spermatozoa that penetrate into immature eggs, into eggs devoid of agglutinating substance, or into eggs already activated exert no effect in the interior. As the spermatozoön produces no cortical effect in these cases, we might generalize by saying that a spermatozoön that has not been concerned in 
cortical reactions cannot enter into the internal reactions of fertilization. This might be due either to a change in the spermatozoön itself during its passage through the cortex, to a change in the internal protoplasm of the egg consequent on the cortical changes, or to both combined. It would be difficult to separate these possibilities, because we cannot isolate a spermatozoön that has been concerned in cortical activation and introduce it into central protoplasm (endoplasm) of another unactivated egg.

However, a very ingenious experiment of Chambers ${ }^{\mathrm{I}}$ throws some light on the problem. It has been shown by other experimenters (see p. I62) that portions of fertilizable eggs are themselves fertilizable; such parts possess a portion of the cortex (ectoplasm) of the egg. Chambers has added a most interesting and significant fact by showing that the internal protoplasm (endoplasm) of the starfish egg is not fertilizable. With the microdissection needle he tore the cortex and allowed endoplasm to flow out; this accumulates in spheres, which may be of considerable size and may contain the egg nucleus. Of forty to fifty such endoplasmic spheres not one could be fertilized; on the other hand the cortical material left behind, which rounds up into a sphere in each case, is fertilizable. If an endoplasmic mass which has flowed out of a tear be allowed to remain connected with cortical material the mass is fertilizable, and the regularity with which segmentation of such a mass proceeds is a function of the amount

${ }^{1}$ The writer is greatly indebted to Dr. Chambers for permission to record these observations in advance of his own publication on the subject. 
of cortical material present. With a minimum of cortical material a fertilization reaction occurs and nuclear division may follow, but in such a case the cytoplasm does not divide.

The writer (I9I4) has previously urged the possibility that the spermatozoön undergoes some modification, necessary for its part in the internal events of fertilization, in its passage through the corte $\dot{x}$ of the egg, possibly by union with fertilizin or other substance of the cortex; in other words, that "the spermatozoön needs itself to be fertilized."

The material of the sperm nucleus is in a different physiological state from the egg nucleus. In the cases in which the sperm enters the egg during maturation the egg nucleus is concerned in the maturation divisions; in those cases (e.g., sea urchins) in which maturation is completed before penetration of the spermatozoön the egg nucleus is in the resting, interkinetic, vesicular state, while the sperm nucleus is in the state of greatest condensation of the chromatin; but in either case the sperm nucleus is associated with cytoplasm which has received the cortical activation and which may hence be regarded as more reactive. It is therefore natural that the karyokinetic phenomena, which constitute the normal reaction of the egg, should center around the sperm nucleus, and the formation of the sperm aster may be regarded as the first step in this process. The cytological study of artificial activation has shown that the cytoplasm has a tendency when activated to form asters spontaneously (Morgan, Wilson). When the sperm nucleus is present all such activity centers around it and is usually inhibited elsewhere. 
The karyokinetic phenomena thus initiated tend to occupy the entire egg, but they are in conflict with the maturation divisions when these have not already occurred, and their extension is in such cases delayed. But after this conflict has disappeared the extension is very rapid. The meeting of the germ nuclei, as previously argued (p. 65), is due to their relation to the single dynamic system of the entire egg, in which they tend toward the center according to the universal rule governing nucleocytoplasmic localization. There is no reason for assuming any such vague, semimystical conception as a "sexual affinity" of the germ nuclei.

Many of the phenomena concerned in the internal events of fertilization or artificial activation are of a general cytological kind; the writer has therefore not seen fit to discuss them, as this is not a treatise on general cytology. We have attempted to isolate from the complex of events those which are peculiar to fertilization as such and to indicate their relations to known physiological processes.

3. General.-As will have been seen from the preceding discussion most of the theories of fertilization are activation theories alone. Boveri's theory of the centrosome, though entirely morphological, is such a theory; such also are the various theories of Loeb, R. S. Lillie, Delage, and others who have used artificial parthenogenesis as a means of analysis. On the other hand, certain older theories, such as that of Oskar Hertwig, take cognizance mainly of the problem of biparental inheritance presented by fertilization. There is obviously need for a theory that shall comprise the main fundamental features of the fertilization reaction, 
viz., specificity, irreversibility, and activation, for these are inseparable. The penetration of the spermatozoön and the union of the germ nuclei are results of these primary factors of the fertilization reaction, and they constitute, therefore, secondary problems, even though from a teleological point of view they represent the essence of the entire process.

It is hoped that the writer's fertilizin hypothesis presented in various places in this book at least supplements other theories of activation and points the way to a more inclusive theory that shall comprise all the main aspects of fertilization.

\section{REFERENCES}

Allyn, Harriet M.

I912. "The Initiation of Development in Chaetopterus," Biol. Bull., XXIV, 2I-72.

Batalllon, E.

1909. "L’imprègnation hétérogène sans amphimixie nucléaire chez les amphibiens et les échinodermes," Arch. für Entwickelungsmech., T. 38 .

I9roa. "L'embryogénèse complète provoquée chez les amphibiens par piqure de l'œuf vierge, larves parthénogénètiques de Rana fusca," Comples rendus de l'Acad. de. Sci., T. т 50.

I9Iob. Le problème de la fécondation circonscrit par l'imprègnation sans amphimixie et la parthénogénèse traumatique," Arch. de zool. exp. et gén., Sér. 5, T. 6, pp. IOI-35.

г 9 I $a$. "Les deux facteurs de la parthénogénèse traumatiques chez les amphibiens," Comptes rendus de l'Acad. de Sci., T. I 52.

I9ı $b$. "L'embryogenèse provoquée chez l'œuf vierge d'amphibiens par innoculation de sang ou de spermes de mammifères," etc., ibid. 
Bataillon, E.

I9I2. "La parthénogénèse des amphibiens et la 'fécondation chimique' de Loeb (étude analytique)," Ann. des. sci.nat., Sér. 9, T. I6, pp. 249-307.

Brachet, A.

I9 I. "Études sur les localisations germinales et leur potentialité réelle dans l'œuf parthénogénètique de Rana fusca," Arch. de biol., T. 26, pp. 337-63.

DeHorne, A.

I9II. "Sur le nombre des chromosomes dans les larves parthénogénètiques de grenouille," Comptes rendus de l'Acad. de Sci., T. I 52, p. I I 23.

Delage, Y.

I90г $a$. See references at end of chapter v.

I902. "Nouvelles recherches sur la parthénogénèse expérimentale chez Asterias glacialis," Arch. de zool. Exp. et gén., Sér. 3, T. Io, pp. 213-35.

I904a. "Elevage des larves parthénogénètiques d'Asterias glacialis," ibid., Sér. 4, T. 2, pp. 27-46.

I $904 b$. "La parthénogénèse par l'acidal carbonique obtenu chez les œufs après l'emission des globules polaires," ibid., pp. 43-46.

I908. "Les vrais facteurs de la parthénogénèse expérimentale. Elevage des larves parthénogénètiques jusque à forme parfaite," ibid., Sér. 4, T. 7, 445-508.

Delage, Y, et Goldsmith, M.

I9I3. La parthénogénèse naturelle et expérimentale. Paris: Ernest Flammarion.

Fischer, Martin H., and Ostwald, Wolfgang.

I905. "Zur physicalisch-chemischen Theorie der Befruchtung," Arch. fiir d. ges. Physiol., Band ro6, pp. 22966.

Guyer, M. F.

I907. "The Development of Unfertilized Frogs' Eggs Injected with Blood," Science, N. S., XXY', 9ro-I I. 
Heilbrunn, L. V.

I9I3. "Studies in Artificial Parthenogenesis: I, Membrane. Elevation in the Sea-Urchin Egg," Biol Bull., XXIV, 343-6r.

I9I 5. See references at end of chapter v.

Henneguy, M. F.

I9I I. "Sur la parthénogénèse expérimentale chez les amphibiens," Comptes rendus de l'Acad. de Sci., T. I52, pp. I $2 \mathrm{I}-23$.

Herlant, Maurice.

I917. "Le méchanisme de la parthénogénèse expérimentale," Bull. sci. de la France et de la Belgique, Sér. 7, T. $50, \mathrm{pp} .38 \mathrm{I}-404$.

I9I3. "Etude sur les bases cytologiques du mécanisme de la parthénogénèse expérimentale chez les amphibiens," Arch. de biol., T. 28, pp. 505-608.

HindeE, E.

1910. "A Cytological Study of Artificial Parthenogenesis in Strongylocentrotus purpuratus," Arch. für Entwickelungsmech., Band $3 \mathrm{I}$.

Just, E. E.

I9I $5 b$. See references at end of chapter $\mathrm{v}$.

LILliE, Frank R.

I9I3. See references at end of chapter iv.

I9I4. See references at end of chapter iv.

I9I $5 a$. See references at end of chapter iv.

I9I $5 b$. See references at end of chapter iv.

LILLIE, R. S.

I908. "Momentary Elevation of Temperature as a Means of Producing Artificial Parthenogenesis in Starfish Eggs and the Conditions of Its Action," Jour. Exp. Zoöl., V, 375-428.

I910. "The Physiology of Cell-Division: II, The Action of Isotonic Solutions of Neutral Salts on Unfertilized Eggs of Asterias and Arbacia," Am. Jour. of Physiol., XXVI, 106-33. 
LILLIE, R. S.

I9I I. "Certain Means by Which Starfish Eggs Naturally Resistant to Fertilization May Be Rendered Normal and the Physiological Conditions of This Action," Biol. Bull., XXII, 328-46.

r9ı3a. "The Rôle of Membranes in Cell-Processes," Pop. Sci. Monthly, pp. I32-52.

г9г3b. "The Physiology of Cell-Division: V, Substitution of Anaesthetics for Hypertonic Sea-water and Cyanide in Artificial Parthenogenesis in Starfish Eggs," Jour. Exp. Zoöl., Vol. XV.

I9I4. "Antagonism between Salts and Anaesthetics: IV, Inactivation of Salt Solutions and Hypertonic Seawater by Anaesthetics," Jour. Exp. Zoöl., XVI, 59 I -6 I 6 .

I9r6. "Mass Action in the Activation of Unfertilized Starfish Eggs by Butyric Acid," Jour. of Biol. Chemistry, XXIV, 233-47.

I9I 5. See references at end of chapter v.

I9r6. See references at end of chapter $\mathrm{v}$.

I9I 7. See references at end of chapter v.

I9I8. See references at end of chapter v.

Lloyd; DOROThy J.

I9I4. "A Critical Analysis of Delage's Method of Producing Artificial Parthenogenesis in the Eggs of the SeaUrchin," Arch. fïr Entwickelungsmech., Band, 38 , pp. 402-8.

Loeb, JACQues.

I9ı. "How Can the Process Underlying Membrane Formation Cause the Development of the Egg?" Proc. Soc. Exp. Biol. and Medicine, VII, I 20-2 I.

I9I3. Artificial Parthenogenesis and Fertilization. Chicago: The University of Chicago Press.

I9I4. See references at end of chapter iv.

I9I 5. See references at end of chapter iv.

I9I6. See references at end of chapter iv. 
Loeb, Jacques, and Bancroft, F. W.

"The Sex of a Parthenogenetic Tadpole and Frog," Jour. Exp. Zoöl., XIV, 275-77.

MCClendon, J. J.

I912. "Dynamics of Cell Division. Artificial Parthenogenesis in Vertebrates," Am. Jour. of Physiol., XXIX, 298-301.

Moore, Carl R.

I9I6. See references at end of chapter $v$.

I9I7. See references at end of chapter v.

Morgan, T. H.

I896. "The Production of Artificial Astrospheres," Arch. fïr Entwickelungsmech., Band 3, pp. 339-6r.

I900. "Further Studies on the Action of Salt Solutions and of Other Agents on the Egg of Arbacia," Arch. fïr Entwickelungsmech., Band Io, pp. 489-524.

Richards, A., AND WoOdWARD, A. E.

I9I 5. See references at end of chapter iv.

Robertson, T. B.

I 9 I $2 b$. See references at end of chapter $\mathrm{v}$.

Wilson, E. B.

I901. "Experimental Studies in Cytology: I, A Cytological Study of Artificial Parthenogenesis in Sea-Urchin Eggs," Arch. fïr Entwickelungsmech., Band I2, pp. 529-96.

Woodward, Alvalyn E.

I9I8. "Studies on the Physiological Significance of Certain Precipitates from the Egg Secretions of Arbacia and Astcrias," Jour. Exp. Zoöl., XXVI, 459-502. 

INDEX 



\section{INDEX}

Activable substance of ovum, r67, I 7 r, $25^{8}$ (see also Fertilizin)

Activation, problem of, $228 \mathrm{ff}$.

Agglutinating substance, II $7 \mathrm{ff}$., $120,154,167,211,228 \mathrm{ff}$., 234, 235 (see also under Spermatozoa, agglutination of)

Alkali, effect on fertilization, 24, I70-7I, I9I, I93

Amphimixis, $32,36,38$

Antagonism of sperm, I 76

Anti-fertilizin, 237

A rbacia, Iо0, Iо9, III, II 2, II 7 , II 8 , I 22, I 23, I 24, I47, I5I, I 54, I 64, I 74

Aristotle, I, 2, 3

Ascaris, 59, 66, 69, 75, I47

Asterias, II I, II 3, I70, I 74, I93

Auerbach, L., I4

Auto-parthenogenesis, 238

Balance of salts in fertilization, I 72, I94

Ballowitz, E., 49, 93

Balzer, F., I89, I9I, I93

Bancroft, F. W., 255, 256 .

Barry, I 2

Bataillon, E., 203, 255, 256

Berlese, I 85

Biparental inheritance, 42

Bischoff, T. L. W., Iо, I I

Blood inhibition, 27, I 73 ff., 232

Blount, Mary, 79

Bonnevie, K., 78, 80

Boveri, T., I9, 60, 66, 71, 74, 82, I62, 266

Brachet, A., 84, 225

Braun, 204

Buller, A. H., 93, 98, r I4

Bütschli, O., I4, 37

Butyric acid treatment in parthenogenesis, I57, I66, 229, 24I, $242,25 I$

Calkins, G. N., 39, 40, 42

Castle, W. E., 205 ff.
Catalysers, 242

Chactopterus, 46, Iог, I40, I76

Chambers, R., I 53, I 54, 264

Chemotaxis, 50, IO $2 \mathrm{ff}$., II4

Child, C. M., 34

Chromosome reduction, 45

Chromosomes in fertilization, 6667

Cohn, E. J., 92, го०, гог, Іоз, I 32

Colloidal morphogenesis, Theory of, 252

Colton, H. S., 204

Conjugation, $37 \mathrm{ff}$.

Conklin, E. G., 72

Cook, A. H., 204

Correns, C., 205, 2I 2, 2 I3 ff.

$\mathrm{CO}_{2}$ production at fertilization, $\mathrm{I} 47$

Cytolysis, 24I ff., 26I

Darwin, C., 205, 2I I, 2 I 5

Dehorne, A., 255

Delage, Y., 25, I40, I43, I62, 233, 240,25 I ff., 256

De Meyer, J., I I4, I 20

De Morgan, I88, I93

Dewitz, J., 93, 98

Doncaster, L., I 88

Driesch, H., r62

Dumas (Prevost et), 9, Io, I I

Dungay, N. S., I6o

East, E. M.,205, 2I 2, 2I5, 2I 6

Echinarachnius, I I 3, I I 7, I I9, I 24, I5I, 230

Eckler, I85

Egg: extracts, Iо9, гпо; nucleus, I6, 63, I58; receptors, 27, 236; secretions, I08, 109, I I0

Ehrlich, 235

Electrical conductivity, $\mathrm{I} 48$

Endomixis, 39, 40

Erdmann, R., 39

External conditions of fertilization, I 70 ff. 
Fertilizable condition of ovum, I 39 ff., I 63

Fertilization cone, 5I, 55

Fertilization reaction, 22, 23, I30

Fertilizin, 27, I40, I42, I75, 23I, $233,237,238,267$

First segmentation nucleus, 65

Fischel, A., I90

Fischer, M. H., 254

Flemming, 17

Fol, H., I5, I6, 58, I6r

Fuchs, H. M., I32, I88, I93, 205 , $207 \mathrm{ff}$.

Gametes, 3 I

Gelation phenomena, I 53, 254

Gemmill, J. J., I38

Germ nuclei, 6o, 65, 68, I 58

Gies, W. J., I33

Glaser, Otto, I 16 , I 8

Godlewski, E., I69, I76, г95

Goldsmith, M., 240

Gray, J., I00, I48, I88, I 89

Grobben, 49

Günther, G., го०, I99

Guyer, M. F., 255

Harper, E. H., 78, 79

Hartsoeker, N., 5

Harvey, E. N., I49

Harvey, William, I, 2, 3

Heąt parthenogenesis, I $43,246 \mathrm{ff}$., 258

Heilbrunn, L. V., I 53, 254, 258, 259

Henking, H., 60, 78

Henneguy, M. F., 255

Herbst, Curt, 169, I 89,193

Herlant, M., 81, 83, I 76, I77, 243, $246,255,256$

Hertwig, G., 202, 203

Hertwig, O., I5, I6, 21 , 23, 25, 8I, I 40, I 60 ff., 256

Hertwig, P., I 99

Hertwig, R., 2I, 23, 8I, I40, I62

Hetero-agglutination, I $22 \mathrm{ff}$.

Hindle, E., 243

Hybrid fertilization, $186 \mathrm{ff}$.; in echinoderms, I88 ff.; in teleosts, I $98 \mathrm{ff}$.; in amphibia, $200 \mathrm{ff}$.

Hypertonic sea-water, in parthenogenesis, I64, 24I, 244
Inbreeding, 215

Inhibition of fertilization by blood, I 73 ff., 232

Iso-agglutination, I22, I 23, 218

Jennings, H. S., $39 \mathrm{ff}$.

Jost, L., 205, 21 13,215

Just, E. E., 25,85 , II 7 , II9, I 24 , I 40 , I 4 I, I 44, I 54, 230, 234,258 , 259

Keber, I 2

Kohlbrugge, J. H. F., I84, I85

Kölliker, A., IO, I I, I2, I0०

Kostanecki, K., 56

Kupelwieser, H., I96, I97

Lallemand, I I, I 7

Lams, 75

Leeuwenhoek, A., 4, 5

Lillie, R. S., 24, I43, I49, I 50, I5 I, I $60,246,249,25 \mathrm{I}, 256,259,263$, 266

Lipolysin, 239

Lloyd, D. J., 253

Loeb, J., 23, 28, 58, 95, I04, II I, I 13, I 6 , I I 8, I $24, I_{32}, I_{42}$, I 45 , I48, I 56, I 59, I64, I69, I 7 I, I 77 , I87, I 9 I, I93, 228, 234 ff., 240 ff., 245,254 ff., $26 \mathrm{I}, 266$

Lyon, E. P., I47, I48, 149

Lysin, I32, I 77, 245

McClendon, J. J., I48, 255

McGregor, J., 49

Mall, F. P., I39

Mark, E. L., I8

Massart, J., 93, 98

Maturation, 44, 45

Maturity of gametes, 24

Maupas, E., 37, 38, 39, 40, 204

Meissner, G., I 2

Merogony, 68, I6 $\mathrm{I} f f$.

Meves, F., 60, 7 I, 75

Minot, C. S., 32

Mitochrondria, 20, 50, 70, 75, 76

Moenkhaus, W. J., I98, 199, 200

Moore, C. R., 25, I18, I54, I55, I65, I67 ff., 229, 23 I

Morgan, T. H., I62, 204, 205, 207, 208, 209, 210, 21 5, 244, 265 
Morrill, C. V., 68

Morris, M., I99

Mrázek, 56

Mulsow, K., 68, 69

Nereis, 46, 5I, 52, 62, 69, 72, 76, 94, 99, I04, I05, I1 3, I22, I 23 , I 39, I 53, I $_{54}$, I $_{55}$, I $_{59},{ }_{2} 8$

Newman, H. H., IgS ff.

Newport, G., I 2, 84

Okkelberg, P., I 48

Osmotic relations, I $49 \mathrm{ff}$.

Ostwald, W., 254

Oxidation changes, $145 \mathrm{ff}$.

Paramecium, $37 \mathrm{ff}$.

Parthenogenesis, 8, 21, 22, I30, I 43, I 59, I6 6 ff., $240 \mathrm{ff}$.

Partial fertilization, I 29, I $55 \mathrm{ff}$.. I65

Patius, 5

Permeability change, $147 \mathrm{ff}$.

Pflüger, E., 20I

Physical changes, ${ }_{5} 2 \mathrm{ff}$.

Pinney, E., I99

Polar bodies, 44

Polyspermy, 5I, 77, 78, 79, 80, 8I , 82,83, I61 260,262

Potts, F. A., 204

Prevost et Dumas, $9 \mathrm{ff}$.

Pronuclei, I5

Radiation, effect on spermatozoa, 203

Reciprocal crosses, I90 ff., $20 \mathrm{I}$

Reighard, J. E., 25, I4I, I 47

Rejuvenation, $3 \mathrm{I}, 34,38$

Reversibility, problem of, 25, I 28 , I6I ff.

Richards, A., 27, I 20, I 2 I, 238

Robertson, 'T. B., I33, 232

Roux, W., 64, 84, 85

Rückert, J., 79

Schücking, A., 95, I34

Schulze, O., 84

Schwann, Th., I I

Seeliger, O., I62.

Self-fertilization, $203 \mathrm{ff}$.
Self-sterility, 26, $203 \mathrm{ff}$.

Senescence, 33,34

Serological comparisons, 26, I 76, 2 I 7,2 I $9,235,236$

Sex chromosomes, 68

Shackell, I47, I48

Shearer, I88, I93

Smith, J. W., 204

Sobotta, J., I 84

Spallanzani, Abbé, 6, 25

Specificity, problem of, 26, I30, I $84 \mathrm{ff}$.

Sperm: aster, 60, 6r, 73; centrosome, I9, 49, 70, 7I, 74; nucleus, $16,63,71$; receptors, 27 , 236

Spermatozoa: activity, 92, 99, I09, I I I , I I 2; agglutination, of, 27, I09, I I 2 ff., I 75, 220; aggregations, 94, I02 ff., 109, I 2 ; behavior, 9 I ff., 96 ; chemotaxis, I02 ff., I I4; discovery of, 4, 5; duration of life, IOI, I3I, I32; energy production, 92; fertilizing power of, I3I, I32 ff., I39; fertilizing substance of, $\mathrm{I}_{3} 2 \mathrm{ff}$.; figures of, 49 ; locomotion, 93; mass effect, I 34 ; parts, 48 ; path of, 64,65 , 84,85 ; penetration of, 12, I6, $22,5 \mathrm{I}, 53,54,64, \mathrm{I} 3 \mathrm{I}, 267$; reactions, $96 \mathrm{ff}$.; thigmotaxis of, $98,99,107$

Stockard, C. R., I60

Stout, 205, 2I 2, 2I4, 2I 5

Strongylocentrotus, I I I, I I8, I 24, I 48 , I 57, I 64, I93

Superposition of fertilization and parthenogenesis, ${ }_{1} 6_{3} \mathrm{ff}$.

Teacher (Bryce and), I39

Tennent, D. H., I89, I90, I93, I95

Tissue specificity, $\mathrm{I} 84 \mathrm{ff}$.

Toxopneustes, $6 \mathrm{I}, \mathrm{I} 48$

Triepel, A., I39

Van Beneden E., I3, I 5, 67

Van der Stricht O., 76

Vejdovsky, F., 56

Vernon, H. M., 189, 193 
Virchow, R., I 7

Viscosity of egg, I 53

Wagner, I 2, I8, I9

Waldeyer, O., I 39

Waldstein, I 85

Warburg, O., I45, 242

Wastenys, H., I 45

Weismann, A., 38, 40

Whitman, C. O., 185
Wierzejsky, A., 56

Wilson, E. B., 25, 49, 60, 61, 64, I $40,158, I 62, I 63,233,244,265$

Winkler, H., I 33

Woodruff, L. L., 39, 238

Woodward, A. E., 27, I 20, I 21 , $23 \mathrm{I}, 238,239,240$

Ziegler, H. E., ${ }_{5} 8$

Zygote, 3 I 


\section{The University of Chicago Science Series}

EDITORIAL COMMITTEE

ELIAKIM HASTINGS MOORE, Chairman

JOHN MERLE COULTER

ROBERT ANDREWS MILLIKAN

The Evolution of Sex in Plants. By John Merle Coulter. $\mathrm{x}+\mathrm{r} 40$ pages, I 2mo, cloth; \$I.০o, postage extra (weight I4 oz.).

Individuality in Organisms. By Charles Manning Child. $\mathrm{x}+2 \mathrm{I} 2$ pages, small I $2 \mathrm{mo}$, cloth; $\$ 1.25$, postage extra (weight I lb. 6 oz.).

The Origin of the Earth. By Thomas C. Chamberlin. xii+272 pages, small I 2mo, cloth; $\$$ I.5०, postage extra (weight I lb. 6 oz.).

Finite Collineation Groups. By HaNs F. BlichFerdt. xii+r94 pages, small I2mo, cloth; \$r.50, postage extra (weight I lb.).

A Chemical Sign of Life. By ShIro TaSHiro. $\mathrm{x}+\mathrm{I} 42$ pages, small I $2 \mathrm{mo}$, cloth; $\$ 1 . \infty$, postage extra (weight I4 oz.).

The Biology of Twins. By Horatio Hackett Newman. $\mathrm{x}+\mathrm{r} 86$ pages, small I2mo, cloth; $\$ 1.25$, postage extra (weight I lb.).

Food Poisoning. By Edwin OAKes Jordan. viii+rí6 pages, small I 2mo, cloth; \$I.००, postage extra (weight I I oz.).

The Electron: Its Isolation and Measurement, and the Determination of Some of Its Properties. By Robert Andrews Millikan. xii + 268 pages, small I $2 \mathrm{mo}$, cloth; $\$ \mathrm{r} .50$, postage extra (weight I lb. $3 \mathrm{oz}$.).

The Living Cycads. By Charles Joseph Chamberlain. xiv $+\mathrm{i} 72$ pages, small I2mo, cloth; \$I.50, postage extra.

Problems of Fertilization. By Frank R. LILlIE. xii+278 pages, small I2mo, cloth; \$r.75, postage extra.

\section{VOLUMES PLANNED OR IN PREPARATION}

Black Body Radiation. By Chardes E. Mendenhall.

Mechanics of Delayed Germination in Seeds. By W. Crocker.

The Rigidity of the Earth and of Materials. By A. A. MicheLson.

Linear Integral Equations in General Analysis. By Eliakim Hastings MOORE. 




